\title{
Radioactive masculinity: How the anxious postcolonial learnt to love and live in fear of the nuclear bomb
}

Dibyadyuti Roy

Follow this and additional works at: https://researchrepository.wvu.edu/etd

\section{Recommended Citation}

Roy, Dibyadyuti, "Radioactive masculinity: How the anxious postcolonial learnt to love and live in fear of the nuclear bomb" (2016). Graduate Theses, Dissertations, and Problem Reports. 6536.

https://researchrepository.wvu.edu/etd/6536

This Dissertation is protected by copyright and/or related rights. It has been brought to you by the The Research Repository @ WVU with permission from the rights-holder(s). You are free to use this Dissertation in any way that is permitted by the copyright and related rights legislation that applies to your use. For other uses you must obtain permission from the rights-holder(s) directly, unless additional rights are indicated by a Creative Commons license in the record and/ or on the work itself. This Dissertation has been accepted for inclusion in WVU Graduate Theses, Dissertations, and Problem Reports collection by an authorized administrator of The Research Repository @ WVU.

For more information, please contact researchrepository@mail.wvu.edu. 


\title{
RADIOACTIVE MASCULINITY: HOW THE ANXIOUS POSTCOLONIAL LEARNT TO LOVE AND LIVE IN FEAR OF THE NUCLEAR BOMB
}

\author{
Dibyadyuti Roy
}

\author{
Dissertation submitted to the Eberly College of Arts and Sciences \\ at West Virginia University \\ in partial fulfillment of the requirements \\ for the degree of \\ Doctor of Philosophy \\ in \\ English Literature
}

Ryan Claycomb, Ph.D., Chair

Dennis Allen, Ph.D.

Charles Baldwin, Ph.D.

Brian Ballentine, Ph.D.

Patrick Sharp, Ph.D.

Department of English

Morgantown, West Virginia

2016

Keywords: Radioactive, Postcolonial, Nuclear Bomb, Masculinity, Gender, PostApocalyptic

Copyright 2016 Dibyadyuti Roy 


\section{Abstract \\ RADIOACTIVE MASCULINITY: HOW THE ANXIOUS POSTCOLONIAL LEARNT TO LOVE AND LIVE IN FEAR OF THE NUCLEAR BOMB}

Dibyadyuti Roy

Radioactive Masculinity explores how the Cold War legacy, of nuclear weapons finding resonance in images of white maleness and masculinity, results in anxious hypermasculine performances. These discursive and physical masculine acts contingent on the symbolic and material power of nuclear weapons, I argue, represent radioactive masculinity, a form of hegemonic militarized masculinity, which is intrinsically linked to the concept of nationhood and sovereignty. This idealized masculinity is fluid and cannot be tangibly or materially realized, much like the constantly decaying radioactive bomb on which it is modeled. Through analyzing a wide range of artifacts from America and India, I show that the anxieties of radioactive masculinity produce belligerent masculine performances, which are always volatile and unsuccessful. While existent scholarship has examined the gendered nature of nuclear technology, the cultural effect of unexploded nuclear weapons has been seldom researched. My project remedies this gap by locating physical and cultural sites in America and India, where the materiality of the bomb is made visible through its associations with male corporeality. This relationship, I argue, is indispensable toward understanding both the continued legacy of the Cold War within the Indian subcontinent, as well as its effects on postcolonial subjectivities.

The dissertation begins with an introductory chapter that chronicles the rise of radioactive masculinity within the American military-industrial complex. Here, I analyze official US government documents and related materials, which perform the equation of the bomb to the hardened white male body. I show that while nuclear technology is not inherently gendered, both the bomb and its production spaces were pre-discursively masculinized in order to counter dual insecurities: of post-Depression era American emasculation and a hypermasculine Nazi Germany. Next, I bring in a comparison to Indian governmental documents to further describe how the transference of American radioactive masculinity into postcolonial spaces creates postcolonial nuclear borderlands, which are co-extensive with all nuclear postcolonial spaces everywhere. Chapter 2 examines the formation of a (pseudo) nuclear public sphere in Americaresulting from the crisis in official publicity about the bomb -in the period following the cessation of above ground testing. By juxtaposing canonical Anglo-American nuclear disaster fiction with postcolonial speculative fiction, Chapters 3 and 4 emphasize that the structures of radioactive masculinity are fluid and not bound to specific spatio-temporal contexts. In Chapter 5, a comparative analysis of Leslie Silko's Ceremony with postcolonial Indian texts from the eco-conservationist Bishnoi community demonstrate how tactical storytelling challenges the strategic structures of radioactive colonization. My dissertation concludes with an examination of minority anti-nuclear cultural productions, which by challenging the ideology of nuclear nationalism implicit in radioactive masculinity, deconstructs dominant Anglo-American nuclear historiography. By challenging the symbiotic relationship between radioactive masculinity and nuclear nationalism these texts initiate Nucliteracy - a dynamic multimodal form of literacythat interrogates dominant and official publicity/secrecy about the bomb. 


\section{DEDICATION}

I dedicate this work to the hibakusha — "explosion-affected [Japanese] people" — who survived the atomic bombings of Hiroshima and Nagasaki in 1945. The problematic and troubling legacy of nuclear weapons etched, quite literally, into their bodies inspired me to pursue this project. 


\section{ACKNOWLEDGEMENTS}

Giving thanks for abundance is sweeter than the abundance itself...

Jalāl ad-Dīn Muhammad Rūmī

I have an overwhelming sense of gratitude.

For my committee. Their patience, their guidance, their support, their intellect and most importantly their encouragement helped me formulate, facilitate and finish this dissertation.

For Dr. Sandy Baldwin and Dr. Ryan Claycomb. Beyond their roles as my dissertation directors, intellectual advisors, and invested guides, I am truly fortunate to have known them personally.

Dr. Baldwin, without whom this dissertation would not have been possible. If I am able to imbibe a small percentage of his intellectual brilliance, his keen insights and above all his generosity as a person, I will consider myself a successful person.

Dr. Claycomb was assigned as my mentor for the first year of graduate school, a role that he has unfailingly performed for the next five years as well. I hope I am able to keep learning more from this fantastic scholar, brilliant teacher and fabulous person for at least another five decades.

For Dr. Dennis Allen, from whom I have learned that no problem is really that problematic: be it academia or life. He has an amazing capability of challenging your ideas and reformulating them, to make them far smarter than you had originally envisioned. Also, I have rarely seen a more charismatic classroom presence and I have duly copied all of his pedagogical strategies in my own courses.

For Dr. Brian Ballentine, who always indulged my sudden unscheduled visits to his office. For taking time off his extremely busy schedule, to patiently answer my queries, address my concerns and for providing unflinching support.

For Dr. Sharp, who was there through lengthy Skype chats, anytime that I needed to consult him. His scholarship and advice not only shaped the framework for this project but also my career goals.

For my friends, Prithish and Broti, whose warmth and love sustained me in Morgantown.

For my advisors and teachers at the University of Glasgow and Presidency College, who introduced me to the rigors of research and academic scholarship.

For my father, Pinaki Roy, a finance professional by trade and a litterateur by choice. Without his constant encouragement and the abridged versions of literary classics that he so diligently bought for me in middle school, I would not have pursued a career in this field.

For my sister, Dibyangana Roy (Bunu). You provided the healthy dose of disconnect required from graduate school and from generally being an adult. 
Finally, for the two women who have shaped my being and existence.

My mother, Dr. Indrani Roy, who completed her PhD in 2005, the same year that I enrolled in college - while working a full-time job, managing two kids and complete house-hold responsibilities. Her patience, determination, and resilience remind me every day that if you decide to touch the moon, it is only a rocket ship away.

My wife, partner, co-academic and best friend, Madhurima Das. On good days, her realism, pragmatism and unconditional support keep me grounded, focused and stable. On the not-sogood days her laughter, positivity and unconditional love help me remember what matters in the end.

Thank you again. 


\section{LIST OF FIGURES}

Figure 1: Signing a Petition in support of Indian Nuclearization .......................................... 4

Figure 2: In Pakistan, people offer prayers in front of the Shaheen ........................................... 4

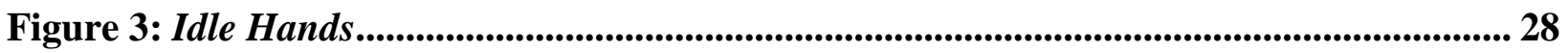

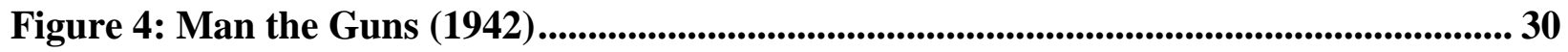

Figure 5: WW-II Propaganda Poster........................................................................... 31

Figure 6: Learn How Dagwood Splits the Atom ............................................................................ 64

Figure 7: Screenshot from Government of Rajasthan website.......................................... 169

Figure 8: Mahabalidan (The Great Sacrifice) ............................................................................ 176

Figure 9: Screenshot of Email communication with Vinod Bishnoi ........................................ 180

Figure 10: Screenshot-Part 2 of Email communication with Vinod Bishnoi ....................... 181

Figure 11: Dead Blackbucks lying in front of a sign that proclaims how the land belongs

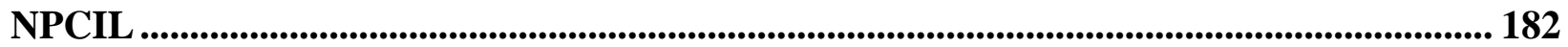

Figure 12: Screenshot-Part 3 of Email communication with Vinod Bishnoi ....................... 182

Figure 13: Pro-Nuclear Doge Meme from the NLP website .............................................. 185

Figure 14: Poster circulated by the Snake River Alliance .................................................. 201

Figure 15: Lord Ganesha Festival in a Simulated Nuclear Test Range............................... 214 


\section{TABle OF ConTents}

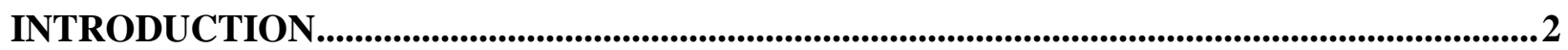

The Journey of the Postcolonial Hypermale: From the Religious to the Nuclear .............................. 3

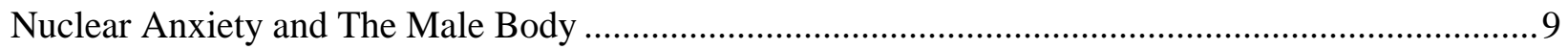

May 1998: A Pikadon for the Radioactive (Male) Postcolonial...................................................... 12

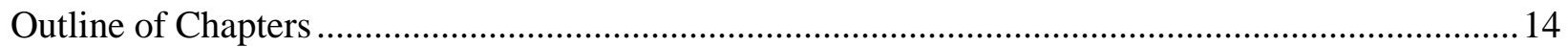

CHAPTER 1: DOCUMENTING RADIOACTIVE MASCULINITY: FROM THE MANHATTAN PROJECT TO THE POSTCOLONIAL BOMB..............................................23

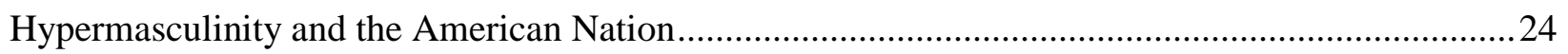

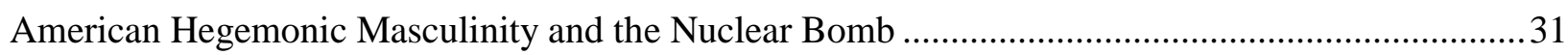

The Mechanics of Co-production: Radioactive Masculinity and the Manhattan Project ....................37

Nuclear Weapons, Postcolonial Statecraft and the National Security Apparatus ...............................50

Two-faced Science: Producing the Postcolonial State through the Nuclear Bomb ........................56

\section{CHAPTER 2: REASSESSING THE NUCLEAR PUBLIC SPHERE: HOW DR.} STRANGELOVE CHALLENGED RADIOACTIVE MASCULINITY ....................................62

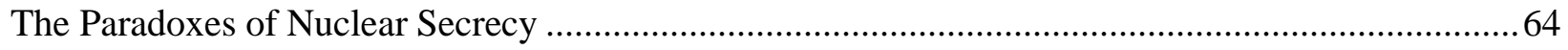

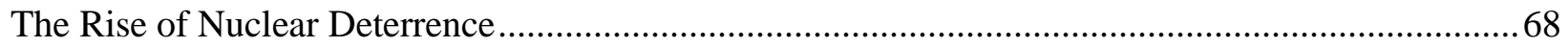

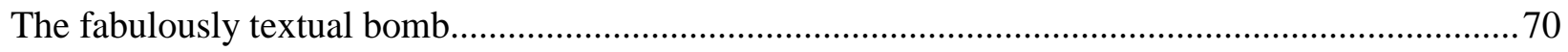

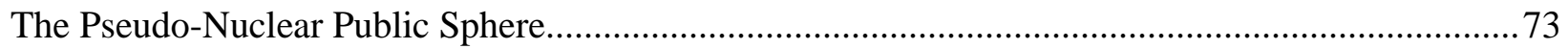

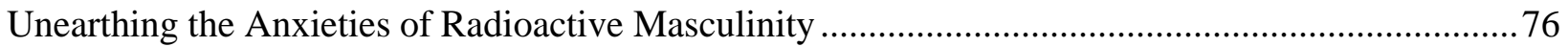

Dr.Strangelove and the Military-Industrial Complex ............................................................... 78

CHAPTER 3: THE QUEST FOR "HARDNESS": CHRONICLING RADIOACTIVE MASCULINITY AND ITS DISCONTENTS IN AMERICAN FICTION ................................93

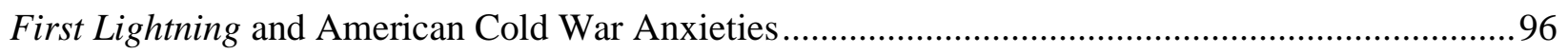

Post-War Domestic Explosion_and rise of the American radioactive male .....................................99

Radioactive Masculinity in American Fictions of Nuclear Disaster.............................................. 103

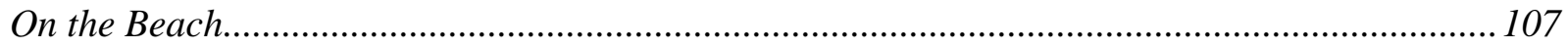


CHAPTER 4: THE QUEST TO BE “HARDER": ANXIOUS ATOMIC PUBLICS AND THE POSTCOLONIAL BOMB

The "Fuzzy" World of SF 124

Speculating Masculinized Wars 125

Postcolonial Radioactive Masculinity in Indian Speculative Fictions 128

CHAPTER 5: STRATEGIC SCIENCE VS. TACTICAL STORYTELLING: DISRUPTING RADIOACTIVE MASCULINITY THROUGH POSTCOLONIAL ECOLOGIES. .146

"Big experiments, Big Payrolls and Big money" 150

Ceremonial Fabulations 153

The Ecojustice of Bishnois 164

Narrativizing Ecojustice, Forming Postcolonial Ecologies

CHAPTER 6: DECONSTRUCTING NUCLEAR HISTORIOGRAPHY: FROM NUCLEAR NATIONALISM TO NUCLITERACY... 185

Masculinity and Militarization in American Nuclear Metanarratives

Reifying American Nuclear Historiography: How Atomic Subalterns Stopped Worrying and Learned to Love the Religious Bomb

Will the Real Atomic Subaltern Please Stand Up? Critiquing Nuclear Historiography through

Nucliteracy..... .209

EPILOGUE .222

NOTES: .228

WORKS CITED: .233 
Weapons of mass destruction have a peculiar fascination. They can generate a warm glow of strength and power carefully divorced from the brutality and genocide on which the potency of the weapons depend (sic)...the imagined radiance of perceived power is hard to miss. (Amartya Sen, Indian Nobel Laureate)

Most analysts have focused on India's relationship with China and Pakistan in explaining its decision to go nuclear. But there are several other significant explanations, and gender is central to them all" (my emphases; Basu and Basu 41). 


\section{Introduction}

On May 11, 1998, Atal Bihari Vajpayee, the Prime Minister of India and leader of the Hindu nationalist Bharatiya Janta Party (BJP) confirmed that India had gone nuclear-again. Speaking to the press personnel gathered the outside his residence, the Prime Minister informed the world that under the aegis of Operation Shakti (Power) India had "conducted three underground nuclear tests in the Pokharan range... with a fission device, a low-yield device, and a thermonuclear device" (Patwardhan, War and Peace). Another two followed these three tests, concluding what was only the second time that India had conducted nuclear tests since their first set of Peaceful Nuclear Explosions in May of 1974. Within less than two weeks Pakistan responded with its own series of six underground nuclear explosions. Eleven nuclear tests in the space of less than a month underlined a harsh reality: the dormant Cold War nuclear arms race had now been effectively transferred into the postcolonial spaces of the Indian subcontinent.

Four days after the Indian nuclear tests, The New York Times published under the heading "NUCLEAR ANXIETY," a letter from the Indian Prime Minister to American President Bill Clinton justifying the "rationale for the tests." The letter replete with adjectives of atonement proceeded to explain that the tests were an absolute necessity due to the "unremitting terrorism and militancy sponsored by it [India's neighbors]," which had made the polity and its citizens very anxious. Without naming either Pakistan or China, Vajpayee's deft rhetoric asserted that the efforts of one India's neighbors who were an "overt nuclear state" to "materially [help] another neighbor of ours to become a covert nuclear weapons state" had left the Indian nation state with little choice (The New York Times). In an analogous gesture, soon after the Pakistani tests, their President Nawaz Sharif came out with a similarly reparative public statement where he termed 
the tests "a defensive step, which [had] become inevitable for us for the sake of our country's security" (Patwardhan, War and Peace). Putting the blame squarely on India, the Pakistani Premier concluded that since "the United States, Russia, and China [had not] use[d] their good offices to protect Asia from the nuclear arms race... [Pakistan had] fully settled the [nuclear] account" (Patwardhan, War and Peace). These statements from the heads of both countries were perceived as mere reconciliatory steps, which were taken to avoid the brunt of global economic sanctions. However, the rhetoric of remorse seemed symptomatic of a larger disease: why were postcolonial thermonuclear powers so anxious?

\section{The Journey of THE Postcolonial HyPermale: From the Religious to THE NuClear}

The premiers of two sovereign postcolonial nations competing with each other to seek approval — from the head-of state of an economically robust neocolonial nation — seemed oddly reminiscent of an earlier time in subcontinental history when "the postcolonial male... [was] one with no agency whose subordinate presence in the colonial lexicon render [ed] him powerless" (Dasgupta and Gokulsingh 5). For the national figureheads of two states that had emerged from the violent legacies of British colonialism and the brutal savagery of the Partition - taking place only five decades before the nuclear tests of 1998 - this moment of apparent triumph for postcolonial science seemed a hardly opportune time to exhibit any form of anxiety. In sharp contrast, however, to the display of sincere diplomatic anxiety from their respective heads of state, euphoric public reactions to the nuclear tests in both India and Pakistan reflected a different model of anxiousness. Images from 1998, poignantly captured in Anand Patwardhan's documentary Jung aur Aman (War and Peace), showed Hindu males in Mumbai signing petitions in blood, supporting India's nuclear program as well as their "dynamic" leader A.B. Vajpayee — who had now been affectionately christened Atom Bomb Vajpayee. 


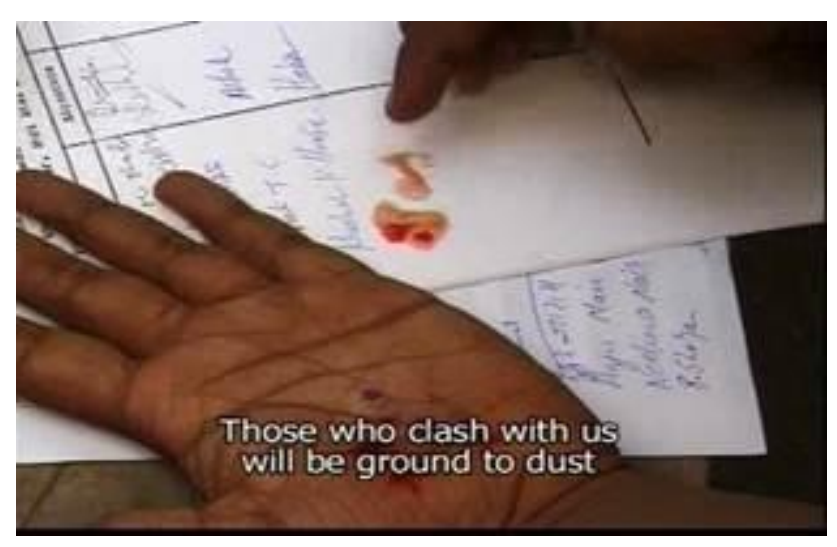

Figure 1: Signing a Petition in support of Indian Nuclearization

In Karachi, Pakistan — even though their official state religion forbids the worship of inanimate objects_-young males kneeled down in a public park and offered namaz (daily prayers) to a full size replica of the Shaheen, the phallic-shaped missile with nuclear capability that the Pakistani government had just exploded in reaction to the Indian Nuclear tests.

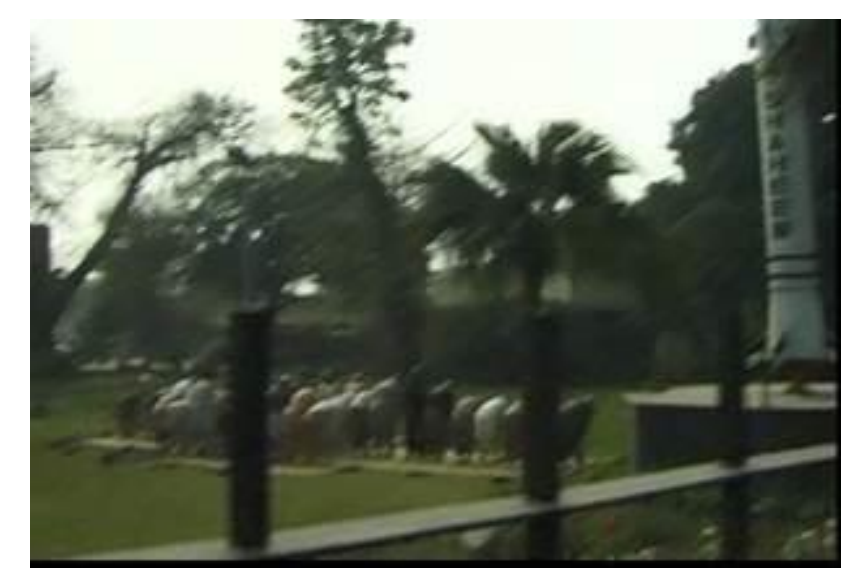

Figure 2: In Pakistan, people offer prayers in front of the Shaheen

The postcolonial bomb had become a fetish object not merely of national strength but of postcolonial male virility, "a great vessel filled with all the unfulfilled aspirations and thwarted dreams of the last fifty years - ambitions of larger and grander place in the world, for a rearrangement of national pride" (Ghosh 11). The traditionally gendered South Asian public sphere had given rise to distinctive atomic publics - male citizens — who seemed not only eager but extremely anxious to exhibit the apparently new-found virility of their nation-state to the 
entire globe. For these gendered atomic publics "the idea of science, epitome and metaphor for the modern... a recurrent theme in anti-colonial nationalist thought" (Making of the Indian Atomic Bomb 26) had seemingly found fruition through the postcolonial bomb. Unsurprisingly therefore, the male citizen - culturally coded as representative of national virility within the South Asian public sphere-was clearly anxious to prove it.

Thus, even in these troubled political times between sparring nations, the bombs had unequivocally united the postcolonial male citizen and the new religion for subcontinental masculinity was evidently radioactive. The insecurities of aggressive religiose masculinity manifested on innumerable female bodies during the Partition seemed to have been suddenly transformed by the nuclear bomb. Subcontinental masculinity seemed intent on celebrating the nuclear bomb - the technological symbol that had apparently helped the postcolonial male body reclaim its virility — from the emasculating legacy of its colonial past. As the noted Indian social scientist Shiv Vishwanathan remarked, "Militarize. Muscularize. Masculinize goes the modernist litany...It is a plea for technology as a sign of toughness" (Patriot Games). But such militarized masculine performances raised a few key questions: what was the connection between nuclear bombs, masculinity and the perceived geo-political power of a nation? More importantly, why was the postcolonial male so anxious to display his new found hypermasculinity that was contingent on the nuclear bomb?

While such national celebrations supposedly conveyed how the postcolonial bomb had culminated the crisis of masculinity — plaguing the Indian subcontinent since the onset of colonization - it vitally emphasized the systemic gendered narrative underlying nuclear discourses. I term such anxious performances of hypermasculinity that are contingent on the symbolic and material power of the nuclear as radioactive masculinity, which I argue, trace their 
lineage back to the Cold War legacy of nuclear weapons finding resonance in images of white maleness and masculinity. In doing so, I take up the category of radioactive masculinity as a form of "hegemonic militarized masculinity" (Jarvis 88), performances of which are intrinsically linked to the concept of nationhood as well as sovereignty. This idealized masculinity is fluid and cannot be tangibly or materially realized, much like the constantly decaying radioactive artifact on which it is modeled. The desire of trying to achieve this idealized and hardened male body is itself responsible for creating an anxiety; an anxiety of hypermasculinity. These hypermasculine performances contingent on nuclearization, through which sovereignty and nationhood are expressed - in both the Anglo-American and postcolonial spheres-reproduce the "institutionalized [white masculine] terror" lying at the heart of nuclear weapons technology.

To further unpack the legacy of postcolonial radioactive masculinity, it is critical to emphasize the history of troubled manhood in colonized nations, especially within the Indian subcontinent. Contrary to the events of Partition when bodies of women were considered opportune spaces for inscripting masculinized ideologies of religion and nationhood ${ }^{i}$ these revelries of the postcolonial radioactive male seemed fundamentally different. The anxiousness of this manhood was embedded in the attempt to recover masculine agency through the materiality of the nuclear bomb. Vitally this anxiety that was manifested, albeit differently -in the diplomatic rhetoric of the heads of state, the mutilation of male bodies in India or their prostration in prayer to the phallic missile in Pakistan — seemed to symbolize the culmination of a certain troubled legacy.

This legacy had emerged from the native male subject being continually essentialized: as either the "effete intellectual" or the hypersexualized native tribal (Macaulay). The nuclear bomb's catastrophic potential promised an iconic global currency that would potentially counter 
this historical crisis: through remasculinizing the postcolonial body politic. Subcontinental nuclearization was made contingent with postcolonial remasculinization and symbolized the consolidation of the native male's intellect with the virility of the native tribal, into a singular resolute structure. Most importantly the formation of this cohesive (masculinized) postcolonial body politic was ostensibly geared toward ending centuries of colonial essentialization. However oddly, the response to this crisis of masculinity seemed a hearkening back to the very same essentialized colonial constructs, from which postcolonial manhood was presumably seeking a release. This new postcolonial body politic was based within a problematic binary: split between the "effete intellectual" epitomized by diplomatic (male) bodies always already anxious to conform to the expectations of their neo-colonial overlords (on whom their countries were economically dependent) and the virile jingoistic male subject, who attempted to internalize into his own corporeality — as a religion — the immense discursive power of the nuclear bomb. Critically, these diverse yet related performances of anxiety seemed to drive home one key point: that the Indian subcontinent had been held hostage since 1945 by "the institutionalized terror represented by the so-called Cold War between the U.S and the U.S.S.R/ Russia" (Abraham 1). Now after almost five decades, this "terror" had been physically manifested through the postcolonial male's anxious subjectivity.

It is hardly surprising though that the postcolonial (radioactive) male would become the locus of societal upheaval, since cultural and social theorists note "[that] masculinity is viewed as a point of intersection of different forms of power, stratification, desire and subjective identity formation" (Haywood and Mac 5; qtd. in Kabesh 29). Therefore, perceiving these performances of postcolonial male subjectivity in the light of the colonial history of the Indian subcontinent lead to multiple questions, some of which this project seeks to address: How were male bodies 
and nuclear weapons made into contingent structures? Are anxious hypermasculine performances an externalization of the inherent anxiety about nuclear weapons? How do such performances of radioactive masculinity configure the constructions of nationhood and sovereignty in America and India? How does the postcolonial radioactive male compare to the militarized white male of the American military-industrial complex where the nuclear bomb first emerged?

To address some of these key questions, this project locates material and discursive sites where the materiality of the bomb is made visible through its effects on male corporeality. I trace a cultural genealogy of nuclear weapons in America and India, while also chronicling the oftentroubling aftermath of such influences. Further, by investigating the workings of nuclear proliferation as well as its allied discourses in India, I emphasize the inextricable link between the nuclear bomb and neo-colonialism in the contemporary globalized world. Moreover, I interrogate in this study how radioactive masculinity (ies) relate to the development of (pro) nuclear publics and resistive counterpublics in the global sphere. Finally, I critically assess how radioactive masculinity underlines the contentious relationship between gender and weapons of mass destruction and enquire into how such a relationship shapes minority livelihoods and subjectivities. Following a cultural studies methodology this project explores the associations between the male body and the nuclear bomb by emphasizing the social, political and cultural dimensions of such a dialogic relationship. Through uncovering the role of the bomb beyond its materiality as an inarticulable object of mass annihilation, I also want to stress its role as a sociocultural object, which grants "freedom for western finance capital and for the vast transnational monopolies under...the umbrella... [of] conventional and nuclear weapons" (Thiong'o 17). As I will continually point out in the course of this study, decoding the nuclear bomb as a critical part 
of neo-colonial machinations involves deconstructing the historical correspondence it shares with the militarized white male body.

NuClear ANXIETY AND THE MALE BODY

Ken Cooper notes in his essay "The Whiteness of the Bomb," that "the bomb was built by people like me for the protection of people like me" (author's emphases; 83), which in encapsulating the ideologies of Anglo-American nuclear hegemony, emphasizes the highly gendered nature of the American military-industrial complex. By underlining the constant need for protecting the ontological status of "whiteness" and "masculinity", which has been a key motif in the colonial project, such a statement envisages the anxiety-fraught relationship between militarization and gendered bodies. In explicitly delineating the nexus between militarization, white masculinity and the nuclear bomb, I argue that this relationship of equivalence results in a hypermasculine anxiety. This anxiety which gets initiated through the masculinist bias embedded in American governmental and official discourses of the bomb-consequently reconfigures the male body in both Western as well as postcolonial political, literary and cultural artifacts. This study emphasizes that any analysis of contemporary masculinities and more specifically postcolonial masculinities will remain incomplete without acknowledging the role played by the nuclear bomb. By functioning as a "techno-national fetish" (Masco 11) the bomb makes dominant performances of masculinity symptomatic of the political and diplomatic supremacy of nuclear weapons states (NWS). In also exploring features of the unexploded nuclear bomb as a "preeminent national fetish... [which has] profound effects regardless of nuclear warfare," (Masco 17) I examine ideologies of radioactive masculinity emerging from the American military-industrial complex and its role in shaping the construction of postcolonial masculinities within the Indian subcontinent. 
Through analyzing performances of anxious masculinity in both American and Indian governmental discourses, literary artifacts as well as popular culture I argue that radioactive masculinity perceives the bomb as the idealized phallic/hypermasculine object, which needs to be embodied in order to achieve the desired masculinity. The process of trying to achieve this desired masculinity results in volatile and threatening male performances and entails a number of ideological moves such as: a) limiting the flow/intensities of femininities and subordinate masculinities that may challenge the dominant masculine constructs; b) "othering" any form/bodily manifestation that does not corroborate the constructions of hegemonic militarized masculinity; c) foregrounding certain manifestations of masculinity by making them contingent and analogous with performances of the war machinery/nuclear bomb ${ }^{\mathrm{ii}}$.

While substantial scholarship has been accomplished by scholars such as Carol Cohn and Brian Easlea ${ }^{\mathrm{iii}}$ in parsing out the gendered nature of nuclear technology, there remains a discursive gap in engaging with the effects of such a relation on postcolonial subjectivities. Similar to the strategies of elision in imperial narratives that disregarded the colonized body in favor of the white male colonizer, narratives ${ }^{\text {iv }}$ influenced by nuclear discourses have consistently denied representation to the feminine subject as well as subordinate masculinities. Such elisions found in Anglo-American and more specifically Cold War American cultural productions have provided a clear hierarchy: where hegemonic (militarized) masculinity exists at the expense of multiple masculinities and femininities. This model of "achievement oriented masculinity... [that] produces a solid impervious and self-sufficient body...both desirable and threatening" simultaneously creates a crisis since such a body is "ultimately a fragile creation determined by its own failures" (Hatty 117). In closely reading primary and secondary texts from both the American and the India sphere, my project charts the contours of such militarized forms of 
hegemonic masculinity—emphasizing the necessity of understanding the structures of radioactive masculinity in order to facilitate a decolonizing narrative.

It must be mentioned here that this project does not merely look for representations of masculinity in literary, cultural and political documents related to nuclearization, but rather interrogates why fears and apprehensions about the nuclear are always already manifested through masculine anxieties, fantasies or acts of hypermasculinity. While hearkening back to the societal concerns with nuclear proliferation envisaged by the now-forgotten project of nuclear criticism $^{v}$, this study breaks from the insular traditions of the aforesaid theoretical model, which by developing "certain linguistic and rhetorical features... [reduced] its intelligibility to nonspecialist readers" and limited "its potential usefulness to anti-nuclearism as a social practice" (Ruthven 9). Instead in parsing the contingent relationship between hegemonic militarized masculinity and the nuclear bomb- through an analysis of political, social and cultural texts-I argue that there is a systemic gendered narrative that lies at the basis of the nuclear arms race, which continues to influence our lived, conceived and perceived lives.

In acknowledging that: "For many years now our profession [teachers] has also been 'fearfully averting its eyes' from what I believe should be one of the central concerns of our teaching and research: the threat of nuclear war," (Zins 13) I emphasize the pedagogic importance of cultural productions emerging from nuclearization. While the end of the Cold war and the easing off volatile nuclear powers from their martial stands has undoubtedly allayed midtwentieth century fears of an imminent nuclear apocalypse, the invisible spectre of the bomb continues to dominate global proceedings. I argue that the perceptible invisibility of the bomb from everyday life is a constructed illusion, maintained by the epistemic apparatuses, which have emanated from the bomb itself. In extrapolating the workings of these epistemic apparatuses, I 
show that gendered nuclear discourses continue to influence processes of radioactive colonization in both Anglo-American and postcolonial spaces. As I trace the associations between hegemonic militarized masculinity and nuclearization across diverse spatio-temporal contexts, I continually emphasize the potential of the bomb as a "world making enterprise that can reorganize how people experience everyday life" (Masco 11). While critics such as Patrick Sharp, Joseph Masco, Paul Williams and Rey Chow have already underlined the necessity of perceiving the bomb as a cultural object and not merely a technological product, this study goes a few steps further. In demonstrating that the Anglo-American nuclear imagination emerging from the American military-industrial complex is unquestionably gendered, I show its decisive role in altering socio-cultural spaces around the world where bombs are located.

\section{MAY 1998: A PIKADON FOR THE RADIOACTIVE (MALE) POSTCOLONIAL}

India's nuclear tests were conducted to shore up people's fluffing self-esteem. India is still flinching from the cultural insult of British colonialism, still looking for an identity. It's all about that (Barsamian and Roy 37).

The story of atomic energy is also the story of postcolonial India (Abraham 5).

Survivors of the 1945 atomic blasts in Hiroshima and Nagasaki used a specific word to describe their reaction to the nuclear bomb that inexplicably changed their lives_pikadon. Loosely translated, this portmanteau word combines the Japanese words pika (meaning 'electric flash') with don (meaning 'thunderous boom'). The word in its entirety is very often used in popular culture to describe the effect of the blinding sound and light on the hibakusha or survivors of the atomic bombings. Unfortunately, those who were closest to the epicenter of the bombings and perished would have merely seen the pika or the flashing light. The closeness to the epicenter of 
the blast would mean, "[T] hey did not hear the thunderous clap that followed the bright flash because they were simultaneously hit with the full force of the bombs" (In their Words). The word pikadon, which is considered a synonym for the atomic bomb, has been a symbol of catastrophic destruction in Japan for the last half-century and more. But more importantly, in recent years the word pikadon is being understood across the world ${ }^{\mathrm{vi}}$ as a synonym for what the bomb means culturally, "not about an event 60 years ago but about now and the future" (my emphasis; In their Words)

Therefore, it becomes increasingly important to emphasize that the events transpiring within the Indian subcontinent in the month of May 1998 did not merely reflect the nuclear politics of two sparring nations. For the first time there had been a cultural pikadon in the Indian subcontinent and the flash and boom of the nuclear tests had percolated far beyond the irradiated desert sands of the test ranges, into the national imagination of the postcolonial male. The fervent nuclear nationalism that had been ignited in the subcontinent, post the nuclear tests in 1998, drove home a crucial but repressed aspect of nuclearity within the subcontinent - that "the issues of national masculinity, self-esteem and anger over Western indifference were prominent" (Krishna 69). This dissertation in foregrounding the need to acknowledge this troubled nuclear anxiety argues for the existence of a specific masculine subjectivity within the Indian subcontinent. Postcolonial masculine subjectivity emerging from the exploitative legacies of colonialism, is always already anxious about its subordinate position in the hierarchy of global masculinities, and continually seeks to redeem itself through its association with radioactive masculinity — consequently giving rise to the radioactive postcolonial.

While the story of atomic energy might quite well be "the story of postcolonial India," (Abraham 5) this study in using that framework goes a step further to argue that the story of 
postcolonial India is indeed also the story of the radioactive (male) postcolonial. The radioactive postcolonial is truly a term that amalgamates aftermath. Much like the radioactivity that is produced and sustained in the aftermath of the nuclear bomb, the postcolonial condition exists in the aftermath of the processes of colonialism. In that sense both these terms are inter dependent on each other, each contingent on the other for its meaning. Simply put the radioactive postcolonial condition, as I argue in this study is deeply implicated in the processes of neocolonialism and manifested through the hypermasculine ideology lying at the basis of nuclear technology. The reasons for postcolonial nuclear anxiety therefore can be easily understood as a fear, emanating and sustained through the excesses of neo-colonialism or more specifically as Hazel Carby notes based in the phenomenon of Americanism:

[a]n aggressive planetary dominance abroad supported and promoted by an unlimited, self-righteous arrogance at home, both of which result in an unleashing of violence against people and the environment unprecedented in world history (12).

In understanding the workings of the Americanism that produces the radioactive postcolonial, this dissertation puts forward the claim that the nuclear bomb plays an undoubtedly pivotal role in creating and manifesting these symptoms of Americanism.

\section{OUtline OF Chapters}

Chapter 1 is a historical survey divided into three sections: a) section one chronicles the threats of post-Depression era emasculation as well as that of an adversarial hypermasculine Nazi Germany, which catalyzed the need for a remasculinization of the traditionally masculine American body politic. Through an analysis of American military recruitment posters as well as 
popular culture artifacts, I show that while nuclear technology is not inherently gendered, both the bomb and its production spaces were pre-discursively masculinized in order to counter the supposed feminization of America. ; b) section two will explicate how radioactive masculinity arose and was sustained within the American-military-industrial complex, anticipating the ideologies of gendered containment Cold War culture. Representative American documents analyzed in this chapter include the Smyth Report of 1945 and the Franck Report, which will allow me to decipher how metaphors of maleness have been an integral part of the American military-industrial complex. ; c) section three deals with how the structures of radioactive masculinity have been transferred into postcolonial spaces. In tracing the development of nuclear weapons in India I underline the postcolonial fetishization of atomic power-as an apparent mode of resistance against the political and cultural domination of erstwhile colonizers as well contemporary neocolonialism. The key texts from the postcolonial sphere are the communications between Dr. Homi J.Bhabha (The 'father' figure of the Indian Nuclear Program) and Jawaharlal Nehru (the first Prime Minister of India), regarding the establishment of the Tata Institute of Fundamental Research (TIFR), which was established in 1954 to further the nuclear bomb program in India. ${ }^{\text {vii }}$ While scholarship exists on how American governmental documents related to nuclearization are seminal to the development of techno-strategic discourse $^{\text {viii }}$, my intervention in this chapter will examine how the effects of radioactive masculinity progressed much beyond the domain of the Anglo-American military-industrial complex. I explore how the institutionalized terror of the Cold War propagated through nuclear weapons finds manifestation in the Indian subcontinent, through the perceived association between nuclear weapons, statecraft and the national security apparatus. My reading of the technical documents from the American sphere will also underline the processes through which 
nuclear technology was constructed as a hypermasculine science, consequently becoming synonymous with the male bodies of scientists that were associated with the American nuclear project. Further, by analyzing the fissures and inconsistencies in the discursive construction of the radioactive male (in American nuclear discourse) I will elucidate on how such a construct was percolated into the postcolonial space.

Chapter 2 traces the development of the American nuclear public sphere and explores how the cessation of aboveground nuclear bomb testing fundamentally altered the nature of hegemonic nuclear discourse. I demonstrate how the removal of nuclear testing from the public arena was accompanied by an abstraction of the catastrophic potential of the nuclear bomb. This move, I argue, to reconstitute the bomb from a performative state-secret to a dominant discursive cultural-political artifact allowed radioactive masculinity to disseminate its influence beyond the limited techno-masculine space of the Manhattan Project. I emphasize here that the reconstitution of nuclear discourse beyond the domains of the military-industrial-scientific complex, which followed the remission of aboveground testing did not imply a democratization of knowledge about nuclear weapons. Rather the hegemonic power implicit in nuclear weapons - and radioactive masculinity — had now been transferred into the discursive tropes of contemporary popular culture. Textual signifiers that were created for public consumption in the post-1962 (aboveground testing) nuclear era maintained discursively, governmental nuclear hegemony. The newly emergent "nuclear public sphere" was therefore a pseudo public sphere: a result of the concerted governmental effort to provide the public domain with an illusion of having a stake/say in the nuclear discourse, while in reality nuclear policies and decisions were still deeply entrenched within the military-industrial complex. I conclude by pointing out that the simultaneous development of nuclear counterpublics during this era—who challenged the 
dominant narrative of American nuclear discourse through representative cultural productions such as Stanley Kubrick's Dr. Strangelove — was synonymous with deabstracting the ideals of radioactive masculinity. I explicate here how Kubrick's movie had for the first time in public discourse, focused the audience's gaze on the originary point of nuclear weapons - the militaryindustrial complex. In unveiling the highly secretive and privatized nature of this technoscientific domain, which had completely alienated themselves from the concerns of the public domain Kubrick promotes the importance of nuclear consciousness to his audience - thereby challenging dominant publicity about the bomb.

Chapters 3 and 4 are allied chapters, which build on the theoretical framework foregrounded in the introduction and the first chapter. In Chapter 3, I show how radioactive masculinity percolated into American Popular Culture through a close reading of canonical nuclear fiction. By looking at both militarized and subordinate (non-hegemonic) male figures in Neville Shute's On the Beach (1957) and Pat Frank's Mr. Adam (1946), I show how these texts are exemplary in illustrating the anxieties implicit in American radioactive masculinity. This textual analysis is preceded by a section that emphasizes how such texts - as products of a tumultuous period for masculinity in America - are influenced by societal trends that saw traditional gender roles being reified, especially in the period between 1949 and1960. The fear of American sovereignty being challenged — externally by the USSR's nuclear weapons and internally by the "penetrative" ideologies of Communism - meant that American sovereignty and the concomitant American manhood needed to both physically and psychologically assert its dominant status within and beyond its boundaries. I point out that policies of containment integral to American Cold War nuclearization shaped the representations of masculinity in the aforesaid texts, subscribing to the national meta-narrative of containment that "attempted to 
reconcile the cult of domesticity with the demand for domestic security" (Nadel xi). Since within the American mythos this attempt at maintaining the cult of domesticity has been traditionally equated with the existence of white masculine figures, such characters find a predominant role in these narratives. By analyzing the fissures and inconsistencies in the discursive construction of the radioactive male in American nuclear fiction, I also trace a link with the questioning of radioactive masculinity within postcolonial fiction.

In Chapter 4, I pair my reading of American nuclear fiction in Chapter 3, with lesser known Indian speculative fiction such as Sami Ahmad Khan's Red Jihad (2012) and Mainak Dhar's Line of Control (2009). I argue that these texts - through their focus on the radioactive Indian male - inaugurate a concurrent critique of postcolonial radioactive masculinity as well as the American and Indian military-industrial complexes. Apocalyptic settings in these speculative texts provide a topos for enacting postcolonial masculine anxieties, which are subsequently countered through making male bodies contingent on the volatile performances of destructive military technology. I stress the unique capability of speculative fiction that as a "fuzzy"- genre it is able to question the gendered narrative of techno-scientific capitalism, which gives rise to apocalyptic technologies and the resultant catastrophes. In utilizing R.W Connell's conceptualization of "hegemonic masculinity," I also preface my analysis with a section that explores the reasons behind the emergence of postcolonial masculine insecurities, which are a result of India's colonial history and its continued legacy within the subcontinent. Both Khan and Dhar's writing posit situations where the dominant constructs of postcolonial radioactive masculinity result in failed performances of manhood, which mirrors the fate of American radioactive (white) males. These paired chapters vitally underscore that while in America radioactive masculinity has been normalized through its percolation into popular culture and 
literature[iii], in India both the hypermasculinity of the military-industrial complex as well as the related anxieties were largely latent, waiting to emerge in its full shape following its nuclear tests in 1974 and 1998.

In Chapter 5, a comparative analysis of Native American literature with postcolonial Indian texts from the Bishnoi community allows me to show how the colonizing ideals of radioactive masculinity exploit soft spaces_-defined by Paul Williams' as “pre-colonized flat unmapped bare canvas on which heroic exploits can be mapped" (author's emphases; 33)_existing within the boundaries of a nation-state. Joseph Masco remarks in The Nuclear Borderlands, that nuclear technology has "consistently targeted minority communities, creating a new form of global environmental discrimination some have called radioactive colonization" (author's emphases; Masco 27) an assertion that is vital keeping in mind that historically atom bombs have been tested in soft spaces. In North America the first bomb was built and developed on Native American lands in New Mexico, while in India the first atomic bomb was exploded in Pokhran, Rajasthan in 1974, which is home to the Bishnois, one of the earliest eco-conservationist tribes in the subcontinent. In both the Native American and the Indian context, the land on which nuclear technology was being tested are perfect examples of soft spaces, allowing for the implementation of the heroic and colonizing ideologies of radioactive masculinity. The nature of exploitation practiced in the tests at Alamogordo, New Mexico was derived explicitly from the ideals of white radioactive masculinity while the tests in Pokharan, India, although of an indigenous nature (since it was carried out by Indians), reflected the same hypermasculine ideals of the American military-industrial complex.

While the detonation of the bombs can be seen as a culminating performance for the hypermasculine ideals of the nuclear complex, this chapter locates how these ideals reconfigured 
the soft spaces where these detonations were performed. Chapter 5 begins by explicating how the trajectory of radioactive colonization is facilitated through the structures of radioactive masculinity. I show the intrinsic link between colonizing scientific methods and gendered nuclear discourses and highlight the role of this strategic scientific nexus in systematically carrying forward the ideologies of whiteness and masculinity. The ubiquity of this nexus in all nuclear weapons states allows the implementation of radioactive colonization in both Anglo-American and postcolonial spaces. This is especially demonstrated in how Native American communities in America and the Bishnoi community in India — both non-normative subjectivities - have been marginalized by the respective country's nuclear ambitions. The following two sections of this chapter foreground the importance of narratives and tactical storytelling as resistive tactics, which can challenge such strategic structures. By juxtaposing an analysis of Native Americanperspectives on the bomb—represented by Leslie Silko's Ceremony —with socio-legal artifacts from and about the Bishnoi community, I show how such subversive counter narratives belong within a tradition of postcolonial ecologies, which interrogates dominant discourses of globalization.

Chapter 6 explores how the hypermasculine anxiety embedded in Anglo-American nuclear historiography came to create conditions for the "national fetishization of the nuclear bomb" (Masco 12), as a currency of global power. These obfuscating tendencies of nuclear historiography, emphasize the colonizing teleology of nuclear technology, which has continually been defined through its association with national strength, militarization and foreign policy strategies. Consequently, while existence in the atomic age implies a literacy of the nuclear, discussions about how nuclear discourse continuously affects our lived realities have been few and far between. While state-sponsored civil defense propaganda such as Duck and Cover are no 
longer foregrounded as a part of American education, contemporary ventures such as the Nuclear Literacy Project (NLP) illustrate the global influence of American nuclear discourses and policies. Such state-sanctioned metanarratives that privilege only certain identities and forms of knowledge about nuclear technology—have "preclude [d] the possibility of mutual, authentic and transformational dialogue between nuclear officials, citizens and the organized members of nuclear counter publics” (Taylor et. al 6) in other Nuclear Weapons States (NWS) as well.

The first section of this chapter explores the development of nuclear historiography within the gendered structures of the American military-industrial complex. I emphasize how this tradition of masculinist nuclear historiography, developed in America during the post WW-II and Cold War period led to the development of civil defense propaganda as well as contemporary nuclear epistemic apparatuses like the aforementioned Nuclear Literacy Project. Secondly, I demonstrate how Anglo-American nuclear historiography leads to the development of atomic subalterns ${ }^{i x}$ and subsequently catalyzed the problematic construction of nuclear nationalism as a strategy of postcolonial resistance. Finally through analyzing Indian nonfictional anti-nuclear texts I argue that they deconstruct the traditions of hegemonic nuclear historiography, which reinserts oppressive and hypermasculine modes of imperial domination into postcolonial India.

In developing this argument I adopt Delueze and Guattari's definition of minor literature, as cultural texts which don't "come from a minor language; it is rather that which a minority constructs within a major language" (1) and has distinct political potential for resisting dominant narratives. Due to the different time periods at which the American nuclear program and its Indian counterpart developed and found fruition, the minor literature which critiques them (in their respective countries) appears at different temporal points. While in the United States the 
cessation of above ground testing in 1963 had led to the change in the nature of the nuclear public sphere, and initiated a critique of the dominant hypermasculine ideologies prevalent in the post WW-II period, a similar response was catalyzed in India after the second set of nuclear bombs tests in 1998. I emphasize that Amitav Ghosh's non-fictional monograph Countdown and Anand Patwardhan's documentary War and Peace (both produced in the aftermath of the Indian nuclear tests in 1998) function as dissenting postmodern signifiers against the narrative of hypermasculine nuclear nationalism. By challenging the symbiotic relationship between radioactive masculinity and nuclear nationalism, these texts initiate Nucliteracy-a dynamic multimodal form of literacy — that interrogates dominant and official publicity/secrecy about the bomb.

Finally, in a pithy epilogue, I emphasize that while the end of the Cold War might have provided a respite to the fantastic visions of nuclear apocalypse, the Atomic Age is far from being a benign relic of world history. In fact it is in the interest of the high nuclear priests to construct nuclear war as "phantasmagoria... a spectral fascination...[to] distract attention from the ongoing daily machinations of the U.S. nuclear complex" (Masco 20) and make it a part of our banal quotidian. Considering that nuclear threats are omnipresent in our everyday life shaping our political, technical and social identities, the only way to counter such a phenomenon would be develop an awareness of nuclearization. My contention is that this dissertation through exposing the hypermasculine ideologies lying at the basis of nuclearization questions the obscure linguistic and "fabulously textual" (Derrida 23) nature of the bomb. In forcing a re-acquaintance with the physical threats of the bomb, I inaugurate the importance of being nuclear literate since "[T]he bomb isn't in your backyard. It's in your body. And mine" (Roy 51). 


\section{Chapter 1: Documenting Radioactive Masculinity: From the Manhattan Project to the Postcolonial Bomb}

India declared its manhood last spring by blasting five nuclear devices. "It had to be done", said the outspoken Hindu nationalist leader Balasaheb Thackeray, "we had to prove that we are not eunuchs (Basu and Basu 39).

In Inclusive Masculinities, Eric Anderson chronicles his experience of meeting Deter, an on-air radio personality from a rural American town, whose offline personality as a staunch supporter of gay rights was completely at odds with his "homophobic on-air sentiments" (Anderson 1). Analyzing this particular phenomenon, Anderson points out that "homophobic discourse [as] a method of retaining...heteromasculine capital [has]...served as a form of heterosexual and masculine social currency" (1). Deter's need for this gendered currency was not surprising as his radio broadcasts catered toward an overtly masculinized audience: football fans. Such discriminatory performances that often characterize strategies of gaining heteromasculine capital are, however, not limited to individual subjects. Mirroring Deter, whose on-air rants kept his heteromasculine identity prominent, the Indian nuclear tests of 1998 signaled the supramasculine performance of a burgeoning postcolonial nation-state. The euphoric celebrations that were sparked across the country heralded a moment when India had finally found-through nuclear weapons - apparent access to the global currency of masculinity. Overnight, India laid claim to being an undisputed stakeholder in the battle for geo-political supremacy. But more importantly, as the Hindu nationalist leader Balasaheb Thackeray reminded the polity, it was the moment that had supposedly culminated the crisis of masculinity tormenting the country since the onset of colonization. 
In understanding the resonance between nuclear weapons and their socio-cultural power-as gendered objects that potentially affect the sovereign narrative of a nation - this chapter explores the associations between structures of manhood and the global proliferation of nuclear weapons. Scholars have continually expounded on the links between hegemonic masculinity, nationhood and sovereignty, while often eliding the influence of weapons of mass destruction within such a nexus. Beginning with a focus on the American military-industrial complex I extrapolate here how this establishment enabled the conditions for the emergence of a specific form of hegemonic militarized masculinity: namely radioactive masculinity. I demonstrate that the ideals of radioactive masculinity find inception within the work and aftermath of the Manhattan project, and show how such a discursive construction lay at the basis of gendered Cold War containment culture. I conclude by pointing out that the ideals of radioactive masculinity being fluid have been seamlessly transferred to postcolonial nuclear spaces that are ensconced within Anglo-American narratives of scientific progress and modernity. This adoption of radioactive masculinity outside America has been facilitated in erstwhile colonized sites through nuclear communications, discussions and technical documents modeled on the American military-industrial complex. Such hegemonic postcolonial nuclear discourses_-based within military-industrial complexes — are influenced by their AngloAmerican counterparts, which themselves emerge from the contingent association between militarization and gendered bodies.

\section{HyPERMASCULINITY AND THE AMERICAN NATION}

Manhood means different things at different times to different people (Kimmel 3). Across paradigms, performance is a moving target, for it is defined as a dynamic event and not a static entity (McKenzie 53). 
Discussions about the performance of hypermasculinity must take into cognizance that the terms performance and masculinity are not singular monolithic ideals: but as the opening quotes enunciate, to be understood through multiple paradigms of performance and manhood. Scholars theorizing on masculinity agree that the concept of male itself is a fluid term that is dependent on the "cultural meaning and prescriptions that are assigned to the biological sex" (Kimmel 1) and are "encoded through a complex process of social, medical and personal gender construction" (Jarvis xi). Unsurprisingly Kimmel notes, “[A]merican men have no history," emphasizing that that they have "no history of themselves as men" (1). Such an assertion underlines the discursive gap in the field of masculinity studies, which until recently impeded the examination of masculinities as a fluid construct across spatio-temporal boundaries.

Kimmel highlights that since the existence of America as an independent nation, different paradigms of masculinity have existed at a certain time and certain forms have gained precedence over others to be understood as the hegemonic masculinity of that era. Charlotte Hooper concurs with Kimmel and points out that in fact the existence of hegemonic masculinity is predicated on the notion that multiple masculinities exist at any point, with hegemonic masculinities gaining dominance in their respective eras. If hypermasculinity is understood to be synonymous with the hegemonic masculinity of a certain period—or in other words the form of masculinity that must be adhered to or else be susceptible to the risk of being feminized/othered - then hypermasculinity will understandably always already involve a considerable amount of anxiety. Such hypermasculinity as Donaldson notes:

[i]s exclusive, anxiety-provoking, internally and hierarchically differentiated, brutal and violent. It is pseudo-natural, tough, contradictory, crisis-prone, rich and 
socially sustained. While centrally connected with institutions of male dominance, not all men practice it, though most benefit from it (645-46)

Kimmel highlights that due to the contiguous existence of hypermasculinity and its resultant anxieties, the American hegemonic male has tried three strategies to deal with it across time periods: to control himself and his own destiny, to exclude others (non-whites, women), and to find avenues of escape when presented with situations of pressure. It is vital to note here that both the anxieties and their resultant coping mechanisms have been primarily restricted to the domain of white heterosexual masculinity, which constantly aims to maintain the status quo. As Hamilton Carroll notes in Affirmative Masculinity white masculinity in general and more specifically within America has historically "suffered from the misconception that their identity has been put in crisis" and attempted to "recoup political, cultural and economic authority in the face of a destabilized male consensus" (4). Such attempts have resulted in the strategy of claiming "white injury...a way of protesting the erosions of white men's advantage while denying that the advantage ever existed" (5). In chronicling the trajectory of these masculine anxieties, Kimmel points out that the initial hypermasculine figure in American history was the construct of the Self-Made Man - a male figure who emphasized his dominance by the wealth and success that he enjoyed in the public sphere. Not surprisingly, the self-made $\operatorname{man}^{\mathrm{x}}$ managed to displace other forms of hegemonic masculinity that existed in the $18^{\text {th }}$ and $19^{\text {th }}$ century such as the Genteel Patriarch (wealthy aristocrat) and the Heroic Artisan (the manual worker) which confirms Charlotte Hooper's assertion that hegemonic masculinity must come into prominence through the sublimation of other models of masculinity.

Significantly, the anxieties of the self-made man in $18^{\text {th }}$ and $19^{\text {th }}$ century America can be related to the development of capitalist economies, which have been built on the ideology of men 
being the masters of their own fate. The self-made man was a construct that thrived on the enterprising man who would gain considerable clout in society by the dint of his own hard work and would consequently be understood as the provider and protector of his family. As can be understood from the concept of the self-made man, the core anxiety for him would be whether he was in control of his own destiny, which would be manifested in his ability to manipulate his economic surroundings. However, towards the end of the $19^{\text {th }}$ century the advent of "rapid industrialization, technological transformation, immigration and the entry of females" (Kimmel 7) into the workforce implied that no individual man could be entirely in control of his economic situation, thereby leading to the breakdown of the self-made man as the hypermasculine figure.

Kimmel underlines that at the end of the century the term "manhood was gradually replaced by the term masculinity" (my emphases; 120) to be understood as all behaviors and attitudes that were not related to the polar opposite understood as femininity. ${ }^{x i}$ The period following the era of the self-made-man, 1900-1930, saw the gradual decline of the working man — who shaped his own destiny through labor while also providing for his family — as the dominant masculine figure. Although the period before WW-I had provided a brief emergence of the male factory worker (as the new hypermasculine figure) the presence of men at the war zones meant that most available jobs were transferred to a female workforce. Thus, after the end of WW- I a large percentage of the American male population was unemployed and the few available jobs were going to the already predominant and skilled female workforce. This jobless anxiety of masculinity was exacerbated by the Great Depression that saw the unemployment figures for males go up from 16 to 25 percent in a matter of three years from 1930-1933 (Kimmel). 


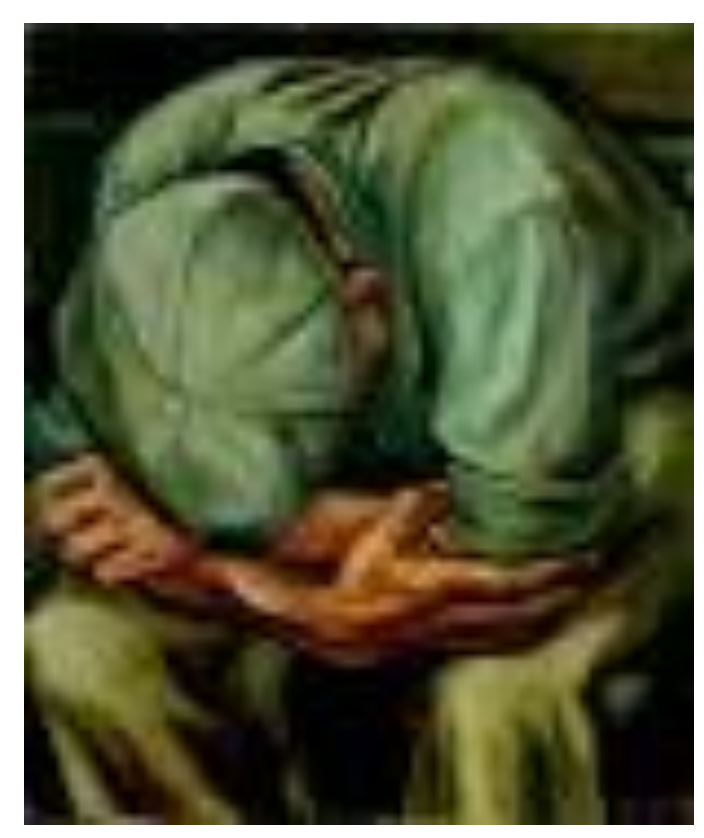

Figure 3: Idle Hands

Will Barnet's lithograph Idle Hands provides a succinct illustration of the crisis plaguing American masculinity during this period as a presumably unemployed worker is seen hunched over, with his head cradled in his arms. The post-depression era, when "approximately one quarter of the male work-force was unemployed and millions of others reduced to part-time and federal relief work" (Jarvis 10) meant that American masculinity was anxious and in desperate need for a revival; a chance that was provided by the onset of the Second World War. Jarvis notes that this Depression era image of anxious masculinity needed to be desperately remedied: for the American nation to be considered a worthy adversary for its enemies. McClelland Barclay's 1942 navy recruitment posters showing sinuous male bodies engaged in loading guns and other martial feats provides direct evidence, of how "representations of powerful male bodies [were] used to communicate impressions of national strength during the war" (Jarvis 13). Such strategies to shore up anxious American masculinity into a government-promotedhypermasculine figure were undoubtedly to boost the metaphorical power of a traditionally masculine body politic. 


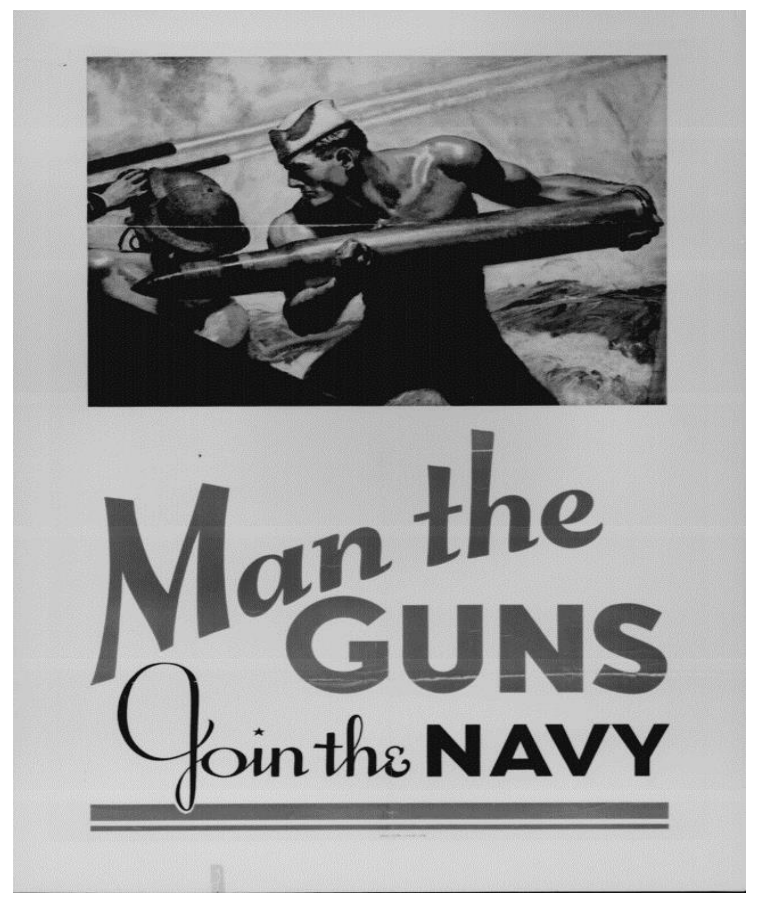

Figure 4: Man the Guns (1942)

This is hardly surprising considering the fact that America was locked in conflict with Germany, a country that thrived on the notion of a hypermasculinized fatherland. Conscious efforts were therefore made by the American government to transform the soft post-Depression era white American male into the hard soldier, who would simultaneously represent the virility of American manhood as well as the power of American nationhood. Most importantly the posters created by Barclay provide important clues about contemporary ideologies of hegemonic masculinity, which were beginning to equate militarized (white) men with hypermasculinity. The slogan "Join the Navy" put forward the implicit argument that being part of a militarized space would translate into gaining certain forms of heteromasculine capital, which would automatically grant access to hegemonic masculinity. Such gendered capital—American war ideology professedwould rejuvenate the unemployed and apparently remasculinized the American man of the postDepression era.

It must be noted here that before WW-II, the hegemonic masculinity of an era irrespective of its martial linkages — be it the Self-Made man or the factory worker-would organically be construed as the hypermasculine paradigm. However, the pre-WW-II period saw a deliberate effort by the American government to specifically equate militarization with hegemonic masculinity. A key example would be the radical transformation in the figure of Uncle Sam-the ideal representative of white masculinity — who became increasingly muscular reflecting the 
physicality of American soldiers. Subsequently Uncle Sam replaced Lady Liberty and Lady Columbia as the sole representative symbol of the American nation.

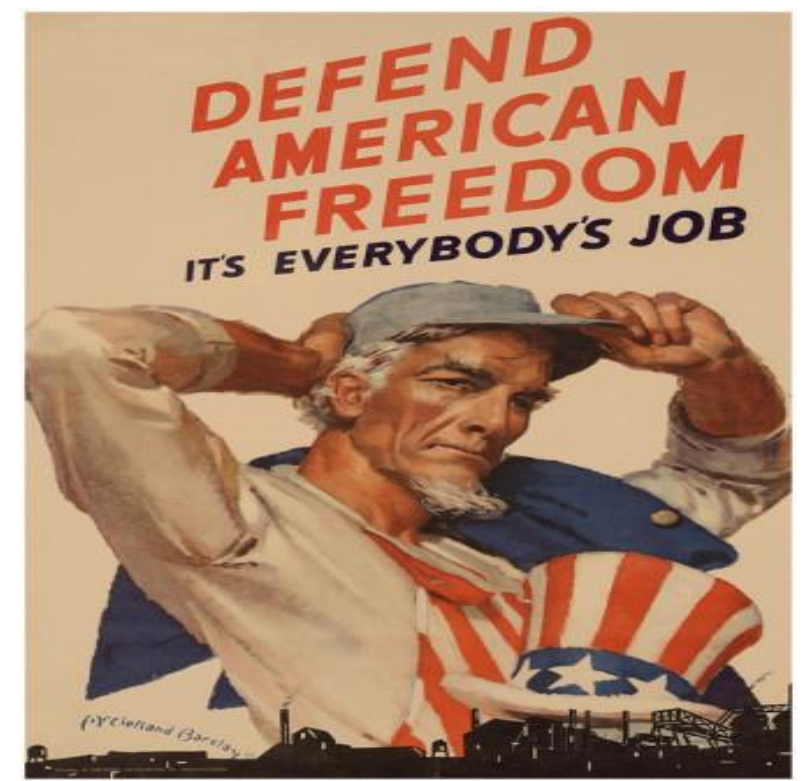

Figure 5: WW-II Propaganda Poster
This period that saw the advent of white "hegemonic militarized masculinity" (Jarvis) anticipated the post-WW-II hypermasculine American figure, which is always already tied to the military industrial complex. Therefore, a simultaneous stress on strengthening of the white male soldier's material body along with an emulation of this figure became key toward promoting the American national ideology of this era. Such a national ideology meant that

(white) soldier's bodies underwent a strict regime of "medical examinations, physical training and sexual containment" (Jarvis 25). These regular exams included checks for homosexuality as well as the containment of soldiers from women of "easy virtue" through military sanctioned brothels: as one of the only places where soldiers could engage in heteronormative sexual relations (ibid). Clearly, the anxieties of white hegemonic militarized masculinity implicit in the national ideology were: the risk of soldier's bodies being contaminated through female contact or through homosexuality and the government needed to keep such factors in check through institutions like the Civilian Conservation Corps (1933-1942) (Jarvis).

Such was the anxiety and obsession of the American state to conserve this white male militarized figure — associated with the might and sovereignty of American nationhood - that the American public was shielded from any images that might portray the vulnerability of these 
soldiers. Wounded soldiers were almost never portrayed in official documents and death of soldiers was sanitized with the help of glorified interments that concealed the body from public view (Jarvis). It was therefore not surprising that this equation of hegemonic masculinity with white militarized masculinity would be a critical component in shaping the contours of arguably the most important project in American martial history—The Manhattan Project.

\section{AMERICAN Hegemonic MASCULINITY AND THE NUClEAR BoMb}

[t]here exists within the multiplicity of types [of masculinity], a largely symbolic, though legitimate, ideal type of masculinity that imposes upon all other masculinities (and femininities) coherence and meaning about what their identities and positions within the gender order should be... while this ideal emerges and develops from within the sociocultural milieu, it becomes essentialized and ultimately reified as the benchmark against which all men must gauge their success in the gender order. This ideal is hegemonic masculinity (my emphases; Howson 3).

Whether power is conceived in classical terms, as the power of the hegemon to govern the subject or... as a disciplining force dispersed throughout society and implemented by many kinds of institutions, science and technology are indispensable to the exercise and expression of power (my emphases; Jasanof 14).

Artifacts, especially technological ones, are shaped by the ideologies that produce them. This fact holds especially true when the American nuclear bomb project is put under the analytical scanner. The national anxiety that had gripped American masculinity in the post-depression era created a societal setup where the breadwinning laborer and his skills- the last effective model 
of American hegemonic masculinity—were considered increasingly feminine. Stephen Meyer, the labor studies scholar notes that

[r]emoving the male traits of brawn and brain from workplace skills, Taylorism and Fordism redefined skill as the endurance of repetitious and monotonous tasks and their speedy and dexterous performances. For both craftsmen and laborers their work became unmanly" (my emphasis; qtd. in Jarvis 17).

Roy Helton's 1940 Harper's article “The Inner Threat: Our Own Softness” perfectly captured the crisis that was plaguing the nation: that America "had become a soft, feminized nation" (qtd. in Jarvis 19). In contrast to Hitler's well-oiled war machine composed of vigorously trained and disciplined German soldiers, who had already occupied large parts of Western Europe, American men were found physically unfit for military service. ${ }^{\text {xii }}$

Therefore, the conditions preceding the construction of the nuclear bomb ensured that these objects of mass destruction were from the very beginning mired within the bounds of an overtly masculinizing setup: one that attempted to rehabilitate the injured manhood of a traditionally masculine nation. A muscularized Uncle Sam replacing Lady Liberty as the state symbol made it evident that "[f]or the US a country waging war with a hypermasculinized German fatherland, clearly a female national symbol would not do" (Jarvis 46). It seemed that "[f]or America to succeed in its upcoming war and for democracy to flourish in the world...the United States [would] need to reinvent its body politic and rebuild the individual bodies of its citizens" (Jarvis 19). Pertinently, while notions of hegemonic masculinity and hypermasculinity have always been key toward framing the ideals of American nationhood, arguably for the first time in the history of sovereign United States such ideals were being focused solely on physicality and more specifically manifested in the corporeality of white militarized bodies. As a 
natural consequence, by the time World War II came about, the muscularized military serviceman had replaced the factory-worker as the sole symbol of American hegemonic masculinity (Jarvis). This social and political desire for a model of hegemonic masculinity based in white male militarized bodies - that would counter both the "feminized American nation" (Helton) and Nazi hypermasculine insurgency—was precisely the framework within which the Manhattan project was conceived and executed. Although ideals of hegemonic masculinity have indeed existed in the American paradigm of nationhood long before the Manhattan project, the bomb became symbolic as an exemplary technological artifact, which would lead to the emergence of a remasculinized and invigorated American body politic. It was no wonder then that the specific form of hegemonic militarized masculinity, which hoped to achieve this aforesaid objective — both psychically and physically—would see itself contingent on the technological performativity of nuclear weapons. ${ }^{\text {xiii }}$

Before delving into the conditions that led to the rise of a very specific form of hegemonic (white) militarized masculinity within the American military-industrial complex, it is crucial to tackle overtly deterministic accounts of nuclear bombs: that argue for an implicit masculinity inbuilt within nuclear weapons. While I have noted in the introduction to this project that cultural connotations of power and masculinity have undoubtedly been historically associated, the specific reasons for a contingent association between white hegemonic masculinity and the nuclear bomb were very much determined by the socio-political situations within which it emerged. As Sheila Jasanof notes

[s]ocial and political arrangements for exploiting, resisting or quite simply accommodating technological change do not emerge, intact and fully formed, in response to innovation and discovery. The design of technology is likewise seldom 
accidental; it reflects the imaginative faculties, cultural preferences and economic or political resources of their makers and users" (my emphases; 16).

Thus, while the relationship between science and culture and their ability to reinforce each other has often been discussed, it is of paramount importance to avoid creating any hierarchy that assigns either of those two constructs any form of primacy over the other. This is especially relevant considering that a significant amount of discussions - that correctly emphasize the socially constructed, performative and normative characteristics of gender categories—often develop a cause-effect relationship between science and technology, and its influence (as well as impositions) on gendered bodies. My emphasis — in deciphering the relationships between nuclear weapons and hegemonic white militarized masculinity—is to recognize the dialectical relationship: where gendered ideologies and militarization form a theoretical and ontological setup that consequently develops a self-reflexive relationship with the settings where it emerges.

Thus, in deliberately avoiding assigning a causal primacy to either scientific innovation or the social conditions within which technological breakthroughs are achieved, I adopt the rhetoric of co-production from Science and Technology Studies to understand the phenomenon of radioactive masculinity. In investigating radioactive masculinity as a "socio-technical formation [that] loops back to change the very terms in which we human beings think about ourselves and our positions in the world" (Jasanof 2), I attempt to underline how this formation is produced and manifested rather differently in each individual context where nuclear weapons are produced, be it the Manhattan Project or within postcolonial spaces. Radioactive masculinity, as a very specific form of co-production emphasizes that, "the workings of science and technology cease to be a thing apart from other forms of social activity, but are integrated instead as indispensable elements in the process of societal evolution" (Jasanof 17). Since military 
technologies are not inherently gendered or "pre-discursively masculine" (Masters 116) it is critical to understand the nature of this hegemonic militarized masculinity that I term as radioactive masculinity, and its self-reflexive relation with the nuclear bomb and the Manhattan project.

While gendered bodies and technologies have been historically associated with each other, this cultural equation drawn between masculinities and technologies is not arbitrary since “powerful technological roles are predominantly occupied by men who thereby have a disproportionate influence in shaping new technologies" (Lohan and Faulkner 835). In supporting the view point that gender and technology share similar models of production, Jennifer Terry and Melodie Calvert argue that:

We could define gender itself as a technology according to the following propositions: Gender is an organized system of management and control, which produces and reproduces classifications and hierarchical distinctions between masculinity and femininity. Gender is a system of representation, which assigns meaning and value to individuals in society, making them either men or women $(5-6)$

Thus such inscriptions of gender onto technology and vice versa reveal "gender as [being] socially constructed, while simultaneously concealing this through technology's supposed

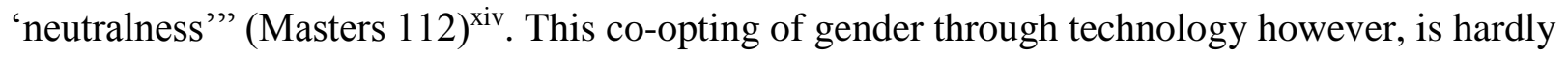
new since as Foucault points out by the end of the $18^{\text {th }}$ century the "docile body" of the soldier had indeed become the primary site for technological inscription by "making soldiers into machines" (Masters 113): 
The human body was entering a machinery of power that explores it, breaks down and rearranges it. A 'political anatomy', which was also a 'mechanics of power' was being born, it defined how one may have hold over others' bodies, not only so that they may do what one wishes but so that they may operate as one wishes, with the techniques, the speed and the efficiency that one determines" (Foucault 113).

Such an ideology became especially pronounced in the case of a nation like America, where manhood has been intrinsically linked to the strength of the body politic and more so during a period when the white male soldier was gradually being constituted as the new model of hegemonic masculinity. Therefore, while the gendering of technology as masculine has clearly been an implicit part of military discourses, what distinguished the Manhattan project was the rise of a new model of hegemonic militarized masculinity that made no claims at "naturalness".

Radioactive masculinity—arising from the anxieties of a "feminized American nation", an emasculated and unemployed male populace as well as the challenges posed by strictly regimented and "hardened" Nazi bodies—-meant that the bomb and its associated discourses needed to be not only male, but also set the paradigm that could sublimate all previous and contemporary models of global hegemonic masculinity. As the rest of this chapter and the larger project in general illustrate, this socio-technical gendered formation called radioactive masculinity, has consequently set the template for male performances inside and beyond the domain of Anglo-American military complexes. Consequently, such a structure of hegemonic masculinity contingent on nuclear weapons, gives rise to a very specific set of masculine anxieties: thereby shaping the narrative of nuclear proliferation as well as the spaces in which such weapons are produced. 


\section{The Mechanics of Co-Production: Radioactive Masculinity and the Manhattan Project}

The politics of the bomb are not written in its wiring diagrams (...) (Wellerstein 16)

"Doctor has just returned most enthusiastic and confident that the little boy is as husky as big brother." (Easlea 96) — this apparently innocuous message of birthing was delivered to the seventy-seven year old Henry Stimson, Secretary of War to the United States Government at the Potsdam Conference in July 1945. Understandably, the officers who had decoded this message wondered if the conference should be adjourned for a day's celebration at "such a virile feat" (ibid). Although the feat that had resulted in this message did not connote an act of biological emergence, it was definitely a cause worth celebration, as a quite extraordinary birthing had indeed taken place. Stimson had been informed through this cipher that The Trinity tests on July 16, 1945 had been successful and America had become the first nuclear weapons nation in the world.

While the aforesaid metaphor of male birth may quite easily be attributed to the historically gendered connotations of war as a masculine activity, such an account would grossly simplify the complicated gender dynamics of the Manhattan project. Deliberately crafted by the American military-industrial complex as an undertaking that would revive both the diminishing masculinity of American men as well as America's waning global stature in 1945-by producing an unimaginable technological artifact of mass destruction- the Manhattan project was preordained to be a site where both the technology to be produced and the creators of said technology would be masculinized, irrespective of their actual gender. While the masculinized philosophy that drove the discoveries in nuclear physics have been well documented ${ }^{\mathrm{xv}}$, little discussion exists about the political and military perceptions in America, which predicated that 
this unfamiliar and advanced science would reestablish America on the path to both masculine and global dominance.

Jordynn Jack notes the spatiotemporal framework of Los Alamos and the Manhattan Project in general are symptomatic of scientific projects that are "linked with positive outcomes...rather than the negative outcomes (such as environmental degradation or the replication of colonial systems of power)" (232). Vitally, auguring the Manhattan project as a techno-masculine space meant that one of the purported "positive outcomes" would be increased American geo-political dominance, achieved through a remasculinized national identity.

Therefore, even during the years preceding the official (and paradoxically secret) establishment of the Manhattan Project, "free exploration" granted to nuclear scientists by military-political administrators in America came with the strict caveat. It was made clear that the products of such a science were "political" (as the military-industrial establishment often reminded the scientists) and of far more importance for the military prospects rather than the intellectual progress of a nation.

My effort here is not to emphasize the political nature of science per se (an aspect which has been the subject of much discussion) but rather explicate the framework of the Manhattan project as not merely a singular space of scientific exploration but rather a cohesion of laboratories $^{\mathrm{xvi}}$, which were domains of highly politicized and gendered activities. It may be pertinent here to reference the work of Science and Technological Studies Scholar, Stephen Hilgartner, who notes that "[p]ractices for creating and contesting ownership....are deeply embedded in laboratories, where they shape both the internal workings of science and science's relations with the outside world" (qtd. in Jasanof 9). Evidence of such co-production is made apparent in The Report of the Committee on Political and Social Problems popularly known as 
The Franck Report, which was produced by scientists working at the Chicago Metallurgical Laboratory and named after its chair James Franck. This reported completed on June 11, 1945 only days before the testing of the first atomic bomb explicitly declares in its preamble that:

$[\mathrm{t}] \mathrm{o}$ treat nuclear power differently from all the other developments in the field of physics is [due to] its staggering possibilities as a means of political pressure in peace and sudden destruction in war. All present plans for the organization of research, scientific and industrial development, and publication in the field of nucleonics are conditioned by the political and military climate in which one expects those plans to be carried out (my emphases; Dannen, para 1 The Franck Report).

The report unequivocally declares that while progress in nuclear physics had been at the forefront of the science since the early twentieth century, the conditions that made the development of nuclear physics of paramount importance were "its staggering possibilities as a means of political pressure in peace and sudden destruction in war." The "political and military climate" referenced in the report delineated precisely those policies that looked at nuclear technology as a remasculinizing technology for the American nation. Easlea ${ }^{x v i i}$, Caputi, Cohn and Zarlengo have dealt comprehensively with how the Manhattan project was a gendered enterprise $^{\mathrm{xviii}}$, manifested in sexist metaphors and overtly masculinized idioms representing the techno-scientific fantasies of a birth, where the female figure had been completely elided. While such scholarship has undoubtedly exposed the gendered nature of the American atomic project, simplistic readings of these works may lead us to assume that such gendered language was merely a result of the skewed populace — consisting largely of male technicians and scientistswho worked on the Manhattan project. 
However, as I emphasize here, the gendered language, masculine metaphors and "other"ing of female and non-white communities_emerging out of the Manhattan project—were not merely strategies of asserting dominant masculine subjectivity. Such key aspects of the Manhattan Project were primarily a enactment of the combined anxiety engendered by both nuclear weapons and the socio-political ideals of white militarized masculinity. Psycho-historian Robert Jay Lifton captures a cross-section of this anxiety through the term nuclearism:

Nuclear weapons alter and blur the boundaries of our psychological lives, of our symbolic space, in ways crucial to our thought, feelings and action. The most contemporary deformation is a pattern, which may be best called nuclearism. By this term I mean the passionate embrace of nuclear weapons as a solution to our anxieties (especially our anxieties concerning the weapons themselves). That is one turns to weapons and to their power, as means of restoring boundaries (82).

In perfectly capturing the crises of the atomic age, Lifton unearths the paradox within which the relationship between hegemonic masculinity and the nuclear bomb situates itself. The Manhattan Project found fruition at a point in American history when the country was desperately seeking a virile masculine identity, which could effectively counter both the internal threat of postdepression era emasculated masculinity as well as the external threat of a hypermasculinized Nazi enemy force. This implied that the technological determinism ${ }^{\mathrm{xix}}$, which coded the nuclear bomb as masculine, emerged from an ideological setup that had preconceived the bomb as the panacea to these dual perils. Radioactive masculinity, as this study underlines was therefore designed to conserve the ideals of heteronormative white militarized masculinity, through making such a model contingent on arguably the most destructive force engendered in human history. 
Thus, while existent scholarship argues for a cause-effect paradigm where the nuclear bomb produced certain forms of masculine discourse that have fundamentally altered our understanding of this technology as well as the social effects it has produced; the exigencies, as I argue, were quite the opposite. The nuclear bomb and the concomitant gendered discourse arose within a space — the Manhattan Project — that had been presaged as a territory to promote and propitiate the same white male privileges, which were in fact responsible for the development of such a space in the first instance. Since the Manhattan project and its ultimate product— the nuclear bomb - were designed for continuing the ideals of white hegemonic militarized masculinity it was therefore natural that the discourses of radioactive masculinity emerging from them would reflect both the psychological anxieties of heteronormative whiteness as well as the physical anxieties associated with an unstable radioactive artifact of mass destruction. ${ }^{\mathrm{xx}}$

Therefore, this socio-technical co-produced formation — radioactive masculinityemerging within the American military-industrial complex, consequently implemented strategies of compartmentalization reflecting specific hypermasculine anxieties. These anxieties of white American heteronormative masculinity either perceived women as perpetual threats who needed to be contained or forced women to adopt and remodel themselves according to the model of masculinity in vogue within the Manhattan Project. Nowhere would this compartmentalizationarising from the anxieties of a militarized hegemonic masculinity contingent with the bomb-be more evident than the physical production sites and laboratories of the Manhattan Project. Although, male metaphors emerging from the project might make it seem that nuclear weapons production was an entirely male endeavor, such an inference would be entirely misleading. The origins of nuclear physics itself lay in the accomplishment of women pioneers in Europe such as Marie Curie, Harriet Brooks, Ida Noddack, Catherine Cammie and Irene Curie amongst others. 
Therefore any preconceived notion that the contours of American nuclear development were masculine (due to the male-dominated nature of this discipline) would be inconstant and fallacious.

Pertinently, the Manhattan Project while composed predominantly (and deliberately some would argue) of male figures had significant female participation in all domains: be it the scientific, domestic or administrative sphere. Such histories were and continue to be carefully elided by the structures of radioactive masculinity based within the American military industrial complex. This legacy of gendered elision is of course also a fallout of the carefully constructed gendered narrative of the bomb and its related events, which "bolster the epistemic authority of science, construct a patriotic narrative of duty and exclude the ethical and political considerations that were attached to the decision to build the atomic bomb" (Jack 231). However, while the collective memory of the Manhattan Project now, unequivocally considers it to be the work of masculine American patriots, the realities of the Manhattan Project are very far away from such simple categorizations.

Such segregationist attitudes seem quite baffling — unless the framework of radioactive masculinity is considered — since the work accomplished in the Manhattan project was not only limited to Los Alamos but dispersed across various other sites that employed a minority yet sizable percentage of women ${ }^{\mathrm{xxi}}$ Oral and written testimonies of women involved in the project found both online ${ }^{\mathrm{xxii}}$ and in print—-such as Julie Des Jardins' The Madame Curie Complex (2010), Jane Wilson and Charlotte Serber's Standing by and Making Do: Women of Wartime Los Alamos (2003), Eleanor Jette's Inside Box 1663 (1977), Leona Marshall Libby’s The Uranium People (1979), and Denise Kiernan's recently published book Girls of Atomic City: Untold Story of Women who Helped win WW-II (2013) - chronicle and critically assess the role of the women 
in the Manhattan project whom "science made invisible" (des Jardins 130). While such accounts chronicle multiple female figures who were subject to the systemic gender discrimination during this project, I will look at a few striking instances, which become exemplary of anxieties engendered by radioactive masculinity. Ruth Marshak, wife of the American physicist Eugene Marshak (deputy head of the theoretical physics group at Los Alamos) provides a particularly telling commentary of the politics of the era that categorized her role as a "physicist's wife":

[D]efense projects were started in college laboratories, armed guards began to pace the thresholds of physics buildings. One's husband grew more secretive about his work, and one knew that his job must be important, for he was immune from the draft. The physicist's wife realized that her husband, in wartime, was more than just a college professor - his was key profession in the defense of his country (Marshak qtd. in Des Jardins 109).

Marshak in describing the secrecy at Los Alamos emphasizes the heavy toll that it took on the wives of scientists who "felt like heroines in a melodrama... whisked away by a husband who had packed up her things, refusing to say anything about their destination" (132). As Des Jardins' notes Marshak was one of the many women whose:

[F]ormer identity was eradicated as numbers replaced her name on driver's license and tax forms. She couldn't vote, divorce, own a phone or a camera or speak freely. Like all wives of scientists at Los Alamos, she was fingerprinted and subject to background checks and readings of the Espionage Act (Des Jardins 133). 
Women were increasingly made aware of their apparently in-bred proclivities at gossiping that made them threatening bodies within the confines of the project. Through regular filming of movies such as The Next of Kin (1942) — a cautionary British war-time production about "a British officer's loose lips, which had led to the bombing of London" (133) - the scientists' wives were constantly reminded: that they were the repositories of secrets, which if leaked could endanger their male partners and more importantly the nation.

Biased rules of sexual conduct predicated by the military clearly demarcated that while male promiscuity was strictly a health concern, similar actions from female figures would be looked at as morally offensive and possible indicators of their treasonous propensity to leak information about the project. In fact as Des Jardins notes " $[\mathrm{t}]$ he military deemed a woman allowing men in her dorm an offense as severe as violent crime" (135). Such decrees are hardly surprising considering that the ideals of radioactive masculinity saw the masculinized American body politic as embodied in each of the white male figures involved in the Manhattan project ${ }^{\mathrm{xxiii}}$. Therefore any form of agency granted to the female entity meant a possible threat to both individual masculinity of the scientists and the contingent national security. The strategies implemented toward the wives of scientists provide evidence that women uninvolved in the technical aspects of the project were increasingly situated in a binary between access and isolation. Jordynn Jack in commenting upon this gendered hierarchy within Los Alamos comments,

[t]hese women were separated, both spatially and temporally, from the scientific activities at Los Alamos. A wire fence separated the Tech Area from the main living area, and for those without the proper security clearance, it represented a black hole that drew their husbands away from them (239). 
This separation was not merely based on who was more scientifically important, but also part of the larger ideologies of this techno-masculine space, which hoped to segregate the beacons of scientific masculine patriotism from the threats of feminization and possible leakage: of both masculine virility and national security.

Former identities of the female partners of male scientists that were eradicated from all public documentation coupled with the gendered demarcations within the project sites, showed the anxieties of a hypermasculinized set-up: one that needed to distance its primary threatnamely women — from any form of personal or national identification. Primarily, such strategies effaced both the individual affiliations of the female figures to their embodied identities as well as their national affiliations to the American body politic. These actions clearly delineated the process of reconstructing a feminized American nation into a hypermasculinized body politic: a structure that both disavowed and segregated itself from threats that could potentially challenge the status quo of white hegemonic militarized masculinity.

Although such a biased treatment of women — who were uninvolved directly with the Manhattan project—might have been justified (albeit fallaciously) by the military and political authorities, what seems baffling is that even female scientists and female technical workers intrinsically associated with the project were subjected to the same treatment. Laura Fermi the wife of renowned physicist Enrico Fermi and an accomplished scientist herself, faced a similar fate leading her to the conclusion that "women, by remaining ignorant about the lab were to avoid spilling the beans" (Des Jardins 133). While for the technically/administratively uninvolved woman, the ideologies of radioactive masculinity decreed the maintenance of strict separation from the laboratories and "Tech-Area," for the female scientist who had to be 
included within this techno-masculine site the covenant was simple: the disavowal of culturally coded feminine values and the adoption of the norms of hegemonic masculinity.

Perhaps, the most bizarre example of a female scientist who suffered due to this oppressive system would Leona Marshall Libby, a physicist and close confidante of Enrico Fermi, who played a critical role in the Manhattan Project. As a twenty-three year old, Libby played a pivotal role when Enrico Fermi's nuclear pile went critical at the University of Chicago in 1942. Unsurprisingly, she along with her husband and fellow physicist John Marshall were invited to join the Manhattan Project site at Hanford, Washington. Libby's position as one of the few female scientists involved integrally with the central outcome of this project meant that she spent most of her time in almost wholly male-dominated organizational spaces. In her own words such a "social location as a woman and a scientist... [was] awkward and alienating for her" (qtd. in des Jardins 138). To avoid this alienation she recrafted herself by physically distancing herself from the domestic world of women "to appear as a scientific professional among peers" $(138)^{\mathrm{xxi}}$. She even went to the extent of adopting masculine attire-namely a heavily padded blazer - that was the closest equivalent to the suits worn by her male colleagues. Even when she became pregnant she continued working, making every effort to ensure that her colleagues were not aware of her condition.

My work clothes—overalls and a blue denim jacket—concealed the bulge and the pockets, containing side cutters, tape measure, slide rule, micrometer, pen and pencil, needle nose pliers, small black notebook and other such essentials produced other such bulges" (Libby 164-65)

In commenting upon her actions, des Jardins remarks "She [Libby] would have relieved herself outdoors if it meant blending in better with her peers" (139). Libby is representative of numerous 
other female scientists and technicians from the Manhattan Project, who have been completely elided from the narrative accounts (by male figures) of the Manhattan Project. The other end of this spectrum are accounts that show the female contributors to the project as, "stock characters of women notable for their sexual, masculine, or maternal characteristics" (Jack 235) or the "lionizing biographies [of male scientists as] highly intellectual beings" (des Jardins 138) that effectively construct white maleness as the primary and only form of valued cultural capital within the domains of the project.

However, any assumption that American radioactive masculinity perceived only white women as threats would be a hasty conclusion, since ethnic minorities faced a similar fate at the hands of this ideological setup. For example at Los Alamos, Spanish American ${ }^{\mathrm{xxv}}$ and Native American women employed as domestic help were embedded "in a spatiotemporal framework separate from the dominant wartime chronotope of Los Alamos” (Jack 243). Ruth Marshak claims unequivocally that the ideologies dominating Los Alamos predicated that "[T]he Indians and Spanish American of New Mexico were the most unlikely of all people to be ushers of the atomic epoch" (3). In Reminiscences of Los Alamos (1980) Elsie McMillan's account, (wife of physicist and Noble laureate Edwin McMillan) shows that the attitude of the scientist's wives toward their domestic helps, mirrored the attitude of segregation practiced toward the white American women by the hegemonic masculinity embedded in this project. In describing an event that has eerie similarities with how Leona Libby handled her pregnancy within the Hanford laboratories, Elsie MacMillan writes of her Native American maid Pascualita:

I will never forget the day Pascualita did not show up. There was a knock on my door and there was Juanita her aunt and she said, 'Pascualita no come, she had 
baby yesterday.' Did I feel guilty! I knew she wore loose dresses but I had no idea she was pregnant (44).

Elsie's account underscores that the ideologies of radioactive masculinity were therefore not only embedded in male bodies but also created hierarchies that predicated specific models of access and agency based on gender, race and ethnicity. Thus, Native American and Spanish Americans who accomplished a significant amount of the legwork in this project are either missing from the official narratives or characterized as "slow and lazy stem [-ming] from racial stereotypes and from the dominant spatiotemporal memory frameworks that grant historical agency to some groups of individuals and not others" (Jack 244). The experiences of ethnic minorities in the Manhattan Project are reminiscent of similar strategies practiced within erstwhile-colonized spaces where the native female subject was subject to a form of double colonization, which made her susceptible to both the throes of colonialism and patriarchy. Of course in the case of the Manhattan Project, the oppression of the Native American and Spanish American women was even more discursively nuanced (although not necessarily less physically violent). The ideologies of radioactive masculinity that marginalized the wives and female scientists in the project also became responsible for creating a framework, where the white female figures became oblivious to the lived experiences of marginalized ethnic communities. In many ways such accounts provide an important inkling toward how ideologies of American radioactive masculinity would get transferred and function within the ambit of postcolonial/marginalized spaces, as will be seen in the larger study.

A lot of these meta-strategies aimed at containing and distancing women as well as other minorities, by perceiving them as tangible threats to the nuclear community seemed to be emanating from the orders of General Leslie Groves, the military overseer of the Manhattan 
project. Groves was known to be of the opinion that the scientists (with the assumption they would all be men) would leave their wives behind to work in classified locales, where they would complete their work free of any "distraction." In his view "[s] cientists were supposed to be objectively disinterested, asexual, and emotionally detached, their only urges purely intellectual and patriotic" (my emphases; des Jardins 134). What seems vital in this masculine paradigm classified by Groves — of arguably the primary radioactive male, namely the atomic scientist - is that it conflates of two specific discourses within white male subjectivity. The "intellectual" and the "patriotic" are the only two "urges" that Groves envisioned in this entity and could very well be seen as a combination of the military-political complex and the scientific establishment within a singular unified American body politic. The individual bodies of scientists were conceived as microcosmic representations of the asexual, unemotional and purely objective masculinity, which would presumably comprise the macrocosmic body politic of America.

Not surprisingly, this vision would be fundamental in shaping the discourse of containment and secrecy in America during the Cold War. The effect of these gendered structures that shared a self-reflexive relation with the military-industrial complex and the Manhattan project were, however, not contained only within the borders of America. As the next section shows radioactive masculinity is equally evident in the techno-scientific discourses that have shaped nuclear weapons development within postcolonial spaces. I explore in the following section the origins of the Indian nuclear program, which in producing the first Indian nuclear weapon also gave rise to the postcolonial bomb: a techno-national fetish which in " its multiple manifestations [becomes] a material force, site of resistance, techno-political space, symbolic 
and cultural referent... [and an] instrument of diplomacy" (Abraham 2) and shapes the narrative of modern South Asia.

\section{Nuclear Weapons, Postcolonial Statecraft and the National Security APParatus}

The conjunctural event that came along to force atomic energy into defining the relation between science, defence [sic] and development was a classic moment of the postcolonial state: the event brought together the insecurities of the new state over control of its territory, natural resources and an ambiguous national threat (my emphases; The Making of the Indian Atomic Bomb 57).

Insecurities of the Cold War era manifested through the American national narrative of containment provided ample evidence of the links between nuclear weapons, statecraft, and the national security apparatus. However, the ramifications of such a nexus were felt far beyond the sites where nuclear technology first achieved fruition. The generalized assumption that nuclear weapons have been decisive influencers of state policy only amongst Cold War participants is proved unarguably fallacious due to the critical role played by nuclear technology in constructing the modern postcolonial Indian nation. Beginning with the Manhattan Project, nuclear bombs and atomic energy have been perceived as being metonymic equivalents of the powerful nation state, capable of granting access to presumably an unforeseen amount of global dominance and influence. Understandably therefore for the newly independent and fledgling Indian state, atomic energy was an unavoidable enigma "both for its tremendous power potential and because it was one area where the most developed and the least developed states would be begin on a relatively even footing" (Abraham 7). Specifically, within the Indian context the violent history of British imperialism and the brutal partition of India based on purportedly religious grounds—with the rise of the new Islamic nation of Pakistan - meant that issues of national development were 
intrinsically connected with developing the national security apparatus. While summarizing the complex dynamics of empire, nation, religion and identity that accompanied this violent epoch in South Asian (and world) history is beyond the scope of this section, my attempt here is to underline that these postcolonial insecurities resulted in the socio-political efforts to enjoin national development with the simultaneous scientific development of nuclear technology.

Any discussion of the Indian nuclear narrative must begin by acknowledging the immense difficulty in studying the Indian nuclear establishment. At the core of this problem lies the issue of secrecy, which while pervading any military-industrial complex is made particularly pronounced in the Indian context. Access to nuclear-related official documents is scarce since

[The] Indian government has been quite unwilling to allow scholars full and unfettered access to the official records of the nuclear complex, on the dubious grounds that the questions of national security are stake. What the state has done is put out $a$ sanitized official narrative of scientific and peaceful progress (...) (my emphases; Abraham 4).

What such a national strategy implies is that most knowledge that exists in the Indian nuclear public sphere is notoriously unreliable as oral and written narratives are often interspersed with ideologically motivated memories of the Indian military-industrial complex. Therefore, while interviews (albeit controversial) of public officials connected with the Indian nuclear project are available, the veracity of their version of events is often difficult to prove. The methodology of my analysis here therefore focuses exclusively on government documents made publicly available by the Indian nuclear establishment, which (although limited in number) provide a relatively stable version of the Indian nuclear program's trajectory. 
In underlining the Indian nation state's vision of nuclear weapons as the ultimate source of national security, it necessary to analyze the role of atomic energy as both a material component in the production of the nuclear bomb as well as atomic energy's part in filling "the discursive vacuum in the production of the postcolonial state" (Abraham 18). In many ways the period immediately following the independence of India presented a conundrum for the political establishment as well as for the newly constituted Indian citizen. Having been discursively and physically elided out of the narrative of modernization, the postcolonial Indian state suffered from multiple insecurities. Constant derision had been meted out to indigenous methods and processes by the British colonial project, particularly directed toward scientists and scientific structures which emerged from colonized subjectivities. While the "British were aware of India's complex diversity in terms of territory, language and religion they were not intent on 'replaying on the Indian stage the European drama of modernity" (Prakash 6; qtd. in Oza 106). This meant that as the Indian nation state took shape, the concept of "Indian science" was discursively a nonexistent entity. Coupled with this insecurity about the lack of scientific expertise, the postcolonial state found itself implicated within the Anglo-American discourse of development: one that fundamentally equates national development with the idea of scientific progress (Chatterjee). Left without any form of agency in this regard, an understanding of nationalism for the newly independent Indian nation-state — both within the discursive and material contextmeant establishing "Indian science and reason as independent from Western forms of knowledge" (Oza 107). This nationalistic goal that was to be achieved through scientific progress also came with a clearly gendered agenda and was hardly surprising since the "problematizing of gendered categories comes of course from the peculiar investment of colonial power in India in the cult of manliness and masculinity" (my emphases; Sinha 446). Thus, any form of 
postcolonial nationalism — that would disrupt imperialist legacies impeding the narrative of Indian scientific progress - would need to challenge, "the ubiquity of the colonialist stereotype of 'effeminacy'... [and an] elaborate colonialist historiography of 'martial' and 'non-martial' races [...]" (Sinha 447). Therefore, political rhetoric—from the very inception of India's nuclear ambitions - saw scientific progress, national development and the masculine strength of the Indian body politic as contingent structures.

In a letter sent on January 1, 1954 from Homi Jehangir Bhabha—-the purported "father" of the Indian nuclear program - to the then Prime Minister Jawaharlal Nehru requesting funds and centers for scientific research, this synonymity between scientific progress and the development of nuclear technology is made explicit. Bhabha writes, "[T]he subjects on which research and advanced teaching would be theoretical physics, especially on fundamental problems with special reference to cosmic rays and nuclear physics" (IDSA). What is particularly fascinating is that Bhabha bases his ambitions for Indian scientific progress through nuclear technology on a specifically American narrative of nuclear technology. In buttressing his argument espousing the need to study nuclear physics, he references the United States' scientific efforts during WW-II and prior to the Manhattan Project:

United States has in the past quarter of a century consistently followed the policy of absorbing not only all the very top scientists from Europe who were prepared to go the States, but also lesser men whose presence there would be a gain (IDSA).

Beyond the immediacy of gendered language that perceives anyone not involved with nuclear technology as "lesser men," Bhabha's assertion underlines how the Anglo-American narrativeof scientific progress through nuclear technology—-formed the basis for India's nuclear program. 
Such were the effects of the Manhattan Project on India's nuclear ambitions that even the laboratories and sites for Indian nuclear research—including the Tata Institute of Fundamental Research — were built by architects involved at Oakridge:

In planning the buildings of the Institute the Council took the view that the latest and best ideas should be incorporated. Accordingly, a noted American firm of architects, Messrs. Holabird and Root and Burgee of Chicago were appointed as the Designing Architects, as this firm had...built several laboratories, including one for the U.S. Atomic Energy Commission at Oakridge [...] (IDSA)

Akin to the American situation in the post-Depression era when the purported emasculation of American manhood had led to a national crisis of masculinity, the Indian state immediately after independence suffered from a crisis of authority. Of course, this was a natural visceral reaction in both the newly constituted nations of India and Pakistan, which had just divorced themselves from over two hundred years of British colonialism. The Partition had left both the countries, especially India, with multiple dominant entities such as the princely state rulers as well as powerful regional leaders, all of who were at odds with a centralized non-British federal government.

The postcolonial state being forced to coexist with colonial state apparatuses was desperately in need — both internally and externally_ of a resuscitating mechanism that would allow for a dominant federal government as well as a robust national security apparatus. Control over atomic energy epitomized that elusive goal. However, it must be emphasized here that while the Indian nation state understood the immense symbolic potential of nuclear technology (especially within the context of projecting a decisive and strong postcolonial state) India's initial forays into atomic energy seemed to be geared (albeit publicly) toward peaceful ends. This 
attitude of India was markedly different from how nuclear technology has always already been publicly equated with the bomb by the global nuclear superpowers. As Itty Abraham notes:

[For] the United States, the Soviet Union, and China, the nuclear question was from the outset a question of the bomb. For the United States, building the bomb moved seamlessly from being a part of the war effort to defeat the Axis powers to being a central element of winning the Cold War against its new adversary, the USSR...Soviet Russia followed a similar path...China, for all [of] Mao's initial posturing about nuclear weapons being 'paper tigers,'... was not averse to accepting help from the Soviets to build bombs (7)

While critical scholarship has been invested with deconstructing a singular conceptualization of the term modern — one that emerges from a European/Western structure — scholars agree that modernity in postcolonial nations is not homogenous and has been manifestly shaped by " $\mathrm{t}] \mathrm{he}$ immediacy of empire and the force of nationalism" (Dube and Dube 7). The first Indian nuclear tests in 1974, therefore, epitomized the postcolonial state's marked attempt to break free from the shackles of imperialist historiography — through the material and discursive power of the hypermodern nuclear bomb. Not surprisingly, India's emergence as a nuclear weapons state that purportedly guaranteed unassailable national security also had a flip side:

[t]he 1974 explosion... [led to] a general deterioration of the security of India's neighborhood, the breakdown of relations with so many countries, and the international distrust of Indian motives and statements [...] (Abraham 16).

Thus, after the initial euphoria subsided, India realized the brunt of global economic sanctions, which consequently led to a muted enthusiasm for nuclear weapons within the domestic sphere. 
The aftermath of the 1974 tests ensured that for over two decades — except for right-wing Hindu nationalist parties like the BJP (Bharatiya Janata Party) and its allies "for whom the nuclear tests were a symbolic of national virility, strength and sovereignty,"-most political parties and leaders distanced themselves from the problematic legacy of nuclear weapons. As has been explicated in the "Introduction" to this project and further explored in Chapter 6, there was little doubt that the postcolonial bomb would therefore make a resounding comeback when the BJP government was voted to power in 1998.

\section{Two-faced Science: Producing the Postcolonial State through the Nuclear Bomb}

[...] Indians have viewed this occasion [the 1998 Indian nuclear tests] as the beginning of the rise of a strong and self-confident India. I fully share this assessment and this dream...I would, therefore, say that the greatest meaning of the tests is that they have given Indian shakti [power], they have given India strength, they have given India self-confidence.

Former Indian Prime Minister, Atal Bihari Vajpayee, in an interview to India Today magazine on 25 May 1998 (qtd. in Oza 104)

While the colonial history of America and India and their narratives of independence have disparate chronologies, they are unified by the ideologies of a masculinized body politic promoting sovereignty through "fortifying gender and sexual boundaries" (Oza 103). Temporal proximities between the atomic bombings of Hiroshima and Nagasaki in 1945 as well as the emergence of India as a sovereign nation in 1947, further exacerbated the effects of atomic 
technology within the Indian subcontinent. This section in emphasizing how the structures of American radioactive masculinity were transferred into the Indian postcolonial space situates the epistemological category of "science" as the fundamental fulcrum on which postcolonial India's “discourse of development" (Chatterjee) has been based. I continue to highlight here how postcolonial India's developmental aspirations equated a resurgent body politic with scientific progress through the development of nuclear technology: a discursive and physical entity that would masculinize this erstwhile colonized space.

Although the exigencies that led to the ordaining of nuclear bombs — as a gendered artifact with immense symbolic and material power-were different in both America and India, my analysis here emphasizes that in both countries, "ideas and expectations about gender are woven through the professional and political discourses [about] how weapons of mass destruction are considered, desired and addressed" (Cohn, Hill and Ruddick 1). In building upon such an assertion, I emphasize that while the conditions for the emergence of radioactive masculinity have always been latently existent within the socio-political imaginary since India's independence, they gained express currency after the second Indian nuclear tests in 1998. In understanding this phenomenon, I illustrate how the second set of Indian nuclear tests in 1998emerging from the historical context of the 1974 nuclear tests — was geared toward the specific goal of (re) masculinizing the Indian nation-state.

This discursive shift that prompted the second Indian nuclear tests can be attributed toward various factors: including the continual geo-political conflict with Pakistan that had particularly escalated during this period as well as a central government led by a right-wing and overtly masculinized Hindu nationalist party that had just been elected. My key assertion here is that the Indian nuclear program has always been motivated by a two-faced vision of scientific 
progress through nuclear technology. One side that looks at the development of atomic power as a necessary scientific endeavor to sustain the postcolonial state's industrial ambitions, while the other sees the development of atomic power as synonymous with the creation of a nuclear bomb, which would grant India access to the aforesaid material and symbolic capital.

This paradox in the national imaginary was made particularly evident during the first Indian nuclear tests in 1974, which were termed as "Peaceful Nuclear Explosions." Scholars note that nuclear testing by a country does not always signal its weaponizing ambitions since "the technologization of the nuclear explosive building process is a discrete step necessary to convert a latent scientific ability to make nuclear explosives into a tangible and reliable process" (Ambivalence 55). Both the rhetoric and the socio-political significance of these "peaceful nuclear explosions," however, needs to be explicated. The mid-twentieth century saw nuclear monopoly move beyond the USA and USSR to other geo-politically dominant states, and importantly to nations such as France and United Kingdom, which had a history of colonization. Some of these countries - from whose colonial legacy many new postcolonial states were emerging - took upon the responsibility of portraying that "atomic energy did not have to be used for weapons alone" (8). In fact their attempts to cement such a perception resulted in many erstwhile colonial powers help setup nuclear programs for their previous colonies.

The first United Nations conference on the peaceful uses of atomic energy held in Geneva in August 1955 was also directed toward this particular goal. Interestingly, this discourse of "peaceful" atomic development was widely accepted, as it proved beneficial to both emerging postcolonial states as well as to their erstwhile colonial overlords. For the newly formed postcolonial states like India, it allowed them to develop a nuclear program with the aid from powerful global players without any fear of retributions or economic sanctions. On the other 
hand for countries like the United Kingdom — who played a significant role in facilitating the Indian nuclear establishment by providing personnel and material help— this "peaceful" trope conveyed that they had moved beyond their colonizing tendencies, while surreptitiously still continuing their military objectives. Of course this often meant that in fledgling postcolonial nations that did not yet have a precise system of nuclear command and control, the scientific establishment gained the upper hand over the political leaders:

Under these conditions...peaceful nuclear programmes (sic) did begin, cheek by jowl with military programmes, often as a result of scientists calling the shots in the absence of strong political direction. In other words, all acknowledged weapon states had military objectives from the outset (Abraham 8).

India, of course, was no exception to this phenomenon and scientists like Homi. J. Bhabha and S.S. Bhatnagar often single-handedly took upon the responsibility of directing Indian science toward the nuclear path. Their attempts were obviously helped by populist nationalistic sentiments that saw nuclear technology as "science in the service of national interest" (Chatterjee 1437). Thus, even while the Indian political establishment claimed peaceful ends for its nuclear means, "[in] real political terms, the objective of the Indian elite [was] not universal disarmament, but rather to move from the side of the discriminated to that of the discriminators" (Chatterjee 1437). Partha Chatterjee's assertion becomes especially vital considering that for a good part of the Cold War era prominent Indian leaders-including the first prime minister of India, Jawaharlal Nehru — preached a policy of decided non-alignment with either the Eastern or Western Blocs. This was also manifested in India championing the cause of nonpartisanship and anti-nuclear weapons proliferation — across the Indian subcontinent as well as the globethrough organizations such as the NAM (Non-Aligned Movement), the Asian Relations 
Conference of 1947 and the signing of the Panchscheel Treaty (Five Principles of Peaceful Coexistence) with China.

However, the problem with India's position of principled opposition against nuclear weapons contrasted strongly with its postcolonial ambitions of becoming a hypermodern nationstate:

With nations turning so often to the past to authenticate themselves, incorporating hypermodernity of this [nuclear] technology into existing national discourse was often a complex feat of rhetorical shifts (Abraham 9).

Thus, the aforementioned "two-faced" vision of science can be clearly attributed to this ambiguous position that an ambitious postcolonial nation like India found itself implicated within: a conflict between maintaining their position of non-alignment with martial ideologies, while trying to embrace the promises of global dominance offered by nuclear technology. What is also fundamentally problematic behind the pursuance of a "peaceful" nuclear program (one that still holds true today) is that, "[the] usual measures of such [nuclear] advancement are always military_usually a nuclear test some place far away from the metropolis" (Abraham 9). Soon it became evident that the development of atomic energy was geared toward the finality of nuclear weapons testing and would become a key aspect of Indian statecraft and the national security apparatus. Continuing on this trajectory that underlines how nuclearization affects the geo-political narrative of a nation, the following two chapters chronicle reactions to radioactive masculinity in the American public sphere before coming back to the Indian context in Chapter 4. This form of thematic progression demonstrates how minority perspectives and counterpublics opposed to nuclearization arise concurrently with dominant discourses on nuclear weapons and nuclear technology, in spite of attempts to silence such voices. However, as I highlight the 
apathy in critical scholarship toward recovering non-hegemonic reactions about nuclearization can be attributed to the removal of nuclear bomb testing from the public sphere and the simultaneous abstraction of the catastrophic potential of nuclear weapons. Both in the American and Indian context, literary and cultural productions challenged the metanarrative of nuclearization through emphasizing the dehumanization implicit in such processes. 


\section{Chapter 2: Reassessing the Nuclear Public Sphere: How Dr. Strangelove Challenged Radioactive Masculinity}

My goodness, aren't atoms wonderful! They are easier to understand than Dagwood!

-Blondie Bumstead in Learn How Dagwood Splits the Atom (1949)

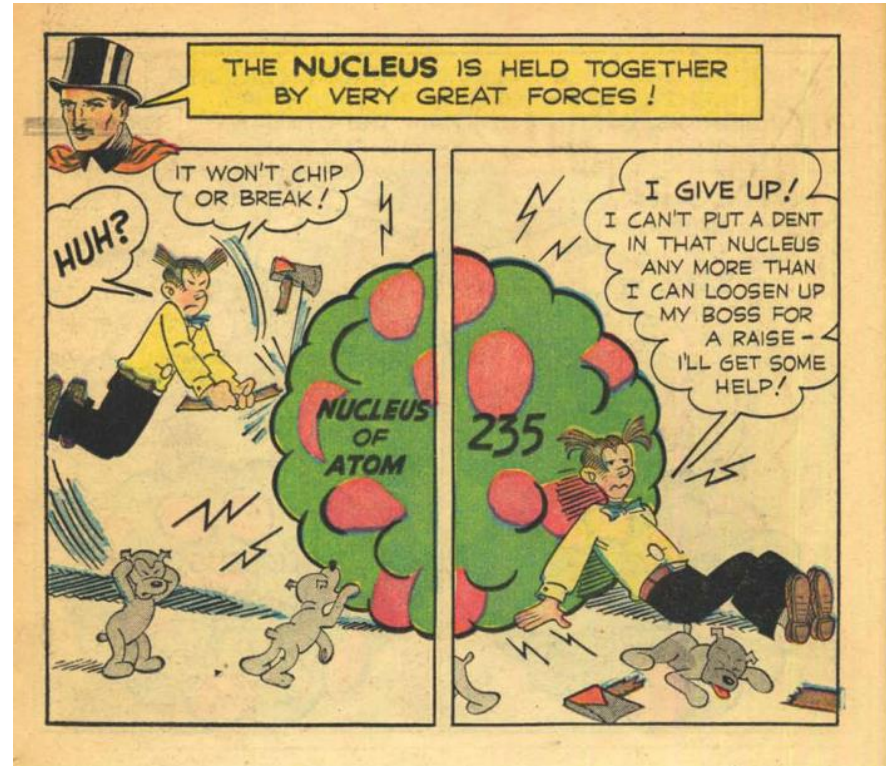

Figure 6: Learn How Dagwood Splits the Atom
On the cover page of the 1949

publication Learn How Dagwood Splits

the Atom, his slightly bemused wife

Blondie affectionately kisses a visibly

perplexed Dagwood Bumstead, as

Dagwood embarks on one of his many

futile attempts to split the nucleus of a

Uranium $^{235}$ atom with an axe. After

multiple comic forays Dagwood finally

manages to split the nucleus of the atom with the help of the hypnotist and magician Mandrake and a "neutron bazooka"-leading to his wife Blondie's relieved assertion that atoms are indeed "easier to understand than Dagwood" (Dagwood 22). Significantly, the connotations of Blondie's seemingly naive remark move considerably beyond the gender-biased rhetoric that typified patriarchal assumptions regarding the American "flapper" culture of the 1950s.

Arguably for the first time, the nuclear phenomenon had broken out beyond the confines of the military-industrial complex into the public sphere. While documents related to the nuclear were 
produced by the American government as early as August 12, 1945, "three days after the destruction of Nagasaki" (Kinsella and Mullen 73) there is considerable debate regarding the public nature of such texts.

Arising from the above premise, this chapter traces the development of the American nuclear public sphere and explores how the cessation of aboveground nuclear bomb testing fundamentally altered the nature of hegemonic nuclear discourse. I demonstrate how the removal of nuclear testing from the public arena was accompanied by an abstraction of the catastrophic potential of the nuclear bomb. This move, I argue, to reconstitute the bomb from a performative state-secret to a dominant discursive cultural-political artifact allowed radioactive masculinity to disseminate its influence beyond the limited techno-masculine space of the Manhattan Project. I conclude by pointing out that the simultaneous development of nuclear counterpublics during this era-who challenged the dominant narrative of American nuclear discourse through representative cultural productions such as Stanley Kubrick’s Dr. Strangelove-was synonymous with deabstracting the ideals of radioactive masculinity. In tracing the genealogy of the nuclear discourses, I will refer to four distinct periods of Atomic Culture ${ }^{\mathrm{xxvi}}$, which are:

a) Early Atomic Culture (1945-1948)

b) High Atomic Culture (1949-63)

c) Late Atomic Culture (1963-1991)

d) Post-Atomic Culture (1992-Present)

I emphasize here that the reconstitution of nuclear discourse beyond the domains of the militaryindustrial-scientific complex, which followed the remission of aboveground testing did not imply a democratization of knowledge about nuclear weapons. Rather the hegemonic power implicit in nuclear weapons - and radioactive masculinity — had now been transferred into the discursive 
tropes found in governmental documents and popular culture. Textual signifiers that were created for public consumption in the post-1962 (aboveground testing) nuclear era maintained discursively the governmental nuclear hegemony. The newly emergent "nuclear public sphere" was therefore a pseudo public sphere: a result of the concerted governmental effort to provide the public domain with an illusion of having a stake/say in the nuclear discourse, while in reality nuclear policies and decisions were still deeply entrenched within the military-industrial complex.

\section{The Paradoxes Of NuClear SeCRecy}

So the atomic Age opened in paradox: Citizens must be informed participants in atomic matters; while national security limits their access to information (Kinsella and Mullen 106).

From its inception, nuclear discourse has been shrouded in a veil of secrecy - a phenomenon that had to be kept secret, as part of the larger psychological warfare that the United States Government was engaged in with its adversaries. This rhetoric —of nuclear weapons having a psychological impact — can be traced back to President Truman's assertion after the bombings of Hiroshima and Nagasaki: that the bomb was meant "to make a profound psychological impression on as many inhabitants as possible" (Garrison 66). The politics of secrecy, integral to this psychological warfare surrounding the bomb initiated during the Manhattan project was continued and strengthened in the immediate aftermath of Hiroshima and Nagasaki. State ordinances such as the 1946 Atomic Energy Act and the 1947 National Security Act "effectively removed huge areas of governmental affairs from citizen's purview" (Masco 1). The subsequent production of the national security state after WW-II meant that the same nuclear program, which had established American supremacy on the global scenario needed to be accompanied by 
an "expansion of state secrecy devoted to protecting it" (Masco 1). Such moves ensured that "with regard to nuclear issues, the public (was) conceived as a crowd to be calmed rather than co-creators of public-policy" (my emphases; Schiappa qtd. in Kinsella and Mullen 7)

On the other hand, the triumph of allied forces in WW-II, accelerated through the nuclear power of American forces meant, "like most of the Manhattan Project scientists, the public feeling was euphoric" (Zeman and Amundson 3). Indeed, the catastrophic power of the nuclear bomb - apparently safeguarding American sovereignty and ensuring the freedom of its citizens from the throes of fascist powers - was also potentially a devastating threat for the nation, if it fell into unfriendly hands. This meant that the due to the threats associated with the bomb it was necessary to be construed as a secret to be paradoxically protected from the very American public that it was purported to protect. In fact, it might be inferred that this atmosphere of constant tension regarding the effective custodianship of nuclear secrets implied that no one was above state suspicion: be it foreign powers or state subjects. Therefore, a clear binary had been established between the military-industrial complex involved in the wartime efforts and the public American population, who were constructed to be passive observers and recipients of the bomb and its effects.

In this context it must be clarified that "belonging to a public seems to require at least minimal participation" (Warner 71) from each personal entity. This implies granting to the personal being at least a minimal level of access to the politics that constitutes the public. However, the policy of secrecy around nuclear discourses implied that the politics of the (pseudo) nuclear public sphere was not only depersonalized but indeed privatized and restricted within the military-industrial complex. In a reversal of the general tenet that the "personal is political" explicated by Michael Warner as that "politics should be personalized," the political 
was no longer personal but privatized - especially in the context of the bomb (Warner 34). The power of the bomb meant that anything related to it was a closely guarded state secret, which needed to be protected. Joseph Masco notes:

A new concept of official secrecy was established in the aftermath of World War II that increasingly positioned citizens as a threat to state security, and separated huge parts of the government from either public scrutiny or citizen participation (1).

While decisions involving the development and consequent deployment of nuclear bombs had never been in the purview of the general population, the end of the war precipitated new national policies that led to the further division: of nuclear-policy makers, scientists and defense intellectuals into highly specialized and compartmentalized structures. In fact one of the striking features of "nuclear weapons science — as a science — is that... it (is) most powerfully determined by nonscientists" (Masco 349) implying that decisions regarding democratizing nuclear discourse were clearly out of the question.

More importantly in the post WW-II period between 1945-1949, American nuclear monopoly implied that American nuclear policy makers were under no coercion to extend nuclear knowledge into the public sphere. The Cold War had not yet proliferated-discursively or materially - and "most Americans wanted to see [this] era as a time of consensus, confidence" (Chernus 5). Interestingly during this period of Early Atomic Culture (1945-1948), when state institutions were involved in fortifying the structures of secrecy around nuclear technology there was a simultaneous celebration of the bomb through popular culture that "shaped public opinion"(Zeman and Amundson 3). One of the first civilian reports regarding the bomb was by the noted journalist William Laurence, the only civilian allowed to witness the Trinity Test (Los 
Alamos, 1945). Laurence perceived the first atomic test as a profoundly elevating religious experience, "sunrise such as the world had never seen.... one felt as though one were present at the moment of Creation" (Laurence 10). Such a response was indeed in tune with the religious imagery that Robert Oppenheimer, one of the lead scientists of the Manhattan project had used after the Trinity Test. Quoting the Hindu Scripture, the Bhagvad Gita, Oppenheimer had commented "Now I am become Death, the destroyer of Worlds" (Rhodes qtd. in Nuclear Technoaesthetics 352). The glorification of the nuclear bomb through religious rhetoric was an especially effective strategy for transforming the bomb into a transcendental discursive signifier and effacing its actual destructive effects, while also elevating these effects into an aesthetic nuclear sublime.

The atomic experience was also lived through comic book representations of the nuclear through popular characters such as Dagwood, Mandrake, Popeye and through various food and beverages such as "an intoxicating beverage known as the 'atomic cocktail', (a) rich desert spiked with liqueur called the 'Atomic Bomb', and an 'atomic bomb ring' available through Kix Cereal" (Zeman and Amundson 3). Viewed through Michael Warner's assertion that the notion of a public enables a "reflexivity in the circulation of texts among strangers who become, by virtue of their reflexively circulating discourse a social entity" (Warner 11), these products of popular culture became the "reflexively circulating" texts—-that were aimed at creating the semblance of dialogue (albeit false) between the nuclear state and its subjects. Such a move to "shape public opinion" through a glorification of the atomic enterprise was critical for the American government, since in the absence of an actual discursive public space, these cultural signifiers played a vital role in legitimating the nuclear program for the American population- 
while also providing them with an illusion of participation in the larger nuclear aspirations of their country.

THE RiSE OF NuCleAR DETERRENCE

The Russians tested their first atomic bomb, and deterrence was in place (Amis 2).

A radical change occurred in the politics of the nuclear public sphere with the successful testing of Soviet Russia's first nuclear bomb "First Lightning" in 1949 and the effective declaration of Soviet Russia as a nuclear superpower. Fears of a nuclear conflict and a consequent holocaust that had been latent within the American national imaginary (since the events of August 1945) were suddenly catalyzed within the general populace. The situation was not helped by governmental discursive models that construed the Cold war as an "apocalyptic struggle" and increasingly suggested "how] communism, nuclear war and economic mismanagement all threatened to destroy the nation utterly" (Chernus 7). The declaration of Soviet Russia's nuclear capabilities was further critical because for the first time in human history nuclear deterrence had been established.

It is vital to explore here the concept of deterrence as a discursive phenomenon: “[d]eterrence depends not so much on possessing military capability and the willingness to use it, as on the communication of messages about that capability and that willingness" (my emphases; McCanles 11). In the period preceding the Soviet nuclear test, the American military industrial complex's unwillingness to extend nuclear knowledge into the public domain was due to the sole presence of America in the nuclear club. Between the years 1945 and 1949, the lack of a competitive or threatening adversary in the global nuclear scenario implied that American nuclear policy was under no pressure to declare itself as either a benign or a malevolent power. 
While documents related to the nuclear such as the Smyth report of 1945 had been released in the immediate aftermath of the Japanese bombings, they were prefaced with disclaimers that stated:

The average citizen cannot be expected to understand clearly how an atomic bomb is constructed... but there is in this country a substantial group of engineers and scientists who can understand such things... The present report is written for this professional group ... ("Preface" Smyth Report)

Such reports clearly indicated a substantial conflict. Even though the official standpoint was that "in a free country like ours such [nuclear] questions should be debated by the people" (Smyth 226), caveats specifying that "persons disclosing or securing additional information by any means whatsoever without authorization are subject to severe penalties under the Espionage Act" implied that the nuclear knowledge needed to confined within the private sphere of the militaryindustrial complex. The entry of Soviet Russia into the nuclear arms race, however, ensured that the American government could no longer maintain their non-committal status quo. As McCanles underlines "communication of messages" (13) suddenly became vital not only toward the process of deterrence but also for addressing public sentiments. Publications such as Learn How Dagwood Splits the Atom — created through a joint collaboration between the United States Military and King Features Syndicate (in the same year that saw Soviet Russia's first nuclear tests)—were motivated specifically towards addressing apocalyptic concerns in the public domain.

In order to allay public fears, government sanctioned documents related to the nuclear sphere began circulating within the purview of the common public. The attempt was to reassure American citizens that atomic power and nuclear bombs were indeed as benign and decipherable as the suburban white middle class American male (Dagwood 27). Atomic knowledge 
disseminated through a genial suburban white middle class male such as Dagwood Bumstead indicated the dual strategies of the American Government: maintaining the feel-good factor created in the post-WW-II America while extending the ideals of radioactive masculinitysynonymous with the logic of nuclear proliferation - into the public domain. A facet of radioactive masculinity made explicit in such cultural productions was the relation between whiteness and the bomb that Ken Cooper points out in his essay "The Whiteness of the Bomb," "the bomb was built by people like me for the protection of people like me" (11). Alan Nadel in supporting such a hypothesis argues that associating nuclearization specifically with a white suburban male was a crucial part of American Cold War Containment Culture that "tried to strictly delineate the boundaries between "us" and "them" in terms of political allegiance, religion and sexuality and in relation to events and the narration of those [Cold War] events" (Williams 9). Nuclear weapons could no longer be a catastrophic secret that was hidden within the military-industrial complex but needed to express their discursive power as "the weapons themselves symbolize[d] the achievements...and attitudes of European and American modernity" (Williams 15). Importantly the only way that such an extension of the privatized "secret" bomb could be made into the public domain, without compromising the governmental hegemony, would be by making the bomb a "fabulously textual" phenomenon (Derrida 23).

\section{THE FABULOUSLY TEXTUAL BOMB}

[T]o anyone who contemplates them, the nuclear weapons can only be a permanent invisible terror that offers no moral enlightenment (Nye 253).

In his influential book American Technological Sublime, David Nye argues, "nuclear weapons are so terrifying that they cannot be experienced through an aesthetic of the sublime" (150). Nye's argument although valid within the domain of civilian discourse, however, becomes 
questionable when purveyed from the viewpoint of the military-industrial complex, which have "banked their careers on a diametrically opposed proposition, namely, that nuclear weapons are so powerful that they fundamentally reshape human consciousness" (Nuclear Technoaesthetics 350). Such a comment underlines the fact that governmental bodies had refrained from producing explicit textual signifiers related to the bomb in the Early Atomic and High Atomic eras because the bomb was visible in the public domain. The performative aspects of aboveground nuclear testing made it a distinctly sensory experience and "the profundity of the [nuclear] sublime ${ }^{\mathrm{xxvii}}[$ being] inexpressible, [placed it] outside language" (ibid).

This non-translatability element of the performative bomb into textual discourses meant that beyond the few governmental reports and caricatured glorifications in popular culture, the bomb found limited linguistic expression during the period of above-ground testing. Understood through Warner's model that posits “publicity...[as] meaning not merely publicness or openness but the use of media, an instrumental publicness associated with advertising and public relations," the bomb in the pre-1962 era was publicized through its sensory influences rather than through any form of discursive practice (Warner 30). Interestingly therefore, the "nuclear public sphere" extant before the ban on above-ground testing was largely a detextualized, nonverbalized sphere, which raises vital doubts regarding the "public" nature of this sphere. Since one of the critical nodes in the creation of a democratic and a consequent "public sphere" is that it must be "self-organized" through textualized discursive spaces, it can be decisively inferred that in the pre-1962 era an actual nuclear public sphere was far from being constituted.

The abatement of American above-ground nuclear testing on July 7, 1962 reconfigured "sensory access to the exploding bomb, both abstracting its destructive potential and encouraging an intellectual engagement with complexity" (Nuclear Technoaesthetics 350). This meant that 
not only had the bomb lost its performative power but also the potency of the bomb had now been transferred back into its place of origin - the nuclear weapons production complexes ${ }^{\text {xxviii }}$. Critically, the loss of the nuclear from the visible arena implied that the military-industrial complex could no longer justify the nuclear program to the general public by following their erstwhile strict policy of discursive containment. However, this crisis in publicity that arose needs also to be contextualized within the larger political and social context, that had led towards the banning of above ground testing. During the period of High Atomic Culture (1949-1963) the series of above ground tests, while providing effective displays for the might of the American Nuclear arsenal, had also led to widespread concern regarding the environmental effects of such tests. In fact "by the late 1950's, public concern about the global health effects of atmospheric fallout was directly competing with the official national security discourse supporting the bomb" (Nuclear Technoaesthetics 354). The Atmospheric Test Ban Treaty of 1963 that ultimately banned all nuclear explosions in the atmosphere, underwater, and outer space lead to underground testing and significantly complicated the nuclear ambitions of the American state during the Cold War era.

While in the techno-scientific domain the challenges of underground testing implied "how to both contain the explosion and make it visible to machine sensors" (Nuclear Technoaesthetics 355) in the political domain it was the challenge of convincing antagonistic powers that the American nuclear arsenal was still markedly superior to that of any other nation. Paradoxically this exhibition of nuclear superiority was critical towards the maintenance of nuclear deterrence. As McCanles notes: "[the] only way in which deterrence can be maintained is through the superiority of one side over the other, because only such superiority is capable of being a credible threat" (15). The visible exploding atom bomb-having now literally gone 
underground along with its ability to influence the human senses — connotated that the dynamic aspect had been subtracted from the nuclear sublime leaving it with a "more limited form, closer to what Kant called the mathematical sublime" (Nuclear Technoaesthetics 355). Indeed it became almost imperative that the dynamic element of the nuclear be compensated and this was accomplished by making the bomb "a fabulously textual phenomenon" (Derrida 23).

It is interesting to point out here that Derrida in his much discussed essay "No Apocalypse Not Now" argues for the nuclear having always been "a phenomenon whose essential feature is that of being fabulously textual, through and through" (Derrida 23). However, as has been already noted in this essay the "fabulously textual" nature of the phenomenon only arose with the removal of the dynamic exploding bomb from the public arena. Indeed "the structures of information and communication...including non-vocalizable language" that had been implicitly behind the performative nuclear bomb during the period of above ground testing, had to be brought out into the public domain to keep justifying America's Cold War nuclear policies (Derrida 23). Of course, considering that such communications and discourses existent within the military-industrial nuclear complex were highly gendered ${ }^{\mathrm{xxix}}$ it was not surprising that the forced percolation of these hegemonic discourses into the public would definitively extend radioactive masculinity, beyond the confines of the military-industrial complex.

\section{The Pseudo-Nuclear Public Sphere}

By 'the public sphere', we mean first of all a realm of our social life in which something approaching public opinion can be formed. Access is guaranteed to all citizens... Although state authority is so to speak the executor of the political public sphere, it is not a part of it (Habermas 49). 
On July 9, 1962, eight days before the last above ground nuclear test in America, Secretary of Defense Robert McNamara delivered the commencement address at the University of MichiganAnn Arbor. The No-Cities speech, as it has been popularly known, besides making a powerful appeal for the continuation of anti-communist policies, also included McNamara's assertion that "I think it is worthwhile to expose the U.S. views on these (nuclear) issues as we have presented them to our allies" (The Atomic Archive). Vitally, for the first time an attempt had been made by a stakeholder in the military-industrial complex to open out nuclear discourse within a public forum. McNamara argued, "[the] mere fact that no nation could rationally take steps leading to a nuclear war does not guarantee that a nuclear war cannot take place" (The Atomic Archive). His rhetoric indicated the goal to justify both the "no-first strike" policy of the United States government and the proliferation of its nuclear arsenal.

McNamara's speech besides inaugurating a series of discursive signifiers related to the nuclear - that would be both textually and verbally reproduced in the next few years ${ }^{\mathrm{xxx}}{ }_{-}-$marked a distinct change in the way nuclear discourse had been previously disseminated. While documents related to the nuclear domain had been published for a "public" audience as early as 1945 (Smyth Report, United States Atomic Bomb Survey of 1946) such documents were clearly created for the military-industrial complex. In marked contrast, the slew of documents emanating from Kennedy, McNamara and others in the era following the ban on above ground testing, were intended specifically for public consumption. The intentionality behind such discursive acts was to show citizens that there was an actual endeavor by the government to make the nuclear "visible" to the public.

Critically it is important to note here that since "national identity is not naturally given but culturally constructed out of principles, ideas, attitudes and values" (Hogan 10) it was 
important that such information disseminated by the American government would be couched within sanitized rhetoric. Therefore, such language contributed toward the anti-communist, free market capitalist ideology that the contemporary American policies postulated. Moreover, in order to make the bomb a visible cultural-political entity that could legitimize US foreign policy it was natural that the destructive potential of the bomb be abstracted. McNamara's assertion in the "No-Cities" speech that "basic military strategy in a possible general nuclear war should be approached in much the same way that more conventional military operations have been regarded in the past" (my emphases; The Atomic Archive) put forward the view that the nuclear bomb was merely another arrow in the American defense arsenal. Reconstituting nuclear technology into such a semi-bureaucratic intellectual project made the bomb into "simply a number, not a visceral understanding of the destructive power of the bomb in relation to the human body" (Nuclear Technoaesthetics 356). Interestingly, this "downgrading” of nuclear weapons into “conventional everyday weapons also served America’s Cold War foreign policy very well. It was also directed clearly to America's Cold War adversary and was part of " [a] semiotic project of signifying to the Communist enemy both [America's] capability and willingness to use nuclear weapons in the national defense" (Taylor 671).

Habermas' prefatory comment to this section clarifies that a public sphere denotes "Access is guaranteed to all citizens"; however, this pseudo-nuclear public sphere that claimed the bomb was like any other "conventional military" artifact disembodied of its catastrophic destructive abilities. This implied that citizen access to a key aspect of the bomb was being restricted. Vitally, the "self-creating" (Warner 71) nature of a public that is a fundamental aspect of the public sphere had been denied, since every node of information was being colored by the ideological assumptions of the state and its legitimizing agencies. The intervention of the state 
and its military-industrial allies denied the possibility of a scenario where "citizens could confer in an unrestricted fashion" about the nuclear (Habermas 49). This naturally implied that the hegemonic nuclear discourses discounted any empowering possibility within this pseudo nuclear public sphere.

UNEARTHING THE ANXIETIES OF RADIOACTIVE MASCULINITY

With the proclaimed end of the Cold War, what is becoming increasingly evident is how the identity politics of manliness during the Cold War.... made, indeed a certain ethics of manhood impossible to represent. (my emphases; Clark 15)

Filmic representations of radioactive masculinity came into vogue as early as 1954. The Atomic Kid (1954) combined the ideas of a uranium-powered manhood with nuclear testing. In this film Mickey Rooney is a uranium prospector who "stumbles onto the Nevada Testing site during an atomic blast. Somehow surviving the blast, he spends the rest of the film not only glowing but trying to market himself as the first human to survive an atomic blast" (Zeman and Amundson 4). The Atomic Kid directed by Leslie H. Martinson and adopted from a story by Blake Edwards is a particularly pivotal cultural production as it shows how a literally radioactive male was at the center of popular culture's imagination of nuclear weapons. The scene in which Barnaby 'Blix' Waterberry, portrayed by Mickey Rooney becomes radioactive is worth summarizing:

Mannequins are depicted sitting around the dinner table in front of their plastic meal, awaiting the predetermined bomb drop... Rooney remains with the mannequin family and discovers at the last minute that an atomic bomb will be detonated over his head. In a deliberately humorous scene, Rooney frantically tries to find a place to hide from the approaching explosion, only to close his eyes and stick his fingers in his ears as the bomb goes off (my emphases; Evans 64). 
Rooney's perception of the nuclear bomb as a "humorous" object that promised purported empowerment for the white American male body along with no real physical danger, reflected the official governmental publicity about the bomb evidenced in earlier texts such as Learn How Dagwood Splits the Atom (1949). Such official publicity percolating now into non-governmental artifacts like The Atomic Kid, illustrated how this aforementioned pseudo nuclear public sphere was indeed very far removed from the devastating realities of nuclear weaponry. Also, by transferring radioactive masculinity from the militarized male body onto the suburban middleclass white male body, such productions underscored the fluidity of this hegemonic gendered construct. Further, it highlighted how popular culture cemented the belief that the postDepression era emasculated American male was finally getting his manhood back, through the symbolic power of the nuclear bomb. In doing so it was fulfilling pre-WW II American national ideologies (as outlined in the last chapter) that had pre-discursively ordained the nuclear bomb as a masculine artifact.

The aspect of masculine empowerment associated with radioactive masculinity and its contingence on nuclear weapons, becomes particularly clear in The Atomic Kid, when the FBI recruits the irradiated Blix to hunt communist spies. Not only was the material power of the nuclear bomb allowing American male soldiers to counter Communist threat on the battlefield, but the bomb's symbolic power was also (apparently) allowing suburban white masculinity to fight the threats of domestic Communism. This domestic champion of Containment Culture- the new age American Cold War Warrior-was explicitly defined as a white virile male, who was no longer restrained to the confines of the military-industrial complex. More importantly, such was the cultural power of this domesticized radioactive male that he completely elided female bodies from cultural narratives: as is demonstrated in The Atomic Kid, which has only one female 
character. The "feminized threat of Communism" (Clark 2) meant that male bodies needed to be "secured" from both these dual threats by adopting the virile ideals of radioactive masculinity, embedded in the Cold War warrior. This identity was of course made normative and invisible:

The ideological extremity of the Cold [War] warrior, whose identity was purified of communism and totalitarianism— but also of gender, race, color, sexuality, or class - was invisible. What helped to keep it invisible was the visibility of a historical—Western — manliness recuperated from the American past, attacked by liberals, and yet undergirding the claims of American nationalism (Clark 1)

While comic abstractions about the bomb reflected the social and political perceptions regarding nuclearization in the Early and High Atomic period, the move to underground testing marked a watershed moment in the Atomic Age. The environmental, political and social concerns that had led to the Atmospheric Test Ban Treaty made their mark on representations of the nuclear as well. The initial caricatures regarding the bomb were now being replaced by cultural treatises that dealt with post-nuclear apocalyptic settings, inaugurating a form of neo-apocalyptic culture where the meaning of the word ${ }^{\mathrm{xxxi}}$ was reconfigured from an uncovering or new beginning; "to an adjective now understood to be a synonym for the catastrophic and the devastating" (Rosen ix).

\section{Dr. Strangelove and the Military-Industrial Complex.}

Everything there is to know about nuclear strategy can be learned from $\mathrm{Dr}$. Strangelove_-John Pike, Former Director of Space Policy, Federation of American Scientists (qtd. in Lindley 474). 
The military-industrial complex includes all those elements of American society-economic, political and professional-that have a material or philosophic stake in a large defense establishment. It includes not only the Armed Services and the companies that produce for them, but politicians in and out of government, workers and union leaders, ordinary citizens and local officials, teachers in schools and academicians--in short all who for reasons of 'pork or patriotism' support the Armed Forces' requirements (my emphasis; Raymond pp.72-73).

The year 1964 was a particularly decisive year due to the production of not one but two filmshaving similar storylines-dealing with post- nuclear apocalyptic scenarios, namely Stanley Kubrick's Dr. Strangelove and Sidney Lumet's Fail-Safe. Dr. Strangelove was adapted from Peter George's novel Red Alert while Fail Safe was from the novel of the same name by E. Burdick and H. Wheeler. Although both films were equally ingenious in challenging the abstraction of the catastrophic power of atomic bomb, considering the limited scope of this chapter I will be focusing on analyzing Dr. Strangelove, as representative of the social and political function that these texts like these accomplished. Scholarly material dealing with $D r$. Strangelove have focused mainly on the "anti-militarism" of Kubrick (Burgess); his sarcastic take on Cold War policies of the U.S. and Soviet Russia (Southern); or on it being a cultural document illustrating the national paranoia of that period (Lindley). While all of these are valid and important claims in reference to this movie, I explicate here how Kubrick's movie went beyond the above assertions to actually promote a form of nuclear consciousness" to his audience - thereby challenging dominant publicity about the bomb. .xxii $^{\text {and }}$ 
In analyzing the film, it is vital to point out the critical importance of the three broad settings; essentially a military base; the 'War Room' where nuclear decisions are taken; and the interiors of a B-52 bomber. In basing his cinematic venture within the confines of these three venues, Kubrick had for the first time in public discourse focused the audience's gaze on the originary point of nuclear weapons - the military-industrial complex. Sue Tweg notes:

The film's three locations look very different but are actually similar in the way they confine the scope and efficacy of individual human action. The locations, united as points along the same spectrum of high-tech impotence, show politicians and militarists, in the hermetically sealed, programmed and sanitized war-room, mayhem amongst the combatants at Burpelson and the B-52 aircrew calmly engaged in following 'Go' procedure” (Tweg 6-7).

Tweg's comments illustrate one of the fundamental features of the military-industrial complex that Kubrick was able to convey in this film - the highly secretive and privatized nature of the techno-scientific coterie, who had completely alienated themselves from the concerns of the public domain. It is a setting where human emotions, values and the larger goal of peace itself has been abstracted, through a deluded model of professionalization, exhibited on the posters in Burpelson base which claim "Peace is our Profession" (Dr. Strangelove). Although the ramifications of the plot-line operating within these three spaces are multiple, the basic premise of this film is deceptively simple: "A renegade U.S. Air Force General, Jack. D. Ripper, orders his B-52 bombers to drop their nuclear weapons on the Soviet Union. This attack may set off the doomsday device that will kill all life on the surface of the earth" (Lindley 475). Since the bombings of Hiroshima and Nagasaki, the American military-industrial complex had been publicized through official nuclear discourse as a tightly knit perfectly functioning machine, 
whose probability of malfunctioning was nonexistent. In fact, this secure paradigm of American nuclear command and control that purportedly legitimated America's status as a nuclear weapons state (NWS) had been one of the principal messages in Sec. of Defense Robert McNamara's "No-Cities" speech:

In short, then, limited nuclear capabilities, operating independently, are dangerous, expensive, prone to obsolescence, and lacking in credibility as a deterrent. Clearly, the United States nuclear contribution to the Alliance is neither obsolete nor dispensable (The Atomic Archive).

Kubrick's movie dismantles these notions of infallibility that had been postulated in governmental rhetoric and percolated through the pseudo nuclear public sphere. In his movie a relatively minor official (at least with reference to nuclear policies) manages to activate Plan $R$ an "emergency war plan where a lower echelon commander may order nuclear retaliation after a sneak attack if the normal chain of command is disrupted" (Dr. Strangelove). Within the movie's plot-line, no such sneak attack has actually taken place and an all-out nuclear attack against the Soviet forces is launched by a General who in the words of the American President, "had got a little funny in the head" (Dr. Strangelove). In satirizing the officials and discourses connected with American nuclear command and control, Kubrick's characterization of Ripper highlights that for all the talk of strict strategic management, the only thing that was required for a global apocalypse to be initiated was for a single individual to go "a little funny in the head." Jack D. Ripper who initiates the nuclear attacks on the Soviets had been convinced that the postcoital fatigue which he had been experiencing was a sure result of a "fluoridation" plot initiated by the Communists: destroying the purity of his "precious bodily fluids" and depriving him of his "essence" (Dr. Strangelove). Ripper's delusional fear about the "loss of [masculine] essence" 
that catalyzes an all-out nuclear holocaust ending human civilization is in fact one of the most natural reactions of the human body following intercourse.

However, the inability of a male military official to recognize such a fundamental fact about the human body provides a telling reminder, of the extent to which radioactive masculinity had abstracted human life. Militarized males within the military-industrial complex now were unable to recognize their own normal bodily processes. More importantly in view of contemporary nuclear public discourse that were putting in their best efforts to abstract and disembody the nuclear, Dr. Strangelove warns us that the military-industrial complex, functioning under the whims and fancies of a select group of privileged individuals was privy to human errors and mistakes. However, unlike the case of any other weapon in human history such a mistake could actually mean the end of civilization.

Kubrick's movie in initiating a trenchant critique of radioactive masculinity and the phallocentric military-industrial complex, anticipates the work of scholars like Carol Cohn and Jane Caputi who have written at length on the gendered nature of nuclear discourse. Gendered linguistic tropes have been a predominant feature of nuclear rhetoric since the conceptualization of the bomb. As the physicist Brian Easlea notes in his book Fathering the Bomb, during the initial days of the Manhattan Project at Los Alamos when scientists struggled to build the bomb, they staked money on whether they would produce a failure or a success - in their lingo a "a girl or a boy." The enterprise was a success and the phallic bombs were subsequently named Fat Man and Little Boy: gendered representations of the masculinizing ideologies from which they had emerged. This masculinist bias of the technocratic sphere also percolated into the public domain such as when the National Baby Association reacted to this birth/explosion by naming Robert Oppenheimer, the leader of the Manhattan project as the "Father of the Year". 
Incidentally Robert Oppenheimer still remains the paradigmatic father figure in an exclusive nuclear community that consists of men such as Edward Teller, "Father of the US H-bomb"; Glenn Seaborg one of the founding "Five fathers of plutonium"; Andrei Sakharov "Father of the Soviet H-bomb" and Admiral Hyman.B. Rickover, "Father of the American nuclear navy" (Cohn).

Such a phallocentric world becomes one of the core issues in Dr. Strangelove and is critiqued through tactics such as the existence of only a singular female figure, Ms. Scott (General Buck Turgidson's secretary) in the entire narrative of the film. Ms. Scott's character portrayed by the British model Tracy Reed is shown (physically) only once throughout the entire film, when she appears provocatively dressed in a bikini in General Buck Turgidson's bedroom. Her inferior and almost invisible position in the military-industrial is clearly delineated: she seductively smokes on a cigarette — a phallic symbol—while receiving calls and relaying the information to her employer and lover General Turgidson. When General Turgidson decides to "mosey over to the War Room for a few minutes," he reminds Ms. Scott "You just start your countdown. I will be here before you can say blastoff' (my emphases; Dr. Strangelove). The implications of such a comment are decisive in the context of radioactive masculinity as Turgidson, one of the highest ranked officials in the military-industrial complex conflates himself with the nuclear bomb. Just like Turgidson's penetration that would purportedly guarantee Ms. Scott orgasmic bliss, the phallic presence of the nuclear bomb within the militaryindustrial complex promised continual geo-political dominance for the American nation-state.

This contingence of masculinity on militarization is even more pronounced in the only other scene of the film where there is a feminine presence (albeit disembodied), when Major T.J. "King" Kong looks at the image of a Playboy centerfold within the B-52 bomber. The model in 
the centerfold is in fact again Tracy Reeds who appears as Miss Foreign Affairs. Tracy Reeds lies nude with a January 1963 issue of Foreign Affairs - Vol. 41, No. 2, strategically draped across her behind" (Stillman 491), a volume that contained Henry Kissinger's critical article on nuclear weapons titled "Strains on the Alliance." It is important to underline here Kissinger's role as one of the first political figures, who had been involved in the textual abstraction of the bomb through his best-selling book Nuclear Weapons and Foreign Policy in 1957. Once Kissinger undertook the role of national security adviser under the Kennedy administration he had also been one of the strongest advocates of the first strike policy. Kissinger's potential disregard for the massive human death toll that would result from such a preemptive strike, mirrors the attitude of his filmic radioactive male counterparts: General Buck Turgidson and Dr. Strangelove. Laura Mulvey argues that within the world of film making the "idea of woman stands as linchpin to the system: it is her lack that produces the phallus as a symbolic presence" (198) a fact which finds resonance in the presence of both of Tracy Reed's characters: Ms. Scott and Miss. Foreign Affairs. Ms. Scott—appearing alone when Buck Turgidson goes to the War Room - is a stand-in object of visual pleasure, in the only scene in the movie where there is the physical absence of a male character. Even in this short interlude it is the absence of the male body that is in fact foregrounded, through the commodified female body (wearing a bikini and smoking a phallic object). With such a scene Kubrick indicates the puissance of radioactive masculinity even in the absence of an actual male body.

In Freudian terms amongst the many possible pleasures being offered by cinema one of the primary ones is scopophilia or the "circumstances in which looking itself is a source of pleasure, just as, in the reverse formation there is pleasure in being looked at" (Mulvey 201). Such a scopophilic activity is understood mainly as "the determining male gaze [that] projects its 
fantasy onto the female figure, which is styled accordingly" (Mulvey 201). This element of scopophilic pleasure becomes critical within the domain of Kubrick's film because the character of Miss. Foreign Affairs signifies not only the representation of the desires of her on-screen lover, but rather the attitude of the military-industrial complex that perceives women as masturbatory images or passive receptors of the phallus. The use of Tracy Reed's image as a Playboy model therefore becomes highly suggestive. Beyond Playboy's status as a glamour magazine, it also featured writers of caliber such as Arthur. C. Clarke expositing on technological issues. Therefore, such texts would be the ideal scopophilic object for the radioactive male — through incorporating both technological knowhow and a woman's fetishized body, within its pages. The moment of cinematic brilliance where Major Kong sits in a B-52 bomber carrying nuclear bombs and peruses Playboy — both potent objects of masculine fetishperfectly symbolizes the anxieties of being a radioactive male

Although there are indeed numerous other scenes in Dr.Strangelove where the male body is physically absent, there is no real lack of phallic signifiers in such moments. As a matter of fact, the very first scene in the film portrays a B-52 bomber being refueled by a larger aircraft, which extends its refueling pipe into the chamber of the B-52. This scene inaugurates the first of many scenes that see the replacement of physical male bodies by their technological phallic counterparts. For example, the two nuclear bombs that are carried by Major "King" Kong into Russia are called Dear John and Hi There. The term "Dear John" became apocryphally wellknown during WW-II as an affectionate address used by a woman in a letter to her husband "John," informing him of her decision to move on with another man. By naming the bomb "Dear John" Kubrick performs a dual task: portraying how such a form of address was perceived in the military-industrial complex — as a major form of emasculation for the male soldier-while also 
critiquing the patriarchal attitude that failed to recognize women as anything more than objects of sexual fantasy. Pertinently, the name of the second bomb "Hi There" points out the next step that would be taken by such an emasculated male soldier. This would be an attempt to court new female companionship using pick-up phrases such as "Hi There." In pointing out how the newly spurned aggressive militarized male figure would approach the (objectified passive) female in order to re-establish his alpha-male status, Kubrick highlights the implicit anxieties of radioactive masculinity. Interestingly such a fetishization of the female body occurs even in the survival kit that is handed over to the air force personnel in the B-52 bombers. The kit that includes "one issue of prophylactics; three lipsticks; three pair of nylon stockings," (Dr. Strangelove) portrays items that may be used to seduce women and essentially use them as objects to alleviate hypermasculine anxiety. In "Sex and Death in the Rational World of Defense Intellectuals" Carol Cohn's seminal article on gendered nuclear discourse, she highlights this element of hypermasculine anxiety within the American military-industrial complex:

Throughout my time in the world of [nuclear] strategic analysis, it was hard not to notice the ubiquitous weight of gender, both in social relations and in the language itself; it is an almost entirely male world (with the exception of the secretaries) and the language contains many rather arresting metaphors (688).

This constant desirable state of hypermasculinity seems to be a necessary cultural capital within the military-industrial complex, which allows discussions regarding nuclear weapons, nuclear war and nuclear strategy to carry on "without any sense of horror or, urgency or moral outragein fact there seems to be no graphic reality behind the words..." (690). From Cohn's analysis it becomes absolutely clear as to why radioactive masculinity is an integral part of the military- 
industrial complex - since the abstraction of the bomb cannot be performed without gaining the heteromasculine capital explicit in this gendered paradigm.

It is therefore not all surprising that Kubrick chooses to reiterate this element of hypermasculine anxiety throughout his film: as recognizing this feature of the military-industrial complex could possibly lead the audience to recognizing how the catastrophic potential of the bomb was being continually abstracted in official publicity. In promoting this form of awareness about the military-industrial complex, Kubrick emphasizes this hypermasculine anxiety as a dominant motif within all the authority figures in his film. Merkin Muffley ${ }^{\text {xxxiii }}$--the American President in this movie and the supposed central authority figure-is often domineered upon by his subordinates, who are the antithesis to his "decent, sensible, likable and humane" demeanor (Burgess 9). In one of his interactions with General Buck Turgidson, as Muffley asks him how the devolution of authority (that had led to the Ripper's order of nuclear attack) was possible, he is immediately rebuked and chastised by Turgidson with the comment: "You approved it sir. You must remember. Surely you must recall, sir...the idea for Plan R to be a sort of retaliatory safeguard." (Dr. Strangelove).

Several other instances in the movie highlight Muffley's character as a "liberal, conciliatory, "man of reason"' (Tweg 7) who tries to reason with the Russian premier about this sudden catastrophe and even allows the Russian Ambassador access into the War Room-a decision that is intensely contested by his military officers. Muffley's inability to negotiate with his military generals does not seem to arise from his incompetence but rather his status as a reasonable man, which seems to contradict the structures of radioactive masculinity needed to function within the military-industrial complex. Since within this world of Dr. Strangelove hegemonic militarized masculinity is the only measure and indicator of manhood, Merkin 
Muffley's status as a non-radioactive male, in fact feminizes him, making him the obvious antithesis to the other radioactive males. His effeminate status is also indicated through his name "Merkin Muffley", which beyond the obvious shortening of "American" is a crude sexual reference to the genital wig used by female prostitutes to cover their "muff" (a euphemism for female genitalia). However, in reference to Dr. Strangelove the connotation of "Merkin" that becomes particularly important is that male actors also used these wigs to play female roles, so that they could expose themselves on the stage. As the public face of the military-industrial complex, the American President Merkin Muffley therefore becomes the "wig" that covers up the phallocentric nature of nuclear discourse - a benign buffer for the anxious and hypermasculine military-industrial community.

Vitally, the actual figure of authority in the movie is the eponymously named scientist who was apparently modeled on a variety of individuals including Edward Teller, Herman Kahn and Henry Kissinger amongst others (Stillman). Interestingly the character of Dr. Strangelove strapped into a wheelchair for a major portion of the movie "mocks not only militarism, Edward Teller and the Pentagon, but all pretensions on the part of men (all of us) who have delivered their environment into the hands of totally amoral technological science" (Burgess 10). Dr. Strangelove's attachment to his wheelchair, his artificial hand that abruptly rises in Nazi salute and his celebration of the concept of M.A.D (mutually assured destruction) indicates not only his enmeshment within the military-industrial complex, but also the legitimation of the bomb within the paradigm of radioactive masculinity. In this unfeeling world of the military-industrial where men have "stopped worrying, i.e. thinking and feeling and learned to love the bomb, i.e. The Machine” (my emphases; Burgess 10), Dr. Strangelove's physical impairments are not a hindrance to his becoming the alpha-masculine figure. Rather it his half-machine half-man status 
where he is literally at one with the bomb, which makes him the naturalized leader of the nuclear community and the purported mast figure in a post- nuclear holocaust world. As Terry Southern one of the scriptwriters for Dr. Strangelove asserts the "movie was an attempt to blast smugness...over a fool-proof [military-industrial] system which may not be" (qtd. in Burgess 10). In doing so Kubrick indicates that it is not the infallible Russian Doomsday Machine that ultimately destroys human civilization but rather the masculinized and militarized ideologies behind such destructive artifacts, which devoid of all morality had devalued and abstracted human life.

What such a discussion also brings forward is the inherently non-democratic nature of the nuclear bomb and its allied discourses. Due to the symbolic and material associations of the national security apparatus, sovereignty, and statecraft with nuclear weapons there is

[...] a fundamental incompatibility between nuclear weapons and the ideals of the democratic state... [the] oppressive conditions surrounding the development of nuclear weapons subvert the capabilities of citizens to acquire, deliberate, and act on information concerning nuclear policy. As a result, the nuclear public is characterized as fragmented, alienated, uninformed, and unable to participate in deliberation with forceful and reasoned discourse (Taylor 671).

Thus, while every attempt might be made to democratize nuclear knowledge and create a dialectic model of conversation, the inherent secrecy and connotations of state security embedded in the bomb will never allow for the constitution of a viable democratic nuclear public sphere. Therefore, expanding access and knowledge about nuclear weapons can only be instituted through self-organized nuclear counterpublics. A movement toward developing such nuclear counterpublics in America - through subversive cultural productions such as $\mathrm{Dr}$. 
Strangelove - therefore became concurrent with American governmental equivocation about nuclear weapon.

The INITIATION OF NUCLEAR COUNTERPUbLiCS

By now, the bomb has almost no reality and has become a complete abstraction, represented by a few newsreel shots of mushroom clouds...As time goes on, the danger increases, I believe, because the thing becomes more and more remote in people's minds. (Kubrick qtd. in Agel 59)

From the initiation of the nuclear into the public imagination through the events of Hiroshima and Nagasaki to the cessation of above ground testing, the nuclear bomb in the public sphere had achieved a full circle, at least psychologically. While Truman's initial speech after the Japanese bombings had exalted the ability of the bomb to make "a profound psychological impression on as many inhabitants as possible" (Garrison 66) it was now increasingly the effort of the government to abstract its catastrophic potential, through a "a few newsreel shots of mushroom clouds." As Constandina Titus remarks in her article "The Mushroom Cloud as Kitsch"

Bursting onto the scene in 1945, the mushroom cloud was immediately recognized as a symbol of U.S. Power. ...the government quickly promoted it to instill awe and fear in the citizenry and thereby build support for Cold war defense policies. Recently, after virtually disappearing... when testing moved underground, the mushroom cloud reemerged as a nostalgic icon (102).

While Titus' claims about current images of the mushroom cloud as nostalgic kitsch are debatable, she does underscore an important point: how an abstraction of the bomb's catastrophic potential has been performed through banalizing the most potent nuclear symbol: the mushroom 
cloud. In view of Titus' remark it becomes vital to emphasize the role played by cultural texts such as Dr. Strangelove, which were produced in the immediate period after nuclear testing moved underground. They inaugurated a nuclear counterpublic space thereby re-embodying the nuclear bomb and its devastating effects.

It is necessary here to also acknowledge a few other notable texts that were being published and filmed in this period: with the singular aim of promoting a nuclear consciousness amongst the general American populace. Fail Safe (1964) released in the same year-directed by Sidney Lumet who adapted it from a novel by E. Burdick and Wheeler-functioned on a similar premise to Kubrick's movie and detailed the inherent fallibility of the military-industrial complex. In Lumet's movie that has a serious tone unlike Dr. Strangelove, a computer malfunctioning leads six US aircrafts to cross their fail-safe points and bomb Moscow. With Moscow destroyed the US president is forced to enter into a bargain with the Russian premier and orders his trusted aide General Black to nuke New York City with Empire State Building a ground zero. The following year saw the production of The War Game (1965) a BBC commissioned documentary-style production that visualizes the terrifying scenario of a nuclear bomb attack on Southern England. The production, which was later banned by the BBC made an "overall presentation of the social collapse at every level despite 'contingency' planning by the authorities" (Tweg 16). Critically, Michael Warner in conceptualizing counterpublics argues that such bodies are "defined by their tension with the larger public... being structured by alternative dispositions or protocols, making different assumptions about what can be said or what goes without saying." (56) Such an assertion maps perfectly onto the reactions that the above mentioned texts elicited in the larger public sphere: while Dr. Strangelove was regarded as "just a zany novelty flick which did not reflect the views of the Corporation (Columbia Pictures) in 
any way" (Southern 80), Peter Watkins' The War Game was banned by the BBC, ironically the same body that had commissioned its production. Interestingly, in both cases Kubrick and Watkins faced opposition from the military-industrial community as well from their very sites of production. This indicated that minoritarian perspectives on nuclear weapons were being "marked off from persons or citizens in general," (Warner 12) delineating them as an aberration within the larger civic body and thereby automatically providing such texts with a subcultural counterpublic space. The radical content in these films connotated the creation of a counterpublic discursive space not only by challenging dominant nuclear discourses in the larger public domain but also by creating a "horizon of opinion and exchange" (Warner 60), which would be utilized by similar cultural documents in the future. ${ }^{\text {xxxiv }}$

Productions from Kubrick, Lumet, Watkins initiated the rise of a discursive space that had re-embodied and concretized the destructive potential of the bomb, but more importantly created counterpublics where the constituents "could engage in communicative processes beyond the supervision of dominant groups" (Asen and Brouwer 7). Paving the way for the rise and development of determined anti-nuclear activists such as Helen Caldicott and organizations such as the Nuclear Age Peace Foundation, films such as Dr. Strangelove highlighted that the "rational" strategies of the military-industrial complex were not only untenable but in fact antihumanist. In the words of Gertrude Stein nuclear counterpublics reminded the public domain that the atomic bomb would surely "destroy a lot and kill a lot, but it's the living that are interesting not the way of killing them" (Stein para 1). 


\section{Chapter 3: The Quest for "Hardness": Chronicling Radioactive Masculinity and Its Discontents in American Fiction}

In the aftermath of the 9/11 attacks, the Internet and the newly emergent social media space saw the rise of political cartoons and graphic animations that presumably sought to artistically combat the catastrophic acts of terrorism, which had ravaged the country. Unsurprisingly many of these cultural productions had Osama Bin Laden as their main subject and a common feature seemed to pervade them all: the sodomization of Osama by phallic signifiers of American masculinity. One of the more infamous ones depicted Osama being anally penetrated by a US nuclear bomb, a notable graphic amongst many others that similarly depicted Osama being violated by unambiguously American structures such as the Empire State Building. This battery of artistic output that deemed it necessary to culturally support George Bush's War on Terror-by transforming iconic American structures into masculine symbols, which violated threatening non-Western male figures such as Osama and Saddam Hussein — provided key insight into the cultural imaginary of post 9/11 America. One that increasingly read,

[t]he destruction of the [World Trade Center] towers [as a] stand in for the violent destruction of the American phallus, their collapse for an embarrassing detumescence...the attack on the twin towers as a closely sequenced double act of penetration/ rape (Mann 5-6).

Clearly the heinous act that had resulted in the deaths of many had become more than merely an act of terrorism against the American nation. American sovereignty and its contingent structure, namely American masculinity had been challenged and the nation needed to produce material 
and symbolic hypermasculine efforts, which would counter this apparent emasculation and challenging of national sovereignty.

This equation of national sovereignty with national manhood in the post 9/11 period that resulted in desperate efforts to reinvigorate American masculinity, however, was not new. Such acts, Susan Faludi points out, resulted from the "suspicion that the nation and its men had gone soft" (8) and were not the first instances of this phenomenon within the American nation-state. Conserving and shoring up hegemonic American masculinity within their purported repositories - white heterosexual male bodies—-has always been central to the discourse of American nationhood and sovereignty. Due to continuously equating a hypermasculinized body politic with its global influence, attempts at maintaining American sovereignty—as well as concomitant status quo for white masculine privilege — has always been tied with combating the associated masculine anxieties. My arguments here extend the discussions from the last chapter and chronicle how structures of radioactive masculinity and its resultant anxiety (ies) moved beyond the domain of the American military-industrial complex. By analyzing the manifestations of radioactive masculinity in American nuclear disaster fiction, I illustrate their pervasive influence in shaping American Cold War Containment Culture.

Contextually, it becomes critical to underline that the conditions from which radioactive masculinity emerged clearly establish this gendered model as the product of a moment of singularity within the American national imaginary. Although currently, associations between hegemonic masculinity and nuclear weapons have become naturalized, such a deterministic method of perceiving the socio-cultural power of a sovereign nation arose from a collusion: between wartime technology and the anxieties of a post-Depression era emasculated America. Pertinently, Manual De Landa in his seminal treatise on sentient technology's effects on war and 
conflict dwells on the concept of singularity, which originally found fruition during the Manhattan Project, as an integral part of nuclear physics. Singularity underlines that specific moment when a group of random variables align to create a situation/phenomenon; one that could never be predicted by observers chronicling those variables minutely, albeit in isolation. In other words the conditions precipitating singularity (although not random events) are almost impossible to predict or govern by the rules that are understood to organize the concerned field. The effects of such moments of singularity are that they often give rise to self-organizing processes which influence both the variable that led to the singularity's production as well as create new processes (De Landa).

My contention here is that while trying to compile a comprehensive timeline of the effects of nuclearization on America and the globe may be impossible and chaotic, there are "moment [s] at the onset of turbulence" (De Landa 15) that need to be identified. These moments or factors allow us to perceive the socio-cultural effects of the nuclear bomb as a "wonderfully ordered process" (12). Such a cultural genealogy of nuclear weapons, I argue, can be constructed through deciphering the contingent relationship between militarization and gendered bodies; and more specifically the nuclear bomb and hegemonic militarized masculinity. This socio-technical formation emerging from the contingence between nuclear weapons and hegemonic militarized manhood—one that I term as radioactive masculinity—-therefore allows for the analysis of how nuclearization is manifested in diverse spatio-temporal contexts.

This chapter underlines that while historically American models of hegemonic masculinity have risen and been subsequently replaced by other temporally relevant structures of manhood, the ideologies behind radioactive masculinity ${ }^{\mathrm{xxxv}}$ have remained the constant template by which post WW-II American manhood and indeed the strength of American sovereignty is 
assessed. ${ }^{\text {xxxvi }}$ This chapter and the following one delineate the cultural effects of the bomb in America and India — albeit during separate eras of history ${ }^{\mathrm{xxxvii}}{ }_{--}$and foreground how the fears associated with nuclearization are manifested through the anxieties of radioactive masculinity. The fallout of this contentious association between hypermasculine anxiety and nuclear weapons naturally finds reflection in the social milieu and the cultural productions from both locations. These two allied chapters look at representative fictional texts where the anxieties of radioactive masculinity are manifested, while being cognizant of both contextual similarities and differences. In tracing the lineage of radioactive masculinity across geographical spaces and time periods, I illustrate the importance of emphasizing the relationship between gendered bodies and militarization, within any discussion of nuclear weapons and nuclear technology.

FirSt LightNING AND AMERICAN COLD WAR ANXIETIES

Nuclear arms race is in large part underwritten by masculine behavior in the pursuit and application of scientific inquiry (Easlea 5).

While the events of July 16, 1945 — when the first atomic bomb was tested on the solitary deserts of New Mexico - undoubtedly contributed to both the political and psychic strengthening of the American body politic, this feeling of global domination would be short-lived. Only four years after, on August 29, 1945, Soviet Russia would become a nuclear-weapons capable state with the RDS-1 also known as First Lightning. Unsurprisingly, masculinist underpinnings have been a vital part of Soviet Russia's nuclear project as well: the first Soviet atomic artifact was resultantly named RDS — an acronym for "Reaktivnyi Dvigatel Stalina”—or "Stalin's Rocket Engine" in Russian, an unambiguous metaphor for both Stalin's virility as well as for the national space which he emblematized (Nuclear Weapon Archive). This unexpected end to solitary American nuclear superiority gave rise to a bitter hostility between two previously 
wartime allies and accelerated the hitherto unseen Cold War in the next few near-apocalyptic decades - dividing the world into two clear political and ideological factions.

In analyzing the entry of the erstwhile USSR as a nuclear weapons state within the global political arena a few aspects must be stressed. While nuclear weapons might have helped weaponize the antagonism within these two super-powers, these artifacts did not inaugurate the tensions that lay at the basis of the Cold War conflict. Although, the USSR and the USA had been part of the same victorious conglomerate in World War II, the term allies could only be loosely applied to them. Their partnership was largely based on both countries' mutual antagonism toward Nazi Germany. As Gaddis notes, the USA and USSR even before the Cold War, were "already at war —ideologically and geopolitically if not militarily—with one another" (my emphasis; 6). However, this conflict had been tempered down quite a bit, albeit temporarily, after the decimation of Hiroshima and Nagasaki in August 1945, which provided both the world a glimpse of America's unassailable military strength while also alleviating USA's own fears of being vulnerable to external threats. The general feeling amongst the American political and military establishment in the post-1945 era, was that the American nuclear monopoly would last for a good six to eight years. This would give them enough time to consolidate and reconstruct post WW-II America, without the fear of facing any external aggression.

However, the USSR's explosion of its own atomic weapon in 1949 reignited American anxiety, which had been (seemingly) laid to rest between the period between 1945 and 1949 . Although, it may be worth pointing out that even in the short period between 1945 and 1949, America was never completely free from the anxiety of its global dominance being challenged. An interesting anecdote, which consolidates this claim, is how America was responsible for discovering the first Soviet Nuclear test, a highly clandestine project. Due to the secretive nature 
of the Soviet nuclear program (much like the Manhattan Project) very little was known of USSR's First Lightning, in the period before it was tested. The result of this secrecy ${ }^{\mathrm{xx} x v i i}$ meant that Soviet Russia made no official declaration about its first atomic bomb. It was in fact American B-52 bombers that had been fitted with radioactive counters, which picked up radioactive traces above and close to the Soviet airspace. This aspect of constant surveillance by America over its erstwhile ally in the pre-Cold War era, highlights the state of latent anxiety that existed even during America's short-lived period of nuclear monopoly: a feature that would be magnified substantially in the Cold War era and ensuing periods (Gaddis).

Explicating the connections between the anxious American military-political establishment and the internal state of the nation as well as its external foreign policy, requires more qualification: especially a more nuanced understanding of weapons of mass destruction and their relationship to the nation-state. As Carol Cohn and Felicity Hill note,

Weapons of mass destruction are not only physical objects, they are political objects, their symbolic importance is key in national and international security debates, as well as in domestic politics. And one aspect of political discourse—so obvious to be usually taken for granted - is that gendered terms and symbols are an integral part of how political issues are thought about and represented [...] (my emphases; 3)

Therefore gendered ideologies that had pre-ordained American nuclear weapons to be developed within the techno-masculine space of the Manhattan Project ${ }^{\text {xxxix }}{ }_{-- \text {carrying within them the }}$ symbolic promise of reinvigorating the emasculated post-Depression era American body politic — would naturally perceive Soviet nuclear capability as a threat to American nationhood and the concomitant masculinity. 
Thus, the American socio-political quest to become harder than the adversary (Soviet Russia), in order to avoid being penetrated within the domestic space through Communism or in the martial sphere through nuclear weapons, made it inevitable that a two-pronged strategy be adopted. Within the domestic space this resulted in political agendas such as the Red Scare with the underlying presumption that "one is soft if one insists that the danger from domestic Communists is small, while one is hard if one holds that "no distinction can be made between international and domestic communism"” (my emphasis; Bell qtd. in Cuordileone 515). In the international domain Cold War political culture dictated that American anxiety about becoming "soft" was countered through the constant attempt to outdo its Communist adversary—by producing bigger and better nuclear weapons - that would presumably keep American anxiety at bay by providing unparalleled masculine hardness.

\section{POST-WAR DOMESTIC EXPLOSION_AND RISE OF THE AMERICAN RADIOACTIVE MALE}

The hard/soft language registers the heightened cold war tensions inspired by that 'amorphous ideological issue' —Communism — against which America stood in stark opposition. But the dualistic imagery was also the reflex of a political culture that, in the name of combating an implacable expansionist Communist enemy, put a new premium on hard masculine toughness and rendered anything less than that soft, timid, and feminine, and as such as a real threat to the security of the nation.

(my emphases; "Prologue" Manhood and American Political Culture viii)

The metanarratives produced about the world-changing spectacle known to be the Cold War often discount what the eminent historian John Lewis Gaddis notes as a defining characteristic of this conflict "[T]he Cold war was fought at different levels in dissimilar ways in multiple places 
over a long time. Any attempt to reduce its history to the role of great forces, great powers or great leaders would fail to do it justice" (Preface xvi). Such an understanding helps us throw light on an often-undermined aspect of Cold War America: one that highlights quotidian American domestic life as a key aspect of its trenchant containment culture and its contingent relationship with American masculinity. Sarah E. James asserts that "[D]uring the Cold War, the family became the contested subject of competing ideological systems" (13), which underlines how the Cold War was manifested internally within the nation. In fact, the "private realm of everyday life, leisure and work" (James 169) were opportune spaces for implementing the diametrically opposed ideologies of the Eastern and Western blocs. While attention has been granted to the "American bombing campaign involving consumer goods instead of explosives" (James 168) that were specifically geared toward women due to "the importance granted to women in... [these] ideological battles," (James 169) there is little discussion behind the reason that traditional gender roles and an emphasis on "hard" manhood sought to make an emphatic come-back during the Cold War era.

Elaine Tyler May notes that this return to traditional models of domesticity in Post WWII America especially between 1940-1960 was indeed counterintuitive. While some scholars attribute the "family boom" to an "inevitable result of a return to peace and prosperity" (May 6), no other period in America (including the post WW-I era) had seen a similar increase in marriage and childbearing:

The demographic trends went far beyond what was expected from a return to peace.

Indeed, nothing on the surface of postwar America explains the rush of young Americans into marriage, parenthood and traditional gender roles. (May 8) 
All evidence suggested that it should have indeed been the other way around: "[I]t might have been otherwise. The Great Depression of the 1930's brought about widespread challenges to traditional gender roles that could have led to a restructured home" (my emphases; May 8). However, in the face of all these contradictory factors postwar America witnessed a domestic explosion, along with a drastic fall in the rate of divorces between the 1940 and 1960. May highlights that this period is often noted to be:

[the] last-gasp of time honored family life before the sixties generation made a major break from the past....In many ways the youths of the sixties resembles their grandparents, who came of age in the first decades of the twentieth century... [and who like their grandchildren] had challenged the sexual norms of the day, pushed the divorce rate up and the birthrate down...It is the generation in between -with its strong domestic ideology, pervasive consensus politics, and peculiar demographic behavior - that stands out as different (my emphases; May 9).

The burning question therefore remains: what changed during this period? Interestingly, while most scholarly discussions of the period focus on the changing role of women from being active participants in the workforce during WW-II to passive recipients of consumerism in the postWW-II period, there is hardly any exposition on the role of men and manhood during this period. While May acknowledges that the raising of children and creating secure "domestic nests" to battle the insecurities of Cold War tensions was largely a masculine initiative, there is meagre analysis of why the domestic space became an opportune space for the survival of American sovereignty; or by extension the synonymous ideologies of hegemonic (white) militarized masculinity. 
Indeed such a conundrum becomes easy to explain when the relationship between American nationhood and American masculinity is brought into the equation. The period that saw this rise in domesticity was a clearly a threatening period for the American nation. While externally nuclear-capable Soviet Russia posed a credible threat, internally "soft" American citizens were susceptible to being penetrated by the machinations of Communism. K.A Cuordileone summarizes the role played by these ideologies of masculinity in "Politics in an Age of Anxiety": Cold War Political Culture and the Crisis in American Masculinity":

In the heady atmosphere of Cold War political culture, the hard/soft dichotomy gradually took a life of its own, existing quite apart from tangible political and strategic considerations and operating in a symbolic milieu in which it often seemed as if the very manhood of the nation and by extension that of its male citizenry was at stake (544).

Much like the phallic shaped American nuclear bombs_Fat Man and Little Boy — that had been unleashed "to make a profound psychological impression on as many of the [Japanese] inhabitants as possible" (Manhattan Engineer District), American manhood needed to both physically and psychologically assert its dominant status within and beyond its boundaries.

In her incisive analysis of atomic age cultural productions, Kristina Zarlengo asserts that American nuclear propaganda made clear distinctions between the role of men and women. The ideal of domesticity that was a critical part of Cold War America needed to be upheld through a reinvigorated masculinity that placed females into an ideal model of oppressed femininity, who were supposed to occupy the role of a passive recipient. Anything that would challenge this status quo would upset the gendered social order of Cold War America and (presumably) evoke the anxiety in the American male and the nation: 
Atomic age public information provided guidelines for civilian behavior during nuclear war that indicated...how good Americans, and good American women, should behave in light of an enemy threat (my emphasis; Zarlengo 930)

Clearly every effort was being made both at the institutional level (by the military-political establishment) and at the domestic level (by hegemonic masculinity) to avoid any form of challenge being put forth against the American man and the associated structures he represented; American sovereignty and nationhood. Unsurprisingly, such a constant effort to align atomic age manhood with nuclear weapons would lend itself to a heightened sense of anxiousness, which became a defining characteristic of the radioactive male in American fictions of nuclear disaster.

\section{RADIOACTIVE MASCULINITY IN AMERICAN FiCTIONS OF NUCLEAR DiSASTER}

One of the major traits of radioactive masculinity across nuclear spaces (as also outlined in the last chapter) is a constant perceived threat to the male body, which needs to be countered since nationhood and masculinity are understood to share a concomitant relationship. Therefore, efforts at shoring up heteromasculine capital are and have been precisely directed at the maintenance of status quo: allowing for the continued survival of the ideologies of hegemonic (white) militarized masculinity. In Cold War America, hegemonic militarized masculinity was seen as guarding the American nation from external threats, through a combination of hard military bodies and military technology. Internally this paradigm would prevent American masculinity (and nationhood) from being "penetrated" by the ideologies of communism. Such perceived threats and anxieties emerging within the Cold War, have since made the domestic space an ideal ground for both accumulating and maintaining the status quo for the male body. Therefore, American radioactive masculinity — a threatened model of white militarized manhood found in literary and cultural texts — battles with this constant anxiety — one that perceives the 
male body as needing to be protected both implicitly and explicitly_from the threats of apparent emasculation that challenge its hegemonic status.

Before embarking on a discussion of radioactive masculinity in both American and Indian literary texts (albeit in two different eras) in this chapter and the next, it may be useful to understand why this motif of anxious masculinity related to the nuclear bomb, is a topic worth discussion. In doing so, it may helpful to refer to Spencer Weart's remarks about how our fear of the nuclear is assigned to various images that are found pervasively in cultural tracts of the atomic age:

Radioactive monsters, utopian atom-powered cities, exploding planets, weird ray devices, and many other images have crept into the way everyone thinks about nuclear energy, whether that energy is used in weapons or in civilian reactors. The images, by connecting up with major social and psychological forces, have exerted a strange and powerful pressure within history. (my emphases; Weart xi)

In trying to understand how a specific form of manhood, radioactive masculinity ${ }^{\mathrm{xl}}$ emerging from a co-production between a technology (the atomic bomb) and hegemonic militarized masculinity - is manifested in cultural tracts, I underline how this paradigm is symptomatic of living with the nuclear bomb. In other words, I continually emphasize in this chapter and the larger project that a socio-cultural account of nuclearization cannot be provided without accounting for the structures of masculinity implicated within its framework and vice versa.

That said, it remains surprising how the domain of scholarship dealing with nuclear disaster fictions - in both the Anglo-American and postcolonial spheres - is sparsely populated. With a few notable exceptions ${ }^{x l i}$ there is an overarching tendency amongst literary scholars and the general reading public alike, to oversimplify the various narratives in this genre as being 
merely simplistic prophecies of impending nuclear doom. A case in point would be an early review of Paul Brians' seminal book on this topic, Nuclear Holocausts: Atomic War in Fiction 1895-1984 which appeared in the Bulletin of Atomic Scientists. Even though Brians' book is a thoughtful reflective take on the diverse goals and manifestations of this literary genre, the reviewer in Bulletin of Atomic Scientists' notes that ultimately Brians underlines the "reactions to and warnings against the actuality of nuclear war" (Hostetter 44). This trend of classifying fiction that deals with nuclear disasters as either cautionary speculative tales or propaganda-laced public service announcements, often sublimates one of the key aspects of this genre, that:

Nuclear war creates such anxiety in most people that they are prone to all manner of strategies of avoidance in discussing it... simple selective ignorance of the problem... [Nuclear disaster fiction] tells us something about our fears and phobias. But fiction, because of its concreteness, can treat the subject in such a way that it is difficult to avoid. In addition, the creation of vivid characters and realistic settings can bring home the impact of a nuclear war in a way that is difficult for nonfiction. (Preface Brians ii)

However, Brians' timely reminder that anxiety is indeed the key feature of nuclear disaster fiction and in all good measure of the atomic age is conveniently forgotten amidst scholarly prescriptions that hope to discern the perfect form of nuclear disaster fiction: one that will purportedly summarize all the horrific aspects of a nuclear apocalypse and the period ensuing thereafter. Of course, the cause of serious scholarship about nuclear disaster fiction has not been helped by the fact that nuclear holocaust has been "trivialized in a variety of ways... as the creator of a mutated super-race, as a background for horror fiction, as an excuse for the ever- 
popular last-man-and-woman theme...as the setting for scenes of violent combat" (The Nightmare Considered 134)

Such trivializations abstract from the reality that fictions of nuclear disaster are in fact distinguished by "what Robert Scholes calls structural fabulations, defined as "a fictional exploration of human situations made perceptible by the implications of recent science" (Dowling 86). Indeed, while Dowling's assertion is well founded, what remains unsaid is that most "implications of science" perceived in nuclear disaster fictions are devised by male scientists or men predisposed to an unquenchable scientific thirst. In emphasizing this idea of science as masculine or the masculinization of science in post-apocalyptic cultural texts (in general) and specifically nuclear disaster fiction, I do not want to either emphasize or endorse the idea of science being a masculine endeavor ${ }^{x l i i}$. Instead in pointing out that most of the apocalyptic or near-apocalyptic situations envisioned in nuclear disaster fictions emerge from machinations created by male characters, I would like to highlight how performances of anxious manhood occupy a central position within this oeuvre of texts. Such male performances are symptomatic of this paradigm of hegemonic militarized masculinity—radioactive masculinity— that irrevocably influenced the socio-cultural spaces within which these literary and cultural texts emerged.

In the earlier chapter I have underlined that the anxieties resulting from the contingent relationship between hegemonic militarized masculinity and the nuclear bomb are manifested differently across spatial and temporal contexts. However, there are clear and well-defined thematic similarities between these diverse models of radioactive masculinity. The resonance between radioactive masculinity in United States and in India seen through literary fiction from these two countries, offers us cross-cultural insight into the tempestuous relationship between 
nuclear weapons and hegemonic militarized masculinity. While most forms of canonical nuclear disaster fiction ${ }^{\text {xliii }}$, are implicated within the "polarization of images", "hard/soft duality" and masculine anxieties (Cuordileone), which lie at the heart of American cold War Culture, I specifically choose to focus here on Neville Shute's On the Beach and Pat Frank's Mr. Adam. These novels while being representative examples of this distinctive genre known as nuclear disaster fiction also bring forth most explicitly the relationship between hegemonic militarized masculinity and the nuclear bomb.

\section{On the Beach}

In The Writing of the Disaster, Maurice Blanchot uses the term Ecriture to "designate what is still left to say when everything that can be has been [...]," (6) a fitting description for the realm of nuclear disaster fiction, which hopes to clairvoyantly speak up for the inarticulable realities of a post nuclear-holocaust world. The novels discussed in this section and the next while advancing a new model of critical self - reflection that foregrounded anxieties about nuclear technology also embody the relationship between white militarized masculinity and the nuclear bomb. Going against the trend of "strategic fictions" produced in the immediate aftermath of Hiroshima and Nagasaki that "bought into the assumption...that deterrence through overwhelming military power was the only way to prevent war...critical fictions [such as On the Beach and Mr. Adam] saw such a military buildup as the surest path to a nuclear apocalypse" (Sharp 154).

Not surprisingly therefore, Shute's 1957 novel, On the Beach, begins with a prologue from T.S. Eliot's The Hollow Men: "This is the way the world ends/Not with a bang but a whimper," an almost immediate reminder that the novel is distinguished from other "strategic fictions" of nuclear disaster. On the Beach suggests that in contrast to the idea that nuclear doom 
would be a sudden painless event, the probable reality would be quite different: a rather painful long-drawn out affair precipitating the termination of humankind. In "The Imagination of Disaster," Susan Sontag notes that the current age is indeed an "age of extremity [where] we live under continual threat of two equally fearful, but seemingly opposed destinies: unremitting banality and inconceivable terror" (42). On the Beach through its deliberately languid narrativization delves into both these extremities, by chronicling the banal everyday lives of a group of individuals living out their last few days, in a post-nuclear holocaust Australia.

The events in the novel begin after an all-out nuclear exchange between multiple nations in the Northern Hemisphere has killed large sections of the population and left other parts of the world uninhabitable due to the radioactive fallout. Australia, by virtue of its geographical location is one of the last places left inhabitable, albeit for a short time, before the fatal radiation reaches its shores. The constant negotiation undertaken by the individual characters in trying to carve out a regular mundane existence in the face of certain death makes On the Beach a perfect simulacrum for Cold War America: where citizens were forced to carry on with their domestic lives while the threat of an all-out nuclear war loomed over them constantly. It is not surprising therefore as to why On the Beach captured the public imagination during the Cold War period, which had "sales of a quarter million [and], it ranked number eight on the 1957 best-seller list for fiction" (Beidler 370). Particularly, in the context of my argument, On the Beach offers a perfect template to analyze the model of radioactive masculinity, due to the multiple representations of troubled masculinity in this narrative. My analysis in this section underlines both the tension between male bodies and technology in this narrative as well as the circumscribed role of female characters who constantly suffer due their relationships with these anxious male figures. 
The term on the beach that Shute adopted from the Royal Navy denotes a retirement from active service and manifests itself in multiple ways within the novel. Of course, the immediate connotation refers to the two primary characters, the Australian naval lieutenant Peter Holmes and the American naval captain Dwight Towers, who are made to deal with the prospect of their last job assignment in a post-nuclear holocaust world. However, the forced loss of their professional vocation and an impending retirement is not the only anxiety characters face in this novel. The novel opens with the newly promoted Lieutenant Commander Peter Holmes waking up in hometown Melbourne, with his wife and his baby daughter beside him. The significance of this morning reflecting a normative scene of domesticity is underlined when the reader becomes aware of Lt. Commander Peter Holmes' crucial meeting later in the day, offering him the prospect of "his first work in seven months... [and] a seagoing job if he were very lucky" (Shute 1). While Holmes' lack of professional engagement had not meant a stop in income as "[T]he Navy Department...had maintained him on full pay throughout these months" (Shute 3) there is a clear sense of discontentment that Holmes harbors and hopes to address through the opportunity of renewed employment. It is not difficult to discern why Shute chooses to initiate the novel in a scene of apparent domestic bliss, especially because it allows for the establishment of a template against which all the latent and overt masculine anxiety in the narrative can be contrasted. More importantly, it helps drive home Peter Holmes' complete enmeshment within the ideologies of hegemonic militarized masculinity: a framework that only perceives military service to the nation as the true metric of self-worth and concomitant masculinity. Family commitments while important can clearly never compete with the satisfaction that Peter Holmes gains from being employed as a vital cog within the military-industrial complex. 
As the narrative progresses the reader is made aware how each human act in this postnuclear world derives from the desperate need to maintain normalcy in a world where only Australia and certain parts of the Southern Hemisphere are still free from the after-effects of a "short, bewildering war...the war of which no history had been written or ever would be written now" (3). Considering that nuclear weapons - representing the very pinnacle of man-made technology — are responsible for the apocalyptic situation in On the Beach, it is apparently surprising that machines and mechanization become the fundamental coping mechanism for characters in this novel. Dowling asserts that one of the distinguishing features of nuclear disaster fiction is "an alienation of man... from contemporary symbols of civilization" (87). Such is made apparent in On the Beach as the reader is made aware that one of the primary symbols of contemporary civilization, namely cars have been made obsolete due to the scarcity of fuel. Importantly, cars and most forms of machinery occupy a fetish position in this novel as most of the primary characters seem preoccupied with aligning themselves and their livelihood with some mode of mechanization. I would like to point out here that this obsession with sophisticated machinery — as a stand-in for the sophisticated technologies of the military-industrial complexis indeed a key aspect of hegemonic militarized masculinity. As Cristina Masters notes, "[t]he making of soldiers into machines is scarcely a new phenomenon, continuing to signify the constitution of the body as a primary site of technological inscription (113) and any loss in mechanization/machinery symbolizes a "rage at our bodily limitations" (Robins and Levidow, qtd. in Masters 113). Thus, in On the Beach, where humans are made conscious of their bodily fragilities as they slowly wither away to radiation in a post-nuclear holocaust world, such rage is magnified and compensated through associations with machines and mechanization. 
Therefore Peter Holmes, an "ingenious man and good with tools" (4) is constantly shown trying to devise new forms of machinery that presumably continue his hegemonic male status while combating the associated anxieties. For his daughter he contrives "a small twowheeled trailer using the front wheels of two motor bicycles... which served them as a perambulator and general goods carrier (2). Holmes' purported ingenuity with machines is crucially an obsession with most characters both male and female in the novel. One of the earliest instances of this obsession is evidenced in Mr. Paul, the local farmer who is quite taken with the trailer that Peter Holmes has devised. He requests Holmes to get him a pair of wheels, so that he is able to partake of this "mechanical ingenuity" as well and presumably the associated manhood embedded in such improvised machinery. Later on in the novel this fetishization of technology is manifested in character's obsession with cars, especially John Osborne, a scientist, who buys a Ferrari and participates in the Australian National Grand Prix. Osborne-a studious and physically unimposing male figure — who is part of Commander Dwight Tower's submarine crew matches the stereotypical characterization of scientist except for his obsession with racing competitions and fast cars. It would not be amiss to note that while the other primary (and radioactive) male characters in this novel are military personnel associated with some form of machinery, Osborne compensates for this lack through the next best thing — technologically advanced racing machines. Importantly, this association also implicates Osborne completely within the model of radioactive masculinity underlined here as an apathetic and dehumanized structure. Osborne unabashedly goes to collect an important mechanical part for his own carfrom the ruins of a car-crash that killed the driver-who was his close acquaintance. As the novel progresses Osborne distances himself from all the human characters and finally decides to 
commit suicide within his Ferrari, evidencing his complete enmeshment within a technologized dehumanized world.

Manifestations of anxious masculinity in this narrative are also succinctly illustrated in the tempestuous relationship between Commander Dwight Towers, the American naval captain, and the Australian Moira Davidson. The character of Dwight Towers - a highly decorated US soldier - who has been forcibly displaced from his homeland and his family due to the nuclear holocaust, is the perfect epitome of a man caught between two worlds. Initially in the novel Dwight Towers, the "quiet soft-spoken man of thirty-five or so with a slight New England accent," (17) comes across as a well-put together person, who seems to have accepted the realities of impending death. Moira Davidson, on the other hand is a twenty-four-year-old vivacious woman who is requested early on in the novel by Peter and Mary Holmes to provide Dwight Towers companionship at their house party. Moira initially comes across as an unstable person, who drinks compulsively, in order to avoid the realities of her world. However, the reader is soon made aware through the interactions between Moira and Dwight that the presumably pragmatic and put together Dwight Towers is an equally troubled figure.

Dwight lives in complete denial of his own family's almost certain death from the nuclear bombings and radiation effects in America. In his conversations with Moira Davidson, he speaks of his wife Sharon and how he looks forward to returning to his wife Sharon and his two children after he finished his current "assignment." It is not difficult to discern why Commander Dwight Towers - an insightful military figure - would choose to delude himself about the almost inevitable fate suffered by his family and instead fantasize about what he would do when he gets back 'home.' As Sontag notes “one of the things that fantasy can do is normalize what is psychologically unbearable, thereby inuring us to it" (42), therefore both Moira and Dwight have 
their own mechanisms of inurement: alcoholism and fantastical delusions. Dwight's refusal to accept the loss of his entire family is deeply implicated within the fact that the acknowledgement of such a momentous loss would almost inevitably invite utter and inconsolable grief. However, as an epitome of militarized masculinity Dwight Towers functions under a framework where any display of masculine emotion — especially PTSD — is constantly likened to female hysteria and a resultant feminization. Sandra Whitworth poignantly captures the troubled nature of militarized masculinity as she notes:

PTSD in men lays bare the fragile ground on which militarized masculinity is built...[C]onsequently, it is a story that most militaries are not keen to acknowledge (112).

Pertinently, this lack of acknowledgement of grief that is an essential feature of radioactive males also creates circumscribed and reductionist portrayals of women characters in this narrative. Critics have looked at Mary Holmes, the wife of the Australian Navy liaison officer Peter Holmes, as an overtly sentimentalist character who is unable to deal with the fact that the end of the world would also denote the death of her newborn baby. However, such discussions ignore the fact that Mary's reactions are actually precipitated by Peter's efforts to pass on the responsibility of euthanizing the baby, to Mary alone. In a poignant episode where Peter hands over the "red box" containing the pills that would bring about the death of Mary and the baby, she declares in an emotional outburst:

I'd never do a thing like that, however ill she [the baby] was. I'd nurse her till the end. You must be absolutely mad. The trouble is that you don't love her. You never have loved her. She's always been a nuisance to you. Well she's not a nuisance to me. It's you that's the nuisance. (my emphases; Shute 119) 
This first and only declaration of Mary's true feelings in the narrative illustrates how the "nuisance" personified by the ilk of militarized males like Peter Holmes and Dwight Towers has brought about such an inhumane apocalypse. Peter's reactions - true to the structures of radioactive masculinity he embodies - is an escape from his own anxieties by passing on the blame completely to,

These bloody women, sheltered from the realities, living in a sentimental dream world of their own! If they'd face up to things they could help a man, help him enormously. While they clung to the dream world they were just a bloody millstone round his neck (my emphases; Shute 119)

Ironically, Peter's complaint is a vital reminder that women exist in this highly masculinized world only to "help a man" tide over their own mistakes and resultant anxieties. Pertinently, Mary and Moira both toil extensively to be effective foils who help the men around them—Peter and Dwight— tide over their own crises, which emerge from their implication within radioactive masculinity. Early on in the narrative Peter justifies taking up his naval appointment—even though he would have to leave behind his new born child and wife in a steadily declining environment—by stating Mary's enmeshment within the world of militarized masculinity: "Mary would be furious if he turned down this job and sacrificed his career. She was a naval officer's daughter born and brought up at Southsea in the south of England" (11). Peter's assumption about Mary's viewpoint simply due to her position as the daughter and husband of military personnel signifies the automatic silencing of women and their subjectivities. Vitally, such a silencing is expected to be broken only when it is beneficial to the cause of militarized masculinity: such as in the case of Moira whose sole aim in this post-nuclear holocaust world seems to be stop Dwight Towers from "bursting into tears" (32) on seeing the 
apparent domestic bliss characterized by Peter and Mary's family. This role is vital within the ambit of this masculinized world since Moira's breakdown would inhibit Dwight from carrying out his martial duties and carry forward the only ideology worth any consideration: white militarized masculinity. Moira performs many different version of herself with Dwight—-the flirtatious femme fatale, the trusted confidante and the concerned friend — at various points of time in the narrative. Such circumscribed performances allow Dwight to continue his role as a vital cog within the military-industrial complex. However, the effacement of Moira's own subjectivity is almost never acknowledged by any of the primary characters and is perfectly summed by Dwight who perceives her as "all mixed up. She drank too much, but some people never could accept things as they were. She was a nice kid, though" (33). This attitude of sexist patronization evinced in Dwight allows illuminating insight into the world of radioactive males. In their quest to be embody the power and catastrophic potential of nuclear bombs, these male figures become paradigms of volatile insecure masculinity, an aspect found especially manifested in Pat Frank's Mr. Adam.

\section{Mr. Adam}

Men have always been more susceptible to certain rays than women (Mr.Adam

While masculine anxiety is externalized onto the obsession with machines and mechanization in On the Beach, Pat Frank's Mr. Adam is far more direct in its treatment of radioactive masculinity: as the material male body itself is made a direct victim of nuclear technology. The narrative of Mr. Adam is deceptively simple: a nuclear explosion in Mississippi, USA gives rise to an "unknown" form of radioactive particle, which renders all male humans infertile, including the yet unborn of the male species. The only person who manages to accidentally evade the 
repercussions of this fallout is the eponymous protagonist of this novel Mr. Homer Adam, who was "fortunately in a lead and silver mine, deep underneath the ground in Colorado" (34) during the event. The novel is narrated from the point-of-view of a journalist, Stephen Decatur Smithnamed after a famous military general and signifying his integration within the throes of an overtly militarized world — who accidentally discovers that the explosions at "great new nuclear fission plants in Bohrville, Mississippi...disintegrat[ing] in an explosion that made Nagasaki and Hiroshima mere cap pistols by comparison" had rendered the entire global male population sterile" (48). Through a fortuitous turn of events, Stephen Decatur Smith encounters the sole person who has eluded this apocalyptic fate of masculinity - Homer Adam — and becomes Mr. Adam's trusted confidante and advisor, as the nation and its citizens stake claim to both Homer and his fertility. Before launching into an analysis of the novel and its larger implications it may be worth noting the enthusiastic response, which this now-almost-forgotten text, evoked immediately after being released. Published in 1946, in the immediate aftermath of WW-II, the novel was a raging success as it

[W]ent through thirteen printings, appeared in a special Armed Services edition in 1947 and was one of the first paperbacks to appear in a Pocket Book Edition in 1948. By 1955 it had gone through eight printings and would continue to be popular for most of the 1950's (Morse 88).

While Frank's easy prose and lucid writing do figure as a prominent factor when analyzing the book's considerable popularity, it cannot be a mere coincidence that a fictional text—about worldwide emasculation through a nuclear mishap — would become wildly popular merely a year after the events at Hiroshima and Nagasaki. Mr. Adam's popularity hinted at larger socio- 
cultural phenomena in post-WW-II America, one that increasingly mapped nuclear anxieties onto the fears of literal emasculation.

The initial implications of this narrative are clear: the loss of male fertility resulting from a nuclear mishap echoed deep-set Cold War fears that a global nuclear holocaust—with resultant the extermination of mankind - was an event destined to happen. While in On the Beach, the male body exists as an extension of the technologies created by the military-industrial complex, Mr. Adam chronicles the ideologies of the masculinized military-industrial complex that produced these apocalyptic technologies. Early on in the novel the relationship between nuclear weapons and masculinized bodies is made clear when the news of worldwide male infertility triggers warlike preparations in America. The narrator Stephen Decatur Smith records a radio broadcast:

Washington-Surgeon General George Gail has announced that he has called a congress of the nation's leading physicians and scientists early next week. They will meet in the capital to plan national re-fertilization. Next you will hear that international wartime favorite, 'Lilli Marlene' [...] (Mr.Adam 30).

The implications of this song cannot be ignored as it was commissioned by the Morale Operations Division of the US Army, a branch of the Office of Strategic Services during World War II that "utilized psychological warfare, particularly propaganda, to produce specific psychological reactions in both the general population and military forces of the Axis powers in support of larger Allied political and military objectives" (Leibovitz and Miller 16). The decided objective of this song, the most popular version of which was sung by Marlene Dietrich, was as Fitzroy McLean notes to reinvigorate the male soldiers through the "the sex-laden, intimate, heart-rending accents of Lili Marlene" (part 3, chapter13) that reminded these soldiers: of the 
sexual (and heterosexual masculine) pleasures that purportedly awaited them at the end of the War. Through the use of this martial ditty in Mr. Adam — as part of a national broadcast about national re-fertilization in a world where all men are sterile - the novel conveys the associations between nationhood and fertile heterosexual masculinity. Clearly, a hypothetical American nation where the male populace was unable to reproduce was no different from helpless American soldiers facing the threat of Nazi insurgency during World War-II. Both situations were equally apocalyptic for the American nation, as the allied structures of heterosexual manhood and national strength were being challenged.

By bringing out the associations between hegemonic militarized masculinity, nuclearization and nationhood, $M r$. Adam also points out the inherent problems within radioactive masculinity (ies). Nuclear technology in this narrative - that in actuality had been structured to remasculinize the presumably emasculated post-Depression era American body politic — also subtracts a key heteromasculine capital: the ability to procreate. In doing so, $M r$. Adam also makes a larger point about how technologies understood through de Lauretis' framework have always already been "techniques and discursive strategies that are put to the service of gender production and construction" (Squier 134). In placing the male body and its anxieties at the heart of questions about human survival in the atomic age, Mr. Adam as a representative of nuclear disaster fiction also challenges the trend of literary fictions that constructed "women as a gendered, socially positioned site of deep subjectivity" (Squier 134). Both On the Beach and Mr. Adam in placing male anxieties at the center of their plot lines also interrogate the traditions of normative Anglo-American fiction, which by focusing on troubled female characters manages to deemphasize anxious masculine subjectivities that create unequal gendered structures. More specifically, representations of radioactive masculinity in these 
narratives and their contingent relationship with science and technology also demystify the idea of scientific inventions as apolitical objects. In fact by showing how masculinity and nuclear technology are enmeshed into each other, these nuclear disaster narratives underline the power of scientific processes that "bring into being and constitute as knowable" (ibid) technological inventions. This is made evidently clear in Mr. Adam, when Homer Adam's corporeal self, the sole fertile male body in the novel is compared to the nuclear bomb by Colonel Phelps-Smythe from the US Army, who has been in put in charge of "handling" Homer Adam:

“Phelps-Smythe put his hand on Homer's drooping shoulder. 'Now, my boy,' he said, 'remember this is in the national interest. Consider-you are just as much a military secret as the atomic bomb"' (my emphases; Mr. Adam 49).

Scholars such as Susan Squier have talked about the importance of analyzing representations of male fertility in both science studies and literature. Her argument delineates the need to see science and literature as "preeminent technologies the enlightenment produced...because they incorporate 'institutionalized discourses, epistemologies and critical practices' to define what is knowable and to bring those objects into being" (134). Mr. Adam stands out as a perfect testament toward science as well as literature's ${ }^{\text {xliv }}$ ability of producing ordered social structures as well as the objects itself, which need to be studied. Particularly, by focusing on a male body and its reproductive capabilities, $M r$. Adam shows us how the male body has indeed been the locus of both scientific anxieties as well as the epistemological node from which dominant (patriarchal) discourses emerge.

In qualifying these assertions, it must be noted that traditionally science and literature have been understood as antithetical structures whereby science objectively constructs the other while literature subjectively constructs the self. However, such a false dichotomy between 
science and literature often simplifies the fact that both science and literature actively construct the self and the other. For example, objects that have been under the lens of scientific inquiry in the $19^{\text {th }}$ and $20^{\text {th }}$ century, "the homosexual, the hospital patient, the criminal, the woman" (Squier 135) have existed in a binary opposition to the subjects that define these objects, which in this case are: the heterosexual, the healthy individual, the law-abiding citizen and the man. Similarly, in literature that emerged in the $19^{\text {th }}$ century and the early $20^{\text {th }}$ century, the objects of inquiryabject women, destitute children and subaltern figures - have often emphasized the normative figures lying at the other end of the racial, classed and gendered spectrum. Therefore, it will only be proper to assert that both science and literature have "frame[d] and shaped[d] our understanding of the things of this world" (Squier 135) either through the knowing subject or the object that is supposed to be known.

What fundamentally distinguishes Pat Frank's Mr. Adam is that the central figure — a literally radioactive male - is both the knowing subject as well as the object to be known. The internalization of atomic power within the male body and its devastating consequences for all male bodies except one is a metaphor for the post-WW-II American military-industrial establishment's perverted version of the American dream. The male figure Mr. Adam as the one and only fertile individual and literally the "only man"-if seen strictly within procreative terms - reflects America's Cold War objective of being the dominant and obviously masculine geo-political force during that period. It is also crucial to note that Pat Frank's novel—where the entire American nation's heteromasculine capital is invested in a single individual namely $M r$. Adam - is a perfect metaphor for the actual situation in Cold War America where all other forms of masculinity were sublimated under the juggernaut of hegemonic militarized white masculinity. 
The novel also anticipates how such sublimation takes place through the military-political establishment literally taking over the individual male body: Mr. Adam becomes a military-asset, one who as his military handler Colonel Phelps-Smythe notes is as valuable as the atomic bomb. While historically, postwar cultural and intellectual discourses in any nation have seen the development of paradigms that have exhorted the need to strengthen a nation, $M r$. Adam drives home the point that American public discourse in the Cold War era was synonymous with male bodies and their performances. This extraordinary connection between white militarized masculinity and nationhood that had "distant origins in the nineteenth-century fears of the feminization of American society" (Squier 135) has consequently shaped the socio-cultural fabric of the America that moved into the $20^{\text {th }}$ and $21^{\text {st }}$ century. In many ways, Mr. Adams foresees the Cold War military logic of Mutually Assured Destruction (M.A.D), which surmised that a full scale nuclear attack followed by a retaliatory response would result in the annihilation of both (or multiple) parties involved in the conflict. Thus, the same nuclear bomb that promised global (masculine) dominance was also invested with the capability of ending humankind, much like how the radioactive after-effects terminate the possibility of human reproduction in $\mathrm{Mr}$. Adam. Cultural productions dealing with masculine anxiety emerging during the Cold War have also played a vital role in shaping discourses that link national capability with masculinity beyond the American domain. As the next chapter chronicles, the quest for "hardness" in AngloAmerican fiction becomes reconfigured within postcolonial spaces and nascent nuclearization becomes a metaphor for challenging colonial legacies as well ensuring the propitiation of dominant ideologies of gender and religion. 


\section{Chapter 4: The Quest to be "Harder": Anxious Atomic Publics and the Postcolonial Bomb}

The precise location of the attack determines which region of Bombay is destroyed. For example, an attack in the Fort area, centered around.... Hutatma Chowk, could destroy large parts of the financial district.... There are also very densely populated areas like Dharavi; if the explosion is targeted in this area, the number of casualties will be very large (Ramana 3)

A ball of fire seemed to emerge from the point of impact and engulfed the skies and the earth. The buildings at the epicenter were wiped off the face of the earth...The ground in Lahore splattered with disorganized concrete... There was no sign of life, human, animal or plant. (Khan 177)

$[\mathrm{O}]$ ne can say with some certainty that the genre of the future-war narrative, both as an identifiable subtype of speculative fiction and as a source of political influence... arrived with the suddenness... of an exploding bomb (Gannon 8).

The total annihilation of Bombay (now Mumbai) and Lahore in the aftermath of catastrophic explosions, thankfully, still remain fictive speculations. Eerie similarities, however, between the apocalyptic futures envisioned by the Indian scientist M.V Ramana in his hypothetical assessment of nuclear threat, Bombing Bombay? (1999), and by Sami Ahmad Khan in his speculative novel Red Jihad (2012) are telling reminders of the blurry boundaries between destructive science and the fictions that speculate about it. While exploding bombs embedded 
with catastrophic potential have remained central to our eschatological conceptualizations for more than a century, future war fiction - a key sub-genre of speculative fiction —and its obsession with apocalypse-inducing technologies illustrates importantly the nexus between gendered bodies and destructive military machinery. In underscoring that "future-war fiction, is, largely fiction for and about individuals who are gendered as 'men"” (Gannon 6), this chapter explores depictions of radioactive masculinity within the little-explored genre of Indian speculative fiction. Apocalyptic settings in these texts, I argue, provide a topos for enacting postcolonial radioactive masculinity, by making performances of subcontinental manhood contingent on the volatile performances of nuclear weapons.

In acknowledging this relationship between male bodies and nuclear weapons, my analysis illustrates that postcolonial masculine anxieties result in the foregrounding of certain forms of manhood in these narratives — as the hegemonic model—by making them contingent and analogous with the destructive capabilities of war machinery. In adopting R.W Connell's conceptualization of "hegemonic masculinity," I explore the reasons behind the emergence of postcolonial masculine insecurities, which, I argue, results from India's colonial history and its continued legacy within the subcontinent. Finally, my examination of representative Indian speculative texts, namely Mainak Dhar's Line of Control (2009) and Sami Ahmad Khan's Red Jihad (2012) emphasizes that making postcolonial radioactive masculinity contingent on the destructive capabilities of military technology results in unstable and threatening masculine performances, much like the unpredictable nature of nuclear weapons highlighted in these texts. I point out that like American nuclear disaster fiction, radioactive masculinity is performed in postcolonial speculative fiction through foregrounding a specific model of "hegemonic militarized masculinity" (Jarvis 2). Pertinently, such postcolonial masculine performances 
through which sovereignty and nationhood are expressed reproduce the ideologies of white colonial masculinity, lying at the heart of nuclear weapons technology. Further, in looking at performances of postcolonial radioactive masculinity, I argue, that Indian speculative novels while adopting the conventions of American nuclear disaster fictions, concurrently critique postcolonial radioactive masculinity as well as the American and Indian military-industrial complexes.

\section{THE "FUZZY" WORLD OF SF}

The realm of speculative fiction is a keenly contested domain. Competition amongst literary productions to be representative of this genre owes not a little to what Samuel R. Delany describes as the key issue with defining speculative fiction, since it is "one of the numerous terms that numerous critics for numerous reasons have decided is inadequate for the numerous things that fall under it" (149). R. B. Gill postulates that while science fiction is dependent primarily on the rigors of the scientific method, speculative fiction challenges the reader's perception of everyday reality. In other words, one of the defining characteristics of speculative fiction for Gill is that it "envisions a systemically different world in which not only events are different, but causes operate by logics other than normal ones" (73). Gill's intervention also raises some crucial questions about the market-driven nature of speculative fiction, which in his view is more of a commercial genre rather than a strictly literary classification. While not discounting the fact that speculative fiction has certain distinguishing characteristics, Gill emphasizes the need to uphold the currently existent "fuzzy definitions" of speculative fiction since they allow us to "raise more ideas than a tighter classification would" (74). Gill's proposition, to allow a fuzzy definition of speculative fiction becomes especially important since there is a tendency amongst both readers and critics alike, to align themselves either against or in 
favor of Darko Suvin's categorization of science fiction: as the "literature of cognitive estrangement" (qtd. in Canavan and Wald 238). While Suvin's specific diktat about the constitution of science fiction may be quite helpful to derive a general overview of this mammoth genre, it also provides a lack of specificity about the literary attributes that are germane to this field. Not surprisingly the umbrella term SF-now understood to include speculative fiction, science fiction and different forms of fantasy - may quite well be the only way of acknowledging the intercontextual plasticity that these genres and subgenres entail. Even though a detailed overview that characterizes the varied and multiplicitious models of SF is beyond the scope of this chapter, for the purposes of my argument I will foreground an understanding of SF, which resists classification and where the "fuzziness works better than hard edges to describe complex relationships" (Gill 75). In acknowledging this fuzzy model that uses "SF" interchangeably for both speculative fiction and the arguably parent genre of science fiction, I will emphasize speculative fiction as the form of SF which offers:

[C]himerical speculations... structur[ing] our collective imagination of what is possible. In this sense we might say that our most theoretical and anticipatory speculations are always 'inside' SF, whether, this relationship is acknowledged or not. Whatever happens, be it landing on the moon, destroying the climate, or electing the first African American President, SF always seems to have gotten there first—and often best. (Canavan and Wald 244)

\section{SPECUlating Masculinized WarS}

The term "science fiction" coined by Hugo Gernsbach in 1926 was expressly influenced by post WW-I scientific and technological demands, making it crucial to emphasize that science, technology and war have always been central to our understanding of SF. This is not in any small 
measure due to the fact that "the battlefield is frequently the stage upon which new technologies are first unveiled... consequences... and application...most dramatically and graphically represented (Gannon 6). Therefore, the links between speculative fiction, masculinity and destructive technologies are not merely "conjectures...about future war in general" (7) but rather a keen commentary on how specific technological innovations of the past and the present that may radically alter human future are shaped by masculinized ideologies. In such forms of SF, science does not become the sole receptacle in which to embed the successes of human civilization but rather an epistemological category, which needs to be critiqued " as a mode of perceiving and cognizing...social structures, relations and hierarchies in which scientific innovations [are] conceptualized" (Canavan and Wald 242). Therefore, such an understanding does not speculate future wars as sites where progress in human civilization is measured, through the technological innovations on the battlefield, but rather questions the gendered narrative of techno-scientific capitalism, which produces such apocalyptic technologies and the resultant catastrophes.

In understanding this idea of gendered techno-scientific capitalism that lies at the heart of the modern technophilic super power state and is frequently the subject of speculative fiction, it is important to underscore both masculinity and technology as political discourses. While representations of technophilic futures in speculative fiction as the central structuring motif of human existence may often seem absurd, it may be useful to point out that the political power of traditionally hypermasculine Anglo-American body politics have been historically predicated on their comparative technological superiority. Joel Dinerstein notes:

Technology has long been the unacknowledged source of European and EuroAmerican superiority within modernity...It is not social justice or equitable 
economic distribution that will reduce hunger, greed, and poverty, but fables of abundance and the rhetoric of technological utopianism (569).

More importantly, military technology has traditionally functioned as the primary site for the manifestation of hegemonic white masculinity, since dominant practices of whiteness are intrinsically mired within the technological developments that emerge from such martial structures. Cristina Masters asserts that technology becomes the constituting ideology for white masculinity to the extent that both "whiteness" and "masculinity" become the structural mechanisms that order social, political and cultural discourse. This is especially relevant to future war fictions where technophilic superpower states reinforce the idea of military technology - a symbolic referent for hegemonic white masculinity — as the ordering device for society.

Considering the self-reflexive relationship between military technology and hegemonic white masculinity, these speculative narratives therefore become reifications of "traditionally [white] male roles, activities and interests, thereby showcasing and celebrating the patriarchy that pervades superpower political practices and governmental structure" (Gannon 8). Of course the idea of international relations and political discourse as being decidedly masculine is not a new concept. Charlotte Hooper in her incisive study Manly States emphasizes that "[t]he world of international relations appears to be a truly man's world, both through the predominance of men in practice and through the masculinist underpinnings... whereby success is measured in terms of the masculine virtues of power, autonomy and self-reliance" (author's emphases; 1). Therefore, functioning within such a discursive model of international politics, attempts by any emerging postcolonial superpower toward global dominance must be intrinsically connected to developing a technophilic, virile and masculine body politic. Particularly in the postcolonial context such a 
body politic must simultaneously deconstruct colonial discourses about subordinate native masculinity while simultaneously challenging the dominant Anglo-American model of hegemonic white masculinity. As my analysis below of Dhar's Line of Control (2009) and Khan's Red Jihad (2012) illustrates, these speculative texts narrativize the national imaginary of postcolonial states (such as India) through performances of postcolonial radioactive masculinity. The postcolonial nation's ambitions of being a technophilic superpower translate into aggressive performances of the indigenous militarized male body. Moreover, these fictions simultaneously illustrate that any postcolonial resistance that is modeled on the preexistent associations between hegemonic white masculinity and military technology is paradoxically bound to reproduce the limiting discourses of neocolonial techno-capitalism.

\section{Postcolonial Radioactive Masculinity in Indian SPECUlative Fictions}

Within the Indian context masculinity becomes a key category for social and historical analysis due to the intersections between ideas of nationhood and maleness in colonial discourses. Manifested skillfully through discursive tropes such as Lord Macaulay's "unlearned native" or Rudyard Kipling's "half-devil-half child," the colonized male subject needed to be represented as inferior to the white colonizer, in order to justify imperial presence within the Indian subcontinent. This meant that instead of acknowledging the multiple models of indigenous masculinity and femininity existent in India, colonial ideologies labored to create monolithic and reductive structures of native masculinity, legitimizing the white patriarch as the hegemonic model of masculinity. ${ }^{x l v}$ As Dasgupta and Gokulsingh note in the introduction to their book Masculinity and its Challenges in India "Masculinities in the colonies were created and perpetuated as a contrast to the colonizer's own masculinity" (8). Such a binary model of perceiving the colonized male subject, coupled with the fact that "masculinity, unlike femininity, is most often unseen...owing to its normativity" (9) meant that the postcolonial male subject is 
constituted through an essentialized but conflicted value system. On the one hand is the legacy of colonial discourses, which "represented [the postcolonial male] with no agency, whose subordinate presence renders him powerless" (9) while on the other are the anti-colonialist hypermasculinized narratives of the Indian freedom movement that looked upon Indian male subjects as the saviors of their symbolic motherland.

Unlike nuclear disaster fiction from the American sphere which has traditionally been based on masculine-value systems functioning around the "weighty [and gendered] triad of .... warfare...new technology and political drama" - thereby reinforcing the "authority and structure of the superpower state" (7)-Indian speculative fiction encounters many more challenges in adopting such a hypermasculine value system. Postcolonial speculative fiction ${ }^{\text {xlvi }}$ that traces its roots to the same structures from which American nuclear disaster fiction emerges, is confronted with a difficult task. This is the challenge of adopting the technophilic and inherently masculinized nature of nuclear disaster fiction while being careful to avoid reproducing the ideologies of neo-colonial techno-capitalism that are an intrinsic part of this genre. Both Line of Control and Red Jihad are distinguished by their apparently paradoxical structure: where the narratives are based on aggressive and threatening masculine performances that are contingent on nuclear weapons, while at the same time interrogating such an association. In doing so, they deconstruct both hegemonic white masculinity that is dependent on structures of militarization as well as the Indian military-industrial complex's ideology of progress through nuclearization, modeled on their American counterpart.

Sami Ahmad Khan's Red Jihad (2012), envisions an Indian subcontinent in the year 2014, where the nuclear-capable states of India and Pakistan are in a diplomatic détente with each other. This peaceful accord has been reached through Pakistan achieving a full-fledged 
democratic government, which has seemingly gained control over the radical elements affecting the stability of the region. However, this fragile peace is broken by the machinations of a Pakistani jihadi leader, Yaseer Basheer who enlists the help of an Indian Naxalite commander, Agyaat. Together, their plan is to infiltrate a secret military base in India, the National Missile Research Centre ${ }^{\mathrm{xlvii}}$, and to apparently use an Intercontinental Ballistic Missile (ICBM) named Pralay against its (Indian) creators. Even before moving into the intricacies of the plot, it is vital to underline the diverse narratives of power and masculinity that are at play here. The core plot of the text that envisions a future where the Indian state is under threat from a nexus between Islamic Jihadis and Maoist Naxalites eerily reflects the realpolitik situation, where these two ideological structures pose a credible threat to the stability and strength of the fledgling postcolonial Indian state. Thus, the portmanteau term Red Jihad manifested in the male bodies of the Jihadi leader and the Maoist Naxalite, fuses into a single structure, the two forms of marginalized (and radical) masculinity that pose a threat to the aspiring masculine Indian body politic. ${ }^{x l v i i i}$

A brief prologue that initiates the novel chronicles an American fighter jet bombing a village in Afghanistan with a large civilian population. Frazer, the white male fighter pilot who believes that he is promoting "peace, freedom and democracy" by bombing innocent civilians (7) functions presumably under the "War on Terror"xlix narrative of George W. Bush that justified achieving an American neo-colonial model of democracy in non-western states through military aggression. Frazer's sense of selfhood is tied intrinsically to the state-of-the art $F / A-18 E$ super hornet jet that he flies, which gives him "greater accuracy... and a psychological edge" (Khan 1), evidencing his enmeshment within the structures of American radioactive masculinity. This model also lends him a sense of apathy for the destructive job he carries out as he is able to 
balance his "conscience with duty" waiting eagerly for his day to be over so that he can catch his favorite show, The Simpsons. The failure of aggressive male performances that are dependent on machines is made apparent as Frazer and his radar system mistake a stone thrown by an Afghani boy, for a "handheld grenade," thereby carpet-bombing and completely destroying a civilian village. The irony is explicit, as the militarized white male ensconced within this highly sophisticated piece of machinery and representing the very pinnacle of American progress is unable to distinguish a harmless projectile from a destructive bomb. Frazer's inability to apply his human instincts - that would have allowed him to perceive the stone for what it was - due to his slave-like dependence on military technology_drives home the structuring motif of this narrative: that threatening male performances contingent on destructive military technology are bound to be catastrophic failures.

The profile of this American jet pilot while seemingly unrelated to the overall plot of Red Jihad is vital, as it delineates the template of white militarized masculinity that is the ordering mechanism for failed postcolonial male performances in the novel. Such influences are made apparent in the character of Indian soldiers such as Lieutenant Colonel Ankit Yadav who epitomizes the postcolonial radioactive male. Yadav is a conflicted character; shown to be a keen lover of literature who reads Pride and Prejudice while at the same time dispassionately reflecting on the futility of tribal protests against the missile complex, where he is employed. His attitude of nonchalant irreverence toward a tribal man who self-immolates in protest against the missile complex—encroaching on a tribal reservation—evidences Yadav's enmeshment within this dehumanized and apathetic model of radioactive masculinity. Much like Frazer in the prologue, Yadav's physical movements are in unison with war machinery namely the "5.56mm MSMC, an INSAS sub-machine gun, slung over his left shoulder." (13). The INSAS rifle 
produced by the Indian Small Arms System - a symbol of indigenous military technology and the Indian military-industrial complex - combined with the postcolonial manhood of Yadav becomes a representative structure for the purportedly "great Indian dream" (17), of achieving global dominance through technophilic superiority. However, keeping in tune with the critique of militarized masculinity that permeates Indian speculative fiction, Yadav is deeply skeptical of the Indian military-industrial complex that he both embodies and perpetuates. In specifically disavowing the politically created nexus between the national security apparatus and the ideals of economic development Yadav acknowledges how the "great Indian dream" is predicated not on human development but on the successes of the "missile tests" and the allied feats of male military personnel, both of which he oversees.

Yadav's actions and attitudes reflect the comments of the cultural historian Jon McKenzie, who claims that contemporary human performances in the twentieth century are predicated on the ideals of "[t]echno-performance... [which] emerged in the US since the Second World War-...[and] the formative stages of Techno-Performance were engineered within the American Cold War apparatus...the military-industrial-academic complex" (1). McKenzie illustrates that meta-models of technology such as computer guided missile systems emerging from the military-industrial complex became the template, which continues to define the way technology percolates from military apparatuses into the civilian sphere. This notion of technoperformance that evaluates the success of human actions by modeling them on "machinic systems" is a key component of postcolonial radioactive masculinity and is found extensively represented in speculative fiction. In emulating technical systems as the paradigm for human and more specifically male performances, the ideologies of militarized masculinity (emerging from Techno-Performance) result in the production of "socio-technical systems" (1), which constrain 
and resist the natural predilections of human selves. Such reduction of human bodies from desiring bodies to socio-technical systems that are only judged on their efficiency with certain assigned tasks, results in dehumanized structures as reflected in this genre of postcolonial speculative fiction. ${ }^{1}$

Pertinently, while Yadav's characterization in this novel reflects a straightforward relationship between the hardened male body and the efficient war machines (like in Neville Shute's On the Beach) Red Jihad also offers other models of postcolonial radioactive masculinity. These male characters who do not carry out martial tasks, however shore up their hegemonic masculine capital, through emulating the practices of militarization. This other spectrum of postcolonial radioactive masculinity is embodied in characters such as A.A. Suryakant, head of the missile development division at the National Missile Research Center and an alumnus of the prestigious Indian Institute of Technology. The bespectacled Suryakant is the stereotypical scientist figure with "cocked head...tongue protruding from between his teeth... [while] solving a complex problem" (22) who harbors many (postcolonial) insecurities about himself, including the inability to converse fluently in English. While an unwavering patriot who genuinely wants to contribute to the scientific progress of his country, the reader is also made aware of Suryakant's aggressive martial attitude that is quick to implement the Indian Ministry of Defense's diktat "Build. One [Nuclear] Missile. Sleek. Shiny. Kick-Ass. Now (Khan 25). Suryakant's willingness to readily accept the ministry's orders reflects a crucial aspect of postcolonial radioactive masculinity, which believes that "only with military self-reliance could the foreign policy of a country be truly independent, and only with such a policy could there be economic development" (my emphasis; 24). 
Through Suryakant's character Red Jihad highlights the critical role played by the scientific Indian citizen within the technophilic narrative of progress envisioned by postcolonial nations like India. While the intrinsic link between science and the project of Indian modernity has been well established (Vishwanathan; Srivastava; Prakash), the explicitly gendered politics of this venture needs to be reemphasized here. As Srivastava underscores:

The project of the transformations of the [colonized] native to the [postcolonial] citizen was, of course, a gendered one and science and reason played a particularly important role in defining the contours of modern subjectivity in India. The national heroes of postcolonial modernity were typically, men (33).

This endeavor to promote the project of Indian modernity through the achievements as well as the embodied selves of male scientists is, of course, not surprising since it addresses two fundamental postcolonial anxieties: about native masculinity and native science. Due to the systemic elision of native scientific achievements from colonial discourses as well as the constant subjugation of native masculinity, the hyperliterate male scientist citizen lays claim to representing the true pinnacle of the postcolonial nation's success, as well as its immersion within modernity.

However, this paradigm of the hyperliterate Indian scientist who has presumably managed to overturn the stigma of backwardness associated with colonial science is still not emancipated from the insecurities of postcolonial masculinity. Suryakant is characterized as constantly fretting over his "baby," the Pralay - a nuclear capable Intercontinental Ballistic missile — due to the fear that the government would be unable to appreciate his genius and pull the plug on his project. His apprehensions are that such a move would be catalyzed by "a babu with absolutely no idea of how much time it took to build a new missile" (Khan 25) emerges 
from his intellectual executions being undervalued within a militarized complex that valorizes aggressive physical performances. While one would assume that the intellectual scientific masculinity embodied by Suryakant would be at par with the militarized masculinity embedded in Yadav - as they are both different forms of radioactive masculinity which exist to buttress the military-industrial complex-such is not the case.

Therefore, scientific male bodies in Red Jihad constantly mimic the ideologies of militarized masculinity in order to achieve the desired hegemonic model of postcolonial radioactive masculinity. In case of Suryakant and the other scientists at the missile silo, this aspiration is manifested in their obsession with the popular combat game Counterstrike, which "techies loved...because it gave them a chance to kill each other in various shooting games" (25). Sami Ahmad Khan's portrayal of the way non-militarized bodies simulate the practices of militarization through violent (albeit virtual) performances, provides a crucial indication of what constitutes postcolonial radioactive masculinity within fledgling technophilic postcolonial nations. While reflecting their counterparts from the American sphere, postcolonial radioactive males in Red Jihad combine the Foucauldian traits of the hardened and disciplined soldier's body with the intellectual prowess of the scientist. Such a combination serves the dual purpose of (apparently) countering both the colonial legacy of emasculation while also embracing the paradigm of militarization, which is seen as crucial to carrying forward the narrative of postcolonial progress through techno-capitalism. This ideology is aptly demonstrated when Suryakant expresses his understanding of the Pralay program, "The directive from the Ministry of Defence (sic) was clear; urgent. Build. One Missile. Sleek. Shiny. Kick Ass. Now” (Khan 25). This phallic object, an obvious symbolic referent for the militarized male body, represents all the aspirational characteristics of postcolonial radioactive masculinity. 
Unsurprisingly and keeping in tune with the fate of radioactive masculinity in this narrative both Yadav and Suryakant meet with violent deaths at the hands of the Jihadi and Naxalite insurgents. Their deaths and the capture of the Indian missile base along with the nuclear-capable missile Pralay sets off a chain-reaction in the Indian subcontinent. The mask of civility that had been apparently assumed by both the Indian and Pakistani military establishments comes off as they prepare for an apocalyptic nuclear fight to annihilation. In a reversal of the usual realpolitik scenario within the subcontinent, the Indian-not the Pakistanigovernment is overthrown by a military coup. The volatility of postcolonial radioactive masculinity is underscored as the Indian army chief General Malhotra gains control of the political establishment, which he fears is getting "too soft" and is resultantly afraid of retaliating against Pakistan. (69). This masculine anxiety of getting "too soft" and arguably "feminized" catalyzes Malhotra's decision to subvert the political leadership, which is led by the Indian Prime Minister Bipolab Roy, a "Feluda-loving" liBengali intellectual. Crucially, the continuous struggle in the narrative between volatile militarized masculinity and other forms of manhood-namely intellectual and reasonable manhood-epitomized by characters such as Bipolab Roy underscores again and again the problematic nexus between technophilic capitalism and the militarized postcolonial male.

The narrative, however, takes a dramatic turn when the missile Pralay programmed to have an unpredictable trajectory—-headed initially toward Amritsar in India changes course and destroys Lahore. This event leads to a realization in both the Indian and the Pakistani military establishments that a nefarious third-party had all along been plotting this event to rekindle hostile relations between the two South Asian super powers. This realization prompts the Indian army chief General Malhotra to hand back power to the deposed Prime 
Minister with the assertion that only the "ideals of democracy" (Khan 146) invested in reasonable figures like Bipolab Roy could bring back peace to the Indian subcontinent. With General Malhotra's explicit statement acknowledging the futility of his coup (and the overall failure of postcolonial radioactive masculinity) co-operation reassumes between India and Pakistan. The two countries decide to launch a joint operation to capture the culprits (Yaseer Basheer and Agyaat) who had catalyzed this sequence of apocalyptic events. While Agyaat is killed, Basheer manages to escape and meet his leader "Sheikh," now discovered to be noneother than Osama Bin Laden, who had apparently faked his death in order to avoid the American search for him. This reunion although is short-lived as the submarine on which Basheer meets Osama is destroyed with the resultant death of Osama and the capture of Basheer by the joint India-Pakistan operations team. The captured Basheer is surprisingly soon taken away from custody in a "suspiciously hush-hush manner" by an unmarked helicopter (Khan 256). In a final twist, it is revealed that Yasser Basheer is actually a senior American (white) military officer who had been deployed undercover in order to "capture the man... we have been hunting so long...the real one" (259). The American military establishment objectively purveys the results of their massive and elaborate operation, which as per their expectations had reestablished the conditions for American political and military dominance in the Indian subcontinent.

While the fictive liberties taken by Sami Ahmad Khan often border on incredulity, the realpolitik implications of this narrative can neither be discounted nor ignored. The revelation that the apocalyptic skirmish between Indian and Pakistan had been devised by American military-industrial complex in order to fulfill geo-political goals underscores the continued influence of American neocolonial imperialism within the Indian subcontinent. The events of this speculative novel, while fictional reflect the continued intervention of American military- 
industrial complex - manifested here through the symbolic figure of Yaseer Basheer-and its efforts to discursively and physically manifest American dominance globally, which Hazel Carby aptly summarizes as “Americanism”:

[a]n aggressive planetary dominance abroad supported and promoted by an unlimited, self-righteous arrogance at home, both of which result in an unleashing of violence against people and the environment unprecedented in world history (12).

This notion of subcontinental powers like India and Pakistan being pawns in the larger global ambitions of Western technophilic states (such as America) is also the structuring motif in Mainak Dhar's Line of Control (2009). Dhar speculates a future where a terrorist regime allied to Al-Qaeda, led by another Osama-like figure called the Emir, has gained power in Saudi Arabia and has decided to use its oil wealth and technological apparatus to spread the ideology of jihad. Emir through funding and manipulating a military leader in Pakistan named Illahi, who overthrows the democratic Pakistani government, plans to catalyze a series of covert and overt attacks on India, which would ultimately lead to a nuclear showdown in the subcontinent. Although the plot structure of Line of Control is significantly less complicated than Red Jihad, the main characters in both novels have a striking similarity to each other. The Indian Prime Minister in Line of Control is the erudite and cultured Vivek Khosla, who prefers reading Khalil Gibran's The Prophet over the daily intelligence reports, his job requires him to survey. His demeanor and attitude is in sharp contrast to his Pakistani counterpart, Illahi, a battle-weary military veteran and follower of the Emir's jihadi doctrine; one who envisions military supremacy as the only way of gaining political supremacy in the subcontinent. However, this apparently simplistic construction of Illahi's character is soon complicated as the reader is made 
aware that Illahi is a terminal patient of cancer, who is averse to exposing his physical invulnerability. Illahi is constantly plagued by his desire to become "the greatest national hero Pakistan ever had" (Dhar 15), which feeds his insecurities. Finally, his anxieties also seem to emerge from the fact that he has no children or a family, which makes him perceive the nuclear annihilation of India as the only legacy that his masculinity is capable of accomplishing.

Illahi, however, is not the only postcolonial figure battling inner and outer demons in this narrative. The Indian section of Dhar's narrative is focused primarily on the character of Colonel Dev Chauhan, a respected officer in the Indian army as well as a tactically-sound tank commander. Dev is introduced in the narrative as he leads his tanks battalion in a mock warexercise against another army tank battalion. With machine-like precision Dev is able to maneuver his numerically disadvantaged tank battalion and gain victory. He is characterized by his aggression, as the end of the tank exercise is followed by Dev's assertion that even though, "[i]t had only been a mock battle...to hone their skills...in a real war, the losers would all be dead" (Dhar 82). It is clear from his monologue that the "tall and strapping" Colonel Dev Chauhan who is a specimen for postcolonial manliness is deeply invested within the ideologies of the military-industrial complex. His penchant to perceive training exercises as the sites to hone his own efficiency as well as that of the fighting machine (to which he is constantly attached) signals his inability to perceive the larger narrative of war-predicated in real life and in this novel on the aggressive and often irrational ambitions of nation states. Dev's perception of his own self and his masculinity is consistent with what the philosopher Bonnie Mann (2014) describes as the ontological weight of gender: 
[i]n the sense that it anchors one's existence... one's sense of belonging to a community and to a world, and one is unmoored if it is undone. This man [sic] may be lost to himself if it is shattered (author's emphasis 1).

Mann's contention is that gender cannot be understood as a "fixed biological thing... [or] a psychological structure...[or] a social thing...[but] a lived reality" (my emphases; Mann 1), which carries with itself an ontological baggage that cannot be shed without some form of upheaval. Reading Dev's character through Mann's lens makes it clear that Dev carries within himself the ontological weight of postcolonial radioactive masculinity, which he is duty-bound to perform, through aggressive and belligerent performances. These machine-like performances are not without its side effects as Dev is shown to be suffering severely from Post-Traumatic Stress Disorder. Dev's PTSD results from an incident where he was unable to save some subaltern army-men under his command from a burning tank. This incident from the past is shown to give him nightmares as well to the constant questioning of his own validity as a military man. As a third generation army-person Dev's anxiety clearly results from the notions of militarized masculinity that he possesses, which predicate that he should be devoid of any form of "weakness," especially emotions. Dev's character is an apt example of the psychological and physical pressures of radioactive masculinity, which lead to similar cases of PTSD across the world. Contextually, Sandra Whitworth remarks:

In the United Kingdom, an estimated ten percent of troops airlifted out of Iraq between January and October 2003 primarily suffered from psychological trauma (Turner et al, 2005). In the United States, disability claims due to PTSD have skyrocketed, with some 34,000 veterans from Iraq and Afghanistan treated at Veteran's Affairs facilities diagnosed with PTSD (Corbett, 2007; 46) ...One 
psychiatrist has recently claimed, by contrast, that the US Department of Veteran Affairs has allowed a "culture of trauma" to blossom within its bureaucracy (my emphases; 1).

Line of Control highlights that this "culture of trauma" - a vital part of radioactive masculinitywhich Dev Chauhan is a victim of, emerges from the complex nexus between the expectations of militarized masculinity as well as that of the emerging postcolonial nation-state. Significantly, while the martial and aggressive performances of Dev Chauhan are expected due to his enmeshment within the structures of militarization, what stands out are the aggressive performances of the non-militarized/civilian males in this narrative. Much like the scientist Suryakant in Red Jihad, Line of Control is also replete with male characters who revel in mindless and presumably uncalled for acts of violence. Epitomized through communal riots that are catalyzed by right wing Hindu fundamentalists in India who decide to persecute Indian Muslims to retaliate against Pakistani aggression, violent civilian (and radioactive) masculinity is found to be at par with militarized masculinity in this speculative novel. Of course the thematic similarities between Red Jihad and Line of Control are palpable here as the perception of India as a masculine Hindu body politic, which is constantly under threat from other forms of masculinity or femininity is again brought to the fore.

Contextually, a distinguishing feature of both novels is the glaring absence of female figures. While Red Jihad has a complete absence of female characters either as main or a subordinate figures, Line of Control has one token female figure: Pooja, who is a TV journalist with a media house. The absence of female characters is generally a problematic aspect of SFespecially future-war fiction-since the othering of femininity functions as a key strategy for masculinizing the fictive topos. One of the reasons attributed for this anomaly is that 
technophilic future states, which are predominantly the landscapes for speculative fiction, have been pre-coded masculine due to the self-reflexive relationship between masculinity and technology. Again, the cultural equation drawn between masculinities and technologies is not arbitrary since "powerful technological roles are predominantly occupied by men who thereby have a disproportionate influence in shaping new technologies" (Lohan and Faulkner 835). However, due to the critical trajectory undertaken by the representative postcolonial speculative fictions discussed here ${ }^{\text {liii }}$ it may be surmised that the lack of female characters drives home a larger point about the discriminatory nature of the military-industrial complex. Jennifer Terry and Melodie Calvert best summarize this reciprocal relationship between gender and technology, manifested in speculative fiction:

We could define gender itself as a technology according to the following propositions: Gender is an organized system of management and control which produces and reproduces classifications and hierarchical distinctions between masculinity and femininity. Gender is a system of representation, which assigns meaning and value to individuals in society, making them either men or women (1997, pp.5-6).

The introduction of the singular female character, Pooja, also helps to underscore the volatility of postcolonial radioactive masculinity in Line of Control as she is often at the receiving end of masculine aggression. In her role as a media personnel working primarily within the militaryindustrial complex Pooja is continually subjected to the male gaze, which fails to perceive her as a working professional and voyeuristically objectifies her as "slim body, chiseled body and long and black hair" (Dhar 16). A specific episode in the novel particularly underscores the relationship of postcolonial radioactive masculinity with female bodies, when Pooja is 
unfortunately surrounded by a violent mob of four males during the communal riots. The naked sexual aggression exhibited by the male rioters during this event provides a telling commentary on contemporary postcolonial manhood. Plagued by colonial insecurities and religious dogma, a large section of postcolonial males continue to perceive the female body as a site for inscribing their maleness and presumably gain access to the hegemonic masculine paradigm.

Although Pooja is able to escape largely due to her quick thinking and the fortunate arrival of a (male) colleague, this fictive event vitally illustrates both the volatility and the fallout of postcolonial radioactive manhood that seeks to emulate the ideals of white militarized masculinity. Even though the characterization of Pooja-predominantly within the 'femalevictim' paradigm does leave a lot to be desired-she also acts as a vital deterrent to the juggernaut of postcolonial radioactive masculinity in this narrative. Through her prowess as a reporter, she makes the political establishment aware of the specific male characters who had fomented communal discord by misinforming the Indian populace. More importantly, a romantic relationship that ensues between Pooja and Colonel Dev Chauhan, when she is asked to report on the war frontier, results in Chauhan disavowing the model of postcolonial radioactive masculinity within which he was entrenched. Dev's romantic involvement with Pooja humanizes him, as he becomes self-aware of his status not merely as an aggressive and efficient military machine but rather as a desiring human being.

Much like Red Jihad, Line of Control also concludes with an utter failure of postcolonial radioactive masculinity. The machinations of Emir and his minion Illahi are discovered and foiled by discerning and reasonable figures in Pakistan, echoing similar characters in India who are able to combat the mindless communal violence being performed again by male characters. Pertinently, the influence of the American military-industrial complex is a key motif within this 
narrative as well: a potential Pakistani nuclear attack on India with an American-made aircraft is thwarted when the Americans remotely activate the fail-safe option, which they had installed foreseeing such apocalyptic emergencies. Moreover, the political dialogues about exercising nuclear options that take place in both India and Pakistan in this novel are shown to be heavily reliant on the USA-USSR paradigm of deterrence during the Cold War. Particularly in an exchange which the Indian prime minister Vivek Khosla has with his trusted aides, the novel stresses the continued legacy of Cold war discursive structures within the Indian subcontinent: “Come on, nukes are for deterrence — that's what the Cold war was all about" (Dhar 251).

Even though fantastical texts have been a part of postcolonial and more specifically the Indian narrative tradition, the genre of SF remains a largely unexplored terrain. In comparison to the Anglo-American canon, where SF has been a distinct genre with some very distinguishing characteristics, the lack of SF scholarship in the Indian sphere does make it a major challenge to locate the features germane to this domain. However, as Samit Basu an acclaimed Indian SF writer remarks, this "lack of stereotypes" (para 1) about what should constitute Indian SF does present both the audience and the writer with new opportunities. The texts that have been discussed in this chapter, while focusing mostly on the socio-political realities of the Indian subcontinent perform the herculean task of both adopting and challenging the global paradigm of SF. In critiquing the ideologies of white militarized manhood implicit in both American and Postcolonial Radioactive Masculinity, Indian speculative fiction becomes a site of difference that questions the limiting gendered discourses of postcolonial development based on Western technophilic nation-states. Maurice Blanchot asserts that the realm of SF offers us futures with "unprecedented problems and unforeseen solutions" (382), where apocalyptic settings keeping in tune with the Greek etymology of the word do provide us with a literal "uncovering" of both 
humanity and technology (apo-un, kalupsis-cover). The onus now lies on us, as to how we deal with the revelations made in them. 


\section{Chapter 5: Strategic Science vs. Tactical Storytelling: Disrupting Radioactive Masculinity through Postcolonial Ecologies}

GEORGE MASON: What's left but flying straight and level and taking it into a dive? Am I right? Unless of course maybe you wanna die.

JACK BAUER: What are you talking about?

GEORGE MASON: You've had a death wish since Teri died. The way things have been going for you the past year, this probably doesn't look like such a bad idea.

You get to go out in a blaze of glory, one of the greatest heroes of all time. Leave your troubles behind (my emphases; 24, "Day 2" Season 2, Episode 15).

In Season 2 of the popular FOX TV show 24, the protagonist Jack Bauer takes on the task of protecting Los Angeles, from a nuclear bomb that has been planted there by a purported terrorist organization. While Bauer and his tactical team from the fictional Counter Terrorist Unit (CTU) are able to find the bomb, they realize that the bomb is "tamper-proof" and will explode if manipulated in any way. The only option entails flying out the bomb into the Mojave Desert and crashing the aircraft, thus saving Los Angeles and its population but ensuring the death of the aircraft's pilot. It is at this precise moment that Jack Bauer, the quintessential white male American hero, steps up. Bauer — who had also lost his wife (Teri) in the previous season and with her his will to live — decides to become the martyr who would accomplish this noble task and explode along with the nuclear bomb. 
However, as Jack conveys his final goodbye to his daughter mid-flight, he realizes the erstwhile head of CTU, George Mason, has snuck onto the aircraft. In a dramatic turn of events, Mason — afflicted with radiation poisoning and with only a few hours to live — convinces Jack to give him the job of crashing the bomb-laden-plane into the desert. As Jack refuses to acquiesce, Mason explains that the real reason for Jack's death wish is not because he wants to be a hero, but rather because of Jack's inability to survive his daily existence. Mason explains that Jack is plagued by the responsibility of his wife's death and the subsequent estrangement from his daughter. In a pivotal scene, the stubborn Jack Bauer finally relents and after taking the parachute that George had thoughtfully brought for him, jumps off to safety.

Jack Bauer's character in 24, particularly in this episode from season 2 epitomizes why (white) militarized masculinity is synchronous with an anxiety that constantly undercuts the very structures that engender it. The death of Jack's wife - murdered by a trusted colleague-turned traitor-foments in Jack a deep sense of guilt. Jack's remorse, arising from his own complicity within the same military-industrial complex that harbored his wife's killer, and coupled with his failure to stop such an act attacks the very idea of heroic American masculinity, which he supposedly embodies. Bauer's desire to end his own troubled life (and anxious manhood), leads him to seek redemption for both his country and his failed masculinity: through a perfect moment of union with the most-powerful technological artifact known to human civilization, the nuclear bomb.

Scholars like Hamilton Caroll have read Jack Bauer's character-especially in the second season — as the epitome of post 9/11 manhood, since the episodes were crafted shortly after the events of September 11. Caroll suggests correctly (albeit incompletely) that "[I]n the figure of Jack Bauer 24 illustrates the transformations of U.S. citizenship after September 11 and yokes 
those transformations to traditional models of American exceptionalism and heroic action" (my emphases; 30). These "traditional models of American exceptionalism and heroic action" are intrinsically mired within the ideologies of white militarized masculinity as has been made especially explicit in cultural productions since the Second World War era. Therefore, it is not difficult to conclude that Jack Bauer's story embodies the dialectical relationship between destructive technology and hegemonic militarized masculinity, as the malaise that plagues nuclear weapon states.

As this chapter points out, the fallout of this self-reflexive nexus between two equally powerful ideologies is not limited to the American sphere. Erstwhile colonized nations-as well as other marginalized sites within the Anglo-American sphere that do not cater to privileged and normative bodies - have been at the receiving end of such masculinized and technologized processes. Paul Williams (reflecting on Neil Gaiman's coinage) terms such sites soft places, "desirable to colonizing nations as ideas and locations in the world that are unmapped and thus unclaimed in European [and American] eyes. Soft places represent "unsettled land in two ways; not yet calm or stable and uninhabited by people who are recognized as people in Eurocentric eyes — in other words Europeans and their descendants" (my emphases; Williams 87). Developing categorization to discuss the role of soft places — such as Australia—in fictional post-nuclear apocalyptic narratives, Williams emphasizes the role of such sites, within the domain of nuclearization.

Williams' assertions ties in seamlessly with the work of Joseph Masco who identifies how nuclear bombs are potent symbolic markers of technological progress for the teleological narrative of Anglo-American modernity. Nuclearization is implemented through radioactive colonialism: a process through which the "international nuclear complex...has consistently 
targeted minority communities for the most dangerous nuclear projects, creating a new form of global environmental discrimination" (Masco 29). This chapter looks at how radioactive masculinity —a hegemonic militarized masculinity that plays a crucial role in implementing radioactive colonization within soft places in America, India and around the globe-is subverted through the narrative practices of marginalized communities inhabiting these spaces. I intend to demonstrate how militarized masculinity in these soft places facilitates the manifestation of Anglo-American strategic science - thereby denying the value of both indigenous knowledge and structures - through epistemic and physical violence. By juxtaposing an analysis of Native American perspectives on the bomb, represented in Leslie Silko's Ceremony, with socio-legal artifacts from the Bishnoi community in Rajasthan who have been marginalized by the Indian nuclear program, I will foreground the value of narratives and storytelling as resistive tactics, which manage to subvert strategic neocolonial science through the creation of postcolonial ecologies.

The arguments in this chapter have been organized into three sections. In the first section I explicate the functioning of strategic science-illustrating its gendered dimensions — as it carries forward the hegemonic ideologies of whiteness and masculinity. The second section analyzes tactical storytelling in Ceremony and how this maneuver disrupts the meta-narrative of radioactive masculinity, which itself emerges from the workings of strategic science. In the third section, I look at narratives from and about the Bishnoi community, emphasizing how such discursive tracts tactically subvert the dominant perspectives about the Indian nuclear program. This section also underlines how the diverse forms of tactical narrativizations, from America and India, are part of postcolonial ecologies that challenge neocolonial forms of globalization. 
"Big EXPERIMents, Big PAYRolls AND Big MONEY"

The Manhattan Project was a turning point in the history of twentieth century science (Hughes 9).

In the introduction to his short yet succinct treatise on the Manhattan Project, Jeff Hughes analyzes two temporally disparate historical images. In the first, Ernest Rutherford, a seminal contributor to the field of radioactivity sits alone in his laboratory at McGill University in the early 1900's, while the other image shows the feverish activity at CERN (Conseil Européen pour la Recherché Nucléaire) in maintaining the UA1 detector, a critical part of the particle accelerator at the European center for nuclear research. These two pictures symbolize the changing role and influence of science between the twentieth and twenty-first century which moved "[f]rom being a relatively inexpensive activity carried out on table-tops in small laboratories" to an enterprise that "demand[ed] massive institutions of its own" (7). Hughes illustrates that this development of science into "big science"- a colossal enterprise that arguably marginalizes other non-militarized disciplines and individuals_-found fruition within the Manhattan Project. Hughes persuasively illustrates how the development of nuclear technology has undeniably changed our perception of "big science" and indeed its strategic uses in the twentieth century. In extending his argument, this section of the chapter looks at how "big science"- epitomized by nuclear technology and nuclear weapons - has always already been strategic science, a paradigm that exists to legitimize the interests and concerns of hegemonic neocolonial structures.

Of course this link between "big science" and the strategic interests of corporatized nation-states - beginning with America in the post-World War II era - is not surprising as "the 
Manhattan Project created new links between scientists and the state, and put science... at the heart of national security" (Hughes 9). It must be emphasized that what we understand to be strategic science arose in Cold War America as "powerful networks of military, university and industrial scientists worked to develop new generations of weapons" (ibid), which would purportedly support America's geo-political dominance in an age of rapid globalization. As the Cold War with Soviet Russia subsided, big science continued to spread its strategic tentacles into other spheres of human activity, further solidifying ideologies that see science and modernity as symbiotic structures. However, this strategic science—which carries forward the neocolonialist state's agenda through modes such as nuclear technology—while seemingly infallible, is in fact susceptible to its own colonizing tendencies.

American physicist Alvin Weinberg pointed out in the early 1960's, during his tenure at the Oak Ridge National Laboratory (a former Manhattan Project Laboratory) the characteristics of big science such as "big experiments, big payrolls and big money" that are "bad for science, because it encouraged scientists to spend money on large scale [strategic] research instead of developing, well thought out experiments" (my emphasis; Hughes 11). While it has been argued by science and technology studies scholars that the disciplinary category of science can be seen as a purely epistemological concept, any scientific enterprise - fortunately or unfortunately —is motivated by the ideological factors that precede its inception. Thus, the problems of strategic science can be easily understood: they involve losing "touch with human problems" (12) and carrying forward the profit-making motives of big corporations and powerful nation states.

In understanding the machinations of strategic science it is critically important to emphasize how this was and continues to be an overtly masculine enterprise. The deliberately gendered nature of the Manhattan Project—designed as a techno-masculine project to 
reinvigorate post-Depression era American masculinity— has been established in previous chapters. What needs to be reasserted here, before moving on to the effects of strategic science on soft postcolonial spaces, is the inherently masculinized nature of any strategic scientific endeavor. The gendering of science is not an inherent feature of scientific inquiry, but rather a socially and culturally created construct. In fact while the workings of science could be seen as a distinctly epistemological process of constant inquiry, the technologies emerging from such science are gendered due to the social and cultural aligning of technologies and masculinities (Lohan and Faulkner).

The equation made between the categories of science and technology is often responsible for the (albeit reductive) associations made between manhood and the workings of science. Keeping in mind the radical feminist critiques of "science" as masculine, which postulate "that the epistemologies, metaphysics, ethics and politics of the dominant forms of science are androcentric and mutually supportive" (Harding 10), it can be inferred that it is indeed the relations of power in a patriarchal world that predicate science as masculinized endeavor. Such structures ensure that "women have been excluded from the processes of defining the [scientific] culture and have been conceived as the other against whom men in power define their [scientific] projects" (Harding 10). Consequently, we have gendered scientific enterprises and an apparent understanding of the technology emerging from such projects as masculine.

Thus, any critique of science and masculinized technology is not an appraisal of the intellectual and practical processes involved in studying the "natural and physical World" (Harding 11). Rather this project and the genre of humanistic scholarship to which it belongs, analyzes the androcentrism that lies at the basis of this supposedly "systematic inquiry." Not surprisingly therefore technology often understood as "science in practice," is in many cases pre- 
discursively gendered, due to its origins within androcentric methods of scientific inquiry. Possibly, the best example of such a pre-discursively gendered technology would be nuclear weapons due to the obvious connotations of inarticulable power associated with this phenomenon. Much like androcentrism which has been understood as "natural and right" (Harding) within the Western and indeed global social order, nuclear technology as well as nuclear weapons have been globally positioned as emblematic of "scientific" progress and rationality. As Ray Acheson notes:

The nuclear weapon discourse is also mired in dichotomies such as hard versus soft security, strong versus weak, active versus passive, and national security versus human security. With remarkable consistency, the masculine-identified sides of these pairs are tacitly attributed more value than the other. (2).

Therefore, both Anglo-American and postcolonial nation-states have regularly disregarded the interests and well-being of soft places as well as the minority and indigenous groups who inhabit them. This is especially true when the value of such sites is decided through juxtaposition with the rather fluidly defined paradigms of "national security" and "global importance" associated with nuclear technology (O’Neill).

\section{Ceremonial Fabulations}

The Age of Ecology began on the desert outside Alamogordo, New Mexico on July 16, 1945 with a dazzling fireball of light and a swelling mushroom cloud of radioactive gases (Worster 339).

In the preface to Ceremony, Leslie Marmon Silko notes that when she initially conceptualized this narrative she thought of it as a: 
[...] a funny story about Harley, the WW II veteran whose family tried but could not keep him away from liquor. But as I wrote about Harley's desperate thirst for alcohol, it didn't seem funny after all, and I realized I wanted to better understand what happened to the war veterans...they were not bad people, yet something had happened to them. What was it? (Silko xvi).

My analysis of Ceremony emerges from this specific question-what had indeed happened to these individuals? As male veterans of a war that had seen the catastrophic atomic bomb simultaneously foreground American neo-imperial dominance and 'harden' American manhood, they seemed unlikely candidates "to stay drunk [for] the rest of their lives" (Silko xvi). Scholars have opined at length about the restorative and reparative potential of Native American and indigenous storytelling as the key motif in Leslie Silko's now canonical novel. However, the value of indigenous stories as a counter-narrative to the colonizing ideologies of white militarized masculinity has been rarely articulated in these critical works. By analyzing the PostTraumatic Stress Disorder (PTSD) of male veterans in Ceremony, especially the protagonist Tayo, I foreground in this section their enmeshment within radioactive masculinity: a very specific form of militarized masculinity that emerges from the contingent association between gendered bodies and the nuclear bomb.

Although the framework of Anglo-American ecocriticism might once have been considered the only choice to analyze texts such as Silko's Ceremony, this chapter adds a postcolonial angle to this literary approach. My analysis acknowledges the deeply embedded processes of colonialism that have shaped and continue to shape an understanding of "America" for the marginalized communities within its national and discursive boundaries. While the "Greening of the Humanities" declared through a New York Times article almost a decade ago 
has definitely provided a "methodology for thinking through the complexity of environmental histories and imagining new directions for our ecological futures" (9), such "directions" are often deeply implicated within the hegemony that imagines ecological awareness as an AngloAmerican endeavor and adopts one "genealogy of ecocriticism as the normative one that is blind to race, class, gender and colonial inequities" (9).

Silko's Ceremony is rendered special by the ecological context within which it is produced. On one hand the story (ies) of Tayo is a markedly linear one: of a WW-II veteran who constantly seeks to outlive the trauma of having been part of military aggressions, without being completely aware of what granted his enemies an adversarial status in the first place. The other crucial and often neglected aspect of Ceremony is Tayo's attempt to recover his own subjectivity from the structures of white "hegemonic militarized masculinity" (Jarvis 88) within which he is implicated and from a geographical location that has been rendered uninhabitable by the processes of radioactive colonization: implemented through the toxic legacy of the Jackpile uranium mines. Ceremony, exposits this theme through what seems to be a fairly uncomplicated narrative: Tayo, a half-white half Native American World War II veteran fails to come to terms with his life as a civilian post WW-II, in the Laguna Pueblo where he grew and spent his childhood and adolescence. Tayo's post-martial existence is plagued by daily nightmares, the most recurring of which incessantly bring backs the death of his fellow soldier and cousin Rocky who had fallen victim to the Japanese army. While Tayo has willingly subjected himself to the treatment offered by the veteran hospital at Los Angeles - an intrinsic part of the militaryindustrial complex — before heading back to the Laguna Pueblo, such treatment has been unable to alleviate either the psychological or the existential crisis that pervades his everyday life. His 
recovery, however, is finally catalyzed through the machinations of his grandmother who employs the assistance of Native American medicine men and their ceremonies.

What however remains elided in such a simplified condensation of Ceremony is the very specific environment within which Silko bases her novel: namely "the Laguna Reservation... located approximately thirty-five miles from Albuquerque, and about seventy miles from Los Alamos, where the first atomic bomb was developed" (Austgen para 2). The connotations of such a setting become particularly relevant when we consider that "[white militarized male] models of American exceptionalism and heroic action," (ibid)—made especially explicit in Cold War post-nuclear apocalyptic fiction — have traditionally been located in such soft places. It is not surprising therefore why Tayo, who is dealing with his engagement with radioactive masculinity, is unable to break free from its effects even after exiting the battlefield: since the very site of his recuperation is the space where the excesses of American militarization and the nuclear complex are most evident. This is why Tayo finds "coming home terribly hard" since his home is not the same as "a [uranium] mine has been dug in a sacred area, a violation of nature that disturbs him deeply" (Silko xxii). Thus, any form of therapy that aims to restore his subjectivity must first acknowledge and redress the oppressed environment within which he is now located. Of course, this also underlines the paradox pervading the Laguna reservation. The reservation, while based within American national boundaries, is effectively othered due to the minority subjectivities that inhabit this space. Ceremony mirrors the thematic preoccupation "woven through all of [Silko's] work which is: the theft...of the native people's longaccumulated and reverently guided wisdom about the natural world" (Silko xxi).

Existing scholarship about Ceremony illustrates how recovering the value and prevalence of Native American ceremonies is critical in helping Tayo reclaim his own subjectivity as well as 
that of his homeland. Ceremony underlines how such a project is not undertaken through one or multiple ethnic rituals, but rather through the ability to fabulate tactical narratives that are bereft of the colonizing and strategic influence of Western scientific processes. My understanding of strategic vs. the tactical is derived from De Certeau, Jameson, and Lovitt's formulation of the strategic as being a "gesture of scientific, political, or military modernity" (5) that manipulates a place to make it susceptible to the dominant discourse. Tactics, on the other hand, emerge and are developed in alterity and otherness. They note that tactics have "no place except in that of the other... [it] vigilantly utilizes the gaps...in proprietary power. It poaches there. It creates surprises. It is possible for it to be where no one expects it. It is wile" (5). While tactical practices that subvert strategic actions can have many manifestations, narratives can be particularly tactical, "by allowing the silenced to speak, by refusing the flattening and distorting effects of traditional logico-scientific methods" (Ewick and Silbey 199). This is made especially clear as Ceremony begins with a prologue that underscores the socio-cultural power of stories:

They aren't just entertainment.

Don't be fooled.

They are all we have, you see, all we have to fight off illness and death (Silko 2).

Susan Sontag's classic account of illness as metaphor is particularly pertinent here, where she argues that although disease "could be considered as much a part of nature as is health," in Western discourse, it has become "the synonym of whatever [is] "unnatural"” (75)." Therefore not surprisingly Tayo is "ill," since his PTSD is really symptomatic of the "unnatural" state of Native American subjectivities as well as the spaces that they inhabit. 
Tayo symbolizes this theft of Native American subjectivity as he keeps reminiscing about the enemy Japanese soldiers he had killed: whose corpses were no different from American soldiers "when they were swollen and covered with flies" (7). He keeps dreaming of a situation where the corporal heading his unit orders him to shoot Japanese soldiers but Tayo is unable to do so: “ [...] it wasn't a Jap, it was Josiah [Tayo's uncle], eyes shrinking back into the skull and all their shining black light glazed over by death" (7). Tayo's misperception of the soldier as his own uncle provides a telling commentary on how white militarized masculinity oppresses bodies across spatial and racial boundaries. While in the battlefield the victims are American soldiers, back home the victims are people like Uncle Josiah whose harmonious relationship with the land they live in, has been erased due to the toxic legacies of nuclear weapons testing and the uranium mines, which fuel such weapons of mass destruction.

Storytelling therefore becomes the primary mode of subjectivity creation in Ceremony. While the novel itself — as a literary performance from Laguna Pueblo native—symbolizes how minority voices write back against colonizing dominant discourses, the power of narrativization does not stop at Silko's meta-literary act. Throughout the novel are strewn instances of tactical storytelling, a key method through which the protagonist and other primary characters gain political and epistemological valence. While the narrative pivots around Tayo's journey of rediscovering his indigenous roots through "ceremonial healing," the reader also derives a fully fleshed out picture of the other major characters. Silko achieves this through the unreliable yet deeply perceptive narration of Tayo, who expounds in detail about both the animate and inanimate objects he interacts with. Tayo's stories show how he "sees the connection between all living things and not their separation as unique biological entities" (Sharp). Early on in the novel as Tayo talks with Harley, his childhood friend and fellow WW II veteran, the reader becomes 
privy to Tayo's stream of consciousness mode of narration that moves seamlessly between the past, present and the future:

Harley had been at Wake Island with Leroy Valdez and Emo. They had all come back with purple hearts, but it didn't seem as if the war had changed Harley; he was still a little fat and he still made them laugh, joking and clowning (19).

Almost immediately after, Tayo notes that while the hale and hearty facade might project apparent happiness Harley's alcohol-addiction made evident his battles with PTSD, which has left Harley emotionless and dehumanized, “[S]omehow Harley doesn't seem to feel anything at all, and he masked it with smart talk and laughter" (21). Tayo, however, refrains from making any judgement on what exactly Harley is "masking." Rather he lets the reader infer that like Tayo, Harley is plagued by the demons of his militarized past. Pertinently, soon after when Tayo learns in a conversation with a doctor that "since the second world war a pattern of drinking and violence not previously seen before, [was] emerging among Indian veterans" (49) it becomes clear that the malaise of white militarized masculinity plagues almost all of the veterans. That this hegemonic militarized masculinity_ or radioactive masculinity — is contingent on the nuclear bomb is made particularly evident through Emo, another veteran and childhood friend of Tayo. Emo believes completely in assimilating with white society and the potent symbol of Euro-American scientific superiority: the nuclear bomb. As Emo narrates his martial exploits it is clear that he sees his own subjectivity and that of his fellow soldiers being both contingent and implicated with that of the nuclear bomb's destructive capabilities: 
We were the best. U.S. Army. We butchered every Jap we found. We blew them all to hell. We should've dropped bombs on all the rest and blown them off the face of the earth (Silko 60-61).

Emo's stories which "rather than celebrating the landscape of the reservation...long for the white world of machines and killing” (“Questing for" 119) epitomize how radioactive masculinity is mired within structures of both whiteness and militarized masculinity. Contextually Sandra Whitworth notes in her essay "Militarized Masculinity and the Post Traumatic Stress Disorder" that:

PTSD tells us a series of stories about militarized masculinity; stories that those who support militaries and militarism would prefer we not think about too deeply...PTSD in men lays bare the fragile ground on which militarized masculinity is built; Consequently, it is a story that most militaries are not keen to acknowledge. (Whitworth 2).

In recovering these unsaid narratives, Tayo's tactical storytelling challenges the suppression of subjectivities, which is implicit within the dominant discourse of whiteness and militarized masculinity. This is particularly evident in Tayo's recollection of his childhood education: "He had believed in the [Laguna] stories for a long time, until the teachers at school taught him not to believe in that kind of "nonsense... [B] ut they had been wrong" (19). However, unlike his cousin Rocky who had "repeatedly shown embarrassment over Laguna traditions and refer[ed] to school science books as the only reliable source of knowledge," (Sharp) Tayo has an inherent belief of in the power of stories, which ultimately leads to his retribution. 
Later on in the novel as Tayo encounters and converses with the Navajo medicine man Betonie and the mysterious Tse'h, he realizes that "the repeated attempts of white groups to decimate the Pueblo culture by destroying its ceremonies" (Austgen para 2) has been physically manifested through the drought that pervades the Laguna reservation, the alcoholism and violence of Indian veterans as well the environmental degradation from the uranium mining. This is of course one of the key themes of Ceremony, as Connie Jacobs's notes: "[T]he story in Ceremony is arresting because it is based on fact and because the horrors at Jackpile have become an enduring toxic legacy for the Laguna people..." (41). Considering the sacred relationship that Laguna people share with the land they inhabit it is not surprising that Tayo is unable "to pull the trigger" on his enemies in the battlefield. His constant awareness that the structures of radioactive masculinity - that make him shoot Japanese soldiers in the battlefield and that are also responsible for the horrific side-effects of uranium mining in his homelandresult in his deep seated physical and emotional malaise. Tayo's dreams reflect his deeply troubled state:

[h] umid dreams of black night and loud voices rolling him over and over again like debris caught in a flood...Sometimes the Japanese voices came first, angry and loud...and the voices would become Laguna voices, and he could hear Uncle Josiah calling to him...But before Josiah could come, the fever voices would drift and whirl and emerge again—Japanese soldiers shouting orders... (Silko 5)

Early on in the text as Tayo's stint in the veteran hospital is narrated, the reader also encounters Tayo's conflict with whiteness, “[F]or a long time he had been white smoke. He did not realize that until he left the hospital, because white smoke had no consciousness of itself. It faded into the white world of their bedsheets and walls" (Silko 14). As the narrative progresses, this "white 
smoke" that had pervaded Tayo's ontological and physical being is gradually cleared away as Tayo realizes that "after the white people came, elements in this world began to shift; and it became necessary to create new ceremonies" (Silko 117). Tayo's recovery from the effects of radioactive masculinity begins as soon as he understands that these "new ceremonies" involve recovering and narrating the stories that had been physically and discursively decimated by Anglo-American modernity. These stories he sees had always already surrounded him,

[E]verywhere he looked, he saw a world made of stories, the long ago, time immemorial stories, as old Grandma called them. It was a world alive, always changing and moving; and if you knew where to look, you could see it (88).

What makes Tayo's characterization particularly poignant is that through him Silko creates a fictional vessel, which could convey the minoritarian perspective on nuclear technology: one that effectively highlights both the deeply discriminatory origin and functioning of the nuclearindustrial complex. Silko underlines in Ceremony that, "Trinity Site, where they exploded the first atomic bomb, was only three hundred miles to the southeast, at white sands" (120). Beyond the smaller stories and plots that pervade Ceremony, the novel clearly is also a socio-political treatise that highlights how "[T]he development of uranium and its use as fuel for the atomic bomb began right in the heart of Indian country in New Mexico...With the prevailing west-toeast wind pattern any site east of Los Alamos was vulnerable to airborne toxins released from the lab" (Jacobs 42).

While the social and historical importance of Ceremony especially within the nuclear context is beyond doubt, my scholarship brings forth a crucial yet neglected aspect of this novel: militarized manhood and its function in propagating the colonizing ideologies of the American 
military-industrial nuclear complex. Scholars have noted that the rhetoric of white manhood pervading post-WW II and Cold War American discourse "took their own whiteness and maleness, together with 'American' authenticity, as unmarked neutral positions of superior reason" (Clark 3). Such a discursive paradigm ensured a "politics of simplification" (ibid) that was heavily resistant to complexities of gender, sexuality and race and propagated an ideology of containment that saw whiteness and masculinity as the only normative categories. Silko's critique of the nuclear age is also therefore an explicit critique of the white militarized masculinity, or radioactive masculinity, which allows for the sustenance and development of colonizing nuclear technology and nuclear weapons.

Pertinently, "subject-centered rationality" (Chatterjee) that has been at the core of postenlightenment modernity is the fundamental ideology that pervades any form of weaponizing science. Nuclear technology, which undoubtedly epitomizes the pinnacle of Western modernity, has naturally been globally understood as the unequivocal bar of scientific success for the rational Anglo-American (male) subject. As a corollary any other form of knowledge production, i.e. indigenous or native interpretations of Nature have been quickly set aside due to their lack of legitimation, by the dominant scientific (Anglo-American) framework. However, various scholars (Abraham; Srivastava) who offer nuanced discussions about the discursive role of nuclear technology within the nation-state more often than not discount the "subject-centered rational" figure from which these discourses emerge. This figure is of course the rational scientific minded (white) Western male, a subjectivity, which forms the template that postcolonial science mimics and hopes to emulate. In the following section, the emphasis is to show how the tactical narrativizations of the Bishnoi community are in fact very specifically oriented toward disrupting the "subject-centered rationality" epitomized in radioactive 
masculinity. Such tactical and non-hegemonic narratives become powerful agents for creating postcolonial ecologies. By disrupting the co-production between colonizing science and patriarchal society—symbolized by radioactive masculinity - they disrupt the very narrative of teleological progress propitiated by post-Enlightenment Western modernity.

\section{THE ECOJUSTICE OF BISHNOIS}

The key to working toward environmental justice then may be ensuring that the people in power cannot monopolize the right to determine what it means (Sachs 9).

The ecojustice or environmental justice movement gained currency and attention in the AngloAmerican context largely from the First National People of Color Environmental Leadership

Summit in Washington in 1991. While the link between environmentalism and social justice had been tenuously charted in academic criticism since the early 19th century, the lack of empirical evidence regarding the "death, disease and discomfort experienced by thousands of people...across the world [due to] most dangerous chemicals, incinerators, nuclear waste facilities, uranium mines, and other environmental hazards" (Reed 221) did not allow for the growth of well-directed academic scholarship till the late 90's. As has been referenced in the previous section, an important part of the ecojustice movement in North America has been "Native American activists...fighting against the devastating impact of uranium mining and nuclear dumping on tribal communities" (Reed 221). However, rarely has academic scholarship drawn explicit connections between man-made ecological imbalances and the people affected by such disturbances, since such activism is " [s] ometimes portrayed as a civil rights movement, sometimes as an environmental movement" (ibid). Consequently I argue that the artifacts analyzed here - including literature that emerges from Bishnoi history and belief system, media 
reports about the oppressed state of the Bishnoi community as well as socio-legal documents chronicling Bishnoi activism against the Indian nuclear complex — belong to a mode of postcolonial ecojustice, which shows that "human rights and environmental issues are inextricably bound together" (Sachs 5).

The ecojustice or environmental justice movement "aims to show that the two are often one" (ibid) as is exhibited in case of the Bishnois' struggle against Indian nuclearization. Particularly, in case of the Bishnois - due to the religious environmentalism that is at the locus of their existence — any movement to redress social ills and address civil rights issue is always already implicated into the ecojustice framework. But the challenge of tracing Bishnois' attempt at ecojustice is deeply implicated within their historically marginalized status. As T.V. Reeds notes:

[The] history of environmentalism has unfortunately often been defined from the perspective of the white middle class [that] often stress literary origins with the rise of environmentalism's literary branch, ecocriticism... [and] the traditional story of modern environmental consciousness often focuses on literary precursors like the English and American Romantic poets, and on literary naturalists like Henry David Thoreau and, a little later, John Muir (my emphases; Reed 222)

The Bishnois, while being eco-conservationists since the early 15 th century have found little or no mention within the (Western) canons of ecocriticism, due to their lack of participation in mainstream Anglo-American environmental discourse. Of course, the fact that almost all of current and former Bishnoi ecocritical literature has been written in Hindi, Gujarati or one of the Rajasthani dialects, further marginalizes them from canonical ecocritical discourses. My attempt 
in this chapter to recover Bishnoi narratives is an important part of contemporary global efforts at expanding environmental consciousness, beyond "the mostly male, mostly white, mostly middle class leaders of the [ecological and ecocritical] movements" (Reed 224).

Further compounding the discursive invisibility of Bishnois in Anglo-American ecocriticism is their social position in India, which has also ensured the elision of anti-nuclear Bishnoi protest movements. To derive a more nuanced understanding of Bishnoi subjectivity and its relationship with eco-justice, a brief background about the community is necessary. In discussing the Bishnois and their relationship with Indian nuclearization it is important to contextualize such an association within the larger narrative of religious environmentalism: the ideology that lies at the basis of the Bishnoi way of life. The Bishnoi movement began in the mid-fifteenth century, through the principles laid down by Guru Jambeshwar and combined the tenets of both Hinduism and Islam to address the larger issues facing communities in the northwestern sections of India. The term "Bishnoi" in the local dialect refers to the twenty-nine tenets of Guru Jambeshwar (Bish= Twenty+ Noi= nine") that defines the ideal way of Bishnoi existence. Bishnoi scholar, Pankaj Jain, summarizes Guru Jambeshwar's tenets in the following way:

[...] eight are about conserving and protecting the animals and trees, including the non-sterilization of bulls, keeping the male goats in the sanctuary, prohibition against killing of animals of animals, cutting down any type of green trees, and protecting all life forms. He also forbade the wearing of blue clothes, because the dye for them is obtained by cutting several shrubs. Seven other rules were about social behavior. They directed his followers to be simple, truthful, content, abstentious, and pure, also to avoid adultery, and making false arguments. He 
prohibited criticizing others and [advised them] to tolerate the criticism of others.

His other ten rules were about personal hygiene and maintaining good health (5960).

As can be seen from Jain's discussions, the landscape and the environment within which the Bishnoi faith is based has a self-reflexive relation with the Bishnoi mode of living. In fact the tree-hugging movement that is now an intrinsic part of ecological modes of dissent around the world, arguably, found its inception in the actions of Amrita Devi from the Bishnoi community. Bishnoi narratives eulogize the memory of Amrita Devi and 363 of her followers who gave up their lives protecting the Khejri tree around 1731 A.D. The legacy of this movement has inspired Indian environmental activism to a great extent, of which the Chipko movement-for forest conservation in the Himalayas - is particularly notable.

While the religious environmentalism of the Bishnois has occupied a peripheral space within mainstream Indian discourse - through media publicized cases such as "the death of Gangaram Bishnoi at the hands of poachers in 2002, [and] the imprisonment of Hindi film actor Salman Khan for killing a blackbuck in Bishnoi territory in 1998," (Chapple 340)_Bishnoi antinuclear protests are completely elided from the Indian public sphere. Although the human rights approach in most areas that deal with issues of environmental degradation, rely on the reformation of the law enforcement system, such a tactic becomes particularly problematic in the soft spaces where radioactive colonization is implemented. This is because the legal guardian of those spaces - namely the state - is itself the entity responsible for the erasure of human subjectivities and the destruction of the environment. While as Carrigan (in building on Ashcroft) notes "Western colonialism is often viewed as a cultural and environmental catastrophe of enormous proportions" (255) that manages to marginalize postcolonial 
populations, the narrative of radioactive colonization is even more complicated due to the nationstate colonizing its own citizens. In such cases the nation-state following the "discourse of development" (Chatterjee) supposedly embodied in nuclear technology and nuclear weapons, effectively "others" non-normative subjectivities within their own sovereign territories. It is crucial to emphasize here that these "discourse[s] of development" under which such projects function in postcolonial spaces, has its clear origins in the Western colonialism and their notions of modernity.

Therefore, the Bishnois' "ontology of land" (Deloughrey and Hadley 6) —in other words the Bishnois' relation with their landscape — that has historically defined this community, has been successfully removed from the dominant narrative of Indian nuclear progress. A most telling example of this reality was made evident when the Pokhran desert range in Rajasthan was finalized as the site for the testing of the Indian nuclear program. In deciding that Pokharanonly six kilometers away from Bishnoi settlements—-would be the site of nuclear testing, Raja Ramanna, a key figure in the Indian nuclear complex had commented that this "closed area with a sparse human population" (Abraham 8) was an ideal place. Such an assertion conflicts directly with the actual reality of the area: home to one of the world's first eco-conservationist communities, who play a critical role in the larger narrative of environmentalism in India.

The Bishnois while being a sizable part of the population in the northwestern states of India (Rajasthan, Haryana, Punjab and Uttar Pradesh) are not considered a part of mainstream Hinduism. Although, current Bishnoi practitioners do identify with Hindu principles and belief systems, the secular origins of Bishnoism occlude them from the hegemonic status granted to Hinduism in India. While exceptions exist, most Bishnois are pastoral farmers or daily-wage laborers ${ }^{\text {liv }}$ having little economic clout or social mobility. This elision from mainstream Indian 
discourse is particularly visible in Rajasthan — the Indian state with one of the highest Bishnoi populations - where the official government website conveniently forgets to acknowledge Bishnoi existence. In a move that is emblematic of how Bishnois are made invisible, the Government of Rajasthan website ignores Bishnois under the "Citizen and Community" section:

The important communities of Rajasthan are the Rajputs, Jats, Brahmans and the traders. The Rajputs are the martial race, known for their chivalry and valour. The Brahmans were the priests and teachers while the Mahajans are still the backbone of the village economy. The Jats and the Gujars are the agricultural communities (Government of Rajasthan).

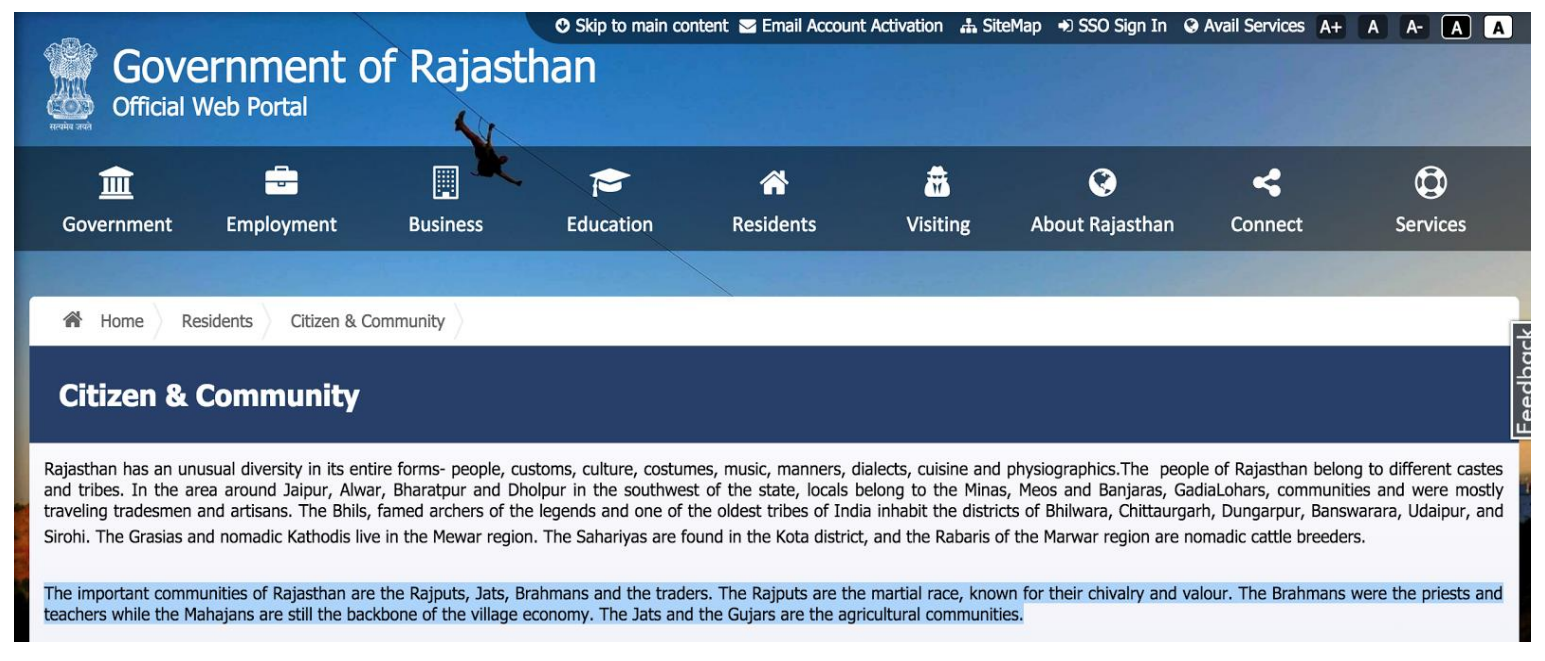

Figure 7: Screenshot from Government of Rajasthan website

It is vital to note here how official state discourse only acknowledges the "important communities" who are productive to the social, economic, and political fabric of the nation-state. The Rajputs noted here as a "martial race" are one of the highest contributors of personnel to the Indian Army and have an entire infantry regiment (the Rajput Regiment) named after them. The 
Mahajans are the main wealth contributors and Brahmans, while not wealthy or martial, merit mention due to their privileged caste-position and their role as temple priests. The Jats and Gujars find relevance due to their agricultural contributions and the Bishnois who are neither martial, nor wealthy or agrarian find themselves missing from the categories of "citizenship" and "community" in Rajasthan.

This combination of liminal religious positionality, lack of monetary resources and their purported irrelevance to the national community ensures that the voice of Bishnoi activism is largely localized and fails to attain any form of currency within South Asian Studies or even postcolonial scholarship. Most importantly, while Bishnoi protests about blackbuck hunting have sporadically found mention in the Indian media and public sphere, they have largely been in issues where a dominant identity (such as a Bollywood film star) or a sensationalist news opportunity (murder) is involved. Considering the powerful and self-reflexive relationship between nuclear weapons, statecraft and the national security apparatus it seems a foregone conclusion that Bishnoi-inhabited land in Pokhran, Rajasthan would be the perfect soft space for the implementation of Indian radioactive colonization.

Before moving any further, it is important to emphasize here how radioactive colonization has affected Bishnoi livelihood since the first nuclear tests in 1974. A 2014 article addresses this fallout:

Forty years after India's Smiling Buddha mission, the villages in the vicinity of the Pokhran test range have long fallen out of the international spotlight. But in the decades since, as they have been beset by what they claim are abnormally high rates of cancer and genetic disorders, these villagers have joined a tragic 
global circle of residents of nuclear test sites around the world who grapple every day with the fear of radiation exposure (my emphases; Desai para 4).

The aftermath of the 1974 nuclear tests that also resulted in crops turning white in nearby lands due to the radiation (Desai), however, did not deter the second nuclear tests from being conducted in the same area in 1998.

These tragic after-effects of radiation, voiced by the inhabitants of Khetoloi and Loharki (villages in very close proximity to the Pokhran test Range), have often been publicly disregarded by the Indian military-industrial complex. The hyperliterate Indian nuclear establishment—namely the Department of Atomic Energy—-has consistently challenged reports of deaths or ecological imbalances, citing that illiterate or semi-literate Bishnoi villagers are unreliable sources to draw information on the effects of nuclear technology. However, independent surveys have confirmed how the ambitious trajectory of the Indian nuclear program has regularly claimed Bishnoi victims:

Dr. Arjun Singh, a former Joint Director of Medical and Health Services in the Jodhpur region, who is also a resident of Loharki village... [carried] out a preliminary medical survey in 2009 in the villages within a 10-km radius range of the explosion site. He and a team of doctors spent more than six months on the study. 'There is a definite rise in cancer, genetic abnormality amongst livestock and skin problems in the villages of inner radius from the test site,' said Dr Singh. At the time of the survey, Loharki had around 17 deaths from cancer and Khetolai, 20 deaths' (Desai para 10).

What is both highly unfortunate and problematic in this discursive battle-between the Bishnois and the Indian nuclear establishment — is that it reinserts the narrative of colonial India into the 
postcolonial state. The illiterate/semi-literate Bishnois versus the hyperliterate military-industrial complex is a throwback to British imperialism when "science played two contradictory roles in colonial discourse, at once making clear to the 'natives' the kind of knowledge that they lacked (which omission justified colonialism itself) and holding out the hope that such knowledge could be theirs" (Seth 377). Not surprisingly therefore, the Bishnois-bereft of political or discursive mechanisms that would allow them to directly challenge the Indian nuclear program-use sociolegal and literary narratives (based in their ideology of religious environmentalism) to challenge the processes of Indian radioactive colonization.

\section{Narrativizing Ecojustice, Forming Postcolonial Ecologies}

$[S]$ o natural is the impulse to narrate, so inevitable is the form of narrative for any report of the ways things really happen, that narrativity could appear problematic only in a culture in which it was absent (White 88).

Regional activism...demonstrates the mutually constitutive relationship between decolonization and denuclearization (DeLoughrey 241).

The formation of postcolonial ecologies derives its impetus from the understanding that any narrative of postcolonial critique is intertwined within a project of ecological recovery. In Culture and Imperialism, Edward Said asserts that "[I]mperialism after all is an act of geographical violence through which virtually every space is explored, charted and finally brought under control...Because of the presence of the colonizing outsider, the land is recoverable at first only through imagination" (77). In pointing out the intrinsic link between the physical and discursive violence of colonization, Said demonstrates that all acts of postcolonial 
writing are inherently ecological (DeLoughrey and Handley 3). While Said foregrounds the "vital role of the literary imagination in the process of decolonization" (DeLoughrey and Handley 4). I extend such an argument to illustrate how this decolonizing imagination is not only limited to the literary context. My analysis of narratives emerging from and about Bishnoi subjectivity emphasize that any form of narrative imagination, emerging from subaltern domains, is vital within the processes of decolonization. Therefore, the narrative imagination behind Bishnoi artifacts must be juxtaposed with the literary imagination of texts such as Silko's Ceremony to highlight how postcolonial ecologies narratively (and tactically) disrupt radioactive masculinity.

While all forms of narrative imagination are imbued with an ideological imaginary that expresses the subject position of the author(s), the subaltern figure's position is decidedly more complicated. Bereft of the cultural (and often linguistic) capital that allows dominant subjectivities to create hegemonic narratives (natural or literary), ${ }^{1 \mathrm{v}}$ subaltern narratives and the causes they espouse fail to achieve any form of socio-political legitimacy.

Moreover, intellectual formations — a key component of social activism — are often unacknowledged within subaltern communities, due to their existence outside the realm of “academic writing and teaching" (Reed 218). Particularly, in the Bishnoi context, there is a need to understand their environmental consciousness as the "material force" (ibid), behind their daily livelihood, which consequently allows them to protest against the hegemonic processes of radioactive colonization. This consciousness emerging from Bishnoi religious environmentalism percolates into their religious and social narratives and is intrinsically connected to the grassroots realities of Bishnoi anti-nuclear protests. 
My analysis here emphasizes that Bishnoi texts do not explicitly carry the message of anti-nuclear protests but narrate how the landscape suffers incessantly from the perils of nuclear proliferation. By foregrounding the "landscape as a participant...rather than a bystander to human experience" (DeLoughrey and Handley 4), these texts use nonhuman agency to tactically subvert the dominant narrative of the Indian nuclear program. In doing so they epitomize a postcolonial ecology which

[m] ust be more than a simple extension of postcolonial methodologies into the realm of the human material world; it must reckon with the ways in which ecology does not always work within the frames of human time and political interest (DeLoughrey and Handley 4).

By acknowledging that the environment cannot merely be seen as a template to materialize human interests and ambitions, the Bishnois directly challenge the dominant state narrative, which sees Pokhran, Rajasthan as merely a desert area fit for nuclear testing: refusing to acknowledge either the biotic or abiotic components that comprise the area's ecosystem.

This is particularly evident in the Bishnoi literary text Mahabalidan (The Great Sacrifice) composed by Dr. Brahmanand, which is a dramatic retelling of how 363 Bishnois sacrificed their lives in an attempt to save Khejri trees around 1731 A.D. The drama narrativizes how the king of Jodhpur Maharaja Abhay Singh, who was known for his devious statecraft, had surreptitiously ordered the felling of Khejri trees in the village of Khejarli, Rajasthan. This move was opposed by the Bishnoi inhabitants, who led by their visionary leader Amrita Devi (Lady Amrita), had subsequently initiated the tree-hugging movement. After an impasse that saw both sides maintain their original stand, the state had unleashed its soldiers on the movement, leading to the death of these peaceful protesters. Reading this text within the contemporary context of Bishnoi 
livelihood makes the parallels between the 18 th century and the 20 th/21st century hard to ignore. In mirroring the helpless nature of current Bishnoi activism against the maleficent Indian nuclear program, Mahabalidan acts as an effective reminder of how the Bishnoi ideals of religious environmentalism must be defended even at the cost of death. This is explicitly underlined in the preface to this book, composed by Dr. Baburam - a Bishnoi academic — who declares:

We get the message from this text that like the brave martyrs chronicled here, we [the current Bishnoi population] too should love our environment. Animals whether domesticated or wild, plants delicate or thorny, flowers beautiful or scented should all be understood to be an intrinsic part of our surroundings (my translation and my emphases; Mahabalidan 12).

This enunciation that underlines the need to conserve human beings, flora or fauna, irrespective of their use value is in direct contrast to the ideology of the Indian nuclear establishment that sees the "closed [Pokhran] area with a sparse human population" (Abraham 8) as expendable. Dr. Baburam's claim also highlights a vital and problematic aspect of ecocriticism: the definitions of nature, which are often dependent on aesthetic notions of beauty. This is particularly important considering that the large tracts of desert area in and around Bishnoi habitat, is neither aesthetically pleasing nor materially productive, thus placing it outside mainstream ecocritical discourse. By illustrating how in canonical ecocritical scholarship and activism, "sunsets apparently count, [but] toxic gases do not [as nature]" this text joins the group of artifacts that perform a "biting critique of the limits of an aestheticizing, pastoral form of [Anglo-American] environmentalism" (Reed 231) 


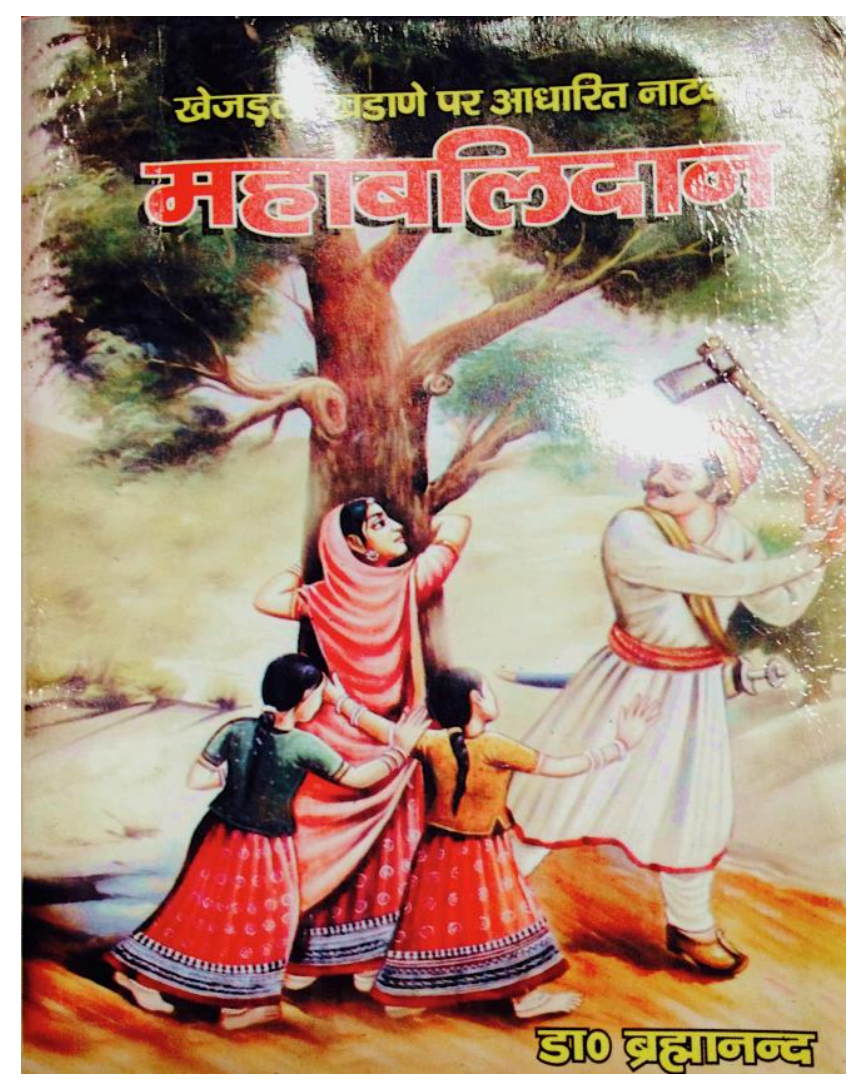

Figure 8: Mahabalidan (The Great Sacrifice)

The massive popularity of this book (which has led to reprints) highlights its important position in Bishnoi culture. However, the text's role as a pedagogic instrument within Bishnoi culture needs to be emphasized. In the introduction the author points out the contextual relevance of his work:

Today across the world the terrible storm of environmental pollution threatens human and animal existence. We should take inspiration and education from these great sacrifices: that for living organisms to survive on this earth, we have to wake up, rise up and save our environment. This is the core message embedded in this story of Great Sacrifice (my translation and my emphases; Mahabalidan 13). While the subaltern status of Bishnoi subjectivities does not allow them to engage in any effective dialogue — about the effects of radioactive colonization — with the national security 
apparatus, such texts provide the basis for developing the narrative imagination that will foster effective resistance. Thus even if the human inhabitants are voiceless, the environment and its history provides legitimacy and agency to Bishnoi concerns and problems.

However, unlike Native American activism against nuclearization, which has found agency within the American nation-state through a (postcolonial) ecology of dissent: comprised of dominant literary figures like Silko and her works as well as Native-American led organizations, Bishnoi activism is characterized by what Gayatri Spivak terms as planetarity. Spivak notes that the problem with reading literary texts emerging from marginalized positions is that it is often dependent "on the rigorous knowledge of the Other in the service of power," (Ghazoul para 4) an Area Studies tradition that has "roots in the Cold War" (ibid). This tradition forces the reading of literary texts from non-normative positions within a binary of Self vs. the Other, that is an untenable framework for reading Bishnoi texts: due to their physical, material and discursive invisibility from all forms of discursive frameworks.

Spivak reminds us that the binaries of Self vs. Other or powerful vs. powerless exist within a discursive system where subjectivity or power are acknowledged categories. Such categories are an intrinsic part of the globalizing narrative of disciplines such as Ethnic Studies or even Ecocriticism that "have not contributed to a rigorous knowledge of the Other, [even] though the Other is constantly invoked" (my emphases; Ghazoul para 6). The regional activism of the Bishnois is not a part of globalization — characterized by "visuality and illumination"—but instead of "planetarity [which] provides a means to think through—but not necessarily to represent that which is rendered invisible, that which is thrown in the shadow" (DeLoughrey 243). The alterity that characterizes Bishnoi literature like Mahabalidan (The Great Sacrifice) implies that on its own, it can never hope to catalyze or mobilize the anti-nuclearization 
movement. Rather, these literary texts are only a small (but critical) part of the overall postcolonial ecology of dissent that characterizes Bishnoi anti-nuclear activism. While this may appear problematic since the message of anti-nuclearism implicit in the religious environmentalism of Bishnoi literary texts may rarely be understood or conveyed, it is in fact a required tactical move. The economically and socially disadvantaged position of the Bishnois entails that any form of direct confrontation against the nuclear program will be unheeded and unrecognized. Therefore, Bishnoi activism against the strategic state machinery is mobilized through a combination of tactical processes, which challenges the dominant narrative that nuclear radiation is now a "familiar part of the everyday environment" (Boyer 314).

The closest parallel of regional activism similar to Bishnois would be the narrative resistance against nuclearization articulated in the Pacific Islands. Much like the soft spaces of Bishnoi habitats in India, the Pacific Islands were constructed as sites of "naturalized atomic weapon production [that] helped eclipse hundreds of nuclear detonations set off in the Pacific islands" (DeLoughrey 244). As DeLoughrey argues, the field of radiation ecology —of which Bishnoi activism is a part—emerged "in the Pacific...the militarized Enewetak Atoll, a chain of islands that functioned as an AEC (Atomic Energy Commission) laboratory for over forty nuclear weapons tests between 1948 and 1958" (238). Mirroring the Bishnoi tactic of indirect dissent against nuclearization through a personification of the environment, Pacific writers like James George, Chantal Spitz and Witi Ihimaera have used the "concept of planetarity" to denaturalize the familiarization of nuclear weapons: a strategy used by the nation-state to banalize nuclear weapons and make them "just one more of the hazards of contemporary living" (Lap 111 qtd. in DeLoughrey 242). 
The Bishnoi attempt at disturbing this forced "familiarization" of nuclear weapons within their lived habitat is also intrinsically connected to a broader understanding of place: one that has infinite meanings and morphologies.... [d]efined geographically...environmentally...genealogically...as well as phenomenologically” (DeLoughrey and Handley 4). Considering that non-human figures also form a critical aspect of place, the Bishnois' ecology of dissent takes up the influence of the nuclear weapons program on wildlife. This is not without its tactical advantages. As has been mentioned earlier, the Indian nuclear complex has summarily dismissed the largely illiterate Bishnoi population's testimonials, about the effects of nuclear radiation on their livelihood. This complete denial of Bishnoi subjectivity has led to the rise of multiple Bishnoi organizations that challenge nuclearization, through adopting the voice of the wildlife inhabiting this area. My discussion here is limited to exploring the work of Akhil Bhartiya Jeev Raksha Bishnoi Sabha (ABJRBS (All India Bishnoi Council for Wildlife Conservation)), which has successfully expanded its anti-nuclear politics beyond Bishnoi inhabited areas. For the ABJRBS the blackbuck and the peafowl-that are sacred animals within the Bishnoi religious corpus - become the primary non-human agents, which help materialize the Bishnois' ecology of dissent.

A striking example of Bishnoi activism in recent years was in 2013, when the ABJRBS challenged the authority of The Nuclear Power Corporation of India Limited (NPCIL) — a government-owned corporation - and fought against the establishment of a nuclear power plant (NPP) in Haryana, a state adjacent to Rajasthan with a sizable Bishnoi population. Vinod Bishnoi — one of the leading lights in this organization — emphasized in my communications with him, how initially the Government of India_-by equating a nuclear power plant with a rise in 
employment opportunities — was able to convince the illiterate population about the need for

such a structure.

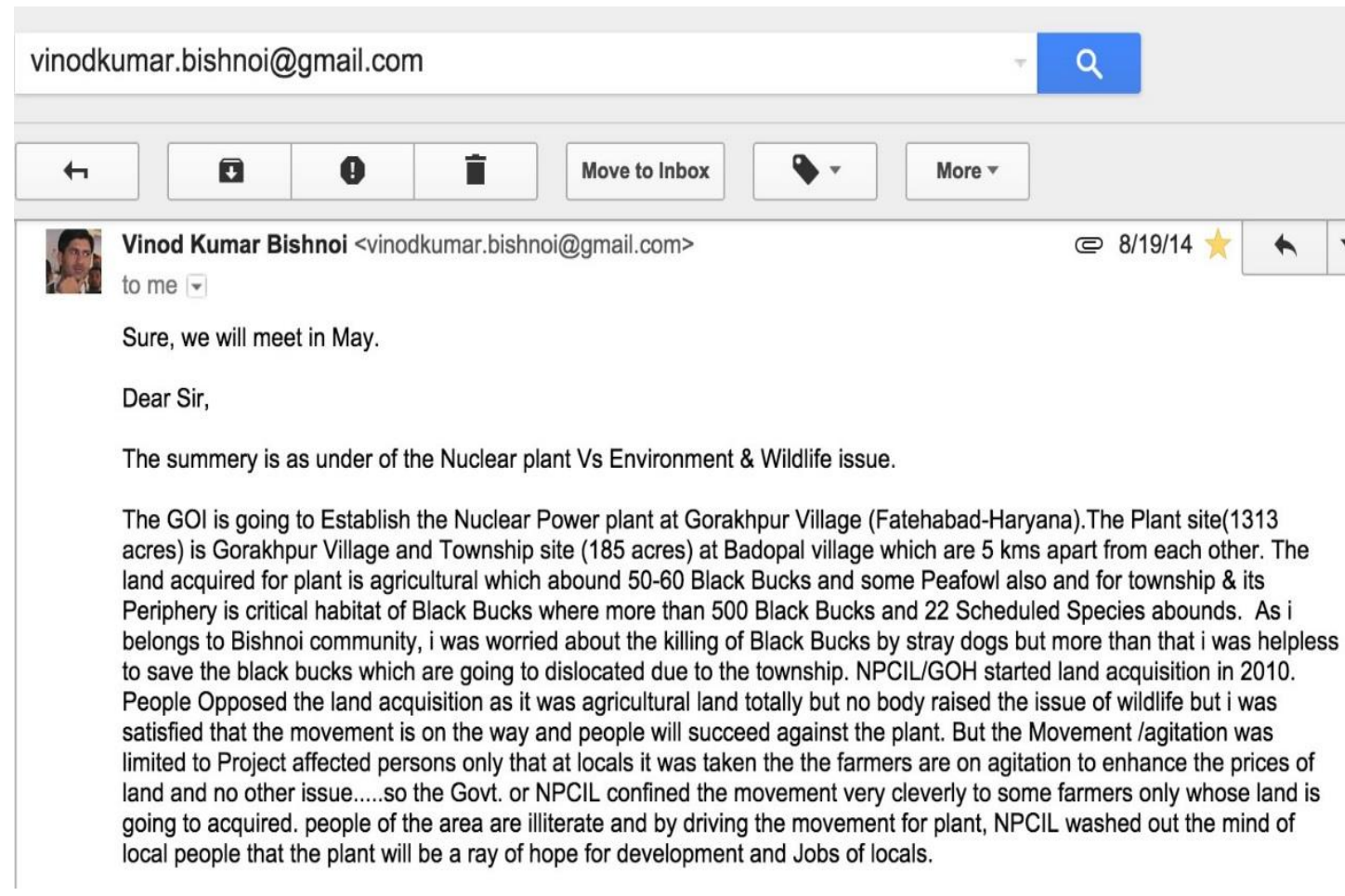

Figure 9: Screenshot of Email communication with Vinod Bishnoi

This blatant exploitation of a marginalized population through promises of economic prosperity provides a telling reminder about how "discourses of development" are the driving force behind Indian nuclear proliferation. Initial protests from the Bishnoi and other tribal communities were rejected by the Government of India sponsored Environmental Impact Assessment (EIA) report that claimed no significant harm would be inflicted on the resident wildlife. Vinod's aggressive rhetoric that claims how, "malafiedly (sic) the EIA report mentioned that there is no Notified area/Protected area such as Sanctuary or National Park within $10 \mathrm{~km}$ of the plant" attests to how the Indian nuclear establishment refuses to acknowledge any wildlife that does not exist within state-sanctioned spaces, such as sanctuaries or national parks. 
I was really shocked that as being the resident of Farm House near the Plant site, i have seen as much wildife along with other species as much there will be not at any protected area in the state. The EIA report has been totally inconsiderate to the existing wildlife by stating that being no Sanctuary or national Park in the vicinity and anticipatory measures not needed. The report suggested that if there is no Protected area than no need to protect the existing wild life including endangered species. So, as per my thinking not declaring the protected area may be fault on Govt. or on wild life official part but why these beautiful creatures will pay for this.

\section{Figure 10: Screenshot-Part 2 of Email communication with Vinod Bishnoi}

Vinod's self-reflexive commentary about why the "beautiful creatures will pay for this [exploitation by the NPCIL]," highlights how the Bishnoi ideal of recuperation - from the excesses of Indian nuclearization - is deeply embedded within a "long historical relationship to a particular environment and culture" (DeLoughrey and Handley 7). Much like the literary imagination of postcolonial writers like Chinua Achebe and Derek Walcott who turn to tropes like Igbo culture and the sea to "recover the suppressed bodies of colonial violence" (DeLoughrey and Handley 8), Vinod's narrative imagination uses the blackbuck's subjectivity to question the processes of Indian radioactive colonization. Unfortunately, the Indian Government/NPCIL continually ignored these Bishnoi voices of dissent until the death of seven blackbucks, which died during the fence building process of the proposed Nuclear Power Plant. Vinod and the ABJRBS then filed a case in front of the National Green Tribunal (NGT) and managed to get an injunction on the proposed construction. 


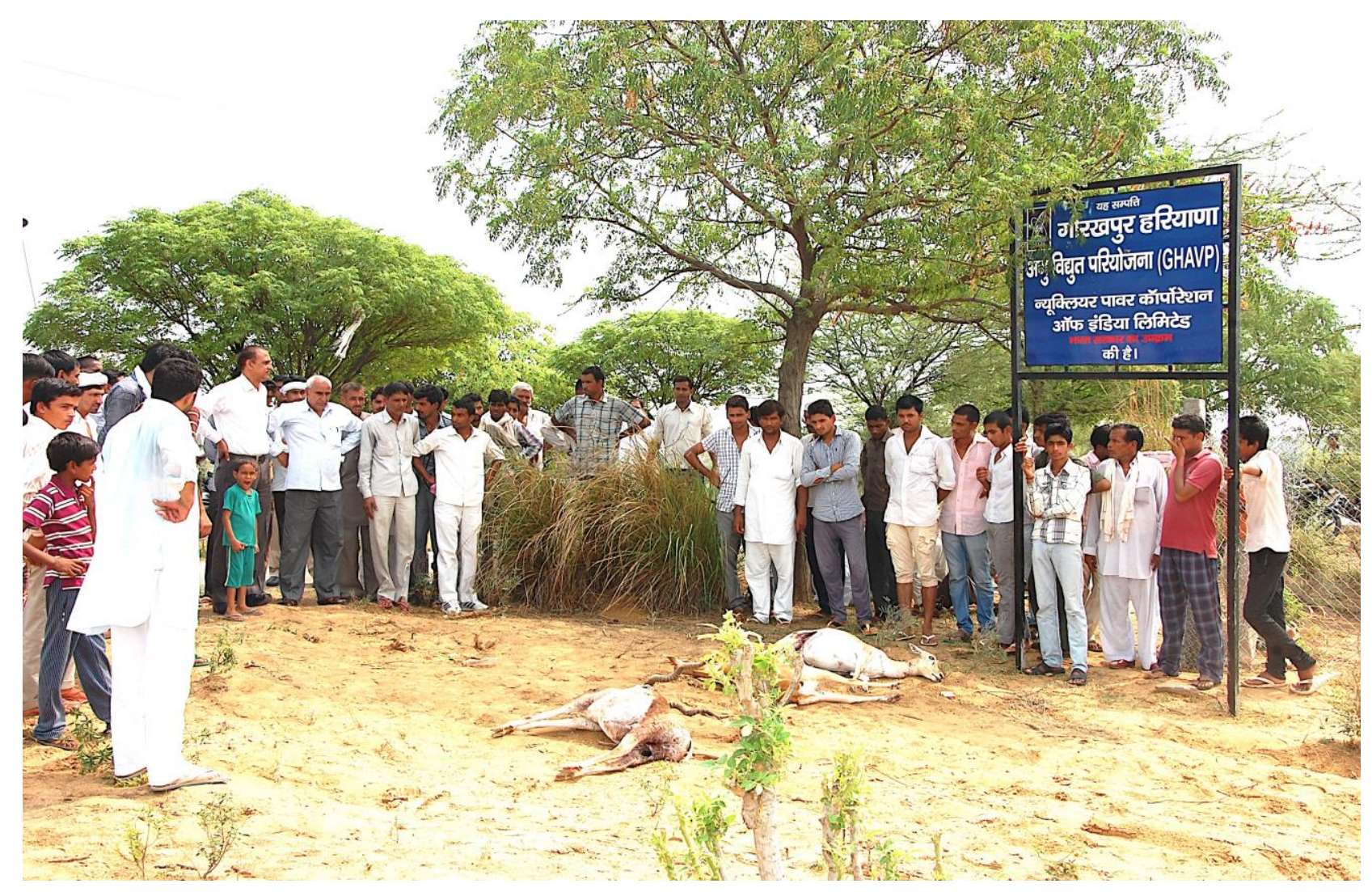

Figure 11: Dead Blackbucks lying in front of a sign that proclaims how the land belongs NPCIL

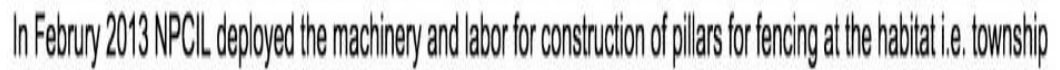

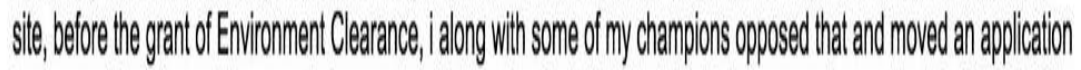

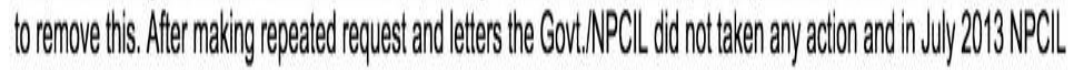

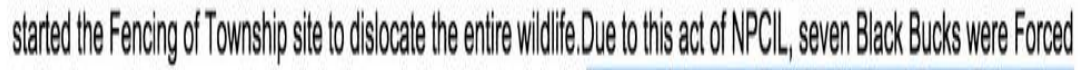

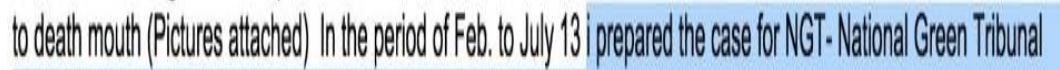

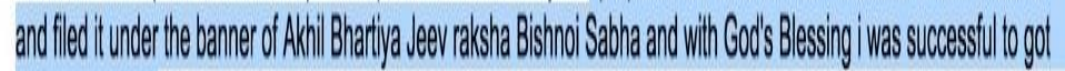

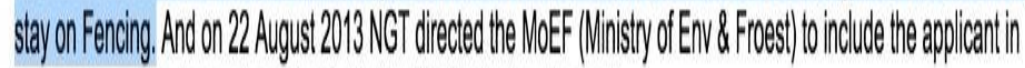

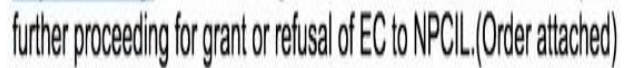

Figure 12: Screenshot-Part 3 of Email communication with Vinod Bishnoi 
The forced necessity of death—as the material event—through which resistance is channelized, eerily mirrors the fate of Bhuvaneswari Devi in Spivak's famous essay "Can the Subaltern Speak?" Spivak notes in this essay that "[There] is no space from which the sexed subaltern subject can speak," (103) epitomized through the Bhuvaneswari Bhaduri, a young woman, who committed suicide in 1926 during her menstrual period. Spivak notes that Bhuvaneswari's choosing of her moment of death was a distinctly political move since her suicide—actually arising from her disappointment at not being able to carry out a political assassination for the Indian freedom movement—-would otherwise be attributed to the shame of an "illicit pregnancy" (104). Spivak's reading of Bhuvaneswari's death sees this act as a "subaltern rewriting" of hegemonic colonial and nationalist constructions of the "third world woman." I read the death of the seven blackbucks in a similar vein, due to the philosophic and religious associations of blackbucks with Bishnoi subjectivity, highlighted in Vinod's narrative. Since there is no space from which the radioactive [Bishnoi] subaltern can really speak, they are forced to voice their concerns through the deceased materiality (ies) of blackbuck bodies. It is also worth noting that any "subaltern rewriting" of hegemonic discourses always comes with a cost: notably with a termination of life in both the cases discussed here.

Much like in colonial historiography where the third world colonized woman figure was equated with an epistemic silence, the marginalized Bishnoi or Native American or Pacific Islander has evidently suffered the same fate within the narrative of radioactive colonization. Challenging radioactive colonization therefore must disrupt the processes of nuclear historiography as well as structures such as radioactive masculinity that play a crucial role in furthering its mechanisms. In the following chapter, which concludes the current version of this 
project I will discuss postcolonial cultural productions that help us deconstruct the hegemonic constructions of nuclear historiography. 


\section{Chapter 6: Deconstructing Nuclear Historiography: From Nuclear Nationalism to Nucliteracy}

Visitors to The Nuclear Literacy Project website_launched in 2012 as a joint venture between the private and public sectors of the American nuclear industry-will immediately notice the numerous memes supporting nuclear technology that populate the website. A particularly striking one is the Nuclear Doge meme, a variation of the popular "Interior Monologue" captioning genre, which shows a radiant Shiba Inu (a Japanese spitz) reminiscing about the glorious aspects of nuclear technology. Such non-threatening methods of publicizing a potentially threatening technology conform to the website's claim of being an "outreach initiative geared towards reaching young, non-technical audiences with information about nuclear energy" (“About” nuclearliteracy.org). However, discerning netizens who follow the trajectory of internet memes will be aware that the "doge meme" was first circulated by a Japanese kindergarten teacher on February 23, 2010, just a year before the calamitous Fukushima Daiichi nuclear disaster took place.



Figure 13: Pro-Nuclear Doge Meme from the $N L P$ website

Official apparatuses publicizing nuclear technology have moved a long way from The Smyth Report of 1945, which unequivocally claimed that "The average citizen cannot be 
expected to understand clearly how an atomic bomb is constructed [...]" (Preface Smyth Report) to current attempts at reaching "non-technical audiences." However, problematic ventures such as the Nuclear Literacy Project that circulate carefully selected information about nuclear technology underline the problematic epistemic function of military-industrial complexes around the word. The meme, in question here, provides a perfect example of how nuclear historiography — the processes through which nuclear technology and nuclear weapons are historicized — not only elides but literally writes over the troubling legacies of nuclear technology. Taylor et al. note the fundamental role of nuclear rhetoric in such historiographies: [m]ilitary, scientific and government elites use nuclear rhetoric (e.g. technical rationality) to accomplish politically regressive outcomes. These outcomes include: mystifying audiences; obscuring the contingency, historicity and human agency underlying policies and operations; promoting hierarchical and authoritarian institutions and neutralizing dissent (5).

The nuclear doge meme through using phrases like "no scared," "such new, clear" and "happy fission very protect" draws a clear parallel between a faithful animal companion and nuclear power, embodying the obscuring capabilities of nuclear historiography. Not only is nuclear technology narrativized as the way forward for meeting human energy needs, but also explicitly coded as benign and friendly, much like the happy Shiba Inu canine in the image. Ironically, the catastrophic repercussions of the Fukushima Daiichi disaster are removed from public memory through another Japanese cultural artifact: one that has now been co-opted through nuclear rhetoric. These obfuscating tendencies of nuclear historiography—elucidated in multiple preceding chapters - emphasize the colonizing teleology of nuclear technology, which has continually been defined through its association with national strength, militarization and foreign 
policy strategies. Although, events transpiring in the August of 1945 implied that existence in the atomic age would become synonymous with a literacy of the nuclear, discussions about how nuclear discourse continuously affects our lived realities have been few and far between. While state-sponsored civil defense propaganda such as Duck and Cover are no longer foregrounded as a part of American education, contemporary ventures such as the Nuclear Literacy Project (NLP) illustrate the continued synonymity between being American and being nuclear literate. The concept of nation and national strength has always been fundamental toward understanding nuclear discourses and scholars like Alan Nadel, Stephen Whitfield and Ira Chernus agree that representing the bomb as a hypermasculine symbol of national power, implied that the bomb was not simply constructed as a technological object. Chernus argues that American Cold War policies that have consequently shaped global nuclear discourses were a largely discursive undertaking. In focusing on Eisenhower and his administration as the major undertakers of US Cold War policies, he points out that the threats of communism, nuclear war and economic mismanagement were all dealt with a "new linguistic paradigm" (Chernus 2), which derived its potency from atomic power. Chernus' contention is that after the Soviet Russia became nuclear bomb capable in 1949, American dominance in the political world could no longer solely rest on their nuclear power. Rather in this scenario "words became the fundamental [American] weapons" (Chernus 21) that constructed national security issues as permanent apocalyptic threats, pushing the nation into a state of incessant national insecurity. This process of using national security issues and constructing them within the binary of good or evil was influenced by Eisenhower's religious views of Augustinian realism leading to what Chernus terms as apocalypse management. 
While Chernus focuses on how nuclear discourses emerging from the military-industrial complex shaped American foreign policies, Alan Nadel highlights how this sense of national insecurity led to the subsequent culture of containment internally within the nation. Containment culture as "one of the most powerfully deployed national narratives" (Nadel 4) in recorded history, used the global Soviet Russia-US binary paradigm to create an $u s$ vs. them duality. This binary ideology was then introduced into every sphere of domestic existence: be it political allegiance, sexuality, race or ethnicity. Most importantly such a metanarrative of containment exhibited the power of national narratives to "contain, codify and intimidate" (Nadel 4) personal narratives, followed by the subsequent development of normative identities within the nation. Paul Williams points out that the understanding of nuclear weapons as white weaponsrepresentative of the "scientific achievements, military superiority" (Williams 23) of white civilization - was nowhere more evident than in the workings of containment culture. American identity was constructed as "white, heterosexual middle class, religious" (Williams 23) and this privileged narrative was impinged by the state through the process of constant repetition. The global influence of American nuclear discourses and policies - that privilege only certain identities and forms of knowledge about nuclear technology—have "preclude [d] the possibility of mutual, authentic and transformational dialogue between nuclear officials, citizens and the organized members of nuclear counter publics" (Taylor et al. 6) in other Nuclear Weapons States (NWS) as well. As a natural consequence nuclear historiography in both Anglo-American and postcolonial spheres equal the legitimation of specific state-sanctioned narratives about nuclear weapons and nuclear technologies.

Within the Anglo-American context, one of the fundamentals strategies through which a dominant nuclear historiography has been crafted and normalized is through nukespeak, a 
heavily gendered discourse that "renders nuclear topics palatable by associating them with personal, familiar, and innocuous [masculine] images" (Taylor and Kinsella 7). Through associating nuclear weapons with whiteness and masculinity that are master signifiers of privilege, nukespeak has successfully abstracted the problems - such as radiation illness faced by minority groups — while also granting only certain racialized and gendered bodies, the authority to expound on nuclear topics. This relationship between nuclear weapons and masculinity has also been a critical part of Russia's state historiography. In her essay "Masculinity in the Personal Narratives of Soviet Nuclear Physicists," Erica L. Fraser explicates how "complexities of masculine identities...both produced and were produced by, the Cold War (46). Echoing narratives from the Manhattan Project (discussed in Chapter 1), the personal narratives of male Soviet nuclear physicists "devote little space to their impressions of their women colleagues [while] they write at length about the men they worked" (Fraser 54). While the cessation of the Cold War and the breakdown of the U.S.S.R has meant that Russia's decidedly gendered nuclear historiography has been dispersed into multiple physical and discursive spaces, the relationship between nuclearization and masculinity is still a tangible part of Eastern European nuclear complexes (Fraser).

Beyond the sphere of Cold War adversaries, such linkages between militarization and gendered bodies have been both adopted and adapted within postcolonial nuclear spaces. Particularly for erstwhile-colonized nations like India who are now Nuclear Weapon States (NWS), crafting a dominant nuclear historiography has been seen as an integral part of resisting the colonial legacy of emasculation. Pertinently, performances of violent masculinity as indicative of the virility of the nation-state are not a new phenomenon within the domain of the Indian subcontinent. The partition of 1947 marked an event where the bodies of women were 
perceived as spaces for the inscription of masculine ideologies of religion and nationhood. But in contemporary times — especially since India's second nuclear tests in 1998—nuclearization and its associated discourses have become dominant sites for the performance of gender and religion. The resulting nuclear nationalism is deeply implicated within the ideologies of Hindu nationalism that is often "seen as a compensatory display of hypermasculinity in opposition to British colonialism's perception of Indian men as effeminate" (Williams 208) as well as a reaction against the purported lower position assigned to India within a discriminatory global nuclear order. Indian performances of radioactive masculinity are therefore contingent on the ideologies of nuclear nationalism - located within the larger tradition of Anglo-American nuclear historiography - that equates possessing nuclear weapons with a robust hypermasculine body politic.

Arising from the above premise, the first section of this chapter explores the development of nuclear historiography within the gendered structures of the American military-industrial complex. I emphasize how this tradition of masculinist nuclear historiography, developed in America during the post WW-II and Cold War period led to the development of civil defense propaganda and anticipated contemporary nuclear epistemic apparatuses like the aforementioned Nuclear Literacy Project. Secondly, I demonstrate how Anglo-American nuclear historiography leads to the development of atomic subalterns ${ }^{1 v i}$ and subsequently catalyzes the problematic construction of nuclear nationalism as a strategy of postcolonial resistance. Finally, through analyzing Indian non-fictional anti-nuclear texts I argue that they deconstruct the traditions of hegemonic nuclear historiography, which reinserts oppressive and hypermasculine modes of imperial domination into postcolonial India. By challenging the symbiotic relationship between radioactive masculinity and nuclear nationalism these texts initiate Nucliteracy - a dynamic 
multimodal form of literacy — that interrogates dominant and official publicity/secrecy about the bomb.

MASCULINITY AND MILITARIZATION IN AMERICAN NuCLEAR METANARRATIVES

We simply could not allow anyone over whom we did not have complete control to gain the overall, detailed knowledge...it was particularly important to keep such matters out of any magazine or newspaper that was likely to read by an enemy agent or anyone whose knowledge...would enable him to guess what was going on (my emphases; Groves 100).

One of the ways by which a scholarly discipline takes stock of itself is by considering its history.... [T]n order to write the history of any scholarly discipline or even a science one must be prepared to ask questions about it of the sort that do not have to be asked in the practice of it (White 81).

Production of nuclear historiography has never been a deliberate process. The shroud of secrecy surrounding the Manhattan project ensured that even after the conclusion of WW II, the American military-industrial complex remained inaccessible to the general public. The first official document that was released into the public sphere was the Smyth Report of August 1945 which explicitly declared, "[t]he average citizen cannot be expected to understand clearly how an atomic bomb is constructed or how it works but there is in this country a substantial group of engineers and scientists who can understand such things" ("Preface" Smyth Report). The implications of such a statement cannot be disregarded, as it clearly locates epistemic superiority in the "substantial group of engineers and scientists," who embodied the hypermasculine as well as the secretive nature of the military-industrial complex. On the other hand the escalating nuclear tensions between US and Soviet Russia ensured that nuclear historiography had to be 
consolidated in order for the discipline of nuclear technology as well as the NWS "to take stock of itself" (White 81). This section looks at the U. S. Strategic Bombing Survey: The Effects of the Atomic Bombings of Hiroshima and Nagasaki (1946) as representative of hegemonic documents produced during the Cold war period that perform a dual role within nuclear historiography: creating nuclear metanarratives while also initiating the elision of atomic subalterns from discursive domains.

While the Smyth Report released in 1945 was the first official American nuclear document to be released into the public sphere, efforts to craft a historical narrative "for planning the future development of the United States armed forces, and for determining future economic policies" had begun as early as 3 November 1944 (Strategic Bombing Survey 8). The committee that produced the Strategic Bombing Survey was launched through a "directive from the late President Roosevelt" (Foreword Strategic Bombing Survey ix) and was not designed to have any direct links with the military. In fact as the foreword notes:

[T] he civilian officials and directors of the survey have not undertaken to write a history of the Pacific war, nor to apportion credit for victory among the various component Allied forces. They have undertaken, as civilians, to present an analysis of the factual material gathered by the Survey and their general appraisal thereof as to the future (my emphases; Foreword Strategic Bombing Survey ix). However, the fact that over two-thirds of the committee's thousand members were serving [male] military personnel underlined both the militarized and masculinist underpinnings of such an endeavor. Even though the Strategic Bombing Survey was "established for the purpose of conducting an impartial and expert study" (Foreword Strategic Bombing Survey ix) of America's war efforts, the journalistic nature of the narration clearly puts into question the 
veracity of such an assertion. This is especially highlighted in the introduction that by constantly focusing on the strengths and successes of martial technologies and strategies gives away the celebration of American militarization, which formed the ideological basis of such a study:

How the original Japanese advance was stopped, how we achieved air superiority, at first locally, but subsequently more and more generally, and over areas deep within the one-time Japanese dominated areas, culminating finally in air supremacy over the Japanese home islands themselves, and how that air superiority was exploited (Strategic Bombing Survey 2).

In analyzing the Strategic Bomb Survey (and other documents in the same genre) Kenneth Werell asserts that

Although much has been written about the bombing [s], few studies merit either the term "analytical' or the term "scholarly." First person and journalistic accounts of derring-do predominate. Perhaps in no other field of history do so many feel and believe so much, rely on so little analysis and proof, and yet write so much (author's emphasis; 702).

Werell's assertion about such military histories is supported by Hayden White's analysis that "in general there has been a reluctance to consider historical narratives as what they most manifestly are: verbal fictions, the contents of which are as much invented as found" (82).

White's comment achieves particular credence within the domain of nuclear historiography where the myth of American epistemic and military superiority marks the ethos for a majority of the narratives. What seems rather surprising is the acceptance that documents like the Strategic Bombing Survey are based on hard facts, when the document clearly provides evidence of its fictive and ideologically motivated narration. Strategic Bombing Survey begins 
with a declaration that the document is an attempt to "reconstruct much of wartime Japanese military planning and execution [that led to the nuclear bombings] and to secure reasonably accurate data on Japanese economy and war production" (Strategic Bombing Survey ix). Paradoxically, the methodology of this survey is markedly suspect: a report about Japanese conditions completely discounts any Japanese or even American Civilian voices and is based only on interviews from the American Army and Navy, which not surprisingly provided "all possible assistance" (Strategic Bombing Survey ix). Reconstructing Japanese wartime history only through testimonies from the American military-industrial complex immediately foregrounds two key aspects of nuclear historiography. Firstly, it establishes that within American nuclear historiography only certain [male and militarized] identities are considered reliable sources. Secondly, by disallowing the presence of voices that could potentially question or contradict the [victorious] American metanarrative, it emphasizes the monologic and discriminatory nature of hegemonic nuclear discourses.

The impulse of metahistories to "gain part of their explanatory effect...by making stories out of mere chronicles" (White 83) is explicitly stated in Strategic Bombing Survey as the document purports to justify the US bombings of Japan by individually analyzing "engagement by engagement and campaign by campaign" (3). Of particular interest is the way the survey begins with a dramatic retelling of the Pearl Harbor incident:

The attack on Pearl Harbor was designed around surprise, the range of carrier task forces, and the power of aircraft to sink surface vessels. It was executed with the loss of 29 Japanese pilots... Allied air power in the Philippines, Malaya, and the Dutch East Indies was virtually eliminated, mostly on the ground, in a matter of days. Those enormous areas, once local allied air power had been eliminated, 
were laid open to occupation in a matter of weeks, at a cost of less than 15,000 Japanese soldiers killed, and with the loss from all causes in the entire campaign of 381 Japanese planes. (Strategic Bombing Survey 4).

In keeping with the tradition of hegemonic narration that conveniently elide certain sections in order to emphasize specific happenings, which support the victorious narrative, Strategic Bombing Survey creates a discernible binary between the supposedly "aggressive" Japanese forces and the "benign" Allied powers. The Japanese who allegedly "virtually eliminated" Allied air power in three countries, while suffering what was apparently "negligible loss", reflects White's claim that "the historical event does not reproduce events it describes; it tells us in what direction to think about the events" (91). Pertinently the use of Pearl Harbor-as an image of American suffering and resilience during that period - mirrors the construction of histories through mythos "which the historian has chosen to serve as the icon of the structure of events" (White 88).

Within this context, Pearl Harbor becomes a metaphor for the helpless American State in the period preceding the atomic bombings of Japan. The strategies adopted in crafting this document provide tell-tale indications of the specific lens through which the American militaryindustrial complex wanted the American population to perceive the events of Hiroshima and Nagasaki: as the act of a vulnerable (American) state against a powerful and ruthless adversary (Japan). Eric Berlatsky points out that such usage of metaphor "always refer[s] to something other than its perceived object... making stable and rigorous analysis impossible" (117). What can be explicated from Berlatsky's argument is the continual elision of the real-the unjustified

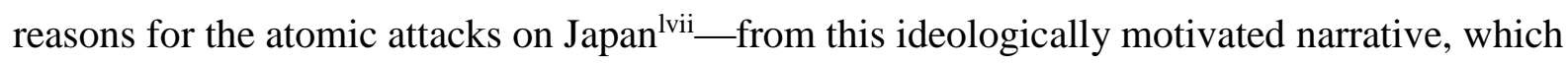


was aimed at justifying American [masculine] nuclear aggression and the deliberate creation of a binary between good (America) and evil (Japan).

The rhetoric of the paragraph quoted above needs to be explicated, especially its emphasis on the Japanese destruction of "enormous...Allied air power" at "cost of less than 15,000 Japanese soldiers killed." The particularly intriguing aspect being that the Japanese loss is quantified as "less than 15,000", while the allied loss gains an immeasurable qualitative status. The desired outcome of such language is not difficult to discern: the hegemonic historical imagination (White) is being transferred onto the nation's subjects who are being made complicit with the American military-industrial complex's reasoning, behind the nuclear bombings of Hiroshima and Nagasaki. The apparent threats against American sovereignty and masculinitynarrated in the Strategic Bombing Survey - consequently helped retrospectively justify both the use of nuclear weapons against Japan as well as the Cold War development of the American nuclear arsenal. Through using metaphoric language that elides Japanese civilian losses from the nuclear bombings (ranging between 150,000-300,000) and by conveniently replacing them with the (comparatively) smaller Japanese military losses, the American military-industrial complex induces for its audience a certain kind of memory of WW-II and of nuclear weapons.

This memory is simultaneously a creation and remembering of state-sanctioned nuclear historiography as well as a forgetting of the massacre accomplished by Fat Man and Little Boy in Hiroshima and Nagasaki. Such narrative strategies symbolize that "Memory cannot be easily opposed to forgetting since the former also involves selection, erasure, and elision for ideological purposes" (author's emphases; Berlatsky 3). Moreover ideological erasures within the Strategic Bombing Survey laid the groundwork for public nuclear discourses—such as Cold War civil defense propaganda as well as contemporary ventures like the Nuclear Literacy Project-that 
promote a specific literacy of the nuclear and reflect the ideological interests of its sponsors. It is pertinent here to reference Deborah Brandt's conceptualization of such "sponsors of literacy" that,

[a]re powerful figures who bankroll events or smooth the way for initiates. Usually richer, more knowledgeable, and more entrenched than the sponsored, sponsors nevertheless enter a reciprocal relationship with those they underwrite (557).

Recognizing the historical role of the American military-industrial complex as the primary sponsor and influencer of global nuclear discourse allows us to understand why there is fragmented knowledge and little contextual understanding of nuclear issues within the public sphere. Following the precedent set by the Strategic Bombing Survey, official nuclear discourses have been "typically dependent on the use of figurative elements such as metaphor (e.g. of containment), and on external discourses such as myth, religion ${ }^{\text {lviii }}$ and literature to sustain their authority and legitimacy” (author's emphases; Taylor and Kinsella 8).

The global epistemic shift due to the advent of nuclear weapons has now been well documented (Rey Chow; Virilio; De Landa). Unfortunately, what often remains undiscussed is that knowledge apparatuses emerging from the American military-industrial complex have not only irrevocably altered American life and culture but indeed global perceptions about nuclear weapons and nuclear technology. Current efforts like the Nuclear Literacy Project that spread hegemonic discourse about nuclearization — namely the benefits of nuclear technology and their importance for national progress - are not a new phenomenon. Wartime militarization along with peacetime knowledge production - involving disseminating particular forms of literacy about the nuclear-has always been an integral aim of the American military-industrial complex. The 
changing methodology for disseminating hegemonic nuclear discourses over the years, however, can be attributed to both the end of Cold War hostilities as well as successful anti-nuclearization movements across the world. I want to stress here that while the contexts for spreading nuclear discourse may be different across the world, all of them mirror the hegemonic interests of national sovereignty, which was pioneered by the American military-industrial complex. Such ideologies more often not result in the privileging of certain racial, sexual and gendered bodies. A potent example of the American military-industrial complex's partisan nuclear literacy would be the civil defense propaganda that was circulated by the FCDA (Federal Civil Defense Administration). The FCDA developed in 1950 under the stewardship of Milard Caldwell took over the responsibilities of civil defense from the National Security Resources Board (NSRB) and illustrated the specific racial imagination of the American military-industrial complex. The use of the first thermonuclear device Mike in 1952 saw the FCDA focusing specifically on conserving white suburbia, as the place where population regeneration would take place in case of a nuclear attack. Such policies were manifested through Jim Crow shelter rules, under which bomb shelters were constructed specifically for white suburban populations at the expense of other minorities. Urban centers that were possible targets of nuclear strikes (and had the majority of the African American population as well as other ethnic minorities) were deliberately neglected with the ideology being that a possible nuclear strike would result in ethnic cleansing and any regeneration would be primarily a white regeneration (Sharp; Williams MacCanell). Sharp highlights that:

Over the next ten years, the FCDA and its successor, the Office of Civil and Defense Mobilization, played a major role in shaping narratives about nuclear weapons...The FCDA's wartime model of propaganda involved a carefully 
orchestrated relationship with private sector media organizations...These supposedly independent media organizations helped disseminate strategic visions that envisioned the white suburban family as the hero of the nuclear frontier (my emphases; 187-88).

This combination of the private and public sector is an aspect that continues to be an integral part of the current American-Military industrial complex. For example The Nuclear Literacy Project's list of sponsors-National Museum of Nuclear Science \& History (America's only congressionally chartered museum in its field), the American Crane and Equipment Corporation which contracts with the government on nuclear engineering tasks as well as pro-nuclear technology media organizations like Atomic Insights and StratusFX Studios-illustrates the apparently eclectic, yet consistent nature of the American military-industrial complex from WWII till the current times (“About” nuclearliteracy.org).

One of the most prominent sections on the Nuclear Literacy Project website is their unit on Nuclear Tourism, which suggests that visiting "a nuclear museum or historical site is a great way to learn more about nuclear energy." The segment goes on to highlight various geographical areas in the US including the "Arco desert in beautiful southern Idaho [where] You can see 4 reactors including 2 aircraft propulsion prototypes, a reactor control room and an interactive remote handling devise." ("Nuclear Tourism" nuclearliteracy.org). Such an idyllic description of the Arco desert nuclear reactor site — maintained by the Idaho National Laboratory (INL) —elides the consistent problems with nuclear waste disposal that this project has created. As revealed in the infographic below produced by the Snake River Alliance - a body that has consistently campaigned against the practices of the INL—nuclear waste produced here has polluted the Snake River Aquifier: the sole source of drinking water for over 300,000 people as well as the 
"lifeblood of Idaho agriculture" (Snake River Alliance) This form of selective literacy about nuclear technology on the Nuclear Literacy Project website is again a reflection of how the American military-industrial complex has traditionally sponsored specific narratives about nuclear technology.

Pertinently the NLP website can trace its legacy back to documents like the Survival under Atomic Attack —one of the representative civil defense publications of the 1950's that was developed by the NSRB - , which similarly challenged "popular representations of the effects of the atomic bomb that sensationalized lingering radiation, mutation and social disintegration" (Sharp 188). Similarities between the carefully crafted rhetoric of Nuclear Tourism and the Survival under Atomic Attack handbook demonstrate how hegemonic nuclear discourse-across spatio-temporal epochs — refuses to acknowledge minority subjectivities who remain invisible in state-sponsored nuclear historiographies. 


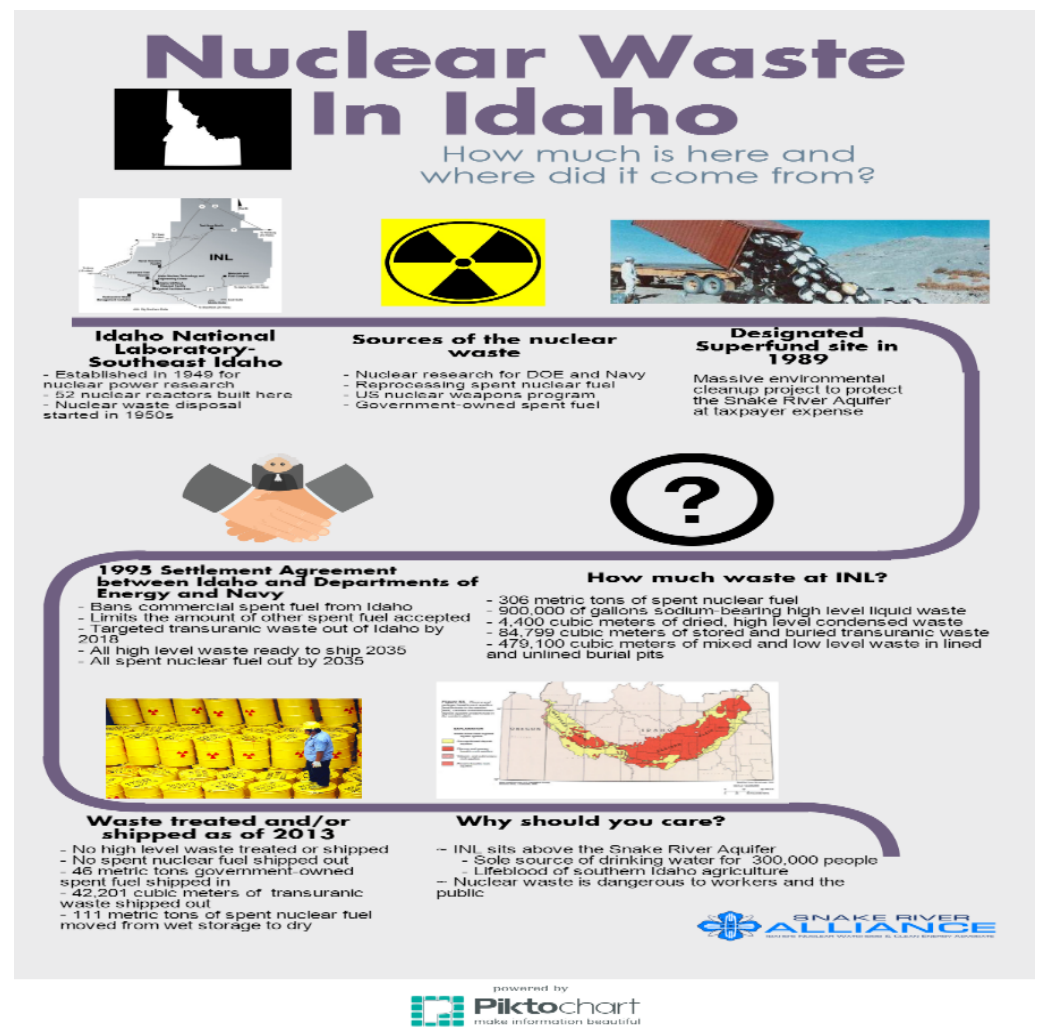

Figure 14: Poster circulated by the Snake River Alliance

These sort of discursive performances seen on the NLP website, which conveniently deny minority perspectives on nuclear technology, are a key aspect of the American military-industrial complex and are deeply entrenched in,

the paradigm of Techno-Performance [that] has emerged in the US since the Second World War....[t]he formative stages of Techno-Performance were engineered within the American Cold War apparatus...the military-industrialacademic complex (my emphases; McKenzie 12).

The key aspect of techno-performance is that all human performances and actions are understood in machinic terms and are judged on parameters of technological efficiency. McKenzie elucidates that the "Cold war marks a change in that all high performance devices [including humans] are modeled on the meta-model—computers or missile systems" (my emphases; 20). As 
a result humans are seen as socio-technical formations rather than desiring machines, which aligns with the structures of radioactive masculinity engendered within the American militaryindustrial complex. This dehumanization implicit in techno-performance finds reflection in hegemonic nuclear discourses — such as the NLP website-emerging from the American military-industrial complex. The NLP's assessment of the Arco desert nuclear reactor merely in terms of its productive potential — that will only benefit nuclear technology production — and is completely divorced from the human development problems, effectively epitomizes technoperformance in the contemporary era.

However, this paradigm of techno-performance can also be seen on the NLP website finds its historical basis within documents like the Strategic Bombing Survey, where a correlation is made between hypermasculinity, technological efficiency, and American national strength. Techno-performance accomplishes two equally important and allied functions in the Strategic Bombing Survey: the celebration of American hypermasculinity and the simultaneous elision of non-Western nations from nuclear historiography (McKenzie 12). One of the first indicators of techno-performance in Strategic Bombing Survey is the constant referral to Japan and its forces as "her allies" (28), as opposed to the United States military, which is either degendered or is represented through third person pronouns. Functioning within the Cold War paradigm of power and knowledge that equated hypermasculinity with a strong body politic, the producers of American nuclear metanarratives were unwilling to exhibit any forms of weakness. This ideology saw identification with femininity as a subtraction from the American potential for techno-performance and strategically feminized their adversaries - in order to evince American hypermasculine superiority. Critically, the Strategic Bombing Survey also forms a perfect example of the discursive performances that have since the Cold War period undertaken a 
continual elision of non-Western military powers. In the section entitled China-Burma-India (Strategic Bombing Survey 68) the document mentions how the atomic attack against Japan was a one-time measure that was "essential to defend India and assist China" (Strategic Bombing Survey 68), since the US was unable to "make substantial forces available" to these countries over a long-term period. Such explicit classification of both India and China as inferior military nations, who are arguably in need of constant rescue by American forces, reflects the very logic of colonialism implicit in nuclear discourses: the legitimizing of imperial presence through creating subaltern entities. The rhetoric reflects Spivak's theorization as to how subalterns are created: "the elites are the ones defining the subaltern consciousness" (11) and the subaltern consciousness is therefore negatively defined as opposed to the elite entity. It is therefore not difficult to discern, why having been constantly subjugated to such strategies of military and political elision, atomic subalterns like India and Pakistan perceived the nuclear bomb as the panacea for purchasing worldwide influence in the latter half of the twentieth century.

\section{REIFYING AMERICAN NUCLEAR HISTORIOGRAPHY: HOW ATOMIC SUBALTERNS STOPPED WORRYING AND}

\section{LEARNED TO LOVE THE RELIGIOUS BOMB}

The history of nuclear development has been profoundly shaped by the manipulation of information through official secrecy and extensive public-relation campaigns.”(“Introduction” Nukespeak xiv)

"The Buddha has smiled again": A single line transmitted to the Indian Prime Minister on 11 May 1998 had reinserted the Indian subcontinent within the sphere of global nuclear historiography. This cryptic message acknowledging India's first nuclear performance in 1974 when the Buddha had originally smiled — signified that Indian military-industry complex had successfully catalyzed the move from "Peaceful Nuclear Explosions" (PNE) to full thermonuclear capability. Within a matter of weeks the Pakistani Prime Minister responded with 
a televised speech declaring, "as a man he did not belong to a cowardly race" (my emphasis; War and Peace). This hypermasculine assertion was soon followed by a series of six underground nuclear explosions in Pakistan. Simultaneous with these hypersensory expressions of nuclear power by India and Pakistan, there arose a discursive arena within the national boundaries of both countries - the space of nuclear nationalism. A purported discriminatory global nuclear order meant that after the 1998 nuclear tests, the nuclear bomb was effectively propagated as an artifact for regenerating Indian nationalistic sentiments, which had once united them against British imperialistic forces. The nuclear bomb was constructed within the discursive domain of nuclear nationalism (that elided away the actual subaltern groups) as the symbolic as well as real referent of power, which could catapult India from its status as a lowly regarded atomic subaltern to a major player in global politics.

The abstraction of the nuclear bomb through a discursive framework was, however, not a new phenomenon. American and Soviet military-industrial complexes during the Cold War had successfully abstracted the destructive potential of the nuclear bomb by emphasizing the presence of the bomb as primarily a discursive entity (McCanles). Nuclear deterrence during this era - that was based upon the circulation of textual signifiers of power-between two power blocs also influenced constructions of the nuclear bomb in popular culture. This abstracted symbol of power was far removed from the tremendous weapon of mass destruction evidenced in Hiroshima and Nagasaki. Such cultural constructions of the bomb as a mode of symbolic power have arguably led to a failure of non-proliferation in many places - through an erasure of the "real" bomb in favor of a "memory" -and been achieved through "selection, erasure and elision for ideological purposes" (Berlatsky 3). Further such a memory of the bomb achieved through a forgetting of its pernicious history has consequently made it a lucrative artifact, for nations with 
colonial pasts. Euphoric joy, therefore, was the dominant popular reaction to the nuclear tests in both India and Pakistan since these nation-states have continually sought access to the material and discursive power offered by nuclearization, in the hopes of creating apparent postcolonial resistance against neo-colonialism. But most importantly the nuclear bomb was constructed in both India and Pakistan — two nations that have historically competed for subcontinental superiority — as the potent combination of religiosity and masculinity that would lead to increased global dominance.

In his essay "The BJP and the Bomb," Kanti Bajpai traces the historical reasons due to which the Indian government undertook the nuclear bomb tests in 1998. Bajpai argues that even though nuclear bomb tests are usually undertaken in the face of adverse national security situations, in actuality there are multiple complicated issues of nuclear politics involved. Bajpai points out that the Indian nuclear tests of 1998 were a unique moment in subcontinental history and was accelerated by three key factors. Firstly, the collapse of the Soviet Bloc at the end of the Cold War ensured that one of India's major allies in the diplomatic arena had been drastically weakened. India had thereby become much more vulnerable to adversarial approaches than it had been during the Cold War Era. The tests therefore were an assertion of power aimed at recasting the global political dynamic, which had become unfavorable toward the Indian polity. Secondly, the global pressure to sign the CTBT (Comprehensive Test Ban Treaty) and the move towards nuclear non-proliferation at the end of the Cold War implied that the 1990's would be India's last chance of attaining nuclear status (read global dominance). Thirdly, an ever strengthening alliance between China and Pakistan — both traditional political rivals of India—meant that it was necessary for India to exert its dominance in the geo-political scenario through the nuclear tests. 
Paradoxically, however, Bajpai asserts that the most important reason for the tests was not external but rather internal. The current Indian government led by the Bharatiya Janatiya Party (BJP), a Hindu nationalist organization who had come to power largely due to their religious and anti-Pakistani manifesto, were under increasing pressure from Western Allies (specifically the USA supporting Pakistan on major issues such as the Kashmir conflict) and catalyzed the nuclear tests. In view of such a scenario, it was necessary for the BJP government not only to assert its external dominance through the nuclear tests but also stay true to their religious ideology that had motivated their rise to power. It was therefore a natural progression that the Indian nuclear bomb would be constructed as a Hindu Bomb - an artifact that offered the combined potency of dominant Hinduism with the hypermasculine attributes of nuclear weapons.

Such forms of subcontinental nuclear nationalism that construct the nuclear bomb as religious are a naturally corollary to the political positioning of postcolonial nations like India and Pakistan: as atomic subalterns who were effectively elided out of global nuclear historiography before their performances as nuclear powers. India and Pakistan were trying to fit themselves within a hegemonic [American] paradigm of nuclear historiography where attaining NWS (Nuclear Weapons State) status is equated with the attainment of geo-political dominance. More importantly, within such a paradigm only knowledge and mastery of nuclear technology can guarantee "information and power [which is] conceived in terms of productive [nuclear] potential" (McKenzie 15). Paradoxically, this implied that the subcontinent was being taken ransom again to Western legitimations of certain forms of knowledge, a phenomenon that had characterized the colonial past of the Indian subcontinent. Therefore, nuclear nationalism, as a discursively constructed sphere, legitimized state-sanctioned nuclear historiographies through which the atomic explosions could be celebrated and not vilified. It was and has been a vital part 
of the project toward promoting the nuclear bomb as a religious artifact and is accomplished by exploiting the troubled communal past, between India and Pakistan since the Partition.

Before analyzing nuclear nationalism, it is vital to understand that the arguments about Indian nationalism espoused in Anglo-American scholarship - more specifically by Cambridge historians - which preceded the work of Indian historians. Such criticism claimed that Indian nationalism was merely a "rivalry between Indian and Indian, its relationship with imperialism that of the mutual clinging of two unsteady men of straw" (Locality Province and Nation 4). Opposing this stream of thought, Indian historians argued for Indian nationalism as a "regenerative force, as the antithesis of colonialism, something that united and produced an "Indian people" by mobilizing them for struggle against the British" (Habitations 6). This postcolonial model of historicism saw Indian nationalism as an indigenous all-encompassing movement where "the conflict of interest and ideology between the colonizers and the Indian people was the most important conflict of British India. All others-whether of class or castewere secondary to this principal contradictions" (Habitations 6). Considering the reductive perceptions of Indian nationalism within Anglo-American historiography it was hardly surprising when in wake of the 1998 nuclear tests, "[e]veryone, even the bitterest [Indian] critics of the decision to conduct the tests, joined the prime-minister in congratulating the scientists and technicians who had carried them out" (How we loved 1437). Such a celebration of the Indian military-industrial complex was however, not a mere celebration of scientific progress. As Subaltern Studies historian Partha Chatterjee emphasizes

[t]he sentiment [of nuclear nationalism] that swayed our political leaders was a different one [from that of traditional Indian nationalism] — that of science in the 
service of national interest...[and] flows out of the idea...that the greatest achievement of national science is to make weapons of war (my emphases; 1437).

Echoing Chatterjee's analysis, the then Indian Prime Minister Atal Behari Vajpayee claimed that "India's nuclear weapons [gave] India self-confidence" (Oza 105). The aforementioned lowly status of India within the global nuclear order-dominated largely by the American militaryindustrial complex - meant that the Indian nuclear tests were constructed (albeit falsely) as a "vicious criticism of US imperial control of nuclear weapons [and] drew together historic adversaries such as the Hindu Right and the Communist Party Of India-Marxist" (ibid). The nuclear bomb was seen as the final cog needed to escape the legacy of emasculation forced on India by British imperialism as well as effectively implement decolonization through challenging American neo-colonialism.

This form of "fetishized sovereignty" represented the "displacement of control of unstable political-economic conditions in the country onto demonstrations of militarized strength" (Oza 105). The Hindu Bomb was being loved and celebrated as the artifact which had unequivocally culminated dual postcolonial anxieties about effeminate native masculinity and underdeveloped scientific acumen. Unfortunately like the theorizations of Cambridge historians that essentialized Indian anti-colonial resistance, the discourses of nuclear nationalism suffered from the same privileged historiographical traditions. My inquiry into Patwardhan's War and Peace and Ghosh's Countdown in the following section explicates the subjectivity of the real atomic subalterns — namely the victims of nuclear tests and anti-nuclear activists—who were and are successfully elided away from the nuclear narratives legitimized by the state and its elite authoritarian agencies. Ghosh and Patwardhan's work, I argue inaugurate Nucliteracy; a 
multimodal discursive model where minority literature/cultural productions perform a postmodern critique of hegemonic nuclear historiography.

Will the Real Atomic Subaltern Please Stand Up? CritiQuing Nuclear Historiography through NUCLITERACY

A minor literature doesn't come from a minor language; it is rather that which a minority constructs within a major language (Deleuze and Guattari 1).

Postmodern history...is most likely to be also post historical in the sense [of] containing history as a significant moment, which may serve as a reminder of the power of history even in its negation ("Whither History? Encounters with Historicism, Postmodernism, Postcolonialism” 241).

On 15 May 1998, four days after the Indian became a thermonuclear power, the Indian Prime Minister Atal Behari Vajpayee—accompanied by colleagues from the Hindu nationalist party to which he was affiliated—visited the Pokhran desert range in Rajasthan, India. As the Indian Prime Minister commemorated this achievement by spreading flowers on the very crater left by the blasts, six kilometers away at the village of Khetoloi, the inhabitants were protesting the cancerous effects, of what had been defined as the crowning performance in Indian history. Significantly these protests at Khetoloi that had neither been acknowledged by the state authorities or the popular media, become the major thematic preoccupation of both Amitav Ghosh's non-fictional treatise Countdown and Anand Patwardhan's anti-nuclear documentary War and Peace. This section of the chapter explores these two texts that arose in the immediate aftermath of the nuclear tests as postmodern cultural signifiers of dissent within the hegemonic domain of nuclear nationalism. Since both texts cover a wide expanse of social, geographical and 
political ground, an analysis of both texts in their entirety is beyond the scope of this section. Instead, I would like to specifically focus on selected sections that perform a postmodern critique of nuclear nationalism and illustrate through an analysis of their representational strategies how these counter-cultural texts resist literacies of power: an "ideology that systematically negates the cultural experiences of many members of society - not only minorities but also anyone who is poor or disenfranchised" (Foreword Macedo). My analysis here categorizes "state-centered transcendent histories" ("Foreword" Habitations of Modernity) like nuclear historiography as being instrumental behind sponsoring such literacies of power.

Before delving into my conceptualization of nucliteracy it is important to understand and explicate the role of hegemonic nuclear discourses within society. Nuclear discourses are unique since the classification made between primary Discourses and secondary Discourses within literacy studies (Gee) cannot be applied to this epistemic model, without accounting for the overlap between them. A cursory overview might merit classifying nuclear discourse into the genre of secondary (dominant) discourses, "the mastery of which, at a particular place and time, brings with it the (potential) acquisition of social goods (money, prestige, status, etc)" (author's emphases; Gee 8). However, the profound influence of hegemonic nuclear discourses-in shaping the living conditions and social privileges of minority and disenfranchised populationsresonates with the definition of primary Discourse that "constitutes our original and home-based sense of identity... [and is acquired] by being a member of a primary socializing group (family, clan, peer group)" (Gee 12). The fact that aligning with certain specific knowledge and practices - embodied in literacies of power - that are sponsored by the military-industrial complex, can have significant impact on both our individual sense of identity and social positions, underlines the struggles of resisting such a framework. 
Therefore, in emphasizing Rey Chow's assertion of "the atomic bomb as an epistemic event," (26) I point out that resisting dominant discourse networks emerging from the bomb requires a democratic model of learning, which acknowledges multiple stakeholders and differing perspectives in the nuclear domain. The portmanteau term nucliteracy therefore, combines the words — nuclear and literacy — to emphasize the centrality of language within the world of nuclear weapons and nuclear technology, as well as the ability of such charged and potentially dangerous discourse to influence our everyday lives. Nucliteracy — a dynamic model of multimodal literacy_adds militarization and masculinity implicit within nuclear discourses as a level of analysis to the study of literacies and expands dominant perspectives on nuclear technology, by putting them into conversation with subjugated minority and indigenous viewpoints. As a model of postmodern critical pedagogy—Nucliteracy — hopes to dismantle epistemic systems emerging from the dominant perspective on nuclear weapons, which maintain social inequities and promote the hegemonic narrative of white supremacy and the technocapitalist state. (Macedo). Since the focus of literacy studies should "not be language, or literacy, but social practices" (Gee 7) I want to highlight how Ghosh and Patwardhan's works in recovering minority histories about nuclear technology epitomize the social practices constituting nucliteracy. War and Peace and Countdown echo both Deleuze and Guattari's introductory quote as well as Dipesh Chakrabarty's claims in "Minority History Subaltern Pasts", which foreground how majority histories are produced not due to the perpetuators having numerical superiority, but because of their ability to legitimize their own ideologies as the normative model. Whilst multiple critics and scholars have perceived the entire project of history creation as a EuroCentric project, it achieves particular resonance in reference to the project of subcontinental nuclear historiography. 
Anglo-American military-industrial complexes have continually delineated the domain for nuclear historiography as well as progressively defined the parameters, which influence the discursive exchanges within such a domain. Such moves have been legitimized through the logic "that compared to them the others were still minors for whom the adults of the world would have to take charge" (author's emphases; Chakrabarty 18). What is particularly interesting in tracing the lineage of these works is their relative obscurity within the sphere of postcolonial cultural texts. Both as an anthropologist as well as a literary figure, Amitav Ghosh's fictional as well as non-fictional writing has gained considerable global critical and popular acclaim. His status as a postcolonial author has also been institutionalized through the presence of a number of his works within the curricula of Indian universities. Surprisingly his 1999 non-fictional essay Countdown has been hardly discoursed upon within literary circles in India and abroad. On the other hand Patwardhan, unlike Ghosh, has always been a marginalized figure within the Indian cultural milieu. Although they share similar class and academic backgrounds - having been educated in prestigious European and American institutions_-Patwardhan's cinematic ventures have focused on controversial issues and have faced various levels of censorship within the Indian subcontinent. His documentary War and Peace released in 2002 was banned by the Indian Government in power (headed by the BJP) at that time, on charges of being seditious and was officially released in India only as late as 2005, after a protracted legal battle.

The historical background of these texts and their authors may not be atypical as they mirror the fate of numerous such texts that have been censored around the world. However, their background becomes particularly relevant within the hegemonic domain of nuclear historiography. Even before the reading population could perform an analysis of the texts and classify them as anti-nuclear, the pre/post publication politics associated with the two texts 
provide evidence of their works being constituted within the realm of minority history. The cultural and political silencing that was and is being continually practiced on these two texts, echo the strategies of majority history, which seeks to silence minority history that includes "in [it] the history of the nation, histories of groups previously excluded" (my emphases; Minority History 3). As works of nonfiction, the narratives discussed here are not artistically unique and follow the traditional forms of linear non-fictional narratives. But what provides them with a distinct postmodern aesthetic is that although the texts itself are attributed to singular authors, none of the narratives are from singular perspectives. Both texts amalgamate multiple nonfictional vantage points and encourage the audience to draw their own conclusions - a key facet missing from hegemonic literacies of power.

War and Peace begins with a provocative image of Mahatma Gandhi being assassinated by the Hindu fundamentalist Nathuram Godse. Patwardhan's voiceover narrates that even though his family was "deeply involved in the national struggle," the fact that they belonged to the same group of upper caste Hindus as Gandhi's murderer, “cured [him] forever of any narrow understanding of nation" (War and Peace). Patwardhan's opening gambit epitomizing nonviolent modes of Gandhian nationalism is immediately followed by the visual chronicling of a gathering celebrating the 1998 nuclear bomb blasts. The juxtaposition of two separate manifestations of nationalism provides clear indications of the unreliability of any such metanarrative. In this scene from the documentary the audience is shown a celebration of the nuclear tests performed by the Shiv Sena Party (Shiva's Army), who were coalition partners of the BJP government in power. 


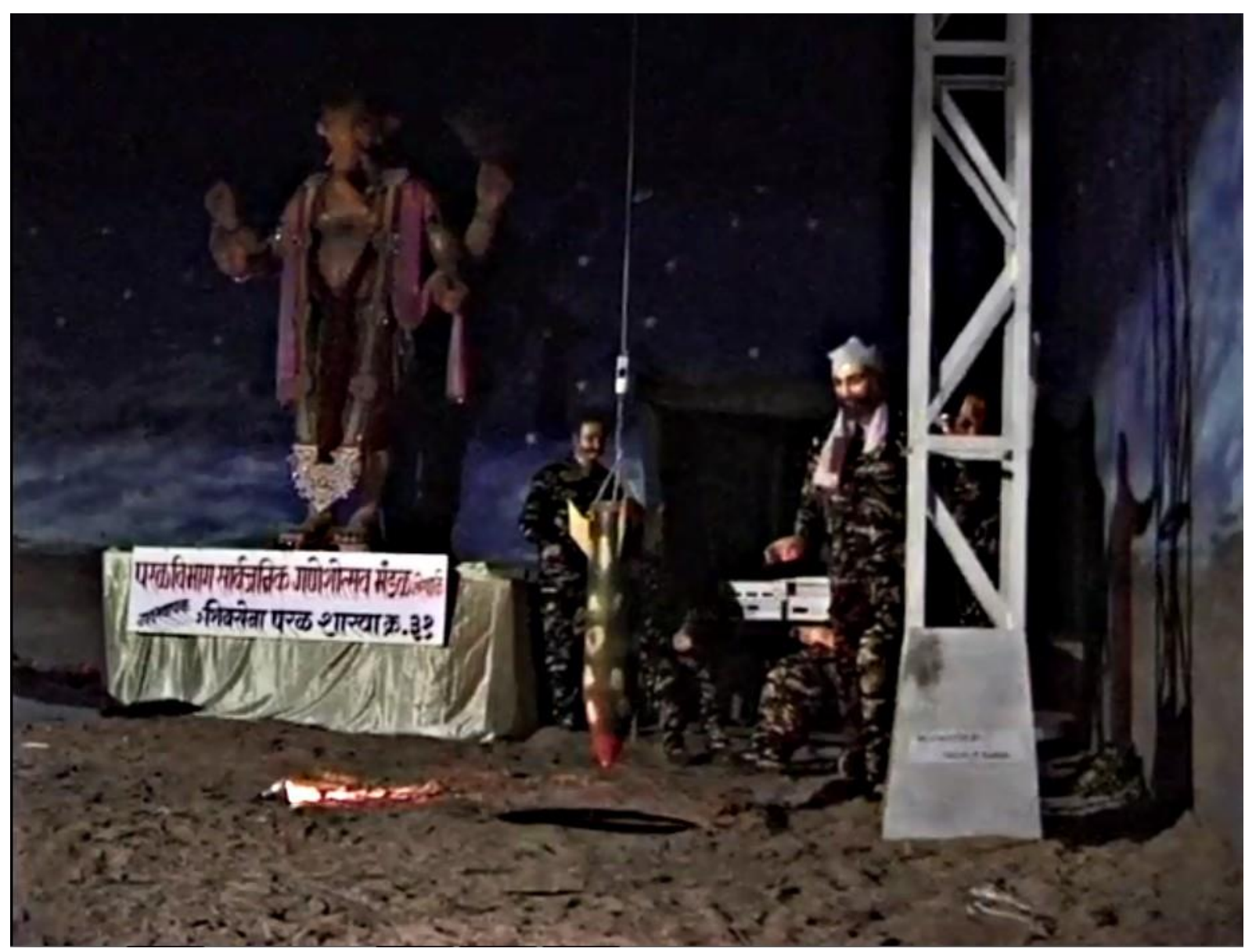

Figure 15: Lord Ganesha Festival in a Simulated Nuclear Test Range

Although, the celebrations seem to have been organized for the worship of Lord Ganesha, the idols as well as the religious symbols (including the Hindu "Om") are seen to have been placed within a simulated nuclear test range. The camera then pans on a theatrical performance within this religious event where a simulacrum of the nuclear tests is being conducted. The narrator of this theatrical event is heard chronicling the story "Just before the tests were to be conducted, a storm came and our scientists became worried. However, due to divine intervention, the storm subsided" (War and Peace). No such record of actual weather problems had been heard of during the Indian nuclear tests and the narrator of this diorama is clearly crafting a fictitious narrative: in order to explicitly fuse religiosity with the nuclear phenomenon (Mukherjee 3). Vitally, throughout this entire period as the camera chronicles the event, there is 
no voice-over from Patwardhan or any attempt to explain the visuals in the documentary. Phelan points out in Narrative Progression, that the way in which a narrative is structured depends on the methodologies used by the author to resolve the inherent instabilities between characters or discourses. Patwardhan's methodology in refusing to provide a metacommentary on how the Lord Ganesha festival unequivocally conflates and blurs the boundaries between Hindu Nationalism, Indian Nationalism and Nuclear Nationalism mirrors Phelan's argument that “all parts of a narrative may have consequences for progression, even if the consequences lie solely on the reader's understanding of the instabilities, resolution and tension" (Phelan 212). Patwardhan's documentary subtitled as "Non-Violence to Nuclear Nationalism” evinces the multiple connotations that hegemonic historiography grants to the words "nation" and “nationalism.” Specifically, Patwardhan points out how definitions of nationhood and nationalism are decided by privileged socio-economic categories. This implies that nuclear nationalism emerging in the wake of the nuclear tests belonged to and was legitimated by the participation of an elite group of empowered individuals.

What underlines the distinctly postmodern aesthetic of Patwardhan's documentary text is his reluctance to provide the audience with any explanatory tool. Such a tactic specifically challenges state-sanctioned nuclear historiography that "gains success in making stories out of mere chronicles" (White 92). Crucially, Patwardhan's documentary is the exact opposite of the drama that he is chronicling within his documentary. Unlike the creators of the theatrical simulacrum of nuclear tests, Patwardhan does not assume that his audience would be ignorant of the fictitious weather story. Shiva Sena's theatrical simulacrum in postcolonial India is a reenactment of colonial strategies, which would often provide fictitious narratives to its subjects in order to impinge a certain interpretation of a phenomenon. Patwardhan's reluctance to provide 
a narrative overview of such events indicates his disavowal of such strategies of representationcolonial and contemporary—and illustrates how signifiers of nuclear nationalism reinsert oppressive colonial practices within the postcolonial space.

A few scenes later Patwardhan captures the raucous celebrations of the nuclear tests by a group of Indian Hindu males outside the BJP's (ruling party) office in suburban Mumbai. As the group of youths slit their palms with a razor to sign their name in blood on a document supporting the nuclear tests, the audience hears the disembodied voice of Patwardhan asking some of the youth "Aren't you worried that if Pakistan launches a nuclear bomb, the target will be your city Mumbai, since it is the closest metropolis?" (War and Peace). The responses that he receives from the bomb supporters are comically uninformed and shallow. They range from "We have missiles that will detonate other missiles" and "We have new technologies" reflecting a false sense of masculine complacence, which emerges directly from nuclear nationalism. Immediately after, Patwardhan shifts his camera to a homeless woman who sits on a sidewalk near the celebrations and is oblivious to the chants of "Victory to India and Victory to Hinduism. India is the only nation that can conquer the world." (War and Peace). Patwardhan's tactics here in deliberately asking questions that are intended to elicit stock and comical reactions from the practitioners of nuclear nationalism, is evidently a method of postmodern parody where, "through a double process of installing and ironizing, parody signals how present representations come from past ones, what ideological consequences derive from both continuity and difference" (my emphases; Hutcheon 93). The representations of Indian radioactive masculinity in this clip are not dissimilar from those of colonial patriarchs in the early part of the 19th and 20th century. Belief in the inherent superiority of their particular gender and nationality—helped them forge ideologies of exploitation to be practiced on minority subjectivities. 
Patwardhan highlights the contingent association between Indian radioactive masculinity and nuclear nationalism, which symbolizes the Hindu nuclear bomb as an artifact of postcolonial resistance. However, ironically such patriotic sentiments are predicated on the same exploitative ideologies that lay at the basis of two hundred years of colonialism and contemporary neocolonialism. By focusing his camera on the homeless woman "who has a blank face of resignation and seems to be completely unconcerned about what is being said" (Mukherjee 16), Patwardhan reasserts to his audience that endorsements of nuclear nationalism completely ignore the tangible economic challenges faced by the Indian subcontinent along with the inconsequential nature of the nuclear project for the poor and unprivileged sections of the country. By demonstrating that actual forms of resistance "cannot be simply opposed to power, since such resistance is inevitably a power play" (my emphasis; Berlatsky 3), Patwardhan's documentary presents images of radioactive masculinity that are in reality immensely vulnerable: to both the ideologies of neo-colonialism and elitist historiography.

Amitav Ghosh's Countdown - although invested with a different form of objectivity than War and Peace — critiques similar elements of elitist nuclear historiography in order to deconstruct the material realities that are continually obscured in metanarratives of the state. Ghosh's effort to capture in writing, the euphoria that ensued in the name of nuclear nationalism, results in a literary work that is difficult to bracket within a specific genre of literature. While the form of the work is that of a non-fictional essay, there are long sections of oral history in the text where Ghosh interviews various individuals from different contexts, who are all connected by their involvement in the nuclear scenario. Throughout the text Ghosh carefully chooses not to comment on the feedback he receives, much in the manner of Patwardhan's documentary, evincing a distrust of metanarratives in the very methodology of his work. Ghosh's work leans 
towards the paradigm of oral history performances that "tends toward a self-consciously evenhanded, dialogue-oriented approach that is less invested in making focused, coherent arguments than in fostering further dialogue" (Claycomb 94). On the other hand the spatial trajectory that Ghosh uses is reminiscent of a travelogue, the only difference being that each of his travel destinations and the people he interviews are implicitly and explicitly connected with the nuclear bomb.

The narrative begins with Ghosh travelling to Khetoloi, a village six kilometers away from the Indian nuclear blast site, which has since 1974 (India's first nuclear test) been at the suffering end of Indian nuclear ambitions. On reaching Khetoloi Ghosh asserts:

Khetoloi was an unusual village.... almost everyone in the village was literate, women as well as men. They were Bishnois, members of a small religious sect whose founder had forbidden the felling of trees and killing of animals. They thought of themselves as the world's first conservationists (my emphases; 4).

Literacy, knowledge and the connotations of power associated with these concepts become a vital preoccupation for Ghosh (like Patwardhan) throughout Countdown, as is evidenced in the brief passage above. His references to the high literacy rates in Khetoloi are an important reminder that within the domain of nuclear historiography, it is only specific forms of knowledge that are legitimated. Thus even though the villagers are educated and articulate enough to voice their concerns regarding how the "effects of the tests... had been felt more severely here than anywhere else" (4), their existence outside the matrix of the Indian military-industrial complex keeps them relegated to their subaltern status. The implicit irony in the statement "they thought of themselves as the world's first conservationists" is unavoidable, as it highlights the 
paradoxical survival of the Bishnois: who as victims of radioactive colonization are unable to translate their philosophy of life-preservation into their own existence.

Ghosh's next interaction at Khetoloi is with a "very articulate" young man to whom the elders had handed the "burden of conversation" and who opines that "[T]he only people who benefit from the tests are the politicians...they bring no benefit to the country" (5). Following this exchange Ghosh remarks that "He (the young man) wouldn't give me his name and nor did I press him" (5) a process through which both the author (Ghosh) and his subject become part of the unreliable narration needed to counter totalizing state-sanctioned nuclear metanarratives. Ghosh's strategy in Countdown is not dissimilar to the one utilized by Salman Rushdie in Midnight's Children, where Rushdie "provides a central narrative and a series of disnarrated events, which he elsewhere labels "errata" because they reveal errors in the narrative" (Berlatsky 110). The central narrative in Countdown is undebatably a critique of nuclear nationalism, accomplished through the recovery of minority histories. Significantly the unreliability/"errata" that forms a critical part of Rushdie's work is derived in Ghosh's context, from the selected interviews that he crafts within the narrative. While the authenticity of the interview process is not in doubt, the contrary viewpoints of his interviewees providing dialectical perceptions of the same event (i.e. the nuclear tests), allows Ghosh to highlight the impossibility of a stable accurate nuclear historiography, which is claimed by official or institutional narratives.

Ghosh like Patwardhan refrains from taking a polemic stance on the politics of nuclearization. Instead he juxtaposes the Bishnoi individual's interview with that of K. Subhramanyam, "the strategic mastermind behind India's nuclear policies," who categorically asserts that "Nuclear Weapons acts like a million pound note...it is apparently of no use...But it buys you credit and that gives you the power to intimidate" (Ghosh 8). Subrahmanyam's rhetoric 
provides explicit proof of how radioactive masculinity functions within the Indian nuclear complex. As the chief architect of the Indian nuclear program, Subhramanyam epitomizes the Indian radioactive male who uses the currency of India's erstwhile colonial masters to talk about the intimidatory and colonizing power of the nuclear bomb. Further, in placing Subrahmanyam's diametrically opposed viewpoint on the nuclear bomb, right after the interview of the young Bishnoi man from Khetoloi, Ghosh offers the reader the opportunity to develop his/her own critique — reminding us of the inevitably ideological nature of all narratives.

This manipulation of facts performed by state agencies is also chronicled by Patwardhan in War and Peace as he interviews Dr. P.K. Iyengar, the head of the Bhabha Atomic Research Center in India who declares assuredly: "Touchwood we have had no problems, no casualties with our nuclear operations, both military and peaceful" (War and Peace). Following a similar strategy like Ghosh, Patwardhan contrasts Iyengar's statement with multiple testimonies of victims of uranium mining from Jadugoda, where India's uranium mines are located. Notably amongst the testimonies is one of Arjun Soren, a local doctor from Jadugoda who suffers from acute leukemia. When asked by Patwardhan what makes him sure that the uranium mines resulted in his cancer, Soren replies that he has lived all his live in a civilian locality, a kilometer away from the mines. Significantly, Soren's testimony is simultaneously juxtaposed with scenes from Iyengar's room, which is filled with awards and trophies that Iyengar has received for his national services. Such a visual montage suggests the Indian nuclear historiography's implicit role in ensuring the negligence of its civilian subjects as well as "Iyengar's manipulative defense of India's nuclear policy” (Mukherjee 19). Soren's testimony in War and Peace mirroring the views of the unnamed young man from Khetoloi in Countdown, underlines the invisible exploitation practiced by the state on its subaltern subjects. 
While atomic experts like Subhramanyam and Iyengar constantly exhort the nuclear tests as a necessary counter to India being perceived as an "object of the global [discriminatory] nuclear order" (Ghosh 8), Patwardhan and Ghosh highlight how Indian nuclear ambitions result in the oppression of the common populace, akin to colonial times. Through an acknowledgement of the other - the real atomic subaltern — who exists in the villages and rural areas beyond the military-industrial complex, their work questions the traditions of elitist nuclear historiography, which "privileges the national over the local, the urban over the rural, and the modern over the traditional" (author's emphases; Gadgil and Guha 35). While the central aim of both War and Peace and Countdown is undebatably a critique of nuclear historiography, Patwardhan and Ghosh are careful to eschew hegemonic traditions of "the sovereign subject as author, the subject of authority, legitimacy and power" (Spivak 7). Such critical practices are emblematic of what nucliteracy hopes to achieve. By providing the minority voices with agency and the ability to refuse being subsumed under "a singular discourse or narrative" (Berlatsky 35), the social practices embedded in nucliteracy hope to challenge strategies of nuclearization, which systematically elide the resistance of opposed subjectivities. 


\section{Epilogue}

In the early 90's, a wrestler called Bryan Clark exploded onto the World Wrestling Entertainment (then World Wrestling Federation) scene. Christening himself as Adam Bomb, this character was billed to be a survivor of the Three Mile Island nuclear meltdown accident. By combining the metaphorical power of the first man in the Biblical tradition with the claims of also being the only man to survive a nuclear fallout, Adam Bomb emphasized his status as the first among his wrestling equals. In keeping true to his created persona, Adam Bomb's signature move on winning a wrestling bout would be throwing rubber nuclear missiles at the audience. More recently, in February 2016, during the run-up to the American Presidential Primaries, the New York Times' columnist David Brooks declared in an opinion editorial entitled “Donald Trump Isn’t Real”:

$[$ T]his is an anxious and angry nation....Professional wrestling generates intense interest and drama through relentless confrontation....Trump brought this style onstage at the first Republican debate....Trump was unabashedly masculine, the lingua franca of pro wrestling (my emphases; Brooks).

Only two years before Trump's ascendance into the political limelight a similar rhetoric had pervaded the run-up to the Indian national elections. In 2014, India's current Prime Minister Narendra Modi — then contender-when asked about the country’s anxiety with a weakening currency had referenced his 56-inch "wrestler-like chest," as a prerequisite for strengthening the 21st century Indian economy. Donald Trump and Narendra Modi's co-opting of wrestling rhetoric — both in their political speech and actions — while seemingly removed from Bryan Clark's imbibition of the nuclear bomb's metaphorical strength into his own body, are connected 
by a vital thread. Such aggressive physical and verbal performances - in spaces separated by over 8000 miles — highlight how acquiring a "[hypermasculine] lingua franca" — dominates societal perceptions of real and perceived power. Although definitions of hypermasculinity are a constantly shifting terrain, performing such gendered capital undoubtedly remains the timetested method for capturing the attention of "anxious and angry [publics and] nations."

In foregrounding the associations between masculinity and nationhood, this study started out by considering the connections between nuclearization and violent performances of postcolonial masculinity. Before beginning this dissertation and during the process of research, I was particularly struck by the discursive gap in the field of postcolonial masculinity studies. With a few notable scholarly exceptions that have been published in the time between conceptualizing this project and its completion, there seems to be a genuine apathy toward discussing the postcolonial man. Interestingly, such a scholarly reluctance mirrors how the nuclear bomb has been successfully elided out of academic discussions and classrooms in postCold War America. It may be crucial here to point out that both the postcolonial man and the nuclear bomb reflect an apotheosis within the particular contexts where they emerged. The nuclear bomb — a symbolic pinnacle for Anglo-American modernity_emerged out of an unprecedented socio-political-scientific phenomenon that saw a conglomeration of the best and brightest minds in the Western hemisphere. Challenging nuclearization therefore often translates into challenging the Western tradition of reason and rationality that is "[seen as] a hallmark of our [Western] modern, democratic, liberal, critical, and scientific civilization" (Nemo 224). Similarly, any critique of postcolonial maleness is often deeply implicated within the fears that such a venture challenges the very tradition of decolonization, of which the rational postcolonial man is arguably both a product and an emissary. 
The definition and discussion of radioactive masculinity in this study has examined such attitudes of complacency, which while championing the case of a "rational society" often fail to accept that "our rational society contains strange inconsistencies" (my emphases; Nemo 224). Thus, while the progress of [nuclear] technology catalyzed through scientific inquiry is laudable, the disassociation created between its technological benefits and the allied human costs, remains a strange inconsistency within this paradigm of scientific rationality. The trajectory of my analysis in chronicling such inconsistencies across diverse spatio-temporal contexts, has led to the answering of some few key questions, while also leading to numerous new ones. For example, my critique of both American and Indian military-industrial complexes has underlined that the private interests of members from these privileged communities, often catalyze the inconsistencies in the narrative of nuclear technology. On the other hand, questions remain about how this strategic collusion between military-industrial complexes and the political establishment can be resisted without disrupting the sovereignty of a nation state? Such questions raised in this study have also underscored the importance of questioning concepts like sovereignty and nationhood in both scholarly and non-academic discussions.

While the end of Cold War hostilities has implied that apocalyptic tensions of a nuclear holocaust have understandably subsided, the world's nuclear arsenal continues to expand. As of 2016, there are approximately 15,350 nuclear warheads across the world and United States and Russia (FAS) own about 93 percent of those warheads. At the 2016 Nuclear Security Summit in Washington, D.C., global leaders also evinced concern at the aggressive nuclearization of China, India and Pakistan. These countries while laying claim only to a small percentage of the global nuclear arsenal are home to a staggering 40 percent of the world's population $(F A S)$. Pertinently, one of the key features of the 2016 summit was the focus on the dirty bomb - that combines 
radioactive material with conventional explosives — and the envisioning of potential threatening nuclear situations:

Saboteurs could breach a nuclear power station and start a reactor meltdown. A renegade Pakistani general could seize tactical nuclear weapons and blow up a city. Radioactive materials, which are found in many hospitals, could cause dirty bomb mayhem at an airport (Reinl).

This nuclear anxiety of a "renegade Pakistani General" seizing tactical atomic weapons is in fact the key motif of speculative novels Line of Control (2009) and Red Jihad (2012) that have been analyzed in this study. Unfortunately, the eerie clairvoyance of these cultural texts contrasts directly with their socio-political importance in the sphere of global nuclear politics.

This dissertation in recovering such arguably, "non-specialist" perspectives on nuclear weapons and nuclear technology, emphasizes that nuclearization is too important and pervasive a phenomenon, to be left only within the domain of the supposed specialists based within militaryindustrial complexes.

Not surprisingly, this critical approach is not new and films like Stanley Kubrick's Dr. Strangelove had critiqued the absurdity of Cold War nuclear deterrence based on concepts like Mutually Assured Destruction (M.A.D), as early as 1964. While the movie remains a cult classic warranting sure-shot inclusion in every American popular culture course, the political and social value of such texts has been forgotten. This is not in any little measure attributable to the systematic banalization of the nuclear apocalypse through its disturbing pervasiveness and familiarity in American Popular Culture.

This phenomenon is, however, not limited to the Anglo-American domain. Shortly after the Indian nuclear tests in 1998, a popular Indian tabloid brought out a cartoon showing the 
Elephant God Ganesha clutching India's new Viagra—the postcolonial bomb. In conflating religion, statecraft and dominant Hindu identity into one normative identity, the postcolonial bomb's perceived strength continues to influence processes of aggressive nuclearization in the Indian subcontinent. A 2011 ICAN (International Campaign to Abolish Nuclear Weapons) survey reports that India's nuclear budget has risen to $\$ 4.9$ billion dollars and ironically the same year a World Bank Survey found that 23.6 percent of India's population—276 million peoplelived on less than $\$ 1.25$ per day. These contrasting figures highlight the cost of nuclearization and the pervasive influence of nuclear budgets on the economically less fortunate in India. India mirrors the situation of many other Nuclear Weapons States: where nuclear policy matters continue to be debated within elite governmental and technocratic spheres, while the minority subjectivities that are at the receiving end of such economic and militarized decisions are rendered invisible.

Especially since the events of 9/11, a constant state of paranoia about the perceivable threats to a nation-state have also catalyzed fears of suitcase nukes - miniaturized nuclearpowered explosive devices—-being used in terror attacks. Such fears have also led to increased measures of militarization being adopted by nation-states and has arguably led to the further flattening of minority perspectives against aggressive state-sponsored military initiatives. One of the larger aims of this project has been to extrapolate how such strategies of militarization affect a nation-state's self-understanding of democracy, freedom of religious and sexual expression as well as the notions of citizenship. Unfortunately, the equation of nuclearization and militarization has received further impetus in a post 9/11 world due to the faceless nature of evil: requiring countries to be on a constant state of high alert, which also becomes "just another contributing factor in the planetary securing of capitalist mode of production, financialisation without borders, 
and the dogmatic protection of private property" ("State of Security" 22). This desire of nationstates to maintain their hegemonic status contrasting with their inability to do so in the face of radical extremism, as well as the rise of non-state power centers has created an untenable atmosphere: one where pacific discourses that question state-sponsored militarization are not only dismissed but often branded anti-national. Narratives from around the world that provide such examples of conflict between the aggressive (dominant) state and its pacific (minority) subjects, show how ideologies of containment - manifested during the Cold War - continue to affect the geo-political narrative of sovereign nations. Acknowledging the gendered ideologies of nuclearization is therefore the first step toward understanding the body burden - a medical term for the amount of radioactivity carried in the human body — always already accompanying weapons of mass destruction. While the total abolition of nuclear weapons may not be a feasible reality, actively questioning the motives of those who sponsor such devastating artifacts might be our only chance to avert the next major catastrophe. 


\section{Notes:}

${ }^{\mathrm{i}}$ The Partition of India was by far the most violent event in the Indian subcontinent. Within a "space of few months, about twelve million people moved between the new truncated India and the two wings East and West, of the newly created Pakistan...[S]laughter sometimes accompanied and sometimes prompted the movement; many others died from malnutrition and contagious diseases. Estimates of the dead vary from 200, 000 (the contemporary British figure) to two million (a later Indian estimate) (Butalia 3)

ii This is consistent with Suzzane Hatty's understanding of hegemonic masculinity as "aspirational, depicting fantasy or fictional characters whose attainments represent the extremes of socially approved masculine achievements" (117).

iiiThe books by these scholars have been referenced in the "Works Cited" section.

${ }^{\text {iv }}$ By which I denote both official and popular discourses about the bomb that have emerged in the North American context.

$v$ "The opening section of the journal entitled 'Proposal for a Diacritics Colloquium on Nuclear Criticism' established that 'critical theory ought to be making a more important contribution to the public discussion of nuclear issues' and proceeded to list a series of nuclear themes that required immediate consideration. Among these were an examination of the nuclear arms race and the 'dialectic of mimetic rivalry it provoked, 'the power of horror' and most pertinently 'the representation of nuclear war in the media as well as in the literary canon"' (Daley para 1). ${ }^{v i} \mathrm{http}: / / \mathrm{www}$.huffingtonpost.com/jim-luce/japans-pikadon-project-hi_b_443568.html

${ }^{\text {vii }}$ My source for accessing these documents was the online repository of documents related to the Indian nuclear program that has been developed by the Institute for Defense Studies and Analyses (IDSA) under the aegis of the Nuclear Proliferation International History Project (NPIHP), a derivative of the acclaimed Cold War International History Project (CWIHP), spearheaded by the Woodrow Wilson International Centre for Scholars, Washington, DC.

viii The term technostrategic discourse, central to discussions on the nuclear, was coined by Carol Cohn "to represent the intertwined, inextricable nature of technological and nuclear strategic thinking...to indicate the degree to which nuclear strategic language and thinking are imbued with, indeed constructed out of modes of thinking that are associated with technology" (Cohn 690).Technostrategic discourses that formulate "rational systems for dealing with the problems created by nuclear weapons" (author's emphases; Cohn 690) not only codify the threats of nuclear war but also reconfigure human bodies in reference to nuclear war scenarios. Humans in technostrategic discourses are understood as logistics or "standing reserve" that merely facilitate the production and sustenance of technological discourses.

${ }^{\text {ix }}$ A term I coin in this dissertation to denote non-Western countries with nuclear ambitions.

${ }^{x}$ I would like to point out here that the Self-Made Man has also existed in most European countries but in America with the lack of hereditary titles, it has been in existence since the very beginning.

${ }^{x i}$ In the larger book project I will highlight how Darwinist visions of gender played a role in this transformation of manhood and manliness into masculinity.

xii "Caroline Bird's description of the 12 year crisis as an 'invisible scar' fittingly illustrates that the depression profoundly marked the bodies of many Americans... while relatively few American actually starved to death, sickness and malnutrition increased dramatically, especially among the unemployed. Many unemployed workers were so malnourished that when they did receive work through New Deal programs or other sources, they had problems physically performing the same work they did before the depression. Nowhere is the story of American men's ill health ...than in... prewar and wartime rejection rates. Between November 1940 and August 1945, the Army rejected close to 6.5 million men, or 35.8 percent of the men they examined for military service" (Jarvis 19).

xiii Darwin's formulation of human evolution saw toolmakers (inventers) as the natural leaders of human civilization. "Man," the toolmaker was explicitly a construction of an ideal male, who literally had his fate in his own hands. This ideology was later fragmented into the masculinity of the scientist-inventor (like Oppenheimer) and the militarized male rugged (GI Joe), which two sides of the same Darwinist coin of masculinity. I am grateful to Dr. Patrick Sharp for adding this aspect to my analysis. 
${ }^{\text {xiv }}$ As I point out in the course of this study, Masters' conceptualization of the "cyborg soldier" as a technomasculine product of twentieth century American military discourse finds inception in the ideals of radioactive masculinity

${ }^{x v}$ Brian Easlea Fathering the Unthinkable (1987) and Julie Des Jardins The Madame Curie Complex (2010)

${ }^{x v i}$ The Manhattan Project was based out of multiple laboratories including over twenty sites directly and indirectly connected with the production of the bomb. It is therefore important to consider the project as a contested domain with multiple stakeholders, instead of the singular narrative of atomic development that it is often projected to be in official discourses. For a list of all the known sites that comprised The Manhattan Project look at: http://manhattanprojectvoices.org/locations

${ }^{x v i i}$ Brian Easlea, a physicist and historian, points out in his book Fathering the Unthinkable, metaphors of male birth and white male privilege were amply used during the Manhattan project evidencing the "masculinist bias steering the development of nuclear weapons" (Caputi 103). Easlea chronicles that a few days after the end of World War II, when Oppenheimer was asked about the motives that encouraged scientists on the Manhattan Project, he answered "it is good to turn over to mankind at large the greatest possible power to control the world." In analyzing Oppenheimer's comment Easlea wryly remarks "Turn over to mankind at large! Perhaps it is not irrelevant to bear in mind that Oppenheimer and the Los Alamos physicists turned over the bomb to a handful of very economically privileged and powerful White Male Americans" (96)

xviii“'[At] Los Alamos in 1945 as scientists struggled to produce the bomb before the war ended they took bets on whether they would produce a dud or a success - in their lingo, a 'girl' or a 'boy'. Their project was a success, and the bomb dropped on Hiroshima was nicknamed "Little Boy." The National Baby Association reacted to this birth/explosion by naming J.Robert Oppenheimer "Father of the Year." Oppenheimer remains the paradigmatic father figure in a select nuclear club that includes such men as Edward Teller, "father of the USH-bomb"; Glenn Seaborg, one of the "five fathers of plutonium"; Andrei Sakharov, "father of the Soviet H-bomb"; and Admiral Hyman B. Rickover, "father of America's" nuclear navy” (Caputi 103-104).

xix Alex Wellerstein notes: "We must beware, however, of a technological deterministic account of the bomb...the deterministic account of the bomb holds that its very fact necessitated certain types of political responses...differing accounts were simply ascribed to a lack of understanding of the bomb's true nature....this is of course not to suggest that there is no basic technical reality to nuclear weapons. But there is much to suggest that these technical realities have been historically less constraining of the visions of the bomb than the deterministic accounts would suggest, and that the realities of the bomb, both technical and political, were mutually and simultaneously developed (an instance of socio-technical "co-production)" (5).

${ }^{\mathbf{x}}$ It would however, be remiss to not note the irony of this situation, since the Manhattan Project came about largely due to the work of Jewish scientists, who had escaped Germany in fears of Hitler's racialized nationalism. Thus, while such male scientists of substantial intellect were averse to discriminatory discourses of race, their reactions to gendered spaces leaves a lot to be desired.

${ }^{\mathrm{xxi}}$ For example thirty percent of the work force at Los Alamos and nine percent of the workforce at Hanford were female. Women also worked extensively at both production and research sites at MIT, Minnesota, Rochester, Wisconsin as well as other universities across the country. (Jack 234; des Jardins 135)

xxii Source: http://manhattanprojectvoices.org/taxonomy/term/4

${ }^{x x i i i}$ Richard Koenisberg in commenting on this phenomenon in his essay The Human Body becomes a Body Politic argues:

"The individual's sense of smallness and limitations is overcome or denied through a psychic mechanism whereby one equates one's ego with an entire nation. Freud said that the ego is ultimately a body ego. Incorporation of the nation into the self, possesses a psychosomatic meaning. The entire nation becomes a part of one's body. One's body becomes a body politic."

${ }^{\text {xxiv }}$ It is vital here to acknowledge the work of the sociologist Joan Acker, who in her seminal essay HIERARCHIES, JOBS, BODIES: A Theory of Gendered Organizations (1990) pointed out that :

"organizational structure is not gender neutral; on the contrary, assumptions about gender underlie the documents and contracts used to construct organizations and to provide the commonsense ground for theorizing about them. Their gendered nature is partly masked through obscuring the embodied nature of work...Images of men 's bodies and masculinity pervade organizational processes, marginalizing women and contributing to the maintenance of gender segregation in organizations. The positing of gender-neutral 
and disembodied organizational structures and work relations is part of the larger strategy of control in industrial capitalist societies, which, at least partly, are built upon a deeply embedded substructure of gender difference."

Since the nuclear bomb has functioned as a vital rhetorical and discursive tool in the "industrial capitalist societies" that Acker mentions, it is only natural that an organization/institution meant to produce the bomb would create the exemplary template for such gender hierarchization.

${ }^{\mathrm{xxv}}$ I use here the terminology used by Jordynn Jack, from her essay referenced in the "Works Cited" Section. xxvi Postulated by Scott C. Zeman and Michael Amundson in their book Atomic Culture: How we learned to Stop Worrying and Love the Bomb. It might be pertinent here to briefly mention why these set of dates are critical towards the division of the Nuclear Age. Early Atomic Culture (1945-49) indicated the period between the bombings of Hiroshima and Nagasaki and the first nuclear bomb test by Soviet Russia in 1949. High Atomic Culture continued till 1963 which was the year when nuclear testing moved underground. Late Atomic Culture beginning in 1963 ended in 1991 with the breakdown of Soviet Russia and the purported end of the Cold-War.

xxvii Masco highlights that "Immanuel Kant offers two species of the sublime that informs nuclear weapons science: the dynamic sublime which is provoked by the terror of seeing a tornado or an erupting volcano from a safe distance, and the mathematical sublime, which begins with the inability to comprehend the scale and vastness of a mountain or a river" (my emphases; 351)

xxviii It is important to clarify here that weapons' production complexes do not denote merely the sites for the physical production of nuclear bombs but rather includes all those sites that represented important mergers of "scientific and institutional power" (Arjun Makhijani in Kinsella 14), essentially including all discursive sites that were involved in the development of the bomb.

${ }^{x x i x}$ As has been referenced in the previous chapter

xxx Some of these documents include:

i) John. F. Kennedy's commencement address at the American University in 1963

ii) John. F. Kennedy's address to the American people on the Nuclear Test ban Treaty,1963

iii) Robert McNamara's "Mutual Deterrence" Speech, 1967

xxxi The word apocalypse derives from the Greek apokalypsis which broken down literally connotes "lifting of the veil/away cover" connoting a new beginning or an end of time itself.(Rosen xiii)

xxxii In the last chapter of this dissertation, I classify all such texts--that contribute toward promoting transparent and unbiased knowledge about nuclear weapons--as being part of Nucliteracy: a nuclear literacy movement.

xxxiii It is apocryphally claimed that Merkin Muffley was modelled after the democratic leader Adlai Stevenson due to his passive nature. (Stillman; Burgess)

${ }^{x x x i v}$ Particularly evident in anti-nuclear productions created in India in the aftermath of the 1998 nuclear tests.

${ }^{x x x v}$ As has been traced in the last chapter, the nuclear bomb arising in the pre-ordained techno-masculine space of the Manhattan Project allowed for the rise of a new model of American maleness, radioactive masculinity-a coproduction between gender and technology — which shares a self-reflexive relationship with the immense power of the atomic artifact.

${ }^{x x x v i}$ Here I would like to draw attention to Bonnie Mann's Sovereign Masculinity, where a similar analysis of warbased masculinity takes place.

xxxvii This is due to the fact that the emergence of nuclear bombs did not occur simultaneously in America and India. India emerged as a nuclear power in 1974, almost three decades after the "Trinity "nuclear test conducted by America in 1945. Understandably, the cultural effects of the bomb while relevant to Indian subcontinental politics did not fully emerge within this geo-political space until after 1974. Some scholars argue that the year 1998, marks the actual watershed moment for the rise of subcontinental nuclear realpolitik due to the chain of nuclear bomb tests unleashed by India and Pakistan.

xxxviii For a detailed reading of the idea of secrecy in nuclear establishments, see Alex Wellerstein

xxxix As noted in the last chapter

${ }^{\mathrm{xl}}$ As noted in the last chapter:

Radioactive masculinity, as a very specific form of co-production emphasizes "the workings of science and technology cease to be a thing apart from other forms of social activity, but are integrated instead as indispensable elements in the process of societal evolution" (Jasanof 17). Since military technologies are not inherently gendered or "prediscursively masculine" (Masters 116) it is critical to understand the nature of this hegemonic militarized 
masculinity that I term as radioactive masculinity, as well as its self-reflexive relation with the nuclear bomb and the Manhattan project

${ }^{x l i}$ Like Paul Brians, David Dowling, Patrick Sharp and Paul Williams

xlii I have discussed in my previous chapter the relationship between masculinity and technology and the idea of gender as technology.

xliii "Canonical" nuclear disaster fiction is synonymous here with Anglo-American nuclear disaster fiction; a bias that is also reflected in the works of scholars such as David Dowling and Donald Hall. In the following chapter I point how postcolonial (Indian) speculative fiction challenges both the institutionalized status of Anglo-American nuclear disaster fiction and the radioactive masculinity implicit within it.

xliv I use here Squier's understanding of literature as a form of writing that is "1) associated with a certain class and sensibility, 2) restricted to imaginative works and 3) viewed as an important source of cultural and economic value" (134).

xlv This marginalization of native masculinity is consistent with Connell's hypothesis, where she asserts that in every societal structure, some forms of masculinity are more valued than others. This form of masculinity accrued with the greatest social capital is usually the hegemonic model of masculinity for that specific era or location. It is important here to underline that normative models of hegemonic masculinity are not always expressed in society through a direct manifestation of power-such as violence - but mostly through cultures, institutions and practices (Connell).

xlvi It is important to note here that the category "postcolonial speculative fiction" is a rather contested and debated term. Scholars have argued that since the terms "science fiction" and "speculative fiction" have a distinct colonialist history associated with them, they should be discarded in favor of a new term, one which specifically describes speculative literature from postcolonial nation states. Others have pointed out that since the tradition of speculative fiction was present in many colonized nations much before it became a popular genre in the Anglo-American sphere, there is indeed a need to take back the signifier by attaching it with emerging postcolonial speculative texts. As Jessica Langer notes that the power of postcolonial speculative fiction lies in its ability of not shying away from "colonial tropes" but rather "hybridiz[ing] them, parody[ing] them and/or mimic[ing] them against the grain in a play of Bhabhaian masquerade" (Langer 4). Many recent works including the texts discussed in this essay along with those anthologized in So Long Been Dreaming: Postcolonial Science Fiction \& Fantasy (2004) and We See a Different Frontier: A Postcolonial Speculative Fiction Anthology (2013) accomplish this task by using AngloAmerican tropes, which are then subverted and made to accomplish decolonizing objectives.

xlvii Modeled presumably on the Defense Research Development Organization

xlviii The notion of India as an essentially masculine nation where the larger nation is composed as a sum total of the male figures in the country is not a new concept. Sanjay Srivastava notes, that the project of Indian postcolonial modernity has been a set of Five Year (Hero) Plans much like the Five Year Economic Development Plans launched by the Planning Commission of India in the post-independence era. Srivastava points out that the masculine "hero" figures who have emerged under the FYP Hero plan embody are unequivocally heterosexual, and their manifestation has been through multiple embodied selves such as the Bollywood hero or the scientific intellectual. Of course the common threat that all these "hero" figures have hoped to counter is the "self-image of effeteness" that came to be "widely accepted among nineteenth century (Hindu) intelligentsia" (35). Therefore all these "figures"- the newest manifestation of which is the militarized postcolonial male as seen in these speculative works-aim to counter the anxiety that "Indians lacked manliness" (35).

xlix Bonnie Mann (2011) notes that in the post 9/11 era, this purported "War on Terror" was synonymous with the project of "reassert[ing] US national manhood that had played an important part in US politics since the humiliating defeat of the Vietnam War and that was reinvigorated by the events of 11 September 2001" (22).

${ }^{1}$ Manuel De Landa in his incisive study War in the Age of Intelligent Machines, notes that such reciprocal relationships emerging within Anglo-American military-industrial complexes have given rise to the ideology where "humans [are always already seen] as no more than the pieces of a larger military-industrial machine: a war machine" (3). In looking at war-games, which simulate martial situations that have no historical precedent—-such as nuclear war-De Landa remarks that the human participants in these exercises are continuously expected to minimize expected errors and thereby become more machine-like in their demeanor. De Landa's hypothesis written by keeping the Cold-War in context holds especially true for the current mode of technological warfare through unmanned aerial vehicles (UAV) and drones. Prospective military drone-controllers train themselves by practicing their skills on seemingly video games based in military settings. Additionally, the popularity of these seemingly 
innocuous military games amongst the civilian population where the gamer's gaze imitates the drone's eye and viceversa provides a striking example of our enmeshment within the military-industrial complex.

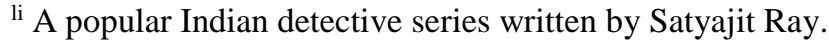

lii While the missile named Pralay is a fictionalized artifact in this novel its etymological roots presumably lie in the real-life INS Pralaya, a missile boat of the Indian Navy which served in the Indo-Pakistani war of 1971. More importantly, the word Pralay which in Sanskrit and Hindi connotes "catastrophe" is double entendre: signifying the apocalyptic nature of the weapon as well as the volatile nature of Indian militarized (and hegemonic) masculinity, which is contingent on this war technology.

liii Since they do make an attempt to interrogate the accepted traditions of Anglo-American future-war narratives.

liv I should note here that during my fieldwork I met with Bishnoi practitioners who were also highly educated and were professionals in the engineering or educational sectors. However, they are a distinct minority who no longer stay in the traditional Bishnoi villages and are largely unaffected by the day-today issue facing the larger Bishnoi community.

${ }^{\text {lv }}$ Here I refer to the categorization of William Labov who differentiates between natural and literary narratives. Labov notes that "A natural narrative will have an abstract, which explains the general purpose of telling the story; an orientation, which identifies the who, what, when and where of the story; a complicating action, the event from which the plot of the story begins; a resolution, the closure of the plot; an evaluation/reflection, the interpretation of the plot; and a coda, the indication that nothing else of relevance to the story happens after the story is complete...[a literary narrative on the other hand] manipulates the six elements of a natural narrative in some way. It may delete the abstract, evaluation or the coda to create space for the reader to fill in those elements according to their own interpretations" (

${ }^{\text {lvi }}$ A term I coin in this essay to denote postcolonial and non-Western nations with nuclear weapons and/or nuclear ambitions in a global nuclear order that is considered discriminatory and biased toward fulfilling the military objectives of Anglo-American nations.

lvii While the debate about the American decision to drop nuclear bombs on Japan continues, it is now accepted amongst historians and scholars that Japan was on the verge of surrendering to Allied Powers even without the nuclear bombings of Hiroshima and Nagasaki. A 2012 report from the Center for Strategic and International Studies (CSIS) underlines that "the declining situation already evident in Japan could have produced a similar decision to surrender without the use of the atomic bomb [...] (para 3 CSIS)

http://csis.org/blog/understanding-decision-drop-bomb-hiroshima-and-nagasaki

lviii As seen in Indian nuclear historiography to be discussed later in this chapter. 


\section{Works Cited:}

"Common Ground: German Photographic Cultures Across the Iron Curtain." Dr Sarah James. Web. 28 Mar. 2016.

“Citizen and Community." Rajasthan.gov.in. Government of Rajasthan. Web. 03 Apr. 2016.

"Environmental Cleanup at the Idaho National Lab - Snake River Alliance." Snake River Alliance. Web. 04 Apr. 2016.

"Pikadon." In Their Words. 2009. Web. 28 Mar. 2016.

"The Nuclear Weapon Archive." A Guide to Nuclear Weapons. Web. 28 Mar. 2016.

"The Relevance of Gender for Eliminating Weapons of Mass Destruction" Acronym Institute for Disarmament Diplomacy. Web. 28 Mar. 2016.

"The Atomic Archive." National Science Digital Library, Division of Undergraduate Education, National Science Foundation Grant. Web. 15 April, 2012.

"The Manhattan Project." Women. Atomic Heritage Foundation and the Los Alamos Historical Society. Web. 05 Apr. 2016.

Abraham, Itty. South Asian Cultures of the Bomb: Atomic Publics and the State in India. Bloomington: Indiana University Press, 2009. Print.

--."The ambivalence of nuclear histories." in "Global Power Knowledge," ed. John Krige and Kai-Henrik Barth, special issue, Osiris, 2nd ser., 21, no. 1 (2006): 49-65.

--. The Making of the Indian Atomic Bomb: Science, Secrecy and the Postcolonial State. London: Zed, 1998. Print.

Acheson, Ray. "Sex, Gender, and Nuclear Weapons." Wilpf.org.uk. The Women's International League for Peace and Freedom (WILPF). Web. 3 Mar. 2016.

Acker, J. "HIERARCHIES, JOBS, BODIES: A Theory of Gendered Organizations." Gender \& Society 4.2 (1990): 139-58. Web. 28 Mar. 2016.

Agel, J., ed. The Making of Kubrick's 2001. New York: Signet, 1970. Print.

Amis, Martin. Einstein's Monsters. New York: Vintage Books, 1990. Print.

Anderson, Eric. Inclusive Masculinity: The Changing Nature of Masculinities. New York: Routledge, 2009. Print.

Ariss, Bruce. Full Circle. New York: Avalon Books, 1963. Print. 
Asen, Robert and Daniel C. Brower. Ed. Counterpublics and the State. Albany: SUNY UP,2001. Print

Austgen, Suzanne M. "Leslie Marmon Silko's Ceremony and the Effects of White Contact on Pueblo Myth and Ritual." history.hanover.edu. Hanover College History Department. Web. 28 Mar. 2016.

Badash, Lawrence, Joseph O. Hirschfelder, and Herbert P. Broida. Reminiscences of Los Alamos, 1943-1945. Print.

Bajpai, Kanti. "The BJP and the Bomb." Inside Nuclear South Asia ed. Scott D. Sagan Stanford: Stanford Security Series/Stanford UP, 2009. 25-67. Print.

Barsamian, David, and Arundhati Roy. The Checkbook and the Cruise Missile: Conversations with Arundhati Roy. Cambridge, MA: South End, 2004. Print.

Basu, Anustup. "The State of Security and Warfare of Demons." Critical Quarterly 45.1-2 (2003): 11-32. Web. 4 Apr. 2016.

Basu, Samit. "Interview." The World SF Blog, 2010. Web. 4 June 2015.

Basu. Amrita and Rekha Basu. "India: Of men, women and bombs.” Dissent: Winter 1999, 3943. ProQuest Social Sciences Premium Collection. Web. 1 Mar. 2016.

Beidler, Philip. "Remembering “On the Beach.” War, Literature, and the Arts. Colorado Springs, CO: Dept. of English, United States Air Force Academy, 1990. pp. 370-382. Print.

Berlatsky, Eric. The Real, The True and The Told: Postmodern Historical Narrative and the Ethics of Representation. Columbus: Ohio State University Press, 2011. Print.

Boyer, Paul S. By the Bomb's Early Light: American Thought and Culture at the Dawn of the Atomic Age. New York: Pantheon, 1985. Print.

Blanchot, Maurice. "The Proper Use of SF." In Andrew Milner, Matthew Ryan and Robert Savage (eds.) Imagining the Future: Utopia and Dystopia. Melbourne: Arena Publications Association, 2006. 375-382. Print.

--. The Writing of the Disaster = (L'ecriture Du Désastre $)$. Lincoln: U of Nebraska, 1986. Print.

Brians, Paul. "Nuclear Family/Nuclear Wars." The Nightmare Considered: Critical Essays on Nuclear War Literature. Ed. Nancy Anisfield Bowling Green, OH: Bowling Green State U Popular, 1991. 151-159. Print.

--. Nuclear Holocausts: Atomic War in Fiction 1895-1984. Kent: Kent State University Press, 1987. Online Edition.

Brahmanand, Dr. Mahabalidan [The Great Sacrifice]. Ghaziabad, India: Sahitya Sansthan, 2013. Print. 
Brooks, David. "Donald Trump Isn't Real." Http://www.nytimes.com/. The New York Times, 2 Feb. 2016. Web. 30 Mar. 2016.

Burdick, Eugene, and Harvey Wheeler. Failsafe. New York: McGraw-Hill, 1962. Print.

Burgess, Jackson. “The ‘Anti-Militarism' of Stanley Kubrick.” Film Quarterly 18.1 (1964): 411. EBSCOhost. Web. 20 April 2012.

Burns, John F. "NUCLEAR ANXIETY: New Delhi Premier Indicates Resolve to Produce Nuclear Weapons." nytimes.com. New York Times, 16 May 1998. Web. 29 Mar. 2016.

Butalia, Urvashi. The Other Side of Silence: Voices from the Partition of India. Durham, NC: Duke UP, 2000. Print.

Calvert, M., \& Terry, J. Processed Lives: Gender and Technology. London: Routledge, 1997. Print

Canavan, Gerry and Priscilla Wald. "Preface-Special Issue on Speculative Fictions." American Literature. 83.2 (2011): 237-249. JSTOR. Web. 15 May 2015.

Carby, Hazel. "Postcolonial Translations.” Ethnic and Racial Studies 30.2 (2007): 213-234. Web. 15 May 2015.

Carrigan, Anthony. "Postcolonial Disaster, Pacific Nuclearization, And Disabling Environments." Journal of Literary and Cultural Disability Studies 4.3 (2010): 255-272. MLA International Bibliography. Web. 3 Apr. 2016.

Carroll, Hamilton. Affirmative Reaction: New Formations of White Masculinity. Durham, NC: Duke UP, 2011. Print.

Certeau, Michel De, Fredric Jameson, and Carl Lovitt. "On the Oppositional Practices of Everyday Life." Social Text 3 (1980): 3. Web. 28 Mar. 2016.

Chakrabarty, Dipesh. Habitations of Modernity: Essays in the wake of Subaltern Studies. Chicago: University of Chicago Press, 2002. Print.

--. "Minority Histories, Subaltern Pasts." Postcolonial Studies 1.1 (1998): 15-29. Academic Search Complete. Web. 3 Apr. 2016.

Chapple, Christopher. "Religious Environmentalism: Thomas Berry, The Bishnoi, And Satish Kumar." Dialog 50.4 (2011): 336-343. ATLA Religion Database with ATLASerials. Web. 3 Apr. 2016.

Chatterjee, Partha. "How We Loved the Bomb and Later Rued It". Economic and Political Weekly 33.24 (1998): 1437-1441. Web. 29 Mar. 2016. 
Chernus, Ira. Apocalypse Management: Eisenhower and the Discourse of National Insecurity. California: Stanford UP, 2008. Print.

Chow, Rey. The Age of World Target: Self-referentiality in War, Theory, and Comparative Work. Durham: Duke UP, 2006. Print.

Clark, Suzanne. Cold Warriors: Manliness on Trial in the Rhetoric of the West. Carbondale: Southern Illinois UP, 2000. Print.

Claycomb. Ryan. "Voices of the Other: Documentary and Oral History Performance in Post-9/11 British Theatre" Political and Protest Theatre after 9/11: Patriotic Dissent. Ed. Jenny Spencer. New York: Routledge, 2011. Print.

Cohn, Carol. "Sex and Death in the Rational World of Defense Intellectuals." Signs: Journal of Women in Culture and Society 12.4 (1987): 687-718. JSTOR. Web. 1 July 2012

Connell, R. W., and J.W. Messerschmidt. "Hegemonic Masculinity: Rethinking the Concept." Gender and Society.19 (6), 829-859. Web. 5 June 2015.

--. Masculinities. Berkeley and Los Angeles: University of California Press, 1995. Print.

Cooper, Ken. "The Whiteness of the Bomb." Postmodern Apocalypse: Theory and Cultural Practice at the End. Pennsylvania: University of Pennsylvania Press, 1995. 79-106. Print.

Cuordileone, K. A. Manhood and American Political Culture in the Cold War. New York: Routledge, 2005. Print.

--. "Politics in an Age of Anxiety': Cold War Political Culture and the Crisis in American Masculinity, 1949-1960". The Journal of American History 87.2 (2000): 515-545. Web. 28 Mar. 2016.

Dasgupta, R.K and K.M Gokulsingh. Masculinity and its Challenges in India. Jefferson, NC: McFarland, 2013. Print.

Daley, Christopher. "On Nuclear Criticism." Alluvium RSS. Department of English \& Humanities at Birkbeck, University of London. 2012. Web. 05 Apr. 2016.

Day 2: 10:00pm-11:00pm." 24. Fox. 4 March 2003. Television.

De Landa, Manuel. War in the Age of Intelligent Machines. New York: Zone Books, 1991. Print.

Delany, Samuel R. The Jewel Hinged Jaw: Notes on the Language of Science Fiction. Middletown: Wesleyan University Press, 1977. Print.

Deleuze, Giles, Félix Guattari and Robert Brinkley. "What is Minor Literature?" Mississippi Review 11.3 (Winter/Spring 1983). 13-33 Google Scholar. Web. 29 November 2012. 
Derrida, Jacques. "No Apocalypse, Not Now.” Diacritics 14.2 (1984): 20-31. JSTOR. Web. 1 July 2011.

DeLoughrey, Elizabeth. Heliotropes: Solar Ecologies and Pacific Radiations. In DeLoughrey and Handley. 235-253.

DeLoughrey, Elizabeth M., and George B. Handley. Postcolonial Ecologies: Literatures of the Environment. New York: Oxford UP, 2011. Print.

Desai, Shweta. "Forty Years after Pokhran Nuclear Tests, Villagers Complain of Frequent Cancer Deaths." Scroll.in. Scroll, 18 May 2014. Web. 03 Apr. 2016.

Dhar, Mainak. Line of Control. New Delhi: Vitasta Publishing, 2009. Print.

Dirlik, Arif. "Whither History? Encounters with Historism, Postmodernism, Postcolonialism" History after the Three Worlds. Ed. Arif Dirlik, Vinay Bahl and Peter Gran, Maryland: Rowman and Littlefield Publishers, 2000. 241-258. Print.

Donaldson, M, What Is Hegemonic Masculinity?, Theory and Society, Special Issue: Masculinities, October 1993, 22(5), 643-657.Web. 1 Mar. 2016.

Dowling, David. Fictions of Nuclear Disaster. Iowa City: U of Iowa, 1987. Print.

Dube, Saurabh, and Ishita Banerjee-Dube. Unbecoming Modern: Colonialism, Modernity, Colonial Modernities. New Delhi: Social Science, 2006. Print.

Easlea, Brian. Fathering the Unthinkable: Masculinity Scientists and the Nuclear Arms Race. London: Pluto Press, 1983. Print.

Evans, Joyce A. Celluloid Mushroom Clouds: Hollywood and the Atomic Bomb. Boulder, CO: Westview, 1998. Print.

Ewick, Patricia, and Susan S. Silbey. "Subversive Stories and Hegemonic Tales: Toward a Sociology of Narrative." Law \& Society Review 29.2 (1995): 197. Web. 2 Mar. 2016.

Foucault, Michel. Discipline and Punish: The Birth of the Prison. New York: Vintage, 1995. Print.

Francis, Gareth. "A Short and Curly History of the Merkin.” The Guardian. 25 June 2003. Web. 2 May 2012.

Frank, Pat. Alas, Babylon. London, Harper Modern Classics, 1959. Print.

--. Mr. Adam: A Novel. Philadelphia: J.B. Lippincott, 1946. Print.

Fraser, Erica L. "Masculinity in the Personal Narratives of Soviet Nuclear Physicists." Aspasia 8.1 (2014): 45-63. Web. 2 Mar. 2015. 
Gaddis, John Lewis. The Cold War: A New History. New York: Penguin, 2005. Print.

Gadgil M. \& Guha R. Ecology and Equity: The Use and Abuse of Nature in Contemporary India. London and New York: Routledge, 1995. Print.

Gannon, Charles. Rumors of War and Infernal Machines: Technomilitary Agenda-setting in American and British Speculative Fiction. Lanham: Rowland and Littlefield Publishers, 2005. Print.

Garrison, Jim. From Hiroshima to Harrisburg: The Unholy Alliance. New York: SCM, 1980. Print.

Gee, James Paul. "Literacy, Discourse, and Linguistics: Introduction." Journal of Education 171.1 (1989): 5-17. Web. 04 Apr. 2016.

Ghazoul, Ferial J. "Comparative Literature as a Phoenix." Rev. of Death of a Discipline. HGender-MidEast. June 2003. Web. 3 July 2015.

Ghosh, Amitav. Countdown. New Delhi: Penguin Books, 199. Print.

Gill, R.B. "The Uses of Genre and the Classification of Speculative Fiction." Mosaic 46.2 (June 2013): 71-86. EBSCOHost. Web. 20 May 2015.

Groves, Leslie. R. Now It Can Be Told: The Story Of The Manhattan Project. Amazon Digital Prints: Da Capo Press, 2009. Print.

Habermas, Jürgen. "The Public Sphere: An Encyclopedia Article" New German Critique 3.1 (1974): 49:55. JSTOR. Web. 15 April, 2012.

Harding, Sandra G. The Science Question in Feminism. Ithaca: Cornell UP, 1986. Print.

Hatty, Suzanne. Masculinities, Violence and Culture. Thousand Oaks: Sage Publications, 2000. Print.

Hershey, John. Hiroshima. London: Vintage, 1946. Print.

Hilgartner, Stephen, Richard Bell and Rory O'Connor.Ed. Nukespeak: The Selling of Nuclear Technology from the Manhattan Project to Fukushima. San Francisco: Sierra Club Books, 2011. Print.

Hogan, Michael J. A Cross of Iron: Harry S. Truman and the Origins of the National Security State, 1945-1954. Cambridge, U.K.: Cambridge UP, 2000. Print.

Hooper, Charlotte. Manly States. New York: Columbia University Press, 2001. Print.

Hostetter, Robert. "Review of Nuclear Holocausts: Atomic War in Fiction, 1895-1984." Bulletin of the Atomic Scientists 43.10 (1987): 45-48. Web. 28 Mar. 2016.

Howson, Richard. Challenging Hegemonic Masculinity. London: Routledge, 2006. Print. 
Hughes, Jeff. The Manhattan Project: Big Science and the Atom Bomb. New York: Columbia UP, 2002. Print.

Hutcheon, Linda. The Politics of Postmodernism. London: Routledge, 1998. Print.

IDSA's Nuclear History Project. idsa.in. Institute for Defense Studies and Analyses. Web. 29 Mar 2014.

"India: Achievements and Challenges in Reducing Poverty." web.worldbank.org. The World Bank, 2011. Web. 04 Apr. 2016.

Jack, Jordynn. "Space, Time, Memory: Gendered Recollections of Wartime Los Alamos." Rhetoric Society Quarterly 37.3 (2007): 229-50. Web. 1 July 2014.

Jacobs, Connie A. "A Toxic Legacy: Stories of Jackpile Mine." American Indian Culture and Research Journal 28.1 (2004): 41-52. Web. 03 Feb. 2016.

Jain, Pankaj. "The Bishnoi: An Ecotheological Community in the Indian Desert." Journal of Vaishnava Studies 19.1 (2010): 58-70. Google Scholar. Web. 1 July 2014.

Jardins, Julie Des. The Madame Curie Complex: The Hidden History of Women in Science. New York: The Feminist Press at CUNY, 2010. Print.

Jarvis, Christina. The Male Body at War: American Masculinity during World War II. Dekalb: Northern Illinois University Press, 2010. Print.

Jasanoff, Sheila."The idiom of co-production."States of Knowledge: The Co-production of Science and Social Order.Ed. Sheila. Jasanoff London: Routledge, 2004. Print.

Jette, Eleanor. Inside Box 1663. Los Alamos, NM: Los Alamos Historical Society, 1977. Print.

Johnson, T. R., ed. Teaching Composition: Background Readings. New York, NY: Bedford/St. Martins, 2008. Print.

Dinerstein, Joel. "Technology and Its Discontents: On the Verge of the Posthuman." American Quarterly 58.3 (2006): 569-595. Project MUSE. Web. 12 Jun. 2015.

Kabesh, Amal. Postcolonial Masculinities: Emotions, Histories and Ethics. London: Routledge, 2013. Print.

Khan, Sami Ahmad. Red Jihad. New Delhi: Rupa Publications, 2012.Print.

Kiernan, Denise. The Girls of Atomic City: The Untold Story of the Women Who Helped Win World War II. New York, NY: Simon \& Schuster, 2013. Print.

Kimmel, Michael. Manhood in America: A Cultural History. Oxford: Oxford University Press, 2011. Print. 
Kinsella, William J. and Jay Mullen. "Becoming Hanford Downwinders: Producing Community and Challenging Discursive Containment." Taylor et al. 73-107.

Krishna, Sankaran. "The Social Life of a Bomb and the "Ontology" of an Overpopulated Society."Abraham. 68-88. Print.

Kristensen, Hans M., and Robert S. Norris. "Status of World Nuclear Forces." Http://fas.org/. Federation of American Scientists, 2016. Web. 04 Apr. 2016.

Kumar, Manish. "Narendra Modi's Talk of '56-inch Chest' Draws Acerbic Response from Sharad Yadav." Ndtv.com/. NDTV, 24 Jan. 2014. Web. 4 Apr. 2016.

Labov, William. "Some Further Steps in Narrative Analysis." JNLH Journal of Narrative and Life History 7.1-4 (1997): 395-415. Web. 03 Apr. 2016.

Langer, Jessica. Postcolonialism and Science Fiction. London: Palgrave Macmillan, 2011. Print.

Laurence, William Leonard. Dawn over Zero: The Story of the Atomic Bomb. New York: A.A. Knopf, 1946. Print.

Leibovitz, Liel, and Matthew I. Miller. Lili Marlene: The Soldiers' Song of World War II. New York: W.W. Norton, 2009. Print.

Libby, Leona Marshall. The Uranium People. New York: Crane, Russak, 1979. Print.

Lifton, Robert Jay, and Nicholas Humphrey. In a Dark Time. Cambridge, MA: Harvard UP, 1984. Print.

Lindley, Dan. “Guide to Stanley Kubrick's Dr.Strangelove.” Political Science and Politics 34.3 (2001):33.9 (Feb. 28 - Mar. 6, 1998). 473-479. JSTOR. Web. 6 November 2012.

Lohan M. and Wendy Faulkner. "Masculinities and technologies: some introductory remarks." Men Masculinities. 6 (4), 319-329. JSTOR. Web. 3 June 2015.

Macaulay, Thomas Babington, John Leonard Clive, and Thomas Pinney. Selected Writings. Chicago: U of Chicago, 1972. Print.

MacCannell, Dean. "Baltimore in the Morning... After: On the Forms of Post-nuclear Leadership". Diacritics 14.2 (1984): 33-46. Web. 4 April 2016.

Maclean, Fitzroy. Eastern Approaches. London: J. Cape, 1949. Print.

Macedo, Donaldo P. Literacies of Power: What Americans Are Not Allowed to Know. Boulder: Westview, 1994. Print.

Mann, Bonnie. Sovereign Masculinity: Gender Lessons from the War on Terror. New York: Oxford UP, 2013. Print. 
--. “The Gender Apparatus: Torture and National Manhood in the US 'War on Terror'," Radical Philosophy. 168 (1), 22-32. Web. 3 June 2015.

Marshak, Ruth. "Secret City” Chapter in Wilson and Serber. np.

Masco, Joseph. The Nuclear Borderlands: The Manhattan Project in Post-Cold War New Mexico. Princeton: Princeton University Press, 2006. Print.

--"Nuclear Technoaesthetics: Sensory Politics from Trinity to the Virtual Bomb in Los Alamos." American Ethnologist. 31.3 (2004): 349-373. JSTOR. Web. 2 February, 2012.

---."The Billboard Campaign: The Los Alamos Study Group and the Nuclear Public Sphere." Public Culture 17.3 (2005): 487-98. Web.

---. "The Nuclear Public Sphere." Ethnografeast III- Ethnography and the Public Sphere, Lisbon Portugal. 20-23 June, 2007. Conference Paper.

Masters, Cristina. "Bodies of Technology.” International Journal of Feminist Politics 7.1 (2015): 112-132. JSTOR. Web. 15 April 2015.

May, Elaine Tyler. Homeward Bound: American Families in the Cold War Era. New York: Basic, 1988. Print.

McCanles Michael. "Machiavelli and the Paradoxes of Deterrence." Diacritics 14.2 (1984): 1119. JSTOR. Web. 1 July 2011

McKenzie, Jon. Perform or Else. London: Routledge, 2001. Print.

Meyer, Steven. "Work, Play, and Power: Masculine Culture on the Automotive Shop Floor, 1930-1960," in Boys and Their Toys? Masculinity, Technology, and Class in America. Ed. Roger Horowitz. New York: Routledge, 2001.Print.

Morse, Donald E. Anatomy of Science Fiction. Newcastle: Cambridge Scholars, 2006. Print.

Mukherjee, Rahul. "Contesting the Discourse of Nuclear Nationalism: Seeing Connections and Identifications in Anand Patwardhan's "Jung Aur Aman” Diss. University of California, Santa Barbara. N.d. ProQuest. Web. 1 December 2012.

Mulvey, Laura. "Visual Pleasure and Narrative Cinema." Narrative, Apparatus, Ideology: A Film Theory Reader Ed. Philip Rosen. New York: Columbia University Press - 1986. Print.

Musial, Joe. Learn How Dagwood Splits the Atom. Prepared with the Scientific Advise of Lt. Gen. Leslie R. Groves, Dr. John R. Dunning, Dr.Louis M. Heil. New York: King Features Syndicate, 1949. Print.

Nadel, Alan. Containment Culture: American Narratives, Postmodernism, and the Atomic Age. Durham: Duke University Press, 1995. Print. 
Nemo, Phillippe. "The Invention of Western Reason." Rationality and Irrationality. Proc. of 23rd International Wittgenstein-Symposium, Kirchberg Am Wechsel, Austria. Vol. 29. Verlagsgesellschaft MbH \& KG, Vienna. 224-41. Print.

"Nuclear Tourism." Nuclear Literacy. Nuclear Literacy Project, 12 Jan. 2012. Web. 06 Mar. 2016.

Nye, David E. American Technological Sublime. New Baskerville, MIT Press, 1990. Print.

O'Neill, Dan. The Firecracker Boys. New York: St. Martin's, 1994. Print.

Oza, Rupal. The Making of Neoliberal India: Nationalism, Gender, and the Paradoxes of Globalization. New York: Routledge, 2006. Print.

Patwardhan, Anand. Dir. War and Peace. Anand Patwardhan, 2002. Film.

Phelan, James. "Narrative Progression." Narrative Dynamics: Essays On Time, Plot, Closure, And Frame. Ed. Brian Richardson. Columbus, Ohio: Ohio State UP, 2002. 211-216. Print.

Prakash, Gyan. Another Reason: Science and the Imagination of Modern India. Princeton: Princeton University Press, 1999. Print.

Ramana, M.V. "Bombing Bombay? Effects of Nuclear Weapons and a Case Study of a Hypothetical Explosion." Security Studies Program, Center for International Studies Massachusetts Institute of Technology, 1999. Web. 5 May 2015.

Reed, T. V. The Art of Protest: Culture and Activism from the Civil Rights Movement to the Streets of Seattle. Minneapolis: U of Minnesota, 2005. Print.

Reinl, James. "Nuclear Security Summit to Focus on Dirty Bomb Scenario." Aljazeera.com. Al Jazeera, 31 Mar. 2016. Web. 1 Apr. 2016.

Rosen, Elizabeth K. Apocalyptic Transformation: Apocalypse and the Postmodern Imagination. Plymouth: Lexington Books, 2008. Print.

Roy, Arundhati. "The End of Imagination.” Out of the Nuclear Shadow Ed. By Smitu Kothari and Zia Mian New York: Palgrave, 2001. 51-70. Print.

Ruthven, Ken K. Nuclear Criticism. Carlton, Vic.: Melbourne UP, 1993. Print.

Said, Edward W. Culture and Imperialism. New York: Knopf, 1993. Print.

Sachs, Aaron. Eco-justice: Linking Human Rights and the Environment. Washington, DC: World watch Institute, 1995. Print. 
Seal, Anil. "Imperialism and Nationalism in India." Locality, Province and Nation: Essays on Indian Politics 1870 to 1940. Ed. Jonathan Gallagher, Gordon Johnson and Anil Seal. Cambridge: Cambridge UP, 1973. 1-28. Print

Seth, Suman. "Putting Knowledge in Its Place: Science, Colonialism, and the Postcolonial." Postcolonial Studies 12.4 (2009): 373-88. Web. 03 Apr. 2016.

Sharp, Patrick B. Savage Perils: Racial Frontiers and Nuclear Apocalypse in American Culture. Norman: U of Oklahoma, 2007. Print.

--."Questing for an Indigenous Future: Leslie Marmon Silko's Ceremony as Indigenous Science Fiction." Black and Brown Planets: The Politics of Race in Science Fiction Hardcover. Ed. Isiah Lavender. Jackson: U of Mississippi, 2014. Print.

Shute, Neville. On the Beach. New York: Vintage, 1957. Print.

Silko, Leslie Marmon. Ceremony. New York: Penguin Books, 1977. Print.

Sinha, Mrinalini. "Giving Masculinity A History: Some Contributions From The Historiography Of Colonial India." Gender \& History 11.3 (1999): 445.Academic Search Complete. Web. 29 Mar. 2016.

Smyth, H.D. The Smyth Report: Atomic Energy for Military Purposes. York, Pennsylvania: Maple Press, 1945. Print.

Sontag, Susan. Illness as Metaphor and Aids and Its Metaphors. London: Penguin, 2002. Print.

--. "The Imagination of Disaster." Against Interpretation and Other Essays. New York: Dell, 1979. 209-25. Print.

Southern, Terry. "Strangelove Outtake: Notes from the War Room" Grand Street 49.1 (1994): 64-80. EBSCOhost. Web. 20 April. 2012.

"Spending on Nuclear Weapons." Icanw.org. The International Campaign to Abolish Nuclear Weapons (ICAN). Web. 01 Apr. 2016.

Spillane, Mickey. Kiss Me Deadly. New York: Signet Press, 1952. Print.

Spivak, Gayatri Chakraborty. Death of a Discipline. New York: Columbia UP, 2003. Print.

--."Subaltern Studies: Deconstructing Historiography” Selected Subaltern Studies Ed. Ranajit Guha and Gayatri Chakraborty Spivak. New York: Oxford University Press, 1998. Print.

--. "Can the Subaltern Speak?" Marxism and the Interpretation of Culture (1988): 271-313. Web. 29 Mar. 2016.

Squier, Susan Merrill. Liminal Lives: Imagining the Human at the Frontiers of Biomedicine. Durham: Duke UP, 2004. Print. 
Srivastava, Sanjay. Passionate Modernity: Sexuality, Class and Consumption in India. London: Routledge, 2007. Print

Stein, Gertrude. "Reflections on the Atom Bomb." Writing at UPenn. N.d.N.p. Web. 2 May 2013.

Stillman, Grant B. "Two of the Maddest Scientists: Where Strangelove meets Dr.No; or, Unexpected Roots for Kubrick’s Cold War Classic.” Film History 20.4 (2008): 487-500. JSTOR. Web. 1 May 2012.

Suri, Manil. City of Devi. New York: WW Norton Company, 2013. Print.

Taylor, Bryan C. ""The Means to Match Their Hatred": Nuclear Weapons, Rhetorical Democracy, and Presidential Discourse." Presidential Studies Quarterly Presidential Studies Q 37.4 (2007): 667-92. Web. 05 Apr. 2016.

Taylor, Bryan C., William J. Kinsella, Stephen P. Depoe, Maribeth S. Metzler, eds. Nuclear Legacies: Communication, Controversy, and the U.S. Nuclear Weapons Complex. Lanham, MD: Lexington Books, 2008. Print.

Thiong'o, Ngugi Wa. Decolonizing the Mind: The Politics of Language in African Literature. London: J. Currey, 1986. Print.

Titus, A Constandina. “The Mushroom Cloud as Kitsch.” Zeman and Amundson 101-124

Tweg, Sue. "Reading Dr. Strangelove.” Australian Teachers of Media 1.1 (1995): 3-21. Web. 03 April 2016.

"Understanding the Decision to Drop the Bomb on Hiroshima and Nagasaki." Understanding the Decision to Drop the Bomb on Hiroshima and Nagasaki. The Center for Strategic and International Studies, 10 Aug. 2012. Web. 05 Apr. 2016.

U. S. Strategic Bombing Survey: The Effects of the Atomic Bombings of Hiroshima and Nagasaki Washington, DC: Government Printing Office, 1946. Print.

Vishwanathan, Shiv. "On the Annals of the Laboratory State." In Ashis Nandy (ed.) Science, Hegemony and Violence: A Requiem for Modernity. Delhi: Oxford University Press, 1988. Print.

--. "Welcome to the Patriot Games". Economic and Political Weekly 33.21 (1998): 1224-1226. Web. 05 Apr. 2016.

Warner, Michael. Publics and Counterpublics. Brooklyn, NY: Zone Books, 2002. Print.

Weart, Spencer R. Nuclear Fear: A History of Images. Cambridge, MA: Harvard UP, 1988. Print. 
Werrell, Kenneth P. “The Strategic Bombing of Germany in World War II: Costs and Accomplishments". The Journal of American History 73.3 (1986): 702-713. Web. 2 Mar. 2015.

Wellerstein, Alex. "Knowledge and the Bomb: Nuclear Secrecy in the United States, 19392008." Diss. 2010. Abstract. Print.

White, Hayden. Tropics of Discourse: Essays in Cultural Criticism. Baltimore: The Johns Hopkins University Press, 1978. Print.

Whitfield, Stephen. The Culture of the Cold War: The American Moment. Baltimore: Johns Hopkins University Press, 1996. Print.

Whitworth, Sandra. "Militarized Masculinity and Post Traumatic Stress Disorder" Rethinking the Wo/man Question in International Relations Eds. Jane Parpart and Marysia Zalewski. London: Zed Books, 2008), pp. 109-126. Print.

Williams, Paul. Race, Ethnicity and Nuclear War: Representations of Nuclear Weapons and Post-apocalyptic Worlds. Liverpool: Liverpool UP, 2011. Print.

Wilson, Jane, and Charlotte Serber. Standing by and Making Do: Women of Wartime Los Alamos. Los Alamos, NM: Los Alamos Historical Society, 1988. Print.

Worster, Donald. Nature's Economy: A History of Ecological Ideas. Cambridge: Cambridge UP, 1994. Print.

Zarlengo, Kristina. "Civilian Threat, the Suburban Citadel, and Atomic Age American Women”. Signs 24.4 (1999): 925-958. Web. 28 Mar. 2016.

Zeman, Scott C. and Michael A. Amundson, eds. Atomic Culture: How We Learned to Stop Worrying and Love the Bomb. Boulder, Colorado: University of Colorado Press, 2004. Print.

Zeman, Scott C. and Michael A. Amundson. "Introduction." Zeman and Amundson 1-10. 